UNIVERSIDADE DE SÃO PAULO

USP

PROGRAMA DE PÓS-GRADUAÇÃO EM ENERGIA

PPGE

(EP/FEA/IEE/IF)

\title{
AVALIAÇÃO SOCIAL DO CICLO DE VIDA DE PRODUTOS \\ Proposta de Método e Avaliação Preliminar do Álcool Etílico Hidratado \\ Combustível
}

Marcelo Costa Almeida

São Paulo

2009 
Marcelo Costa Almeida

AVALIAÇÃO SOCIAL DO CICLO DE VIDA DE PRODUTOS Proposta de Método e Avaliação Preliminar do Álcool Etílico Hidratado Combustível

Tese apresentada ao Programa de PósGraduação em Energia da Universidade de São Paulo para obtenção do título de Doutor em Energia.

Orientador: Prof. Dr. José Roberto Moreira Co-orientadora: Prof.a Dr.a Patrícia Helena Lara dos Santos Matai 
AUTORIZO A REPRODUÇÃO E DIVULGAÇÃO TOTAL OU PARCIAL DESTE TRABALHO, POR QUALQUER MEIO CONVENCIONAL OU ELETRÔNICO, PARA FINS DE ESTUDO E PESQUISA, DESDE QUE CITADA A FONTE.

FICHA CATALOGRÁFICA

Almeida, Marcelo Costa.

Avaliação social do ciclo de vida de produtos: proposta de método e avaliação preliminar do álcool etílico hidratado combustível. / Marcelo Costa Almeida; orientadores José Roberto Moreira, Patrícia Helena Lara dos Santos Matai. - São Paulo, 2009 144 p.: il.; $30 \mathrm{~cm}$.

Tese (Doutorado - Programa de Pós-Graduação em Energia) EP / FEA / IEE / IF da Universidade de São Paulo.

1. Álcool como combustível - 2. Avaliação de ciclo de vida 3. Desenvolvimento sustentável. I. Título. 


$$
\begin{aligned}
& \text { UNIVERSIDADE DE SÃO PAULO } \\
& \text { PROGRAMA DE PÓS-GRADUAÇÃO EM ENERGIA } \\
& \text { EP - FEA - IEE - IF }
\end{aligned}
$$

\section{MARCELO COSTA ALMEIDA}

"Avaliação social do ciclo de vida de produtos: Proposta de método e avaliação preliminar do álcool etílico hidratado combustível"

Tese defendida e aprovada em 19/03/2009 pela Comissão Julgadora:

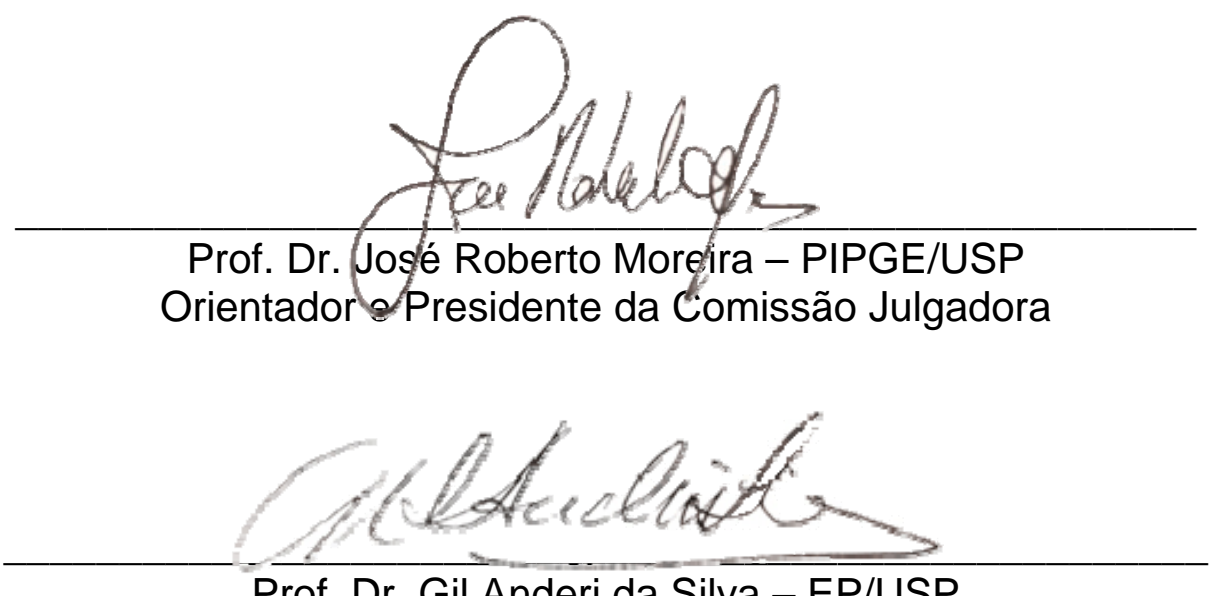

Prof. Dr. Gil Anderi da Silva - EP/USP

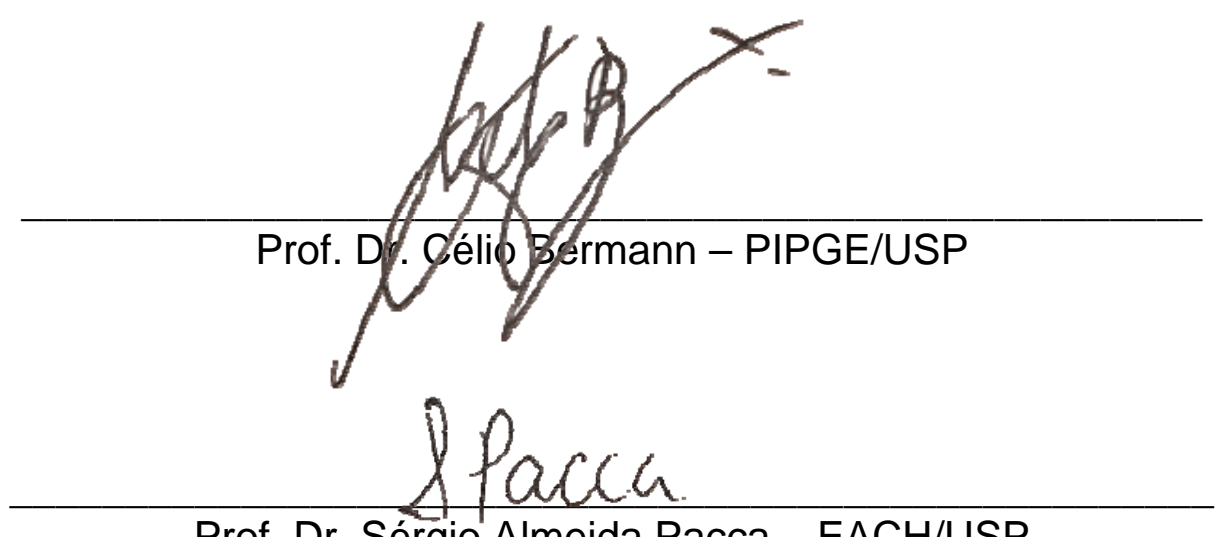

Prof. Dr. Sérgio Almeida Pacca - EACH/USP

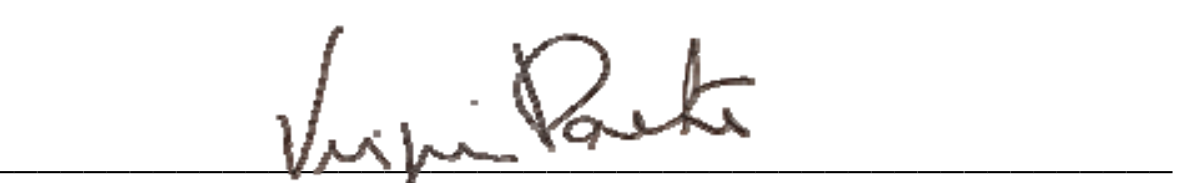

Prof. Dr. Wrgínia Parente - PIPGE/USP 


\section{AGRADECIMENTOS}

Ao prof. Moreira, por me aceitar como seu orientado, permitindo que dos ombros deste gigante minha aprendizagem e meu horizonte fossem tão amplos quanto meus sonhos.

À Carmen por todo o amor, carinho, apoio e compreensão, pela companhia nos momentos difíceis e por muitas doces lembranças.

À Tati pelo amor e carinho, por me fazer ver a vida e o mundo sob outra luz.

À meu pai, especialmente pelo gosto da leitura e da escrita.

À minha mãe, especialmente pelo gosto de estudar e aprender.

Aos meus avós maternos, Maria e Batuta, pela acolhida quando sai de casa.

Aos meus avós paternos, Laura e Tidin, pela herança de suas fortes personalidades quando precisei resistir.

À meus tios e tias por terem de diversas formas contribuído para minha formação.

Ao primo Sérgio, que me indicou São Carlos, por onde comecei este caminho, e cuja profissão de engenheiro sempre me fascinou.

Ao prof. Gregolin e à profa Sati pelos primeiros ensinamentos em pesquisa.

Ao prof. Agnelli por me apresentar a ACV ainda nos idos de 1998.

Aos meus amigos e colegas no PPGE, especialmente Alexandre G., Francisco H., Fernando R., Orlando C., Bispo, Ariel, Tânia, Marilyn, Aline e Hirdan.

Aos professores e amigos do IEE, especialmente C. Scarpinella, M. Faga, R. Pessine, R. Zilles, Edmilson M., Patrícia M., Sinclair.

À Fátima, Penha e Lourdes da Biblioteca do IEE pela simpatia e dedicação em auxiliar na pesquisa bibliográfica.

À Rosa, Jisa, Adriana e Cláudio da secretaria do PPGE pela amizade e presteza.

Aos professores amigos e membros da banca Virgínia, Bermann, Gil Anderi, Pacca.

Ao Dr José Calvo e toda equipe do Campus de Exceléncia pela maravilhosa experiência de conhecer grandes nomes da ciência, política e economia, entre eles Dr Bernardo K. cuja palestra influenciou minha visão da sustentabilidade.

Finalmente, à Deus por tudo, mas especialmente pelos momentos difíceis que me ensinaram a perder, a esperar, a resistir e a crescer, compreendendo alguns dos porquês que sempre nos perguntamos.

não há mal que bem não faça, nem bem que mal também, tão bem, não há 


\section{DEDICATÓRIA}

Aos meus sobrinhos que já chegaram: Gustavo, João, Beatriz, Pietro e Mariana e aos que ainda virão. 
“(...) Ela tinha a pele manchada. Estava doente, os olhos e o nariz avermelhados. (...) padecia de pobreza. O hospital recebia por dia milhares de enfermos que sofriam dessa mesma chaga. (...) sintomas diversos, estado febril, purulências, dores, velhice. (...) a todos eles era comum o tumor inexpugnável da pobreza." (RODRIGUES, Leandro. Gerúndio. Revista Pesquisa Fapesp. Número 148. pp 112-113. junho de 2008.)

Definições para "Pobre" e "Pobreza" no Novo Dicionário Básico da Lingua Portuguesa. Folha / Aurélio.

Pobre. Adj. 2 g. 1. Que não tem o necessário à vida. 2. Cujas posses são inferiores à sua posição ou condição social. 3. Que revela pobreza. 4. Pouco produtivo. 5. Mal dotado, pouco favorecido: pobre de inteligência. 6. Digno de lástima; que inspira compaixão.

Pobreza. S. f. 1. Estado ou qualidade de pobre. 2. Falta do necessário à vida; penúria, escassez. 3. A classe dos pobres. 


\section{RESUMO}

ALMEIDA, Marcelo Costa. Avaliação social do ciclo de vida de produtos: propostas de método e avaliação preliminar do álcool etílico hidratado combustível. 2009, 144p. Dissertação de mestrado - Programa de Pós-Graduação em Energia, Universidade de São Paulo.

Esta Tese propõe e aplica um método de Avaliação Social do Ciclo de Vida de Produtos. Os indivíduos que compõem o recurso humano desempenham o papel de vetor entre o sistema social e o sistema de produto. Duas categorias de sustentabilidade social são definidas: 1) Atendimento de Necessidades Básicas; e, 2) Autonomia Intelectual. O Indicador desenvolvido para a primeira categoria é a Renda Monetária Anual, medida em unidades monetárias. O indicador desenvolvido para a segunda categoria é a Escolaridade Ajustada pela Duração do Vínculo. A escolaridade dos indivíduos, medida em anos equivalentes de estudo, é multiplicada pelo número de meses em que houve o vínculo entre o sistema social e sistema de produto através de cada indivíduo, no ano de referência da avaliação. Critérios de referência são desenvolvidos para a avaliação dos indicadores. A renda e a escolaridade ajustada são impactadas por fatores que avaliam a gravidade da desigualdade entre os indivíduos do conjunto recurso humano e entre estes e os indivíduos do conjunto consumidor. Os resultados são comparados com valores de referência para condição mínima de sustentabilidade em cada categoria de sustentabilidade. Um modelo matemático é desenvolvido para que nenhum desempenho positivo em uma, ou mais categorias, seja suficiente para anular o desempenho negativo em qualquer categoria, ou categorias, avaliada. Este método é aplicado em uma avaliação preliminar do Álcool Etílico Hidratado Combustível.

Palavras-chave: Álcool como Combustível; Desenvolvimento Sustentável; Avaliação de Ciclo de Vida de Produtos 


\section{ABSTRACT}

ALMEIDA, Marcelo Costa. Social Life Cycle Assessment of Products: method proposal and preliminary assessment of hydrous ethanol. 2009, 144p. PhD Thesis Programme of Post Graduation in Energy, University of São Paulo.

A method for Social Life Cycle Assessment of Products is proposed and applied. In this method, the individuals that constitute the human resources play the role of vectors connecting the social system and the product system. Two categories of social sustainability are defined: 1) Basic Needs Fulfillment; and, 2) Intellectual Autonomy. The Annual Monetary Income, in monetary units, is the indicator of the former category. The Job Duration Adjusted Schooling is the indicator of the later category. The individuals's schooling, in years of study equivalent, is multiplied by the number of months that the link between the social and the product systems lasted, in the reference year of the assessment. Reference criteria are defined for the assessment of the indicators. The income and the adjusted schooling are impacted by two inequality gravity factors. One factor concerns the inequality gravity among the individuals of the human resource. The other factor concerns the inequality gravity between the individuals in the human resource and the consumer groups. The results are compared to reference values of minimum sustainability for each category of sustainability. A mathematical model for aggregation of category indicators is developed to not allow that a positive result for any category indicator, or set of categories, offsets a negative result in any other sustainability category, or set of categories. This method is applied to a preliminary assessment of the Hydrous Ethyl Alcohol Fuel.

Keywords: Alcohol as Fuel; Sustainable Development; Life Cycle Assessment of Products 


\section{SUMÁRIO}

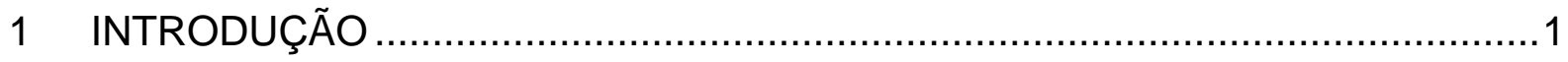

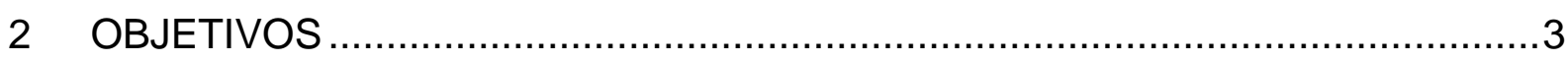

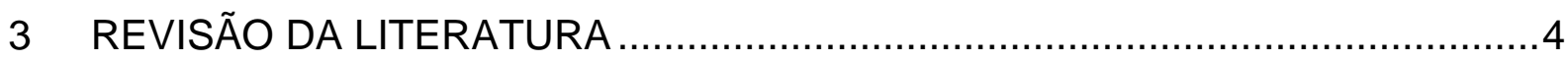

3.1 Avaliação do Ciclo de Vida de Produtos (ACV) .......................................

3.1.1 Princípios da Avaliação de Ciclo de Vida (ACV) ................................. 4

3.1.2 Estrutura da Avaliação de Ciclo de Vida.............................................

3.2 Avaliação Social do Ciclo de Vida de Produtos ........................................ 8

3.2.1 Áreas de Proteção Social ............................................................ 10

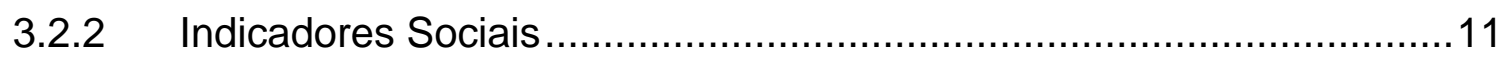

3.2.3 Classificação de Indicadores Sociais ................................................14

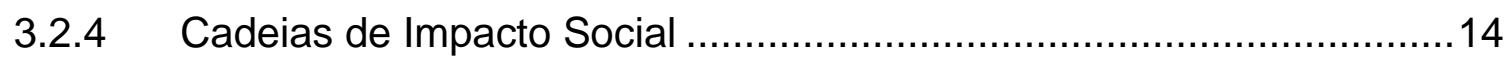

3.2.5 Abordagens ao Processo de Consumo na ACV Social ......................17

3.2.6 Propostas de Métodos de ACV Social ............................................17

4 PROPOSTA DE MÉTODO PARA AVALIAÇÃO SOCIAL DE CICLO DE VIDA DE

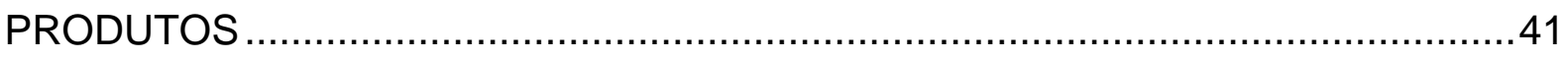

4.1 A Dimensão Social de Sistemas de Produtos ........................................41

4.2 Categorias de Sustentabilidade Social de Produtos ……........................42

$4.3 \quad$ Indicadores de Sustentabilidade Social de Produtos ................................43

4.3.1 O Indicador da Categoria de Sustentabilidade Atendimento de Necessidades Básicas

4.3.2 O Indicador da Categoria de Sustentabilidade Autonomia Intelectual .45

4.3.3 A importância da Desigualdades na Sustentabilidade Social ..............47

4.4 Critérios Operacionais de Sustentabilidade Social de Produtos .................48

4.4.1 Critérios Operacionais para Atendimento de Necessidades Básicas ..48

4.4.2 Critérios Operacionais para Autonomia Intelectual .............................48

4.5 Índices Parciais de Sustentabilidade Social de Produtos...........................49

4.5.1 Índice Parcial de Atendimento de Necessidades Básicas ...................50

4.5.2 Índice Parcial de Autonomia Intelectual ..........................................51

4.5.3 Gravidade da Desigualdade na Sustentabilidade Social ....................52

4.6 Índice de Sustentabilidade Social de Produto ............................................56

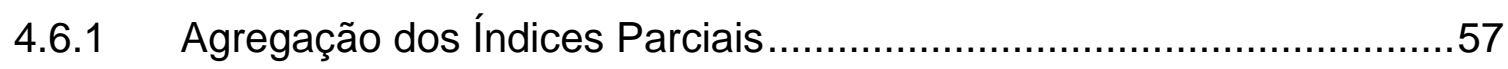

4.6.2 Obtenção do Índice de Sustentabilidade de Produto ...........................60 
5 AVALIAÇÃO SOCIAL DO CICLO DE VIDA DO AEHC 62

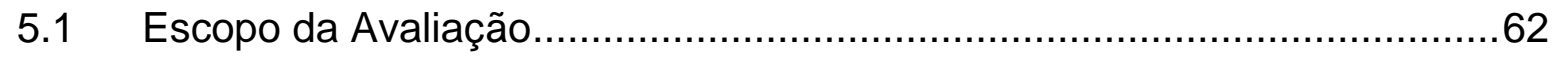

5.1.1 Função, Unidade Funcional e Fluxo de Referência .............................62

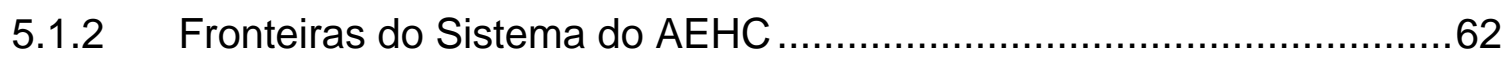

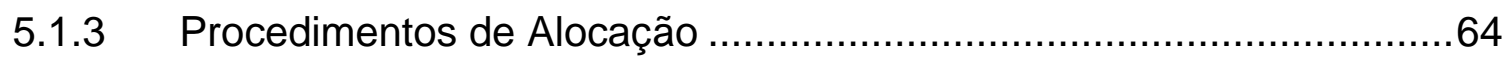

5.1.4 Tipos de Impacto e Método de Avaliação de Impacto ...........................64

5.1.5 Requisitos de Qualidade dos Dados ................................................64

5.2 Inventário Social do Álcool Etílico Hidratado Combustível..........................66

5.2.1 Recuperação e Tratamento dos Dados .............................................66

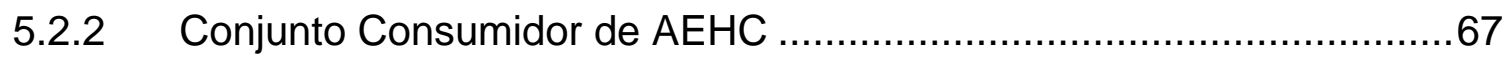

5.2.3 Inventário Social do Comércio Varejista do AEHC .............................72

5.2.4 Inventário Social do Transporte de AEHC ……...............................76

5.2.5 Inventário Social da Produção de AEHC ………..............................77

5.2.6 Inventário Social do Cultivo de Cana-de-Açúcar..................................84

5.2.7 Inventário Social das Atividades de Apoio à Agricultura .......................88

5.2.8 Inventário Social do Óleo Diesel ...................................................94

5.2.9 Inventário Social dos Fertilizantes Agrícolas .....................................99

5.2.10 Inventário Social dos Defensivos Agrícolas ......................................102

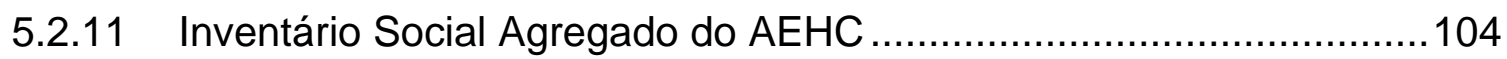

5.3 Sustentabilidade Social do Álcool Etílico Hidratado Combustível ..............111

6 CONCLUSÕES E CONSIDERAÇÕES FINAIS ............................................114 


\section{LISTA DE TABELAS}

Tabela 1 - Diferenças metodológicas entre as disciplinas fundamentais da avaliação ambiental do ciclo de vida (Engenharia) e da social (Ciência Social). 18

Tabela 2 - Influência de danos ambientais sobre canais sociais. 21

Tabela 3 - Influência de processos sociais sobre impactos ambientais.

Tabela 4 - Tipos de capital que uma sociedade pode usufruir e exemplos de indicadores.

Tabela 5 - Principais áreas de impacto social e exemplos de indicadores. 23

Tabela 6 - Estimativa preliminar do dano ao bem-estar global, dados de 2002 ......35

Tabela 7 - Estimativa preliminar do dano global da ansiedade não-clínica. 35

Tabela 8 - Indicadores aditivos, descritivos geral e específico. 38

Tabela 9 - Valores médios ponderados do Salário Mínimo (SM) e do Salário Mínimo Necessário (SMN) e valor anual do SMN, em reais, valores nominais. .44

Tabela 10 - Grau de escolaridade e respectivos anos-equivalentes de estudo adotados no método proposto nesta tese.

Tabela 11 - Código CNAE 2.0 e CNAE 95 das classes de atividade econômica que compõem o sistema do AEHC.

Tabela 12 - Distribuição dos vínculos totais declarados à RAIS e percentuais por faixa etária, de 2003 a 2007.

Tabela 13 - Exemplo de especificação da consulta e dimensões da tabela dos resultados.

Tabela 14 - Níveis de escolaridade disponilizados na RAIS e respectivos anos equivalentes de estudo adotados no método proposto.

Tabela 15 - Quantidade de habilitações tipo AB, A e B, para condução de veículos em dezembro de 2007, no Brasil.

Tabela 16 - Consumo de combustíveis veiculares no Brasil, em 2007, em toneladas equivalentes de petróleo (tep) e participação percentual. 69

Tabela 17 - Indivíduos e renda anual total, em Reais de 2007, dos conjuntos consumidor total, consumidor de combustíveis para veículos leves e de AEHC, em 2007.

Tabela 18 - Consumo brasileiro de AEHC no Setor de Transporte.

Tabela 19 - Indivíduos consumidores e renda anual por litro de AEHC consumido, em 2007. 
Tabela 20 - Vínculos, anos equivalentes de estudo contratados totais e por vínculo, para o Conjunto Consumidor, em 2007.

Tabela 21 - Indivíduos e anos equivalentes de estudo por litro de AEHC consumido, em 2007.

Tabela 22 - Vínculos, renda anual total e média por vínculo no comércio varejista de combustíveis, em todo o Brasil, em 2007.

Tabela 23 - Participação em base energética do consumo de combustíveis no setor de transportes, em 2007.

Tabela 24 - Vínculos e renda anual total, alocados ao AEHC, no comércio varejista de combustíveis, em todo o Brasil, em 2007.

Tabela 25 - Vínculo e renda anual no comércio varejista de combustíveis, por litro de AEHC comercializado, em 2007.

Tabela 26 - Vínculos, anos equivalentes de estudos (AeqE) total e por vínculo no comércio varejista de combustíveis, em todo o Brasil, em 2007.

Tabela 27 - Vínculos e anos equivalentes de estudo (AeqE) total e por litro, no comércio varejista de combustíveis, em todo o Brasil, para o AEHC, em 2007. .75

Tabela 28 - Total de indivíduos, renda anual e anos equivalentes de estudo, total e por indivíduos, na atividade Transporte Rodoviário de Cargas, em 2007.

Tabela 29 - Vínculos totais, renda anual total e média por vínculo, na produção de álcool etílico, no Brasil, em Reais, valores nominais, de 2000 a 2007.

Tabela 30 - Produção Brasileira de álcool etílico hidratado (AEHC) e anidro (AEAC) combustíveis, no Brasil, em mil metros cúbicos, de 2000 a 2007.

Tabela 31 - Propriedades do álcool etílico hidratado (AEHC) e anidro (AEAC) combustíveis.

Tabela 32 - Produção brasileira de álcool etílico hidratado (AEHC) e anidro (AEAC) no Brasil, em quilojoule, e participação do AEHC, de 2000 a 2007. 79

Tabela 33 - Vínculos totais e renda anual total, alocados para a produção de álcool etílico hidratado, no Brasil, de 2000 a 2007.

Tabela 34 - Vínculo e renda anual, por quilojoule de AEHC, no Brasil, de 2000 a 2007.

Tabela 35 - Vínculo e renda anual, por litro de AEHC, no Brasil, de 2000 a 2007 ...80 Tabela 36 - Vínculos, anos equivalentes de estudo (AeqE) total e por vínculo, na produção de álcool etílico, no Brasil, de 2000 a 2007. 
Tabela 37 - Vínculos e anos eq. de estudo (AeqE), alocados para o AEHC, de 2000 a 2007.

Tabela 38 - Vínculos e anos eq. de estudo (AeqE), por quilojoule de AEHC, de 2000 a 2007.

Tabela 39 - Vínculos e anos equivalentes de estudo (AeqE), por litro de AEHC produzido no Brasil, de 2000 a 2007.

Tabela 40 - Vínculos totais declarados na RAIS, Renda Anual total e por vínculo, no cultivo de cana-de-açúcar, no Estado de São Paulo, de 2000 a 2007.

Tabela 41 - Quantidade de cana-de-açúcar produzida, em toneladas, e valor da produção em mil Reais, valores nominais, no Estado de São Paulo, de 2000 a 2007.

Tabela 42 - Vínculo e renda, por tonelada de cana, no Estado de São Paulo, de 2000 a 2007.

Tabela 43 - Vínculo e renda, por unidade monetária do produto em São Paulo, de 2000 a 2007.

Tabela 44 - Vínculos, anos equivalentes de estudo total e por vínculo do conjunto recurso humano no cultivo de cana-de-açúcar, no Estado de São Paulo, de 2000 a 2007.

Tabela 45 - Vínculo e anos equivalentes de estudo (AeqE) por tonelada de cana-deaçúcar, de 2000 a 2007

Tabela 46 - Vínculo e anos equivalentes de estudo (AeqE) por unidade monetária do valor da produção de cana, no Estado de São Paulo, de 2000 a 2007.

Tabela 47 - Municípios selecionados para o levantamento de dados da atividade de apoio à agricultura de Cana-de-Açúcar e produção municipal.

Tabela 48 - Produção total de cana-de-açúcar nos municípios selecionados, em todo o Estado de São Paulo, de 2000 a 2006.

Tabela 49 - Vínculos, renda anual total e média por vínculo, nas atividades de apoio agrícolas, em municípios do Estado de São Paulo selecionados, de 2000 a 2007...90 Tabela 50 - Vínculo e Renda, por tonelada de cana produzida, nas atividades de apoio à agricultura, em municípios selecionados do Estado de São Paulo, de 2000 a 2007.

Tabela 51 - Vínculo e Renda, por unidade monetária em Reais de valor de produto, em municípios selecionados do Estado de São Paulo, de 2000 a 2007.Específico..91 
Tabela 52 - Vínculos, anos equivalentes de estudo total e por vínculo, na atividade de apoio à agricultura, nos municípios selecionados do Estado de São Paulo, de 2000 a 2007.

Tabela 53- Vínculos e anos eq. de estudo (AeqE) por tonelada de cana, de 2000 a 2007

Tabela 54 - Vínculos e anos eq. de estudo (AeqE) por unidade monetária, de 2000 a 2007.

Tabela 55 - Entradas e produtos das refinarias brasileiras de 2000 a 2007, em toneladas equivalentes de petróleo (tep).

Tabela 56 - Vínculos Totais, Renda Anual Total e Renda Anual média por Vínculo, na cadeia produtiva do petróleo, no Brasil, de 2000 a 2007.

Tabela 57 - Participação percentual do óleo diesel no total dos produtos das refinarias Brasileiras, em base energética e produção em mil metros cúbicos. 96 Tabela 58 - Vínculos, renda an. total e média por vínculo, para o diesel, Brasil, de 2000 a 2007.

Tabela 59 - Vínculos e renda por litro de diesel produzido.

Tabela 60 - Vínculos, anos equivalentes de estudo total e por vínculo na cadeia produtiva dos produtos das refinarias.

Tabela 61 - Vínculos e anos eq. de estudo (AeqE) alocados ao diesel em base energética.

Tabela 62 - Vínculos e anos equivalentes de estudo (AeqE) por litro de óleo diesel.

Tabela 63 - Vínculos totais declarados na RAIS, Renda Anual total e média do período, na produção de fertilizantes agrícolas, no Brasil, em 2007.

Tabela 64 - Produção Nacional de Fertilizantes Intermediários, em 2007.

Tabela 65 - Vínculos e renda por quilograma de fertilizante, em 2007. 100

Tabela 66 - Vínculos e anos equivalentes de estudo na cadeia produtiva dos fertilizantes agrícolas, em todo o Brasil, nos anos de 2006 e 2007.

Tabela 67 - Vínculos e anos equivalente de estudo por quilograma de fertilizante.

Tabela 68 - Vínculos totais declarados na RAIS, Renda Anual total e média do período, na produção de defensivos agrícolas, no Brasil, de 2006 a 2007. 102

Tabela 69 - Produção da Indústria de Defensivos Agrícolas. 
Tabela 70 - Vínculo e renda anual por quilograma de ingrediente ativo produzido.

Tabela 71 - Vínculos e anos equivalentes de estudo na produção de defensivos agrícolas, em todo o Brasil, em 2006 e 2007.

Tabela 72 - Fatores de ajuste das populações das atividades para o fluxo de referência.

Tabela 73 - Resultados para renda anual média e a mínima sustentável requerida para a população total, a população consumidora e a população recurso humano do sistema do AEHC, em função do fluxo de referência. 108 Tabela 74 - Resultados para anos equivalentes de escolaridade contratada média e a mínima sustentável requerida para a população total, a população consumidora e a população recurso humano do sistema do AEHC. 108 Tabela 75 - Elementos de cálculos dos fatores de gravidade na desigualdade na distribuição de renda e de escolaridade, fatores de gravidade e índice de Gini. ....110 Tabela 76 - Resultados da avaliação de sustentabilidade social. 111

Tabela 77 - Indivíduos normalizados para o fluxo de referência no sistema do AEHC.

Tabela 78 - Renda da população do sistema do AEHC, normalizada para o fluxo de referência.

Tabela 79 - Anos equivalentes de estudo da população total do sistema do AEHC, normalizados para o fluxo de referência de 2 litros de AEHC. 


\section{LISTA DE ILUSTRAÇÕES}

Ilustração 1 - Fluxograma esquemático das etapas realizadas na fase de Definição do Objetivo e Escopo em uma ACV (Elaboração do autor).

Ilustração 2 - Fluxograma esquemático dos passos da Análise de Inventário

(Modificado de ISO 14044:2006)

Ilustração 3 - Evolução entre 1993 e 1999 de artigos científicos sobre a Avaliação de Ciclo de Vida (BAUMANN \& TILLMAN, 2004).

Ilustração 4 - Exemplos de cadeias de impacto ambiental e social (HUTCHINS \& SUTHERLAND, 2008).

Ilustração 5 - Estrutura do método SELCA O'Brien, Doig \& Clift (1996).

Ilustração 6 - Eco- e socioeficiência como estratégias para a sustentabilidade

econômica. (DYLLICK AND HOKERTS, 2002 apud SCHIMIDT et al., 2004).

Ilustração 7 - Estrutura da composição dos fatores de ponderação totais no método da Socioeficiência (SCHMIDT et al., 2004).

Ilustração 8 - Cadeias de impactos socioeconômicos entre alterações em processos ou produtos e as consequências finais à saúde humana (NORRIS, 2006).

Ilustração 9 - Representação esquemática do gap de mortalidade (área A), do gap de saúde (área $A+B$ ) e do gap de bem-estar (área $A+B+C$ ) (Weidema, 2006).

Ilustração 10 - Representação das interações entre o sistema de produto e o sistema social através dos conjuntos recurso humano e consumidor.

Ilustração 11 - Número médio de indivíduos por unidade familiar, residente em domicílio particular, levantado na PNAD 2006, por região geográfica Brasileira (Fonte: IBGE, 2005).

Ilustração 12 - Curva genérica para os índices parciais das categorias de

sustentabilidade.

Ilustração 13 - Representação das curvas $\alpha$ e $\beta$ e das áreas A, B e C, usadas no cálculo dos fatores de gravidade da desigualdade $\mathrm{Gi}^{\star}$ e $\mathrm{Gi}{ }^{\star \star}$. 53

Ilustração 14 - Estrutura do Índice de Sustentabilidade Social de Produtos. .56 Ilustração 15 - Curvas obtidas da agregação de índices parciais com mesmo valor e sinal.

Ilustração 16 - Curvas obtidas para um único índice parcial, para a combinação de dois índices parciais de igual valor e sinal, e para combinações de índices parciais de diferentes valores, mas mesmo sinal. 
Ilustração 17 - Curvas obtidas da agregação índices parciais com sinais diferentes.

Ilustração 18 - Curvas possíveis para combinações de dois índices parciais quaisquer. 60

Ilustração 19 - Curva da Sustentabilidade Social de Produtos.

Ilustração 20 - Sistema do álcool etílico hidratado combustível (AEHC).

Ilustração 21 - Curvas $\alpha$ cons, $\beta$ cons e de Lorentz da distribuição da renda anual no conjunto consumidor de AEHC, em 2007.

llustração 22 - Curvas $\alpha$ cons, $\beta$ cons e de Lorentz da distribuição dos anos

equivalentes de estudo (AeqE) do Conjunto Consumidor, em 2007.

Ilustração 23 - Curvas $\alpha$ rh, $\beta$ rh e de Lorentz da distribuição de renda no comércio varejista de combustíveis, em 2007.

Ilustração 24 - Curvas $\alpha$ rh, $\beta$ rh e de Lorentz da distribuição dos anos equivalentes de estudo (AeqE) no comércio varejista de combustíveis, no ano de 2007. 75 Ilustração 25 - Curvas $\alpha$ rh, $\beta$ rh e de Lorentz da distribuição de renda, no transporte rodoviário de cargas, em 2007.

Ilustração 26 - Curvas $\alpha$ rh, $\beta$ rh e de Lorentz da distribuição dos anos equivalentes de estudo, no transporte rodoviário de cargas, em 2007.

Ilustração 27 - Vínculos por litro de AEHC, no Brasil, de 2000 a 2007. Ilustração 28 - Renda anual do recurso humano por litro de AEHC, no Brasil, de 2000 a 2007.

Ilustração 29 - Curvas $\alpha$ rh, $\beta$ rh e de Lorentz da distribuição de renda na produção de álcool etílico, em 2007.

Ilustração 30 - Curvas $\alpha$ rh, $\beta$ rh e de Lorentz da distribuição dos anos equivalentes de estudo (AeqE) na produção de álcool etílico, no ano de 2007.

Ilustração 31 - Renda anual por tonelada de cana na atividade de cultivo de canade-açúcar, no Estado de São Paulo, de 2000 a 2007.

Ilustração 32 - Curvas $\alpha$ rh, $\beta$ rh e de Lorentz da distribuição de renda, no cultivo de cana-de-açúcar, no Estado de São Paulo, em 2007. .86 Ilustração 33 - Curvas $\alpha$ rh, $\beta$ rh e de Lorentz da distribuição dos anos equivalentes de estudo (AeqE), no cultivo de cana-de-açúcar, no Estado de São Paulo, em 2007. 
Ilustração 34 - Curvas $\alpha$ rh, $\beta$ rh e de Lorentz da distribuição de renda nas atividades de apoio agrícola, em municípios selecionados do Estado de São Paulo, em 2007.92 llustração 35 - Curvas $\alpha$ rh, $\beta$ rh e de Lorentz da distribuição dos anos eq. de estudo na atividade de apoio à agricultura, municípios selecionados do Estado de São Paulo, em 2007. 93

llustração 36 - Participação percentual dos produtos, em relação ao consumo de petróleo e líquido de gás natural nas refinarias, de 2000 a 2007 (MME, 2008). 95 llustração 37 - Curvas $\alpha$ rh, $\beta$ rh e de Lorentz da distribuição de renda na cadeia do diesel, 2007.

llustração 38 - Curvas $\alpha$ rh, $\beta$ rh e de Lorentz da distribuição dos anos equivalentes de estudo (AeqE) do Conjunto recurso humano da cadeia produtiva do óleo diesel, em 2007.

Ilustração 39 - Curvas $\alpha$ rh, $\beta$ rh e de Lorentz da distribuição de renda na cadeia produtiva dos fertilizantes agrícolas, em 2007.

Ilustração 40 - Curvas $\alpha$ rh, $\beta$ rh e de Lorentz da distribuição dos anos equivalentes de estudo (AeqE) da cadeia produtiva dos fertilizantes agrícolas, em 2007. 101 llustração 41 - Curvas $\alpha$ rh, $\beta$ rh e de Lorentz da distribuição de renda na produção de defensivos agrícolas, em 2007. 103 llustração 42 - Curvas $\alpha$ rh, $\beta$ rh e de Lorentz da distribuição dos anos equivalentes de estudo (AeqE) na produção de defensivos agrícolas, em 2007. 104 llustração 43 - Sistema de Produto do AEHC com os fluxos físicos e de recurso humano em função do fluxo de referência. Ilustração 44 - Curvas $\alpha$ rh, $\beta$ rh e de Lorentz da distribuição da renda no conjunto recurso humano do sistema do AEHC, em 2007. Ilustração 45 - Curvas $\alpha$ rh, $\beta$ rh e de Lorentz da distribuição da escolaridade contratada no conjunto recurso humano, no ano de 2007, para o sistema do AEHC. 


\section{LISTA DE EQUAÇÕES}

Equação 1 - Modelo genérico dos índices parciais das categorias de sustentabilidade.

Equação 2 - Obtenção do índice parcial da renda monetária anual, IpRMA.

Equação 3 - Obtenção do Índice Parcial Escolaridade Ajustada, IpEA

Equação 4 - Escolaridade ajustada média do recurso humano associado ao fluxo de

referência do sistema de produto.

52

Equação 5 - Obtenção do fator de gravidade da desigualdade na distribuição da variável entre os indivíduos do conjunto recurso humano.

Equação 6 - Obtenção do fator de gravidade da desigualdade na distribuição da variável entre os indivíduos dos subconjuntos recurso humano e consumidores. ....55

Equação 7 - Agregação de índices parciais de mesmo sinal. .57

Equação 8 - Agregação de índices parciais com sinais diferentes. 59

Equação 9 - Obtenção do Índice de Sustentabilidade de Produto. 60 


\section{LISTA DE SIGLAS}

ACV - Avaliação do Ciclo de Vida

LCT - Life Cycle Thinking

LCC - Life Cycle Costing

ILO - International Labor Organization

SELCA - Social and Environmental Life Cycle Assessment

ELCA - Environmental Life Cycle Assessment

SLCA - Social Life Cycle Assessment

AIST - Agência de Governo Japonesa

SNTT - Sociedade para a Tecnologia Não-Convencional

OMS - Organização Mundial da Saúde

PIB - Produto Interno Bruto

SII - Social Impacts Indicator

RII - Resource Impact Indicator

YLL - Years of Life Lost

YLD - Healthy Years Lost due to Disability

DALY - Disability Adjusted Life Years

YWL - Years of Well-being Lost

QALY - Quality Adjusted Life Years

AACV - Avaliação de Atributos no Ciclo de Vida

DIEESE - Departamento Intersindical de Estatística e Estudos Sócio-Econômicos

SM - Salário Mínimo

SMN - Salário Mínimo Necessário

PNAD - Pesquisa Nacional por Amostra de Domicílios

IBGE - Instituto Brasileiro de Geografia e Estatística

WCED - The World Commission on Environment and Development

IpANB - Índice Parcial da Categoria de Sustentabilidade Atendimento de

Necessidades Básicas

IpAI - Índice Parcial da Categoria de Sustentabilidade Autonomia Intelectual IpRMA - Índice Parcial do Indicador da Categoria de Sustentabilidade Renda Monetária Anual

IpEA- Índice Parcial do Indicador da Categoria de Sustentabilidade Escolaridade Ajustada 
IpSSP - Índice Parcial Agregado de Sustentabilidade Social de Produto

ISSP - Índice de Sustentabilidade Social de Produto

AEHC - Álcool Etílico Hidratado Combustível

$\mathrm{PCl}$ - Poder Calorífico Inferior

CNAE - Classificação Nacional de Atividades Econômicas

RAIS - Relação Anual de Informações Sociais

MTE - Ministério do Trabalho e Emprego

PDET - Programa de Disseminação de Estatísticas do Trabalho

GNV - Gás Natural Veicular

tep - toneladas equivalentes de petróleo

MME - Ministério de Minas e Energia

EADV - Escolaridade Ajustada por Duração do Vínculo

AeqE - Anos equivalentes de Estudo

AEAC - Álcool Etílico Anidro Combustível

GJ - Giga-Joule

$\mathrm{t}$ - Tonelada

$\mathrm{R} \$$ - Reais

LGN - líquido de gás natural

ANDA - Associação Nacional para Difusão de Adubos

SINDAG - Sindicato Nacional da Indústria de Produtos para Defesa Agrícola $\mathrm{RH}$ - Recurso Humano 


\section{INTRODUÇÃO}

A crescente globalização das cadeias produtivas e a preocupação com 0 desenvolvimento sustentável tornam imprescindível avaliar a dimensão social do ciclo de vida de produtos (NORRIS, 2006; JORGENSEN et al., 2008).

$\mathrm{Em}$ todo o mundo, todos os dias, são tomadas decisões que afetam o meio ambiente e a vida das pessoas. Cada vez mais, as instituições são questionadas sobre sua performance ambiental e social, e têm sido responsabilizadas pelas precárias condições de trabalho em suas instalações e ao longo de sua cadeia produtiva (DREYER; HAUSCHILD \& SCHIERBECK, 2006).

Entretanto, como dar suporte aos responsáveis, em qualquer ponto do planeta, na tomada de decisões que afetam a vida de outros indivíduos, em qualquer outro ponto do planeta? Pergunta Norris (2006).

A Avaliação Social do Ciclo de Vida (referida deste ponto em diante apenas como ACV Social) é a resposta (DREYER, HAUSCHILD \& SCHIERBECK (2006). Apesar das dificuldades metodológicas para integrar a dimensão social na mesma estrutura da Avaliação Ambiental do Ciclo de Vida (referida deste ponto em diante apenas como ACV), a abordagem combinada torna o processo transparente e mais completo (O'BRIEN, DOIG \& CLIFT, 1996). Pois, permite compreender a interação entre estas duas dimensões decorrente da existência de um sistema de produto (HAUSCHILD, DREYER \& JORGENSEN, 2008). De outra forma, seriam necessárias ferramentas de avaliação social que gerassem resultados a serem interpretados juntamente com os resultados da ACV (DREYER; HAUSCHILD \& SCHIERBECK, 2006), de forma não necessariamente integrada e por isso limitando a compreensão da sustentabilidade do produto.

A cadeia produtiva do álcool etílico é intensiva em recurso humano, diversamente remunerado e qualificado. Atualmente, paralelo à expansão da produção para suprir a demanda interna e externa de biocombustíveis, também apresenta mudanças tecnológicas que afetam a demanda de recurso humano, especialmente na fase agrícola de produção da cana-de-açúcar. Enquanto a expansão cria novos postos de trabalho, as mudanças tecnológicas têm reduzido a demanda de mão-de-obra (MACEDO, 2005). Setores da sociedade, brasileira e internacional, frequentemente polemizam sobre estas mudanças (ANDRADE, 1994). 
O álcool etílico produzido da cana-de-açúcar no Brasil é socialmente sustentável?

A mudança tecnológica observada, resultando em menor demanda de mãode-obra, porém mais qualificada e melhor remunerada, conduz o álcool etílico para uma melhor condição de sustentabilidade social?

Estas não são perguntas que têm respostas simples. Como será visto nos capítulos seguintes, a dimensão social é muito complexa, inclui questões culturais, demográficas, políticas etc. As respostas destas questões devem ser dadas pela sociedade, segundo suas prioridades, porque é ela quem mantém o sistema de produto ao demandar o álcool etílico hidratado combustível para consumo.

Neste sentido, esta tese busca contribuir para o debate de duas maneiras. Primeiramente, apresenta uma proposta de método para ACV Social de Produtos, que adota como referencial critérios amplamente aceitos na sociedade. $\mathrm{E}$, complementarmente, conduz uma avaliação preliminar da sustentabilidade social do álcool etílico hidratado combustível consumido no Brasil. 


\section{OBJETIVOS}

O objetivo geral desta tese é desenvolver um método para avaliar a contribuição de sistemas de produtos para a sustentabilidade social. Este novo método é baseado na metodologia de Avaliação de Ciclo de Vida de Produtos. Nesta proposta, os indivíduos que constituem a mão-de-obra atuam como vetor de atributos quantificáveis e agregativos ao longo do sistema de produto.

Constituem objetivos específicos para o desenvolvimento do método e realização de um estudo de caso:

1) definir categorias de sustentabilidade;

2) definir critérios operacionais para as categorias de sustentabilidade;

3) definir indicadores e aspectos sociais adequados, levando em consideração a disponibilidade de dados;

4) introduzir no resultado dos cálculos dos indicadores de sustentabilidade um fator associado à gravidade da desigualdade na distribuição dos aspectos inventariados;

5) desenvolver um modelo de integração de resultados de indicadores de sustentabilidade;

6) conduzir uma avaliação preliminar da sustentabilidade social do álcool etílico hidratado combustível (AEHC) produzido a partir da cana de açúcar; e,

7) Identificar oportunidades de melhoria do desempenho social do sistema do AEHC. 


\section{REVISÃO DA LITERATURA}

\subsection{Avaliação do Ciclo de VIDA de Produtos (ACV)}

Há diversas publicações que tratam da ACV, seus desenvolvimentos e aplicações. Entre os periódicos se destaca o "International Journal of Life Cycle Assessment", disponível no Portal de Periódicos da CAPES. Entre os livros, podemos citar HENDRICKSON, BAVE \& MATTHEWS (2006), BAUMANN \& TILLMAN (2004), HEIJUNGS \& SUH (2002) e CHEHEBE (1998). Há também dissertações e teses defendidas em várias instituições brasileiras, com destaque para o Grupo de Prevenção à Poluição da Escola Politécnica da Universidade de São Paulo, que inclusive orientou uma dissertação apresentada no Programa Interunidades de Pós-Graduação em Energia ${ }^{1}$. Outra dissertação sobre ACV também foi apresentada no mesmo programa em 1999². A Associação Brasileira de Normas Técnicas publicou, em 1998, uma edição brasileira da ISO 14040:1997. As normas internacionais ISO 14040:1997, ISO 14041:1998, ISO 14042:2000, ISO 14043:2000 foram substituídas pela ISO 14040:2006 e pela ISO 14044:2006.

Uma breve introdução dos conceitos básicos e da estrutura da metodologia de Avaliação de Ciclo de Vida de Produtos (ACV) é apresentado nas sub-seções seguintes (de 3.1.1 até 3.1.2.4), com base nas normas ISO 14040:2006 e ISO 14044:2006.

\subsubsection{Princípios da Avaliação de Ciclo de Vida (ACV)}

A ACV avalia os aspectos ambientais e impactos potenciais associados a um sistema de produto, através da compilação de um inventário das entradas e saídas, da avaliação do impacto ambiental potencial, associado às entradas e saídas, e da interpretação dos resultados das fases de análise de inventário e avaliação de impacto em relação ao objetivo do estudo.

\footnotetext{
${ }^{1}$ Ribeiro, Flávio de Miranda. Inventário de ciclo de vida da geração hidrelétrica no Brasil - Usina de Itaipu : primeira aproximação. Dissertação (Mestrado). Silva, Gil Anderi da, orient. Programa Interunidades de Pós-Graduação em Energia. 2 v. São Paulo, 2003.

${ }^{2}$ Martins, Osvaldo Stella. Análise de ciclos de vida : como contribuição à gestão ambiental de processos produtivos e empreendimentos energéticos. Dissertação (Mestrado). Bermann, Célio, orient. Programa Interunidades de Pós-Graduação em Energia. 155 p + anexos. São Paulo, 1999.
} 
Deste modo, a ACV gera informações que permitem compreender o desempenho ambiental de um sistema de produto específico ou comparar dois ou mais produtos, a fim de se determinar a superioridade ou equivalência entre eles. As informações geradas podem auxiliar na elaboração de políticas públicas, no planejamento estratégico, na definição de prioridades, na revisão de processos ou produtos ou no desenvolvimento de novos processos ou produtos.

As principais características da ACV são:

1) a abordagem sistemática dos aspectos ambientais de um sistema de produto, desde a extração da natureza dos recursos desejados até a disposição na natureza dos resíduos produzidos;

2) a iteratividade entre as suas etapas; e,

3) a avaliação do sistema de produto em referência à sua função.

Como toda técnica, a ACV tem limitações e pode não ser a abordagem mais adequada para investigar qualquer questão ambiental de produtos ou processos. Por esta razão, a ACV deve fazer parte de um processo decisório mais amplo, onde outras técnicas também são utilizadas para fornecer informações ambientais complementares e informações sobre outras questões de interesse. As principais limitações da ACV típica são apresentadas a seguir:

- subjetividade em vários níveis e fases do processo;

- dependência da disponibilidade de modelos adequados;

- dependência da disponibilidade e qualidade dos dados;

- ausência das dimensões social e econômica;

- ausência das dimensões temporal (representação estática do sistema de produto), e espacial (assume-se que o todo o sistema ambiental é homogêneo).

\subsubsection{Estrutura da Avaliação de Ciclo de Vida}

A condução de estudos de ACV envolve as seguintes quatro etapas:

1) Definição de Objetivo e Escopo;

2) Análise de Inventário;

3) Avaliação de Impacto; e,

4) Interpretação. 


\subsubsection{Definição do Objetivo e Escopo}

A fase de Definição do Objetivo e Escopo fornece o plano inicial para a condução de uma ACV. Nesta fase, se determina a razão pela qual é conduzido o estudo de ACV e são descritos o sistema de produto e as categorias de dados. O objetivo e o escopo influenciam a direção e a profundidade do estudo, tratando questões como extensão geográfica e horizonte de tempo e a qualidade necessária dos dados requeridos. A llustração 1 apresenta a estrutura da etapa de Definição de Objetivo e Escopo.

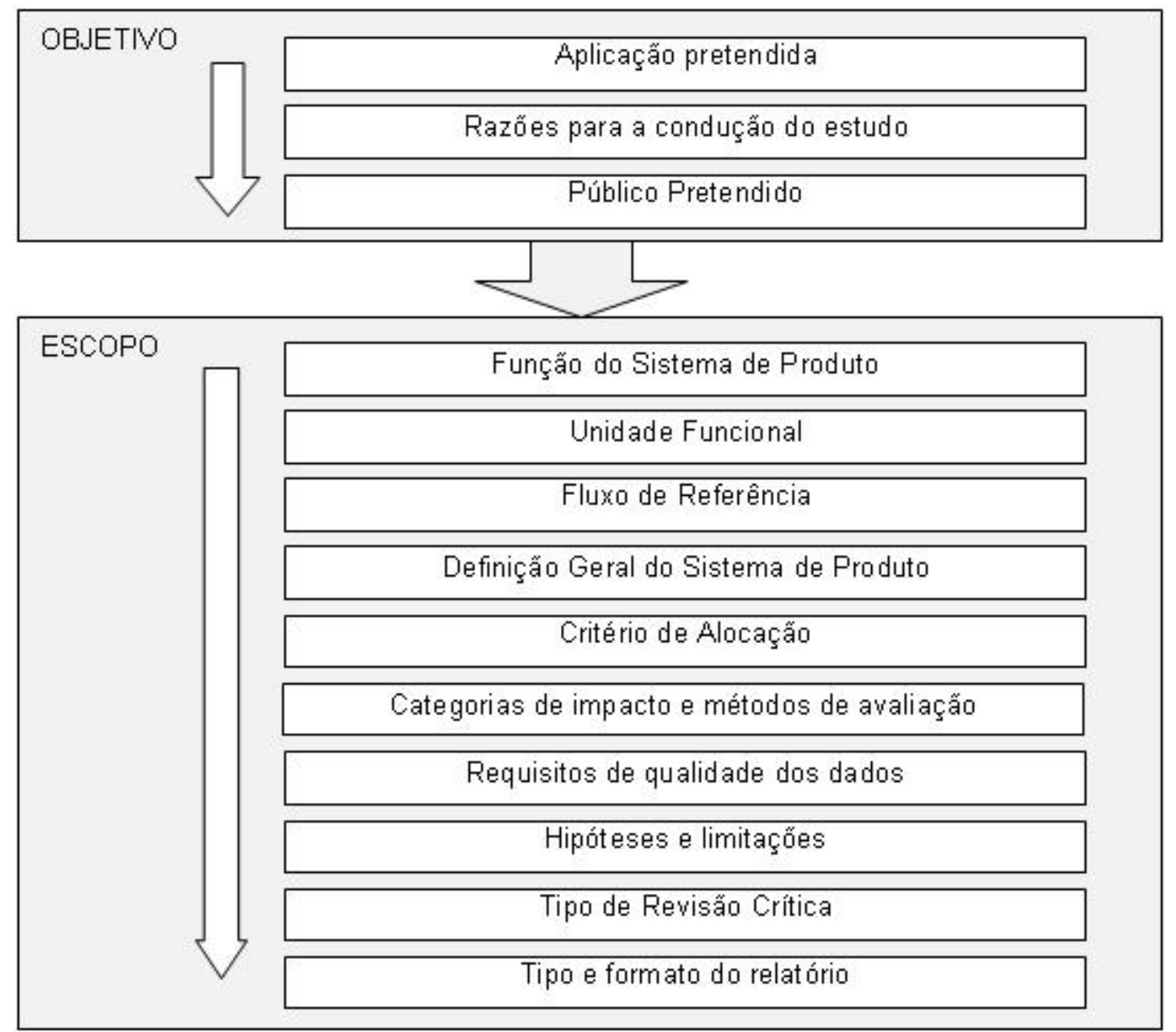

llustração 1 - Fluxograma esquemático das etapas realizadas na fase de Definição do Objetivo e Escopo em uma ACV (Elaboração do autor).

\subsubsection{Análise de Inventário do Ciclo de Vida}

A Análise do Inventário do Ciclo de Vida envolve uma sequência de atividades que se inicia com o planejamento da coleta de dados e termina na consolidação do inventário, como mostra a llustração 2. O inventário consolidado constitui a fonte de 
dados para a fase de avaliação de impactos, em uma ACV completa, ou para a fase de interpretação do ciclo de vida em estudos denominados Análise de Inventário de Ciclo de Vida. Ao longo do seu desenvolvimento, pode-se tornar necessário rever os requisitos de qualidade dos dados, bem como outros itens da fase de Definição de Objetivo e Escopo, em decorrência do maior conhecimento adquirido sobre o sistema de produto.

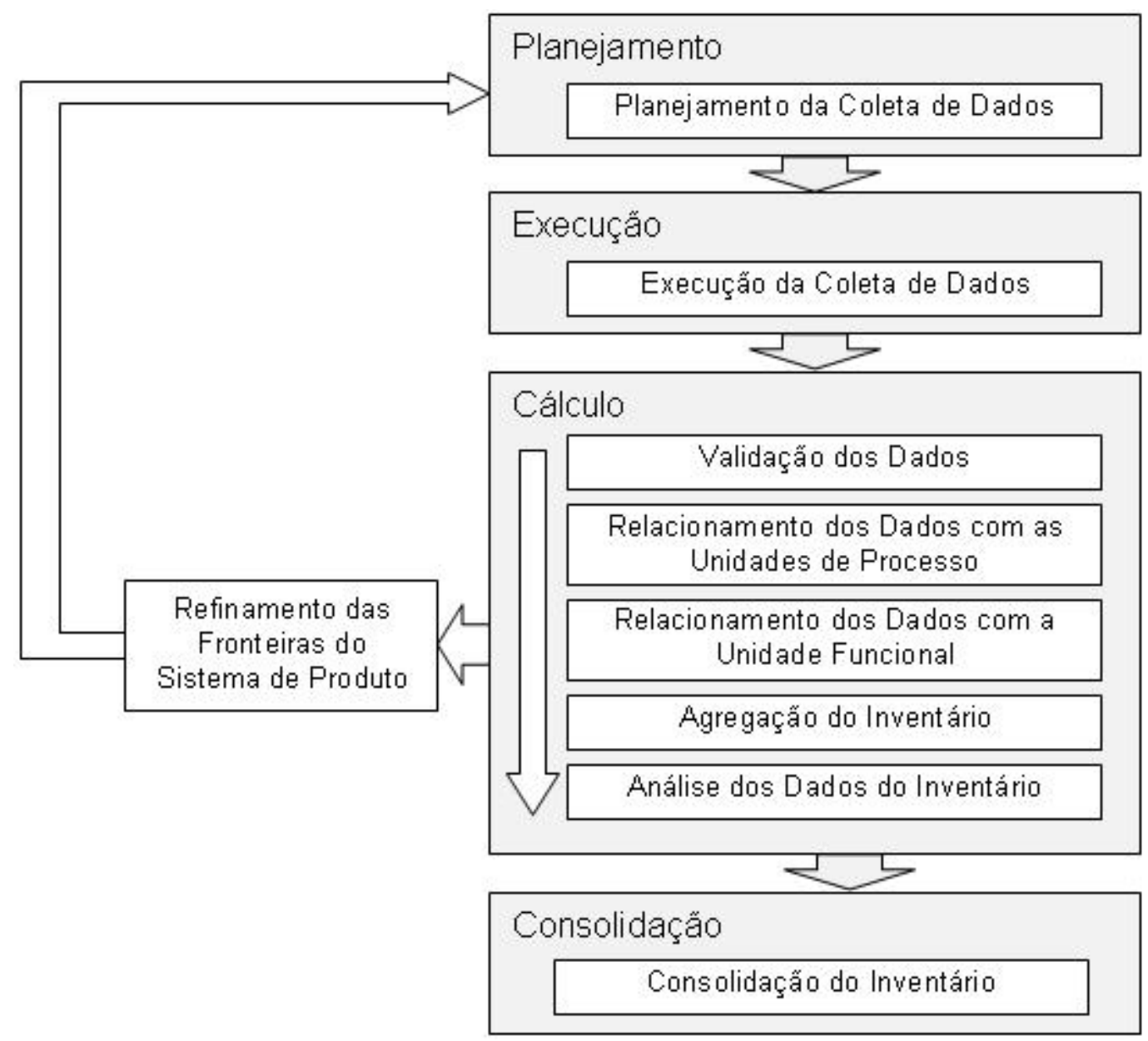

llustração 2 - Fluxograma esquemático dos passos da Análise de Inventário (Modificado de ISO 14044:2006).

\subsubsection{Avaliação de Impacto do Ciclo de Vida}

$\mathrm{Na}$ Avaliação de impactos, os dados do inventário são sistematicamente relacionados às categorias de impacto definidas no escopo (classificação) e multiplicados por fatores de caracterização desenvolvidos em métodos de avaliação de impacto (caracterização). Estes são os passos obrigatórios da Avaliação de Impactos que levam à obtenção do perfil de impactos ambientais do sistema de produto. Estes passos obrigatórios possuem embasamento científico, 
diferentemente dos passos opcionais que são a normalização, a ponderação e o agrupamento.

$\mathrm{Na}$ normalização, o perfil obtido da caracterização é comparado com informações de referência, para se obter a magnitude relativa de cada impacto ambiental. Na ponderação, são atribuídos pesos aos resultados de cada categoria de impactos. O agrupamento transforma os resultados dos indicadores das diferentes categorias de impacto em um indicador único.

\subsubsection{Interpretação do Ciclo de Vida}

$\mathrm{Na}$ fase de interpretação do ciclo de vida, os resultados da análise de inventário e da avaliação de impacto são abordadas conjuntamente, ou no caso da análise de inventário de ciclo de vida apenas a análise de inventário, de maneira consistente com o objetivo e escopo do estudo, para gerar conclusões e recomendações.

A fase de interpretação pode envolver o processo iterativo de revisar 0 escopo do estudo, bem como a natureza e a qualidade dos dados coletados consistente como o objetivo e escopo do estudo.

\subsection{Avaliação Social do Ciclo de Vida de Produtos}

A busca por uma metodologia de ACV Social é fortemente influenciada pelo sucesso da ACV (HUTCHINS \& SUTHERLAND, 2008). Entretanto, 0 desenvolvimento e a aplicação da ACV Social ainda são embrionários (HAUSCHILD, DREYER \& JORGENSEN et al., 2008). A ACV Social está no estágio em que grande parte das questões fundamentais não foram resolvidas de forma consensual, diferentes abordagens emergem, hipóteses são testadas e discutidas (JORGENSEN et al., 2008). Embora existam métodos para avaliar impactos sociais, não existe um código de conduta para incluir a dimensão social na idéia de ciclo de vida (LCT Life Cycle Thinking) (KRUSE et al., 2009).

Como declaram Kruse et al. (2009), os métodos propostos são largamente inconsistentes entre si e, geralmente, uma conclusão comum é de que mais esforços devem ser realizados, seja na proposta de novos métodos, na busca de uma abordagem consensual, ou na disponibilidade de dados e informações requeridas pelos métodos propostos. Labuschagne \& Brent (2006), por exemplo, declaram que 
a viabilidade de aplicação do método que propõem é limitada pela disponibilidade de informações sobre a pegada social, 'social footprint', das regiões incluídas no escopo geográfico do sistema de ciclo de vida do produto avaliado.

Segundo Klöpffer (2008), as principais dificuldades na ACV social parecem ser: 1) como relacionar quantitativamente os indicadores existentes à unidade funcional; 2) como obter dados específicos de cada região; 3) como decidir entre tantos indicadores possíveis; 4) como quantificar os impactos adequadamente; e, 5) como avaliar os resultados. Especialmente em relação a afirmação de haver vários indicadores, Haes (2008) discorda da existência de indicadores adequados ao propósito de uma ACV Social nos moldes da ACV. Haes (2008) destaca, como exceção, apenas o indicador 'horas de trabalho' definido por Hunkeler (2006), embora comente ainda que este indicador pode ser interpretado de forma ambígua, sua ocorrência pode ser igualmente positiva ou negativa, caso a caso, o que não é desejável.

Labuschagne \& Brent (2006) afirmam que o nível atual de desenvolvimento de medidas e indicadores sociais no ciclo de vida é semelhante ao estado de desenvolvimento da $\mathrm{ACV}$ há cerca de 20 anos. A llustração 3 apresenta a quantidade de publicações identificadas em um levantamento em bases de artigos científicos, para o período de 1993 a 1999, como uma medida do desenvolvimento da metodologia de ACV.

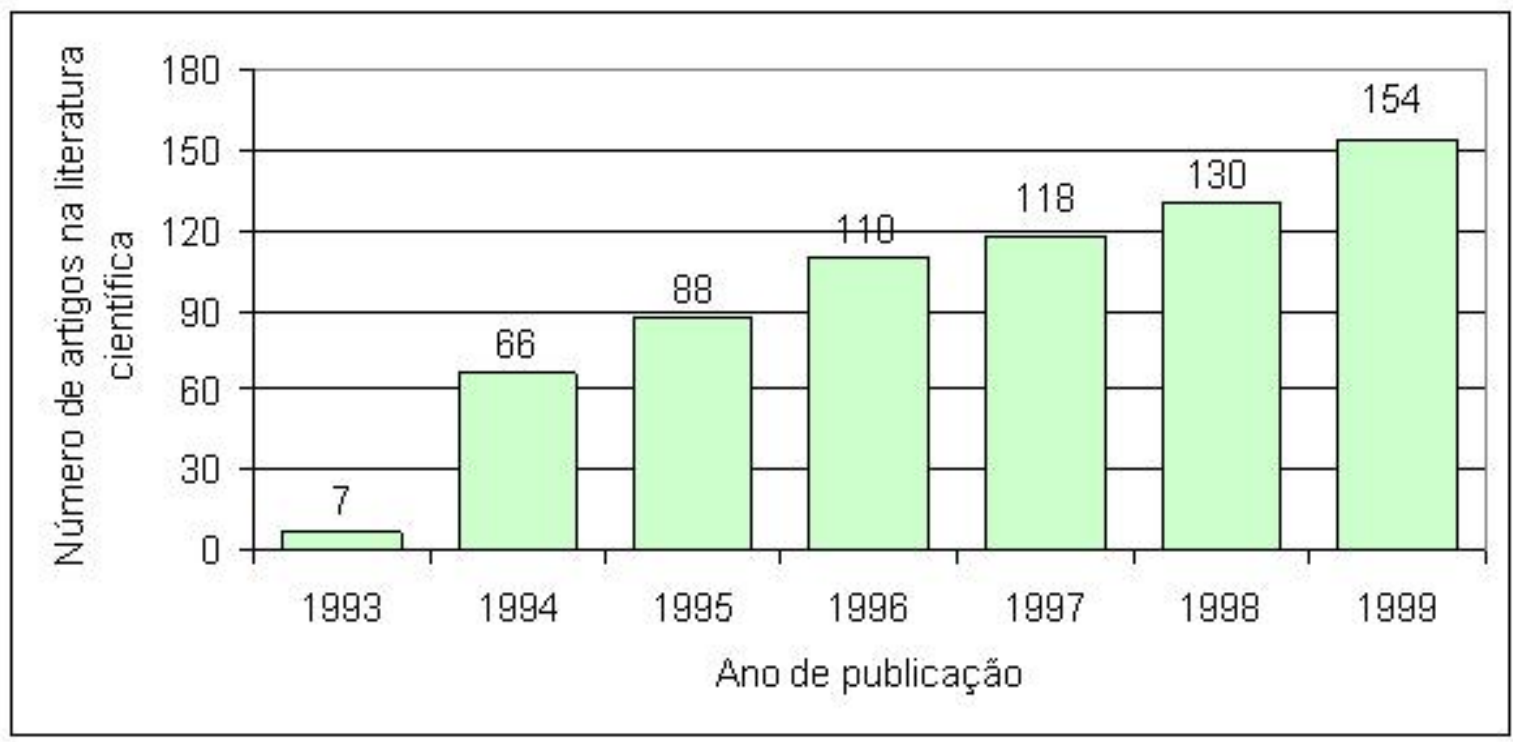

Ilustração 3 - Evolução entre 1993 e 1999 de artigos científicos sobre a Avaliação de Ciclo de Vida (BAUMANN \& TILLMAN, 2004). 
A ACV Social é vista como um complemento necessário à $A C V$, esta já com certa maturidade, e à Avaliação de Custos no Ciclo de Vida (LCC - Life Cycle Costing), menos desenvolvida que a ACV, mas muito mais que a ACV Social (HUNKELER, 2006). Como afirmam Labuschagne \& Brent (2006), a inclusão de aspectos sociais nas ações e debates sobre sustentabilidade sempre foram marginais, quando comparadas às dimensões ambiental e econômica, especialmente na perspectiva empresarial.

Para alguns autores, como Dreyer, Hauschild \& Schierbeck (2006), na ACV social, a empresa é a unidade fundamental do sistema de ciclo de vida do produto, e não o processo. Portanto, o inventário tem foco na conduta da empresa. Outros autores, como Barthel (2006) e Hunkeler (2006), por exemplo, apresentam propostas de ACV Social com foco no processo, bastante semelhantes à ACV.

A complexidade na medida dos impactos sociais também é variável entre as propostas de ACV Social (JORGENSEN et al., 2008). Algumas propostas defendem modelos detalhados e geograficamente específicos. Esta abordagem requer uma quantidade imensa de dados e torna necessário uma substancial redução do sistema de produto. Outras propostas utilizam fontes estatísticas e têm caráter macrosocial, como no caso de Norris (2006), ou microsocial, como em Hunkeler (2006) e Barthel (2006).

Haes (2008) não concorda com a afirmação de que a ACV Social, integrada metodologicamente à ACV típica, venha a ser a ferramenta mais adequada para tratar amplamente a dimensão social no ciclo de vida de produtos. Isto devido às diferenças entre o sistema social e o sistema ambiental. Ele acredita que a ACV social terá um papel complementar à $\mathrm{ACV}$, podendo ter pontos onde a integração é possível.

\subsection{1 Áreas de Proteção Social}

Dreyer, Hauschild \& Schierbeck (2006) declaram que é necessário definir claramente áreas de proteção social, semelhantes às definidas na ACV, que são Saúde Humana, Ambiente Natural, Recursos Naturais e Ambiente Humano. Jorgensen et al. (2008) afirmam que estas Áreas de Proteção, existentes na ACV, não são suficientes ou adequadas para a ACV Social, por terem sido desenvolvidas com foco ambiental. Dreyer, Hauschild \& Schierbeck (2006) reconhecem que a 
qualidade, positiva ou negativa, de um impacto sobre uma Área de Proteção Social pode depender da cultura, estrutura política e estágio sócio-econômico de desenvolvimento de cada sociedade.

Em uma ACV social, uma compreensão ampla da vida humana é necessária. Dreyer, Hauschild \& Schierbeck (2006) apontam três requisitos mínimos para uma vida saudável e digna:

1) Saúde, significando uma vida saudável e longeva;

2) Dignidade, significando usufruir de respeito e inclusão social; e,

3) Atendimento das necessidades básicas.

Com base nestes três requisitos, Dreyer, Hauschild \& Schierbeck (2006) propõem uma Área de Proteção Social denominada Dignidade e Bem-Estar Humanos. Os impactos sociais ficam, então, definidos como aqueles que causam dano ou benefícios à esta área de proteção.

Por outro lado, Norris (2006) considera que os aspectos sócio-econômicos do ciclo de vida de produtos seriam incluídos na área de proteção Saúde Humana, pois a consequência final dos impactos sociais e econômicos sobre as pessoas seria uma maior ou menor expectativa de vida saudável.

\subsubsection{INDICADORES SOCIAIS}

As propostas de ACV Social reúnem uma grande diversidade de categorias de impacto e respectivos indicadores, a maioria qualitativos (JORGENSEN et al., 2008; KOPFLER, 2008). Haes (2008) afirma que até o momento, nenhum indicador social proposto, mesmo os quantitativos, pode ser incluído e compreendido dentro da ACV. Entretanto, este indicador apresenta ambiguidade.

De acordo com Griesshammer et al. (2006), muitas listas de indicadores mascaram a complexidade dos itens individuais. Trabalho infantil é um exemplo. A definição de uma idade limite para o trabalho não é simples. Nas convenções da Organização Internacional do Trabalho (ILO - International Labor Organization), há várias idades limites para o início de atividades laborais. A idade geral para admissão no trabalho é 15 anos, podendo ser 13 anos se for trabalho leve. Se o trabalho envolver risco a idade é 18 anos, ou 16 anos em algumas condições. Adicionalmente, em regiões onde a economia e a estrutura educacional não estão suficientemente desenvolvidas, é possível ter uma idade geral mínima de 14 anos, podendo ser 12 anos em trabalhos leves. 
Griesshammer et al. (2006) também apontam que há indicadores que mudam seu significado dependendo do contexto geográfico em que ocorre. O indicador taxa de ausência do trabalho, pode ser usado para avaliar a saúde dos trabalhadores. Em algumas sociedades e alguns setores, este indicador por ser adequado. Mas em sociedades e setores altamente competitivos ou com relações de trabalho precárias, as pessoas irão para o trabalho mesmo doentes para não perderem o emprego.

Alguns métodos propostos de ACV Social adotam indicadores de impacto enquanto outros adotam indicadores de dano. Nos métodos que abordam indicadores de impacto, uma grande variedade de temas são tratados. Porém, nas abordagens orientadas ao dano, também não há consenso quanto a seleção das categorias de indicadores (JORGENSEN et al., 2008).

Segundo Jorgensen et al. (2008), as abordagens orientadas ao dano têm a vantagem de refletir o dano potencial direto sobre uma Área de Proteção. Portanto, em teoria, esta abordagem não requer uma ponderação dos resultados. Entretanto, para conectar os estressores, aspectos sociais, às áreas de proteção é necessário modelar uma cadeia de impactos de forma quantitativa e estável. A vantagem das abordagens orientadas ao impacto, apontada pelos mesmos autores, decorre dos resultados serem próximos dos elementos quantificados no inventário. Sendo mais compreensíveis para o tomador de decisões. Outra vantagem das abordagens orientadas ao impacto, seria a baixa ou controlada influência de valores subjetivos nos resultados finais. A modelagem de cadeias de impacto necessariamente envolve a inclusão de valores subjetivos que se acumulam ao longo da cadeia.

Hunkeler (2006) afirma que indicadores sociais como moradia, cuidados com a saúde, educação e necessidades básicas são muito dependentes da região onde ocorrem. Portanto, é importante especificar a distribuição geográfica do trabalho demandado no ciclo de vida.

O problema de usar como indicador o número de ocorrência de eventos reside no fato de que o sistema de registro das ocorrências pode ter falhas. Em uma ACV social avaliando comparativamente a conduta de empresas, uma empresa com sistema mais eficiente de registros pode ser julgada erroneamente em relação à outra com um sistema ineficiente de registros (JORGENSEN et al., 2008). Para evitar este problema, Dreyer, Hauschild \& Schierbeck (2006) propõem a quantificação dos esforços para prevenir a ocorrência de eventos que resultem em impactos negativos. Weidema (2006) propõe para a quantificação de trabalho infantil 
o cruzamento de dados demográficos sobre a população infantil e os registros escolares. Desvios entre os dados destas duas fontes seriam um indicativo de que crianças estaria de alguma forma sendo restringidas em sua autonomia, seja por trabalho infantil ou outras causas.

De acordo com Jorgensen et al. (2008), apesar do reconhecimento de que dados específicos levam a resultados mais acurados sobre a performance social de empresas, dados genéricos à semelhança dos bancos de dados para ACV ambiental também podem ser usados. Neste sentido, Norris (2006) e Hunkeler (2006) propõem a utilização de um único indicador, para o qual os dados estejam disponíveis. o que pode limitar a relevância dos resultados da avaliação. O método de Norris sempre indicará que a criação de empregos deveria ocorrer sempre nos países mais pobre, pois lá os impactos sociais positivos serão maiores.

Segundo Norris (2006), duas questões importantes na consideração de impactos sócio-econômicos, são:

1) a ocorrência de desvios ou erros sistemáticos nas estimativas; e,

2) a observância se valores médios de impactos são relevantes.

Em relação ao uso de valores médios, Norris (2006) comenta que há muitas evidências de que a maior parte da renda adicional associada ao crescimento econômico fica com os indivíduos mais abastados. Nos EUA, quase 2/3 dos ganhos das rendas dos homens foi para o $1 \%$ mais abastado, em um país onde $20 \%$ da população tem mais que $85 \%$ da riqueza total.

Para superar a questão de valores médio agregados, como renda média e expectativa média de vida, abordagens distribucionais têm ganhado foco. A seleção da renda limite, em um escopo regional, nacional ou internacional, também deve ser considerada. A renda necessária para garantir um padrão adequado de vida varia substancialmente entre os países, e mesmo dentro destes, podendo variar até entre grupos familiares, dependendo de características demográficas como números de pessoas por unidade familiar. Finalmente, o desenvolvimento econômico dos indivíduos pode gerar novas necessidades que antes não existiam (NORRIS, 2006). 


\subsubsection{CLASSIFICAÇÃo DE INDICADORES SOCIAIS}

Griesshammer et al. (2006) propõem que os principais indicadores sociais relacionados a um produto podem ser classificados em:

1) efeitos positivos ou negativos particularmente severos, diretamente atribuídos ao sistema de produto;

2) aspectos de utilidade e impactos sobre consumidores; e,

3) efeitos indiretos do uso do produto sobre a sociedade.

Muitos indicadores podem ser associados a mais de uma dimensão. Emprego e renda, por exemplo, podem ser atribuídos tanto à dimensão social como econômica. Aspectos da categoria de impactos na saúde podem ser atribuídos às dimensões ambiental e social (GRIESSHAMMER et al., 2006).

De acordo com Griesshammer et al. (2006), há dois sistemas complementares de classificação dos aspectos sociais. Na fase de definição de escopo e análise da ACV Social, deve-se agrupar os aspectos segundo os grupos afetados, 'stakeholder approach'. Na fase de avaliação, os aspectos podem ser também organizados por categorias de impacto.

Quatro categorias de grupos afetados são propostas para a classificação de indicadores sociais na fase de escopo (GRIESSHAMMER et al., 2006): 1) recurso humano (trabalhadores/empregados); 2) comunidade local; 3) consumidores; e, 4) sociedade em geral (nacional e ou global).

Para classificação na fase de avaliação são recomendadas as seguintes categorias de impacto (GRIESSHAMMER et al., 2006): 1) vida e longevidade; 2) saúde; 3) autonomia; 4) segurança pessoal, patrimonial e tranquilidade; 5) igualdade de oportunidades; 6) participação e Influência; 7) herança cultura; 8) produtividade humana; e, 9) recursos (capital natural e antropogênico).

\subsubsection{CADEIAS DE IMPACTO SOCIAL}

Diferentemente da $\mathrm{ACV}$, onde a relação causal que define a cadeia de impactos, desde os dados do inventário até o dano potencial a uma das áreas de proteção, já é aceita pela comunidade científica para a maioria das categorias de impacto, na ACV Social estas relações ainda estão sendo desenvolvidas (JORGENSEN et al, 2008). Aos buscar integrar na ACV todos os diferentes aspectos sociais, é essencial tratar cada impacto com relação à sua posição na 
cadeia de impactos ou nas diferentes categorias de danos. O conceito de cadeia de impactos foi introduzido na ACV social recentemente e as definições dos resultados dos inventários, indicadores de impacto intermediários e indicadores de danos, ainda não são precisas (WEIDEMA, 2006; HUTCHINS \& SUTHERLAND, 2008).

Segundo Weidema (2006), nas diferentes propostas de ACV Social, os elementos do inventário são tão distintos quanto: 1) itens do inventário (por exemplo, horas de trabalho infantil); 2) indicadores intermediários (por exemplo, educação perdida resultante das horas de trabalho infantil); 3) danos a valores instrumentais (por exemplo, renda perdida); e, 4) danos a valores intrínsecos tanto à saúde humana quanto ao bem-estar (por exemplo, limitações de autonomia), ou ainda a valores com valor de patrimônio (por exemplo, língua e costumes).

Da mesma forma que no ambiente biofísico, a modelagem da cadeia de impactos sociais pode ser tanto 'botton-up' como 'top-down'. Entretanto, Weidema (2006) sugere que a abordagem Top-down é mais adequada pois evita esforços desproporcionais em relação à importância dos impactos dos diversos indicadores possíveis.

Entre as cadeias de impacto relativamente simples de modelar estão (WEIDEMA, 2006):

1) saúde e segurança ocupacionais, baseado nos registros de ocorrência de doenças e acidentes de trabalho que podem ser relacionados aos danos à saúde;

2) o valor educacional de uma atividade ou ocupação, medido como aumento resultante da renda ao longo do restante de vida do indivíduo, em relação à média, considerando como impacto à produtividade humana (área de proteção); e,

3) trabalhos forçados e encarceramento, bem como trabalho infantil, que resultam na privação da realização de atividades que proporcionem desenvolvimento físico e mental adequados.

Cadeias de impacto com modelagem complexa são (WEIDEMA, 2006):

1) falta de acesso à seguridade social, que além do impacto imediato também apresenta impactos de longo prazo devidos à distribuição desigual na população;

2) os efeitos distribucionais sobre saúde, bem-estar e produtividade humanas é uma das cadeias de impacto mais complexas;

3) uso de recursos locais, que também possui um caráter distribucional;

4) igualdade de oportunidades, onde a dificuldade de modelagem inclui a renda a que os indivíduos se viram privados, bem como sua distribuição; e, 
5) Restrições à participação e influência e os movimentos populacionais.

A questão da distribuição dos aspectos sociais entre os indivíduos da população é uma dos pontos-chave na modelagem da cadeia de impactos. Os impactos não afetam todos os indivíduos da sociedade da mesma forma. Especialmente os indivíduos mais carentes sofrem impactos maiores, tanto positivos quanto negativos (WEIDEMA, 2006)

A llustração 4 apresenta cadeias de impacto ambiental e social simplificadas. As setas com linhas sólidas representam relações bem conhecidas e estabelecidas, enquanto que as linhas pontilhadas representam relações ainda não estabelecidas.

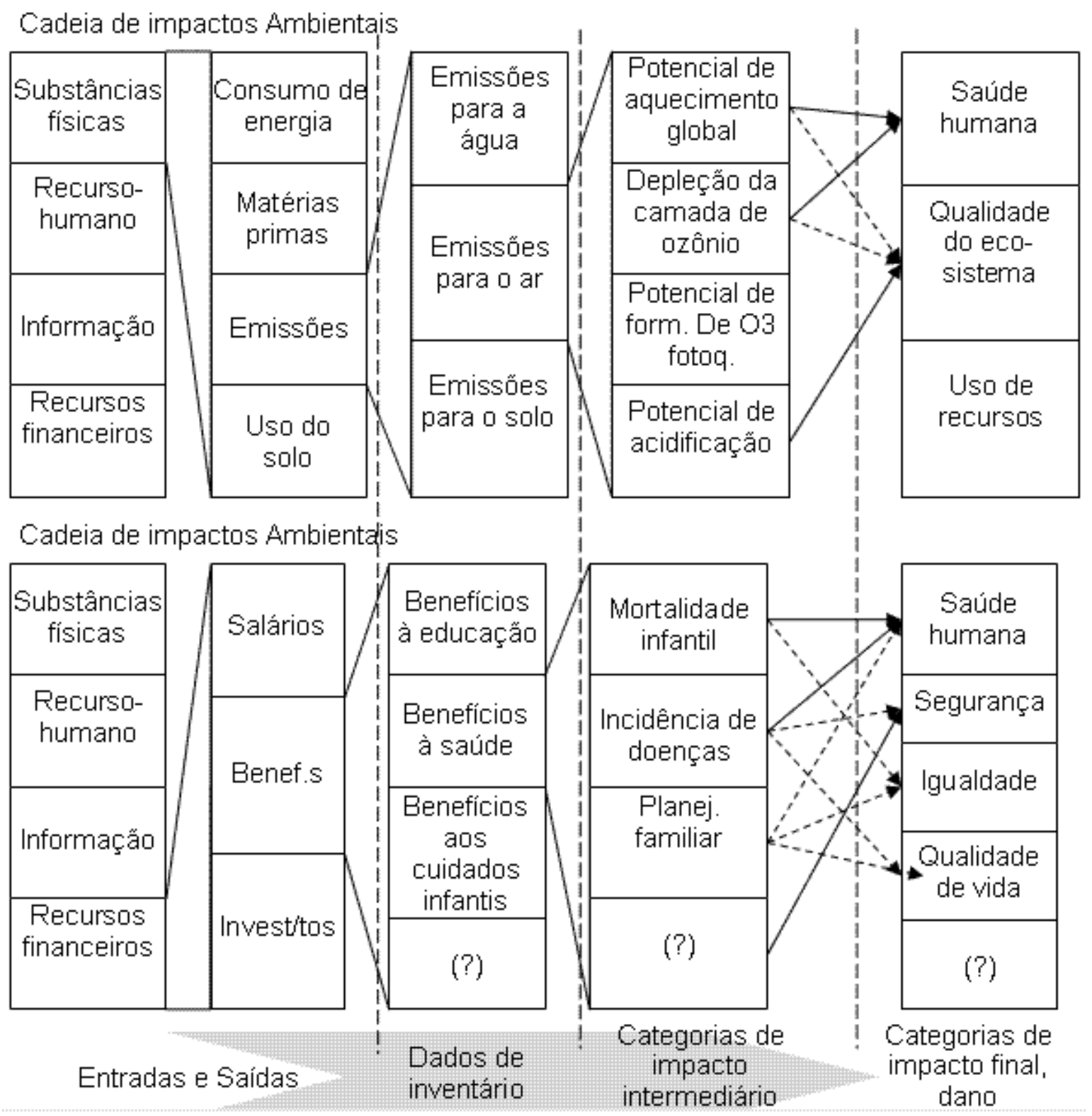

llustração 4 - Exemplos de cadeias de impacto ambiental e social (HUTCHINS \& SUTHERLAND, 2008). 


\subsubsection{Abordagens ao Processo de Consumo na ACV Social}

No que diz respeito à inclusão dos impactos sociais da etapa de uso, muito pouco foi proposto até o momento (JORGENSEN et al., 2008). Este fato pode ser atribuído à diversidade de impactos possíveis, de acordo com o produto avaliado, como afirmam Dreyer, Hauschild \& Schierbeck (2006) que sugerem uma categorização de produtos.

Griesshammer et al. (2006) declaram que a inclusão de impactos relacionados à etapa de uso é complexa e sugerem a inclusão da questão ainda na definição da unidade funcional do produto. Além da utilidade técnica, uma variedade de outros fatores como demanda de tempo, conveniência, prestígio etc. são importantes na demanda do produto pelo consumidor.

Barthel (2006) aponta duas dificuldades para a inclusão de impactos na etapa de uso do produto: 1) a função específica do produto, suas características na forma de usar e a dependência com o perfil dos usuários; e, 2) não existe uma sistemática para coleta de dados e relacionamento destes à unidade funcional.

\subsubsection{Propostas de MÉtodos de ACV Social}

As subseções seguintes descrevem resumidamente as principais propostas de métodos de ACV Social publicadas até o momento. A menos que indicado o contrário, a descrição e discussão dos métodos em cada subseção é baseada exclusivamente nos artigos que apresentam cada método.

\subsubsection{A ACV Social no Método SELCA}

O'Brien, Doig \& Clift (1996) apresentam um procedimento, integrado à ACV, para avaliação da dimensão social (processos sociais e políticos), no processo de tomada de decisão. Este método é denominado Avaliação Social e Ambiental do Ciclo de Vida (SELCA - Social and Environmental Life Cycle Assessment). O método SELCA investiga quais setores sociais geram impactos ambientais e como estes canais sociais são organizados e mantidos. Em outras palavras, o método SELCA indica os impactos ambientais quantitativos, diretos e indiretos, e a determinação social, organização e controle das rotas de impacto. O objetivo do método é identificar a ação social, ou desenvolvimento tecnológico, que pode ser promovido para gerar efeitos positivos no ciclo de vida investigado. 
A avaliação social e a ambiental têm origens em referenciais metodológicos diferentes, com distintas orientações disciplinares (O'Brien, Doig \& Clift, 1996), como mostra a Tabela 1.

Tabela 1 - Diferenças metodológicas entre as disciplinas fundamentais da avaliação ambiental do ciclo de vida (Engenharia) e da social (Ciência Social).

\begin{tabular}{|c|c|c|}
\hline Questão Metodológica & Ciência Social & Engenharia \\
\hline $\begin{array}{l}\text { Conceito de 'ciclo' e suas } \\
\text { consequências }\end{array}$ & $\begin{array}{l}\text { Processo instável com } \\
\text { fronteiras móveis e } \\
\text { complexas; foco analítico } \\
\text { na interconexão de } \\
\text { sistemas; reprodução e } \\
\text { variabilidade }\end{array}$ & $\begin{array}{l}\text { Processo estável com } \\
\text { fronteiras fixas; foco } \\
\text { analítico na conexão linear } \\
\text { entre partes componentes; } \\
\text { repetição ou continuidade } \\
\text { de impactos }\end{array}$ \\
\hline $\begin{array}{l}\text { Conexão entre o 'sistema' } \\
\text { e processos } \\
\text { socioeconômicos }\end{array}$ & $\begin{array}{l}\text { Processos socio- } \\
\text { econômicos constituem o } \\
\text { sistema que dão origem } \\
\text { aos danos ambientais }\end{array}$ & $\begin{array}{l}\text { Processos socio- } \\
\text { econômicos fornecem } \\
\text { respostas a operações } \\
\text { técnicas e podem afetar } \\
\text { danos ambientais }\end{array}$ \\
\hline Natureza dos dados & $\begin{array}{l}\text { Principalmente dados } \\
\text { primários, combinado com } \\
\text { dados secundários }\end{array}$ & $\begin{array}{l}\text { Algumas operações } \\
\text { descritas por dados } \\
\text { específicos do processo; } \\
\text { uso de dados fornecido por } \\
\text { operadores no sistema }\end{array}$ \\
\hline Abordagem metodológica & $\begin{array}{l}\text { 'Botton-up', abordagem } \\
\text { desagregada do sistema }\end{array}$ & $\begin{array}{l}\text { 'Top-down', abordagem } \\
\text { integral do sistema }\end{array}$ \\
\hline
\end{tabular}

(Adaptado de O'Brien, Doig \& Clift, 1996)

Duas consequências importantes, das diferenças metodológicas entre a avaliação ambiental e a social para o desenvolvimento do SELCA são: 1) a necessidade de adoção de um modelo mais complexo para a dimensão social do ciclo de vida de produtos; e, 2) não ter a unidade funcional como referência, possivelmente uma grande fonte de dificuldades metodológicas. A Ilustração 5 apresenta a estrutura do método SELCA composta pela avaliação ambiental (ELCA) e pela avaliação social (SLCA). 


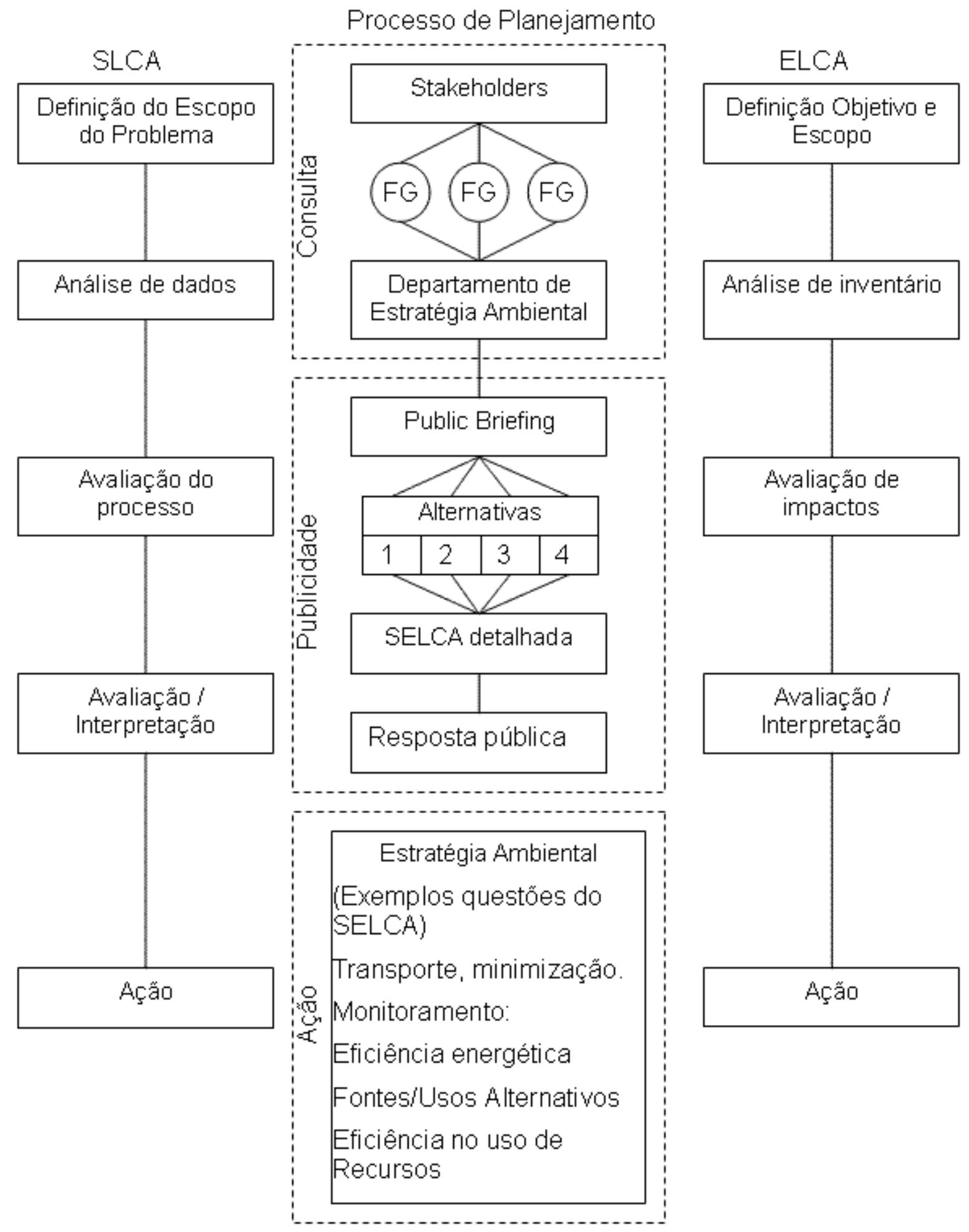

Ilustração 5 - Estrutura do método SELCA O'Brien, Doig \& Clift (1996). 
Segundo O'Brien, Doig \& Clift (1996), vários métodos de coleta e análise de dados sociais estão disponível, dos quais três são adotados no SELCA: 1) entrevistas; 2) análise de documentos; e, 3) Painéis com representantes de grupos afetados.

O método SELCA pressupõe que a definição do problema/objetivo é obtida de consultas e negociações entre todos os interessados/afetados. Podem ser organizados painéis para discutir o estudo com representantes de diferentes setores, e definir as dimensões ambiental e social de problemas locais. Este processo é importante porque usualmente a consulta à comunidades locais ocorre após definição de vários pontos por grupos específicos.

Após a definição dos problemas ambientais, os objetivos e a extensão do sistema a ser avaliado podem ser fixados para expressar as preocupações capturadas nas discussões e negociações com todos os grupos afetados. Deve-se produzir uma declaração das dimensões dos processos e alternativas para modificação ou melhoramento, com ampla divulgação para a sociedade.

A fase de definição de escopo identifica os parâmetros técnicos, sociais e ambientais iniciais associados às diferentes alternativas para se alcançar os objetivos. Processos operacionais e regulatórios importantes e as fontes de informações também precisam ser identificados. As fronteiras geográfica e temporal da avaliação também são definidas no escopo, bem como a abordagem metodológica, as hipóteses e os processos que serão incluídos. Os resultados da definição de escopo também devem ser divulgados para encorajar contribuições. As Tabela 2 e Tabela 3 a seguir apresentam as influências potenciais identificadas de danos ambientais sobre os canais sociais, e as influências que os processos sociais têm sobre os impactos ambientais, respectivamente.

As informações obtidas do método SELCA podem ser utilizadas em várias aplicações. A interpretação dos resultados pode gerar propostas de política ou estratégia ou recomendações sobre níveis de responsabilidade dos atores envolvidos. Os resultados da dimensão social e da dimensão ambiental podem ser divergentes quanto aos cursos de ação requeridos ou expor questões contrastantes. O método SELCA pretende reunir aspectos diferentes da sustentabilidade para gerar uma análise mais abrangente do desenvolvimento econômico e social. 
Tabela 2 - Influência de danos ambientais sobre canais sociais.

\begin{tabular}{|l|l|l|l|}
\hline Impacto Ambiental & \multicolumn{1}{|c|}{ Variável } & \multicolumn{1}{|c|}{ Influência } & $\begin{array}{l}\text { Exemplo de Área } \\
\text { Afetada }\end{array}$ \\
\hline $\begin{array}{l}\text { Exaustão de } \\
\text { recursos }\end{array}$ & $\begin{array}{l}\text { Custo e } \\
\text { disponibilidade de } \\
\text { matérias-primas; } \\
\text { diversidade }\end{array}$ & $\begin{array}{l}\text { Política pública } \\
\text { econômica, práticas } \\
\text { de negócios, } \\
\text { demanda }\end{array}$ & $\begin{array}{l}\text { Emprego e renda, } \\
\text { condição de } \\
\text { trabalho e vida, } \\
\text { invest.s sociais }\end{array}$ \\
\hline $\begin{array}{l}\text { Toxicidade, ruído, } \\
\text { qualidade do ar }\end{array}$ & $\begin{array}{l}\text { Saúde, incômodo, } \\
\text { conflito social }\end{array}$ & $\begin{array}{l}\text { Ação das } \\
\text { comunidades, } \\
\text { operação de } \\
\text { estabelecimentos }\end{array}$ & $\begin{array}{l}\text { Prioridades e } \\
\text { gastos públicos } \\
\text { locais, redes de } \\
\text { monitoramento }\end{array}$ \\
\hline $\begin{array}{l}\text { Gases ácidos, } \\
\text { aquecimento global, } \\
\text { depleção da } \\
\text { camada de ozônio }\end{array}$ & $\begin{array}{l}\text { Saúde, qualidade } \\
\text { do solo, erosão, } \\
\text { produtividade } \\
\text { agrícola }\end{array}$ & $\begin{array}{l}\text { Política pública } \\
\text { ambiental, } \\
\text { investimento } \\
\text { tecnológico }\end{array}$ & $\begin{array}{l}\text { Custos de proteção, } \\
\text { adaptação e } \\
\text { remediação, custos } \\
\text { em saúde }\end{array}$ \\
\hline
\end{tabular}

(Fonte: O'Brien, Doig \& Clift, 1996).

Tabela 3 - Influência de processos sociais sobre impactos ambientais.

\begin{tabular}{|l|l|l|l|}
\hline Proc. Sociais & \multicolumn{1}{|c|}{ Variável } & \multicolumn{1}{c|}{ Influência } & \multicolumn{1}{c|}{ Área Afetada } \\
\hline Controle & $\begin{array}{l}\text { Estrutura de } \\
\text { tomada de decisão, } \\
\text { classificação de } \\
\text { materiais }\end{array}$ & $\begin{array}{l}\text { Condições de } \\
\text { operação do } \\
\text { processo, tipo/nível } \\
\text { de participação }\end{array}$ & $\begin{array}{l}\text { Saúde ocupacional, } \\
\text { gestão de resíduos, } \\
\text { composição das } \\
\text { emissões e resíduos }\end{array}$ \\
\hline Organização & $\begin{array}{l}\text { Distribuição de } \\
\text { tarefas e benefícios }\end{array}$ & $\begin{array}{l}\text { Responsabilidade } \\
\text { sobre processos } \\
\text { Imateriais espec., } \\
\text { perdas /ganhos } \\
\text { públicos/privados }\end{array}$ & $\begin{array}{l}\text { Circ. de materiais, } \\
\text { agregação/separação } \\
\text { de resíduos, } \\
\text { desenvolvimento } \\
\text { tecnológico }\end{array}$ \\
\hline Ação & $\begin{array}{l}\text { Uso, suporte ou } \\
\text { resistência à } \\
\text { componentes do } \\
\text { processo }\end{array}$ & $\begin{array}{l}\text { material, promoção } \\
\text { ou paralisação de } \\
\text { atividades }\end{array}$ & $\begin{array}{l}\text { Geração de resíduos, } \\
\text { localização de } \\
\text { unidades, seleção de } \\
\text { tecnologias }\end{array}$ \\
\hline
\end{tabular}

(Fonte: O'Brien, Doig \& Clift, 1996). 


\subsubsection{A ACV Social Baseada no Conceito de Socioeficiência}

Schmidt et al. (2004) apresentam um método orientado a processos para avaliar a dimensão social de produtos. Este método é denominado de Socioeficiência e se integra à metodologia de eco-eficiência desenvolvida pela BASF. A ecoeficiência e a socioeficiência aumentam a performance ecológica e social em relação à criação de valor pela empresa. Estas abordagens avaliam apenas a melhorias ecológicas ou sociais relativas, que podem ser alcançadas pelo crescimento econômico, produzindo mais com menos impactos. De acordo com este conceito, a eco- e a socioeficiência contribuem para a sustentabilidade econômica da empresa, mas não necessariamente para sustentabilidade ecológica ou social, como mostra a llustração 6.

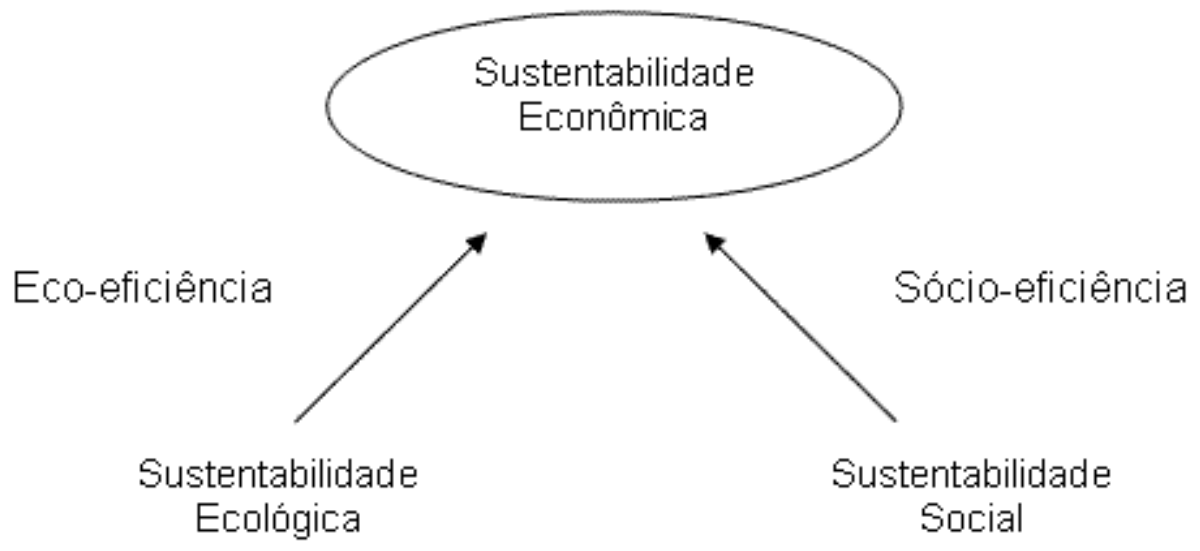

llustração 6 - Eco- e socioeficiência como estratégias para a sustentabilidade econômica. (DYLLICK AND HOKERTS, 2002 apud SCHIMIDT et al., 2004).

Produtos e processos socialmente sustentáveis são definidos por Schmidt et al. (2004) como: "Um produto ou processo é superior em relação à dimensão social da sustentabilidade, comparado com produtos ou processos alternativos, se este contribui mais para se alcançar objetivos sociais estabelecidos no debate internacional sobre desenvolvimento sustentável, ou se sua contribuição negativa é menor que a contribuição negativa das alternativas."

O método da Sócio-eficiência inclui os quatro tipos de capital que uma sociedade pode usufruir, apresentados na Tabela 4. Com base nestes quatro tipo de capital, a sustentabilidade social deve considerar os seguintes objetivos (BERGERSCHMITT \& NOLL, 2000 apud SCHMIDT et al. 2004): 1) Melhorar ou preservar os 
tipos de capital disponíveis para a geração atual e para as futuras; e, 2) promover a igualdade de oportunidades entre as gerações no acesso ao capital social.

Tabela 4 - Tipos de capital que uma sociedade pode usufruir e exemplos de indicadores.

\begin{tabular}{|l|l|}
\hline Tipo de Capital & \multicolumn{1}{|c|}{ Exemplos de Indicadores } \\
\hline Capital social, propriamente dito & $\begin{array}{l}\text { Redes sociais, associações e instituições } \\
\text { agrupadas por normas comuns e relacionamento } \\
\text { baseado na confiança }\end{array}$ \\
\hline Capital humano & $\begin{array}{l}\text { Capacidade produtiva das pessoas baseada em } \\
\text { suas habilidades, educação e saúde }\end{array}$ \\
\hline Capital físico / construído & Equipamentos, fábricas, infraestrutura, prédios \\
\hline Capital natural & Bens ambientais, solo, flora, fauna, florestas \\
\hline
\end{tabular}

(Fonte: BERGER-SCHMITT \& NOLL, 2000 apud SCHMIDT et al. 2004)

Schmidt et al. (2004) citam seis áreas de impacto na ACV Social, identificadas em um estudo do Öko Institute, apresentadas na Tabela 5. Estas áreas são conceitualmente idênticas às Áreas de Proteção definidas na ACV.

Tabela 5 - Principais áreas de impacto social e exemplos de indicadores.

\begin{tabular}{|l|l|}
\hline Área & \multicolumn{1}{|c|}{ Exemplos de Indicadores } \\
\hline Saúde humana & Prevenção de acidentes e doenças \\
\hline Nutrição & $\begin{array}{l}\text { Garantia de suprimento suficiente de } \\
\text { alimentos }\end{array}$ \\
\hline Condições de vida & Garantia de condições dignas de vida \\
\hline Educação e pesquisa & $\begin{array}{l}\text { Promoção da educação, treinamento } \\
\text { vocacional e P\&D }\end{array}$ \\
\hline Trabalho e condições de trabalho & $\begin{array}{l}\text { Criação de trabalho, atendimento às } \\
\text { normas internacionais de trabalho, } \\
\text { remuneração adequada }\end{array}$ \\
\hline $\begin{array}{l}\text { Outros aspectos de responsabilidade } \\
\text { social corporativa }\end{array}$ & $\begin{array}{l}\text { Comércio justo com países em } \\
\text { desenvolvimento }\end{array}$ \\
\hline
\end{tabular}

(Fonte: Schmidt et al., 2004) 
Um requisito básico para indicadores no método da Socioeficiência é que eles sejam adequados à estrutura da ACV. O uso de estatísticas industriais, como também afirma Barthel (2006), pode ser usado no cálculo de índices sociais. Nas etapas de produção e disposição de resíduos, os indicadores podem, a princípio, ser aplicáveis a qualquer produto, uma vez que é a estrutura destas operações que define os impactos sociais, e não o produto em si.

Para se obter o perfil social, os resultados individuais dos indicadores sociais investigados são agregados. Como os indicadores têm importâncias diferentes, Schmidt et al. (2004) propõem um sistema de ponderação baseado em dois tipos de fatores distintos: 1) fatores de ponderação por relevância; e, 2) fatores de ponderação subjetivos ou atribuídos pela sociedade. Os fatores de ponderação por relevância indicam a extensão da contribuição, devida aos produtos ou processos investigados, às questões sociais em nível nacional, e devem ser calculados para cada avaliação. Os fatores de ponderação subjetivos são constantes para todas as avaliações em uma mesma região geográfica, no mesmo escopo temporal. Estes fatores expressam uma avaliação subjetiva da importância dada pela sociedade sobre questões sociais. Os fatores de ponderação totais são obtidos pela média geométrica dos fatores de ponderação por relevância e subjetivos. A Ilustração 7 apresenta a composição dos fatores de ponderação totais.

\section{Fatores de Ponderação}

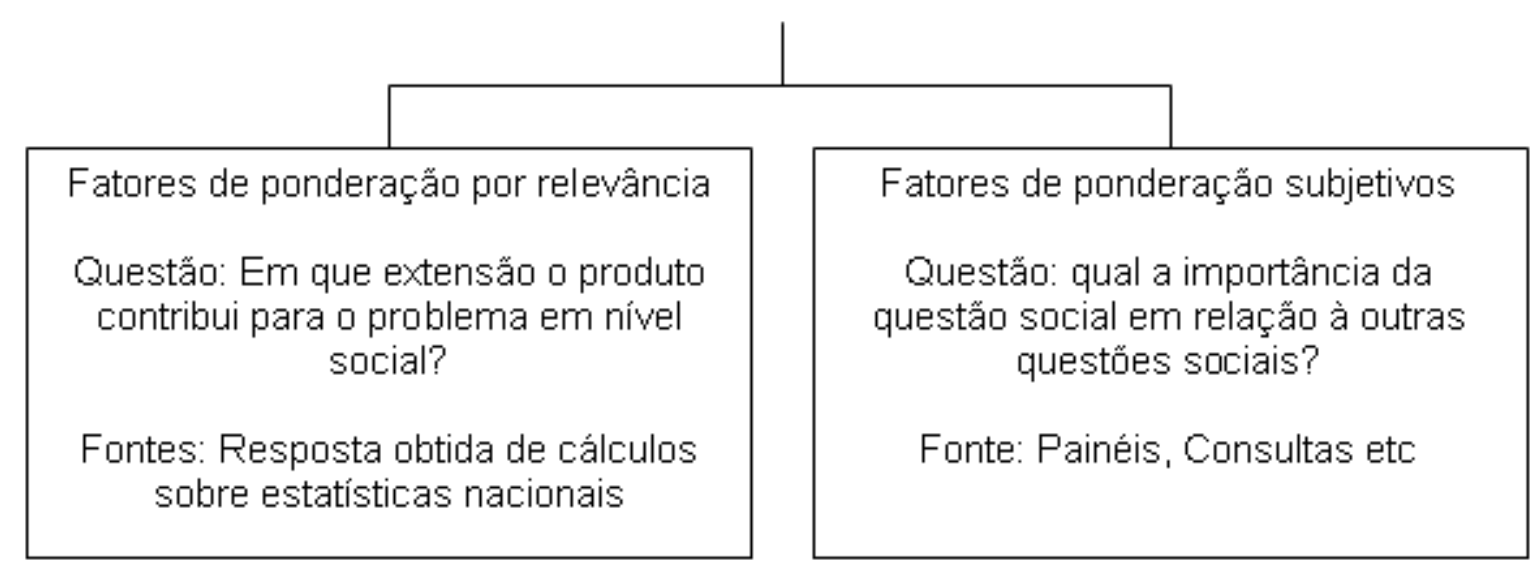

llustração 7 - Estrutura da composição dos fatores de ponderação totais no método da Socioeficiência (SCHMIDT et al., 2004). 


\subsubsection{A ACV Social Baseada na Conduta das Empresas}

Dreyer, Hauschild \& Schierbeck (2006) propõem um método para ACV social com foco na avaliação dos impactos sociais que ocorrem dentro da esfera de influência da instituição interessada no estudo. Deste modo, os resultados do emprego deste método objetivam dar suporte à instituição na tomada de informações, considerando os impactos nas vidas das pessoas afetadas pelo ciclo de vida do produto. Os autores defendem que a ACV Social deve ser orientada à instituição, ao invés de ser orientada aos processos. Pois, os impactos sociais estão relacionados, mais claramente, à conduta da instituição e à forma como esta se organiza e administra suas atividades.

Neste método, a etapa de uso do produto no ciclo de vida não é avaliada. Segundo Dreyer, Hauschild \& Schierbeck (2006), diferentemente das demais etapas do ciclo de vida de produtos, os impactos sociais decorrentes do consumo não podem ser atribuídos à conduta da instituição, mas unicamente ao ato de consumo do produto, pois é voluntário. De acordo com os autores, os impactos sociais associados ao consumo são sempre positivos, pois estão relacionados à satisfação de uma demanda.

Uma consequência da abordagem orientada à instituição é que a relação entre a conduta da(s) empresa(s) ao longo do ciclo de vida do produto e o produto não é direta e quantificável, como é a relação física entre os processos e os produtos. Portanto, é necessário buscar uma forma de relacionar os perfis sociais das instituições ao longo do ciclo de vida ao produto.

Dreyer, Hauschild \& Schierbeck (2006) adotam um modelo de avaliação com duas camadas de informações, uma obrigatória reunindo parâmetros comuns a qualquer instituição e outra opcional que reúne parâmetros específicos das instituições envolvidas.

Dreyer, Hauschild \& Schierbeck (2006) sugerem um fator de proporção que representa um peso atribuído ao perfil social de cada empresa. Este fator torna agregável os impactos sociais ao longo do ciclo de vida do produto. O peso de cada instituição pode ser determinado de várias formas, uma vez que ainda não há consenso sobre a mais adequada. Uma proposta é considerar a quantidade de horas de trabalho das pessoas em cada instituição, ajustada à unidade funcional definida para o produto. Outra possibilidade é relacionar à geração de valor ao longo 
da cadeia produtiva, considerando os balanços monetários de cada instituição ou etapa do ciclo de vida.

A decisão sobre quais parâmetros adotar para o cálculos dos fatores de proporção das instituições ou etapas do ciclo de vida deve obedecer a dois critérios: 1) é importante que sejas bem conhecidos e aceitos por todos os interessados no estudo, pois a definição dos fatores de proporção introduz subjetividade, desvios e tendências; e, 2) é de grande importância que os dados ou informações, necessárias para o cálculo dos fatores, estejam disponíveis para todas as instituições que constituem o sistema de ciclo de vida do produto.

Os perfis sociais das instituições podem ser mais ou menos abrangentes de acordo com a definição do escopo da avaliação e da complexidade da modelagem. A estrutura proposta por Dreyer, Hauschild \& Schierbeck (2006) permite trabalhar com várias categorias de impacto social, que reunidas dão uma impressão global da conduta social do ciclo de vida do produto. A interação de uma instituição com as pessoas afetadas (funcionários, comunidade local e sociedade como um todo) é bastante específica e complexa, o que dificulta a construção de um modelo geral de impactos sociais.

\subsubsection{A ACV Social Baseada nos Danos à Saúde Humana}

Norris (2006) descreve um método, desenvolvido pela Agência de Governo Japonesa (AIST) e pela Sociedade para a Tecnologia Não-Convencional (SNTT), para quantificar a magnitude potencial e a importância relativa de cadeias de impactos socioeconômicos na saúde. A metodologia da ACV foi expandida para incluir estimativas da variação na renda relacionadas à variação no consumo. $O$ objetivo deste método é permitir que a ACV capture, ainda que de forma preliminar, a influência sobre a saúde de mudanças de longo prazo nas atividades econômicas dos ciclos de vida de produtos. Também foi desenvolvido um método de avaliação de impactos no ciclo de vida, que inclui consequências à saúde devidas às cadeias de impactos socioeconômicos. A llustração 8 apresenta, de forma simplificada, cadeias de impactos socioeconômicos, desde a alteração no projeto do produto ou processo até o dano à saúde. As setas sólidas indicam a cadeia de impactos ambientais da ACV, enquanto que as setas pontilhadas indicam a cadeia de impactos socioeconômicos. 


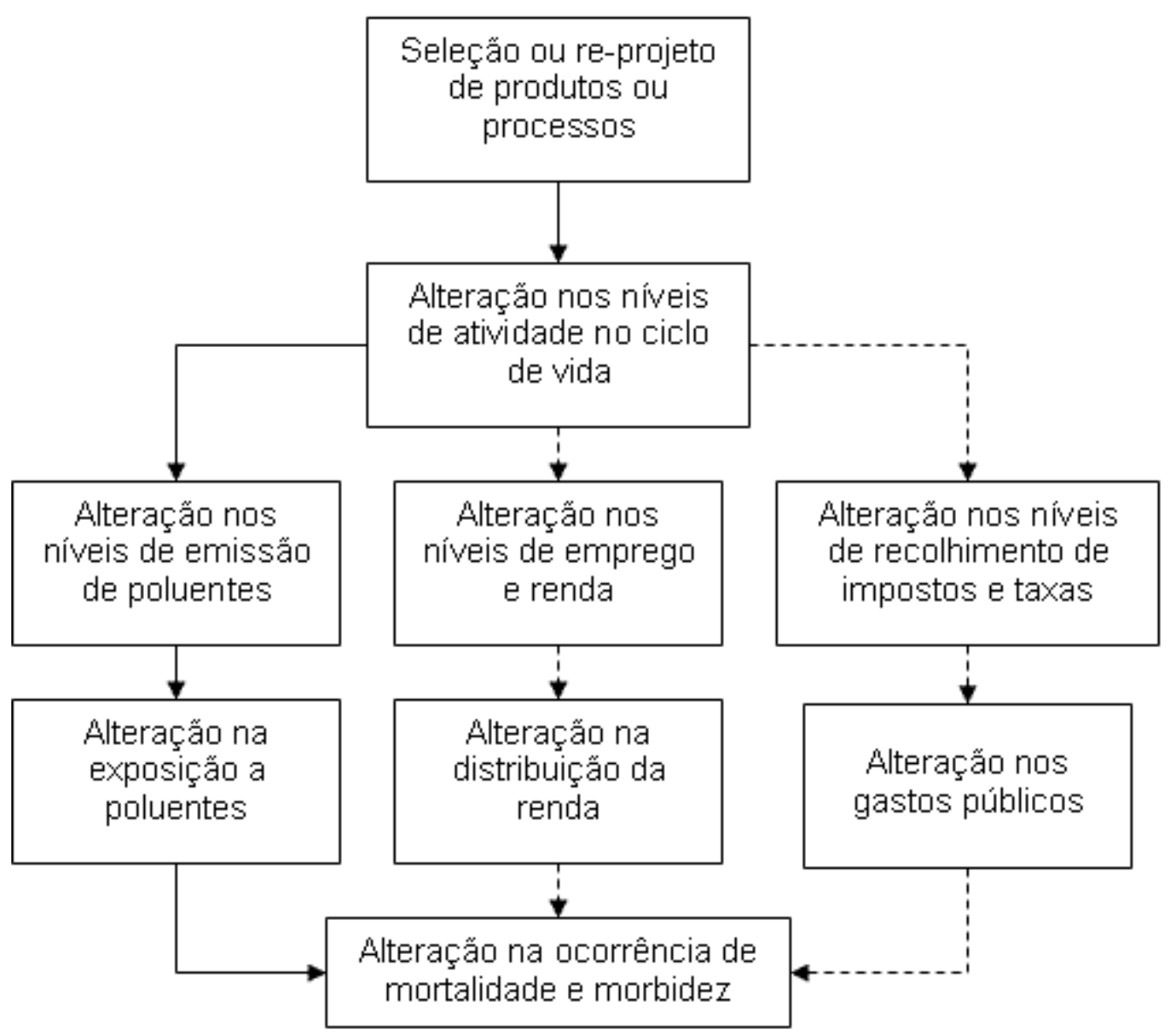

llustração 8 - Cadeias de impactos socioeconômicos entre alterações em processos ou produtos e as consequências finais à saúde humana (NORRIS, 2006).

Norris (2006) afirma que há fortes evidências de que a correlação entre os indicadores médios de renda e de saúde, nos vários países, pode ser explicada pela diferença na ocorrência de indivíduos com baixa renda e no nível dos gastos públicos na área de saúde. O escritório Europeu da Organização Mundial da Saúde (OMS) declarou a pobreza como o determinante mais importante para a condição de saúde precária (OMS, $2002^{3}$ apud NORRIS, 2006). Outro estudo da OMS aponta que países com condições precárias de saúde e educação tem mais dificuldade em alcançar um desenvolvimento sustentável, que países com melhores condições nestas áreas (OMS, 2001 ${ }^{4}$ apud NORRIS, 2006).

\footnotetext{
${ }^{3}$ OMS - Organização Mundial da Saúde. Escritório Europeu. European Health Report, Copenhagen. 2002.

${ }^{4}$ OMS - Organização Mundial da Saúde. Comissão de Macroeconomia e Saúde. Macroeconomics and Health: Investing in health for economic development. Genebra. 2001.
} 
O método descrito por Norris (2006) propõe uma relação não-linear entre a expectativa média de vida ao nascer e o Produto Interno Bruto (PIB) per capta, deste país ou região, expressa na equação:

$$
L E=a-b \times G N P P C^{-c}
$$

O termo ' $L E$ ' é a expectativa média de vida em anos, GNPPC é o PIB per capta de um país em dólares de 1999 ajustados pela paridade no poder de compra, e os parâmetros 'a', 'b' e 'c' são estimados pelo modelo em unidades de 'anos de vida por unidade monetária'.

A variação na quantidade de anos de vida vividos por uma população, $\triangle A V$, devida a uma variação na produção econômica de um país ou região, $\triangle G N P P C$, é dada pelo produto entre o número de indivíduos da população e a variação na expectativa média de vida $\Delta L E$, antes e depois da variação na produção econômica, como expressa a equação:

$$
\triangle A V=P o p \times\left(L E_{(G N P P C 1)}-L E_{(G N P P C 0)}\right)
$$

Esta equação pode ser reescrita para expressar a variação na quantidade de anos de vida vividos em função dos parâmetros 'a', 'b' e 'c', da população, do PIB inicial e da variação no PIB, como mostra a equação seguinte:

$$
\Delta A V=b \times P o p^{c+1} \times\left(G N P P C_{0}^{-c}-\left(G N P P C_{0}+\Delta G N P P C\right)^{-c}\right)
$$

Os resultados deste método apontam uma relação positiva entre crescimento econômico e impactos sociais que promovem a saúde e o bem-estar. Entretanto, Norris (2006) observa que séries temporais internacionais sobre a influência do crescimento econômico na redução da pobreza e melhoria da saúde pública indicam que estes resultados variam entre os países. A redução da pobreza requer que a renda e os benefícios do desenvolvimento alcancem as pessoas que, de outra forma, estariam em condição de pobreza. 


\subsubsection{A ACV Social Baseada na Quantificação das Horas de Trabalho}

Hunkeler (2006) apresenta uma metodologia, baseada na ACV, para avaliação social comparativa do ciclo de vida de produtos. O indicador adotado é a quantidade de horas de trabalho. As horas de trabalho, obtidas para cada etapa do ciclo de vida, são relacionadas à unidade funcional e agregadas ao longo do ciclo de vida. Este indicador é avaliado em relação a quantidade necessária para atendimento de necessidades básicas do indivíduo.

Uma ACV Social orientada às horas de trabalho implica que as características da dinâmica do trabalho em diferentes regiões (duração de jornadas de trabalho, estrutura salarial etc.) influenciam o resultado final. Hunkeler (2006) afirma ainda que evoluções tecnológica que resultem em maior produtividade, com redução de postos de trabalho, resultam sempre em impactos sociais negativos.

O método de ACV Social proposto por Hunkeler (2006) é composto de 5 etapas principais:

1) Levantamento de um inventário de aspectos ambientais para cada unidade de processo e para cada região.

Este inventário de aspectos ambientais é representado por uma matriz vetor $I_{i n}$, onde o índice 'i' se refere a um elemento do inventário e o índice ' $n$ ' se refere ao produto sendo avaliado.

2) Levantamento das horas de trabalho necessárias em cada unidade de processo para cada região geográfica.

O levantamento das horas de trabalho corresponde à matriz horas de trabalho, $E_{i j}$, onde o índice 'i' tem o mesmo significado que no vetor $I_{i n}$, e o índice 'j' corresponde à etapa do ciclo de vida onde ocorre o elemento 'i' do inventário. A componente $e_{i j}$ da matriz $E_{i j}$ corresponde às horas de trabalho relacionadas ao elemento 'i', na etapa 'j', do ciclo de vida de 'n'. A matriz de horas de trabalho, $E_{i j}$, é independente do produto avaliado, sendo dependente apenas da região geográfica.

Para os produtos intermediários, presentes no vetor $I_{\text {in }}$, as horas de trabalho são as relacionadas com os processos envolvidos para sua produção. Para as emissões presentes no vetor $I_{\text {in }}$, as horas de trabalho relacionadas são estimadas em função da atuação de indivíduos no monitoramento e/ou remediação. 
Uma matriz de correlação $\alpha_{i G}$ é desenvolvida para expressar a razão entre as horas de trabalho para duas regiões, para um elemento específico do inventário. Por exemplo, se a extração de um dado recurso na Rússia demanda $150 \%$ mais tempo de trabalho que na Alemanha, tomada como referência, o valor do elemento da matriz $\alpha_{i G}$ para este aspecto é de 1,5. A matriz $E_{i j} G$ representa as horas totais de trabalho obtidas do somatório de todos os produtos cujos processos ou atividades estão localizados em uma região geográfica $\mathrm{G}$, e é dada pela equação:

$$
E_{i j} G=E i_{j} \times \alpha i G
$$

3) O inventário de aspectos ambientais e o inventário de horas de trabalho são combinados para gerar a matriz de trabalho total, $H_{k j}$, dada por:

$$
H_{k j}=I_{i n} \times E_{i j} G
$$

O índice ' $k$ ' define um inventário de uma região geográfica específica e o índice 'j' tem o mesmo significado que em $E_{i j}$.

Cada produto tem sua própria matriz $H$, onde cada elemento $h_{k j}^{n}$ representa as horas de trabalho relacionadas a um elemento específico do inventário de ciclo de vida do produto 'n', para uma região geográfica ' $k$ ', na etapa 'j' do ciclo de vida.

4) Fatores regionais de caracterização são estimados.

O fator de caracterização, $C_{A}^{G}$, para uma região $\mathrm{G}$, corresponde ao número de horas de trabalho relacionada à uma categoria de impacto específica 'A'. Hunkeler (2006) propõe as seguintes categorias de impacto:

- moradia;

- saúde;

- educação; e,

- outras necessidades básicas.

5) Os fatores obtidos no quarto passo do desenvolvimento do método são aplicados no resultado do terceiro passo, para obtenção do perfil social do ciclo de vida do produto. 
O resultado final da ACV social proposta por Hunkeler é a matriz $S_{A}^{G, n}$ obtida da equação:

$$
S_{A}^{G, n}=\frac{\left(R^{G, n} \times W_{A}\right)}{C_{A}^{G}}, \operatorname{com} R^{G, n}=\sum H_{k n}
$$

O termo $R^{G, n}$ significa as horas totais de trabalho para todo o ciclo de vida do produto ' $n$ ', na região ' $G$ '; WA é um fator de ponderação arbitrário que distribui os empregos totais entre os impactos sociais avaliados, por exemplo numa abordagem igualitária com quatro categorias de impacto, seria igual a $1 / 4=0,25$.

Se for de interesse obter o resultado final em toda a cobertura geográfica, para uma determinada categoria de impacto, A, basta aplicar o somatório das regiões individuais, como mostra a equação a seguir.

$$
S_{A}^{1}=\sum S_{A}^{G, 1}
$$

\subsubsection{A ACV Social "Indicador de Impactos Sociais"}

Labuschagne \& Brent (2006) propõem um método para avaliar a sustentabilidade social de projetos e tecnologias na indústria de processos denominado Indicador de Impactos Sociais (SII - Social Impacts Indicator). Os autores definem critérios para medição dos impactos sobre os sistemas sociais que interagem com o sistema de ciclo de vida do processo ou tecnologia.

Este método foi desenvolvido tendo como base o método de avaliação de impactos ambientais proposto anteriormente por Brent, denominado Indicador de Impacto ao Recurso (RII - Resource Impact Indicator). O método RII considera o estado ambiental ou a pegada ecológica atual e a desejada ('target'), calculando a distância entre estes estados.

O método SIl considera quatro grupos definidos como áreas de proteção social: 1) Recurso humano interno; 2) População externa; 3) Performance Macro Social; e 4) Participação de grupos afetados.

O procedimento de cálculo do SII segue a seguinte equação: 


$$
S I I_{G}=\sum_{C} \sum_{X} Q_{x} \times C_{C} \times N_{C} \times S_{C}
$$

O termo $\mathrm{SII}_{\mathrm{G}}$ é o indicador de impacto social calculado para um determinado grupo social, obtido pela somatória de todas as cadeias de impacto de todas as intervenções sociais categorizadas para um dado sistema de ciclo de vida. Qx é a quantificação de uma intervenção social ' $X$ ' de uma categoria de impactos sociais ' $C$ ', que é uma informação específica dos impactos sociais do projeto ou tecnologia sob avaliação. Cc é o fator de caracterização para a categoria de impactos ' $C$ ', para a intervenção ' $X$ '. Nc corresponde ao fator de normalização para a categoria de impacto ' $C$ ', representado pelo inverso da condição ou estado desejado, na região em que ocorre o impacto. Esta informação pode ser obtida das informações sobre a pegada social para a região específica.

Labuschagne \& Brent (2006) propõem três formas para se expressar os dados das categorias de impacto em unidades equivalentes: 1) Abordagens tipo Avaliação de Risco, com uma avaliação subjetiva da probabilidade de ocorrência, frequência e intensidade potencial do impacto; 2) abordagens quantitativas, como medidas de custos e medidas diretas no sistema social impactado; 3 ) abordagens qualitativas, usando escalas de valor adequadas.

A extrapolação das intervenções de um projeto ou tecnologia não é indicada devido às especificidades regionais e características de conduta de cada instituição.

A inexistência de informações sobre a pegada social, 'social footprint', para todas as regiões e de informações sobre projetos e tecnologias dificultam a aplicabilidade do método para todas as categorias de impacto envolvidas. De modo que os autores sugerem a redução do número de categorias de impacto, o que afeta a abrangência do estudo. Quanto à escassez de informações sobre a pegada social, os autores apontam que esta é uma questão mundial.

\subsubsection{A ACV Social Baseada na Qualidade de Vida}

O método apresentado por Weidema (2006) avalia as consequências à saúde de impactos sociais. As seguintes categorias de impactos relacionados à área de proteção Vida Humana e Bem-Estar são consideradas:

1) Vida e Longevidade;

2) Saúde; 
3) Autonomia;

4) Segurança Pessoal, Patrimonial e Tranquilidade;

5) Igualdade de Oportunidades; e,

6) Participação e Influência.

O dano à vida é quantificado como morte prematura, afetando a longevidade da população. Variações na expectativa de vida são medidas em 'Anos de Vida Perdidos' (YLL - Years of Life Lost). A expectativa média de vida pode ser comparada à expectativa máxima de vida, quando não ocorrem mortes prematuras, para efeito de normalização.

A quantidade total de YLL para uma população pode ser ilustrada graficamente na forma do 'gap' de mortalidade, área A na llustração 9. O 'Gap' de Mortalidade corresponde à área entre a curva de sobrevivência e a curva de expectativa máxima de vida de toda a população. A curva de sobrevivência pode ser interpretada como a proporção da população que permanece vida a cada idade.

Impactos não fatais sobre a saúde humana também são medidos em função do tipo de deficiência (doença ou ferimento) e da duração da condição de deficiência. A unidade utilizada é 'anos-deficiência'. A cada forma de deficiência é atribuído um grau de severidade, numa escala de 0 a 1 . O grau de severidade 0 (zero) tem, por definição, a mesma severidade que a morte. O indicador é denominado anos de vida saudável perdidos por deficiência (YLD - Healthy Years Lost due to Disability). O indicador desta categoria de danos pode ser somado ao YLL resultando na unidade 'Anos de Vida Perdidos ou Ajustados por Deficiência' (DALY - Disability Adjusted Life Years).

O valor total de YLD para uma população é ilustrado na Ilustração 9 pela área $B$, delineada no limite superior pela curva de sobrevivência e no limite inferior pela curva que representa a expectativa de saúde. A expectativa de saúde corresponde à soma dos anos vividos com saúde perfeita (estado de saúde =1) e dos anos vividos com estado de saúde menor que 1, de acordo com a severidade da doença. A soma da área A com a área B resulta no 'Gap' de Saúde.

Em analogia aos impactos na saúde, outros impactos sobre o bem-estar requerem medidas da incidência e duração. Da mesma forma que os impactos à saúde, pode-se atribuir graus de severidade a estes impactos, em escala de 1 a 0. Novamente, 0 tem a mesma severidade que a morte. O indicador desta categoria é 'Anos de Bem-Estar Perdidos' (YWL - Years of Well-being Lost). Este indicador é 
comparável ao YLL e ao YDL, podendo-se portanto somá-los. A unidade do indicador resultante é 'Anos de Vida Ajustados pela Qualidade' (QALY - Quality Adjusted Life Years). Assim, o valor total do bem-estar não relacionado à saúde para uma população corresponde à área C na llustração 9 . O limite inferior é representado pela curva de expectativa de bem-estar e o limite superior pela curva de expectativa de saúde. A expectativa de bem-estar é a soma dos anos vividos com autonomia completa (estado de bem-estar $=1$ ) e dos anos vividos com bemestar menor que 1. A soma das áreas A, B e C é chamado de 'gap' do bem-estar.

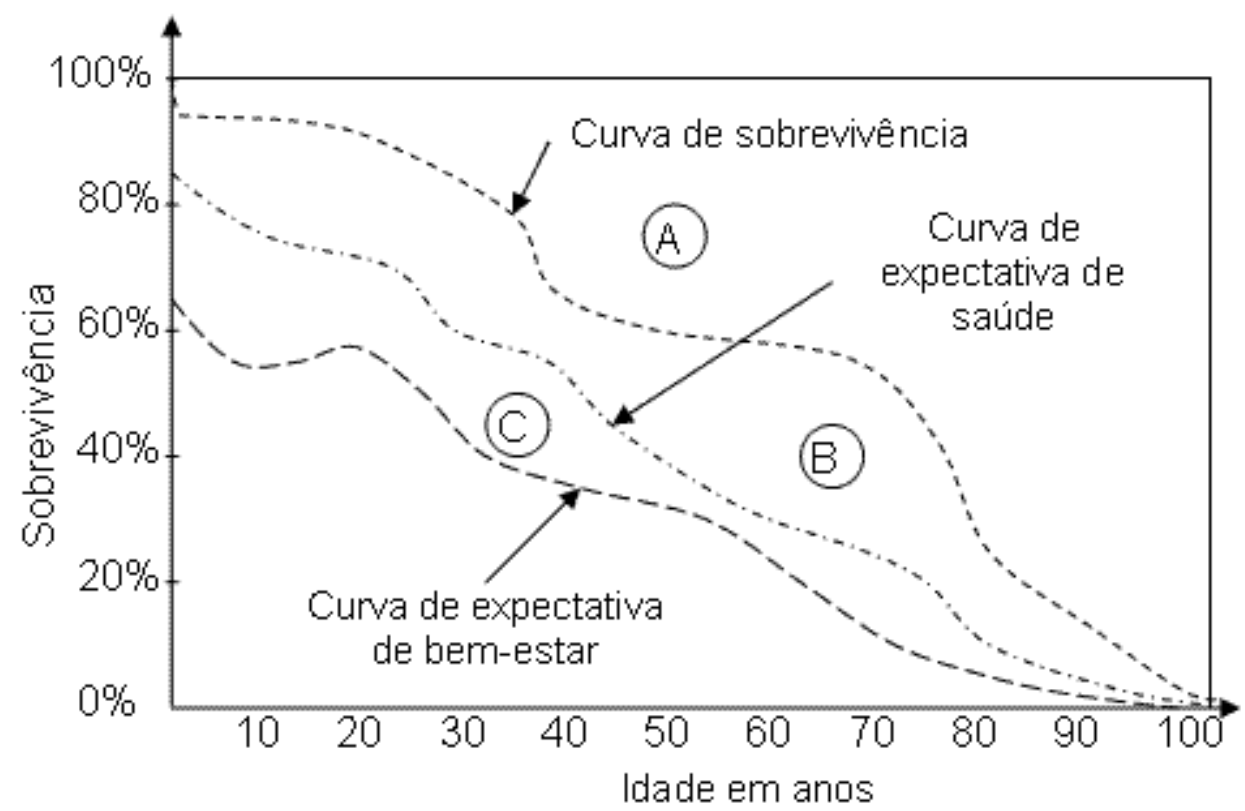

llustração 9 - Representação esquemática do gap de mortalidade (área $A$ ), do gap de saúde (área $A+B)$ e do gap de bem-estar (área $A+B+C$ ) (Weidema, 2006).

A categoria de impactos Autonomia significa ter controle sobre si e sobre seus recursos, além da saúde. De fato, impactos à saúde podem ser vistos como impactos à autonomia. Os impactos à autonomia podem ser passivos (restrições ao comportamento autônomo individual) ou ativos (comportamento forçado). De acordo com a natureza das restrições, os impactos à autonomia podem ser agrupados em:

1) Restrições que subjugam completamente o comportamento autônomo/voluntário, como escravidão, trabalhos forçados, detenção, aprisionamento, jornadas excessivas de trabalho, trabalho infantil, etc.

2) Restrições à integridade mental ou física, como tortura, mutilações, tratamentos ou punições degradantes, restrições sobre a sexualidade ou fertilidade. 
3) Restrições relacionadas a aspectos específicos de comportamento autônomo/voluntário, como migração, imigração, casamentos arranjados, liberdade de expressão, culto, regras morais etc.

A categoria de danos à segurança pessoal, patrimonial e tranquilidade cobrem a sensação psicológica de estar inseguro ou estressado. Além desta ansiedade direta, podem estar também envolvidas mudanças no comportamento relacionadas à sensação de insegurança ou estresse.

As Tabela 6 e Tabela 7 apresentam um cálculo preliminar dos danos globais para todas as categorias de impacto e para a categoria de impactos Ansiedade, respectivamente. $\mathrm{Na}$ Tabela 7 , assume-se que cada item tratado é uma causa de ansiedade independente e tem uma QALY de 0,1. Desconta-se 10\% para compensar a ansiedade já considerada nos impactos à saúde.

Tabela 6 - Estimativa preliminar do dano ao bem-estar global, dados de 2002.

\begin{tabular}{|l|c|c|}
\hline & (E+6 Daly) & Perc. do bem-estar total (\%) \\
\hline Valor inicial de bem-estar & 6.230 & 100 \\
\hline Impactos & -1.700 & -27 \\
\hline Mortalidade & -960 & -15 \\
\hline Impactos não letais à saúde & -930 & -15 \\
\hline Restrições à autonomia & -300 & -5 \\
\hline Ansiedade & -160 & -3 \\
\hline Desigualdade nas oportunidades & -380 & -6 \\
\hline Restrições na participação & 1800 & 29 \\
\hline Valor líquido do bem-estar &
\end{tabular}

(Fonte: Weidema, 2006)

Tabela 7 - Estimativa preliminar do dano global da ansiedade não-clínica.

\begin{tabular}{|l|c|c|c|}
\hline Impacto & $\begin{array}{c}\text { MM de pessoas } \\
\text { afetadas anualmente }\end{array}$ & $\begin{array}{c}\text { QALY } \\
\text { (por pessoa afetada) }\end{array}$ & MM QALY \\
\hline $\begin{array}{l}\text { Acesso inadequado à } \\
\text { serviços de saúde }\end{array}$ & 1.600 & $-0,09$ & -140 \\
\hline $\begin{array}{l}\text { Acesso inadequado à } \\
\text { seguridade social }\end{array}$ & 680 & $-0,09$ & -61 \\
\hline
\end{tabular}

Continua. 
(Continuação da Tabela 7)

\begin{tabular}{|l|c|c|c|}
\hline Impacto & $\begin{array}{c}\text { MM de pessoas } \\
\text { afetadas anualmente }\end{array}$ & $\begin{array}{c}\text { QALY } \\
\text { (por pessoa afetada) }\end{array}$ & MM QALY \\
\hline $\begin{array}{l}\text { Ameaças de violência } \\
\text { ou crimes violentos }\end{array}$ & 130 & $-0,09$ & -12 \\
\hline $\begin{array}{l}\text { Invasão de } \\
\text { propriedade, ou } \\
\text { tentativa, para roubo }\end{array}$ & 220 & $-0,09$ & -20 \\
\hline $\begin{array}{l}\text { Trânsito ameaçador } \\
\text { ou traumatizante }\end{array}$ & 140 & $-0,09$ & -13 \\
\hline $\begin{array}{l}\text { Condições de } \\
\text { trabalho estressantes }\end{array}$ & 600 & $-0,09$ & -54 \\
\hline Total & & & -300 \\
\hline
\end{tabular}

(Fonte: Weidema, 2006)

\subsubsection{A ACV Social para Cadeias Produtivas}

Hutchins \& Sutherland (2008) propõem um método para caracterizar a sustentabilidade social de uma cadeia produtiva. Cada empresa participante de uma cadeia produtiva tem um valor de performance social, 'sj', para cada indicador de performance 'j'. Uma medida da sustentabilidade total da empresa, Sc, pode ser obtida somando os valores de cada indicador, como na equação abaixo.

$$
S_{C}=\sum_{j=1}^{n}\left(W_{j} \times S_{j}\right)
$$

O elemento 'Wj' corresponde ao fator de ponderação do indicador de performance 'j', e pode variar caso a caso, a critério do estudo. A performance social da empresa em relação à cadeia produtiva é obtida com base no valor da produção de um determinado produto da empresa, V. Desta forma, a contribuição da empresa que ocupa a posição mais avançada na cadeia produtiva, para a sustentabilidade desta, 'Zc", é dada por: 


$$
Z_{C}=S_{C} \times V
$$

Da mesma forma, a performance de sustentabilidade social dos fornecedores, $\mathrm{Zi}$, é dada por:

$$
Z i=S_{i} \times C_{i}
$$

Ao invés do valor de mercado do produto, ' $\mathrm{V}$ ', utiliza-se o custo 'Ci' para a empresa que adquire o produto intermediário do fornecedor 'i'. O termo Si é obtido da mesma forma que SC.

A performance de toda a cadeia produtiva, ZO, é obtida somando a componente da empresa principal com a somatória de seus ' $k$ ' fornecedores como mostra a equação abaixo.

$$
Z_{O}=\sum_{i=1}^{k} Z_{i}+\left(S_{C} \times V\right)
$$

\subsubsection{A ACV Social Baseada em Indicadores de Sustentabilidade Existentes}

Kruse et al. (2009) propõem a operacionalização de padrões de sustentabilidade já aceitos, com um conjunto de indicadores socioeconômicos amplamente aplicáveis, para complementar a ACV. A seleção dos indicadores considera tanto as questões de grande relevância para a sociedade como a disponibilidade de dados e o interesse dos grupos afetados.

Três critérios são propostos para nortear a seleção de indicadores: 1) relevância, 2) praticidade, 3) validade. A relevância do indicador requer que este considere normas de sustentabilidade estabelecidas de forma compreensível. O critério de praticidade trata da medição acurada do indicador ou existência e fácil coleta de dados. A validade do indicador se relaciona especificamente com o método de coleta do dado.

Os Indicadores socioeconômicos selecionados são agrupados segundo dois tipos: indicadores aditivos e indicadores descritivos. Os indicadores aditivos devem 
atender a dois critérios: 1) serem quantitativos; e, 2) serem relacionáveis à unidade funcional. Por outro lado, os Indicadores descritivos devem seguir os seguintes critérios: 1) serem medidos ou descritos quantitativa ou qualitativamente ao longo de qualquer ponto do ciclo de vida; e, 2) não serem relacionáveis à unidade funcional. Os indicadores descritivos podem ser subdivididos em outros dois grupos: indicadores específicos e indicadores gerais. Da mesma forma que os indicadores aditivos, indicadores descritivos gerais devem cobrir valores sociais amplos. Indicadores descritivos específicos, por outro lado, são orientados a impactos socioeconômicos relevantes de produtos ou processos específicos. A Tabela 8 apresenta alguns exemplos de indicadores.

Tabela 8 - Indicadores aditivos, descritivos geral e específico.

\begin{tabular}{|c|c|c|}
\hline Indicador Aditivo & Ind. Desc. Geral & Ind. Desc. Específico \\
\hline Custos de produção & Salário necessário & Contribuição para a renda \\
\hline Custos trabalhistas & Benefícios trabalhistas & Preço justo \\
\hline $\begin{array}{l}\text { Custos trabalhistas por } \\
\text { gênero }\end{array}$ & $\begin{array}{l}\text { Horas trabalhadas média } \\
\text { por semana }\end{array}$ & $\begin{array}{l}\text { Acesso de trabalhadores } \\
\text { ao emprego }\end{array}$ \\
\hline $\begin{array}{l}\text { Custos trabalhistas por } \\
\text { origem do trabalhador }\end{array}$ & $\begin{array}{l}\text { Concentração de } \\
\text { estabelecimentos }\end{array}$ & $\begin{array}{l}\text { Ocorrência de operador- } \\
\text { proprietário }\end{array}$ \\
\hline Valor adicionado & Distribuição etária & Atendimento às leis \\
\hline Pessoa-hora & Trabalho forçado & \multirow[t]{2}{*}{ Cota de produção } \\
\hline Pessoa-hora por gênero & Discriminação por gênero & \\
\hline \multirow{4}{*}{$\begin{array}{l}\text { Pessoa-hora por origem } \\
\text { do trabalhador }\end{array}$} & Direito de organização & \multirow{4}{*}{$\begin{array}{l}\text { Adjacência do trabalhador } \\
\text { em relação ao local de } \\
\text { trabalho }\end{array}$} \\
\hline & Idade mínima & \\
\hline & $\begin{array}{l}\text { Distância percorrida para } \\
\text { trabalhar }\end{array}$ & \\
\hline & $\begin{array}{l}\text { Acesso a banheiro e água } \\
\text { potável }\end{array}$ & \\
\hline
\end{tabular}

(Fonte: KRUSE et al., 2009) 


\subsubsection{A ACV Social Baseada em Fontes Estatísticas}

Barthel (2006) afirma que fontes estatísticas podem ser usadas para fornecer dados sociais úteis para um método de ACV Social orientado ao processo. A abordagem proposta se baseia nas seguintes hipóteses:

1) em um setor da indústria (com tipos de processos similares) os impactos sociais de cada unidade do sistema são proporcionais à quantidade de trabalho humano envolvido; e,

2) a quantidade de trabalho humano envolvida é proporcional ao valor adicionado pela unidade de processo.

A segunda hipótese, no entanto, parece ser equivocada. Como argumenta Haes (2008), um elevado valor em horas de trabalho pode significar tanto que muitos postos de trabalho estão envolvidos, como que o processo é obsoleto e tem baixa produtividade.

A combinação do perfil dos trabalhadores, de uma atividade, com a relação de níveis de qualificação leva à obtenção do perfil de qualificação do trabalho para cada atividade. Este perfil mostra quanto tempo de trabalho é requerido na empresa em cada nível de qualificação. Para este procedimento, as seguintes hipótese são tomadas:

1) o tempo de trabalho anual não varia substancialmente entre trabalhadores de diferentes níveis de qualificação; e,

2) a proporção dos funcionários para os quais não há dados tem a mesma estrutura de qualificação que a proporção para qual há dados.

O perfil social é calculado com base no tempo, medido em segundos, de trabalho, da qualificação do trabalho, e das taxas de acidentes fatais e não fatais associados à unidade monetária do valor adicionado pelo processo. O valor adicionado de cada unidade de processo é determinado subtraindo o custo das entradas dos valores das saídas. Este método está embutido no software de ACV GaBi.

\subsubsection{A Avaliação de Atributos no Ciclo de Vida (AACV)}

Conforme afirma Haes (2008), a AACV não é especificamente um método de ACV social. Entretanto, como um processo pode ter como atributo uma certificação social, é possível aplicá-lo. O método AACV utiliza modelos de ciclo de vida 
existentes para agregar dados sobre atributos de processos ao longo da cadeia produtiva. O objetivo é calcular a quantidade total de produtos de todos os processos relevantes em uma cadeia produtiva cujos processos: 1) têm o atributo de interesse; 2) não têm o atributo de interesse; ou, 3) faltam dados sobre o status do processo em relação ao atributo (NORRIS, 2006).

Spillemaeckers (2007) apresenta um método de ACV social desenvolvido e utilizado pelo governo Belga desde 2003, que tem a mesma essência da AACV. As empresas que comprovam que as convenções da OIT são atendidas em toda sua cadeia produtiva recebem um selo de responsabilidade social. 


\section{PROPOSTA DE MÉTODO PARA AVALIAÇÃO SOCIAL DE CICLO DE VIDA DE PRODUTOS}

A Avaliação Social do Ciclo de Vida de Produtos, proposta nesta Tese, é desenvolvida a partir da definição de categorias de sustentabilidade e seus indicadores, do estabelecimento de critérios operacionais e de índices parciais como resultados destas categorias. Os resultados dos indicadores das categorias de sustentabilidade são utilizados na obtenção de um índice agregado parcial que é, finalmente, transformado no Índice de Sustentabilidade do Produto, atendendo aos critérios operacionais de todas as categorias avaliadas.

\subsection{A Dimensão Social de Sistemas de Produtos}

Um sistema de produto interage com o sistema social através de indivíduos, que desempenham as funções de recurso humano e/ou consumidor. A sobreposição entre estes conjuntos de indivíduos leva à quantificação de um número maior indivíduos do que o obtido pela soma dos indivíduos físicos. Entretanto, isto não afeta a avaliação, independentemente da extensão em que ocorre, pois esta considera a função dos indivíduos no sistema de produto.

A sobreposição é clara quando se avalia produtos, como alimentos e energia, destinados ao consumo interno de um país. Neste caso, praticamente todos os indivíduos do conjunto recurso humano são também consumidores potenciais. A exclusão entre estes conjuntos ocorre quando o sistema de produto é total, ou parcialmente, dedicado a um conjunto consumidor distinto do conjunto recurso humano, por natureza geográfica, social, econômica, etc.

A llustração 10 apresenta as interações entre o sistema de produto e o sistema social, em (a) o recurso humano está totalmente incluído no conjunto consumidor e em (b) os dois conjuntos são completamente excludentes. Em ambos os casos, a distribuição dos valores das variáveis de interesse pode ser diferente entre os conjuntos. Esta diferença é discutida na seção 4.5.3. 

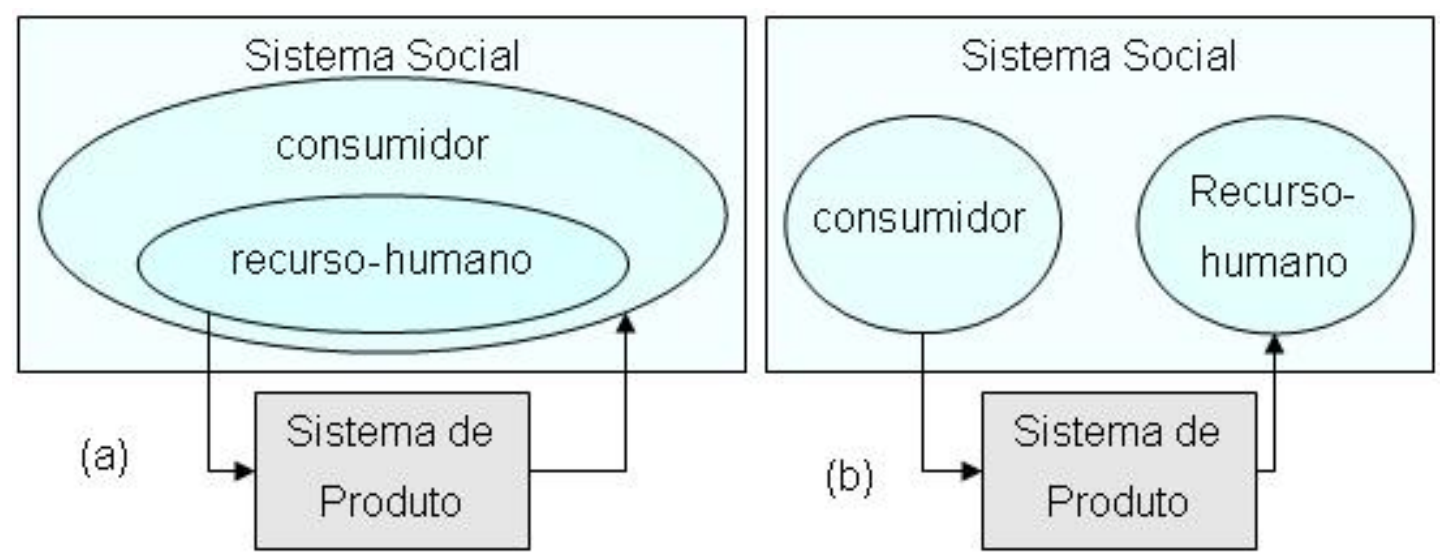

llustração 10 - Representação das interações entre o sistema de produto e o sistema social através dos conjuntos recurso humano e consumidor.

\subsection{Categorias de Sustentabilidade Social de Produtos}

Duas categorias de sustentabilidade são propostas para a avaliação social do ciclo de vida de produtos: 1) Atendimento de Necessidades Básicas; e, 2) Autonomia Intelectual.

O Atendimento de Necessidades Básicas corresponde à capacidade do indivíduo ter acesso a produtos e serviços, necessários para sua sobrevivência digna, e de sua unidade familiar, no sistema social.

A Autonomia Intelectual corresponde à condição que confere ao indivíduo capacidade crítica frente às questões que afetam sua vida, e capacidade de participar ativamente na organização e desenvolvimento do sistema social e do sistema de produto que o emprega.

O Atendimento de Necessidades Básicas e a Autonomia Intelectual dos indivíduos, em um sistema social, não são atribuições de sistemas de produtos. Portanto, devem ocorrer, garantidos pelo próprio sistema social, independente da existência de sistemas de produto. Entretanto, à medida que os sistemas sociais se tornam mais complexos, um número crescente de sistemas de produto é necessário para atender as necessidades e desejos de indivíduos, que passam a desempenhar a função de consumidor. Consequentemente, outros indivíduos são demandados para desempenhar a função de recurso humano. Se esta demanda ocupa indivíduos, para atender à outros indivíduos, os sistemas de produto envolvidos devem assegurar ao recurso humano empregado, no mínimo, condições suficientes ao seu desenvolvimento humano dentro do sistema social a que pertence. 


\subsection{INDICADORES DE SUSTENTABILIDADE SOCIAL DE PRODUtoS}

Para a avaliação da sustentabilidade social de produtos é necessário a definição de indicadores, quantitativos e agregáveis ao longo do ciclo de vida, para cada categoria de sustentabilidade.

\subsubsection{O Indicador da Categoria de Sustentabilidade Atendimento de NeCEssidades BÁsicas}

A renda monetária anual é adotada como o indicador da categoria de sustentabilidade social Atendimento de Necessidades Básicas. Outros benefícios do trabalhador, incluindo os não monetários como plano de saúde, cesta básica, acesso a clubes etc., podem ser introduzidos futuramente, através da valoração em unidades monetárias, de modo que possam ser somados à renda monetária anual.

A categoria de sustentabilidade social Atendimento de Necessidades Básicas trata do atendimento, através de uma renda mínima, das necessidades vitais básicas com moradia, alimentação, educação, saúde, lazer, vestuário, higiene, transporte e previdência social para um indivíduo e sua família. Esta renda mínima é descrita no Artigo 7o, inciso IV da Constituição da República Federativa do Brasil, promulgada em 5 de outubro de 1988 (SENADO FEDERAL, 2006). Entretanto, a Constituição não define o número de indivíduos que constitui cada unidade familiar, e permite interpretar que este salário mínimo se refere à renda de um único indivíduo que é responsável por suprir toda a demanda da unidade familiar.

O valor desta renda é estimado mensalmente pelo Departamento Intersindical de Estatística e Estudos Sócio-Econômicos (DIEESE), e é denominado de Salário Mínimo Constitucional ou Salário Mínimo Necessário. Na estimativa deste valor, o DIEESE considera uma família composta por dois adultos e duas crianças que têm o padrão de consumo de um adulto (DIEESE, 2005). A Tabela 9 apresenta os valores anuais médios ponderados do Salário Mínimo (SM) e do Salário Mínimo Necessário (SMN), de1997 a 2007. 
Tabela 9 - Valores médios ponderados do Salário Mínimo (SM) e do Salário Mínimo Necessário (SMN) e valor anual do SMN, em reais, valores nominais.

\begin{tabular}{|c|c|c|c|}
\hline Ano & SM (R\$) & SMN (R\$) & $\mathbf{1 2} \times \mathbf{~ S M N ~ ( R \$ ) ~}$ \\
\hline 1997 & 117,33 & 802,55 & $9.630,60$ \\
\hline 1998 & 126,67 & 878,09 & $10.537,08$ \\
\hline 1999 & 134,00 & 901,14 & $10.813,68$ \\
\hline 2000 & 147,17 & 967,07 & $11.604,84$ \\
\hline 2001 & 172,75 & $1.072,68$ & $12.872,16$ \\
\hline 2002 & 195,00 & $1.188,69$ & $14.264,28$ \\
\hline 2003 & 230,00 & $1.421,01$ & $17.052,12$ \\
\hline 2004 & 253,33 & $1.482,61$ & $17.791,32$ \\
\hline 2005 & 286,67 & $1.510,36$ & $18.124,32$ \\
\hline 2006 & 337,50 & $1.500,71$ & $18.008,52$ \\
\hline 2007 & 372,50 & $1.679,77$ & $20.157,24$ \\
\hline
\end{tabular}

(Fonte: DIEESE Salário mínimo nominal e necessário, disponível em www.dieese.org.br)

O número de pessoas constituindo a unidade familiar no cálculo do SMN pelo DIEESE é conservador em relação aos resultados da Pesquisa Nacional por Amostra de Domicílios (PNAD), realizada pelo Instituto Brasileiro de Geografia e Estatística (IBGE), em 2006. A llustração 11 apresenta os resultados do número de pessoas por unidade familiar na PNAD para as regiões geográficas do Brasil e a média nacional (IBGE, 2006). Pode-se afirmar que, ao menos para este subconjunto da população brasileira, a estimativa do salário mínimo necessário realizada pelo DIEESE é sensivelmente superior à realidade da unidade familiar brasileira média atual, com 3,2 indivíduos por arranjo familiar contra 4 da estimativa do DIEESE. 


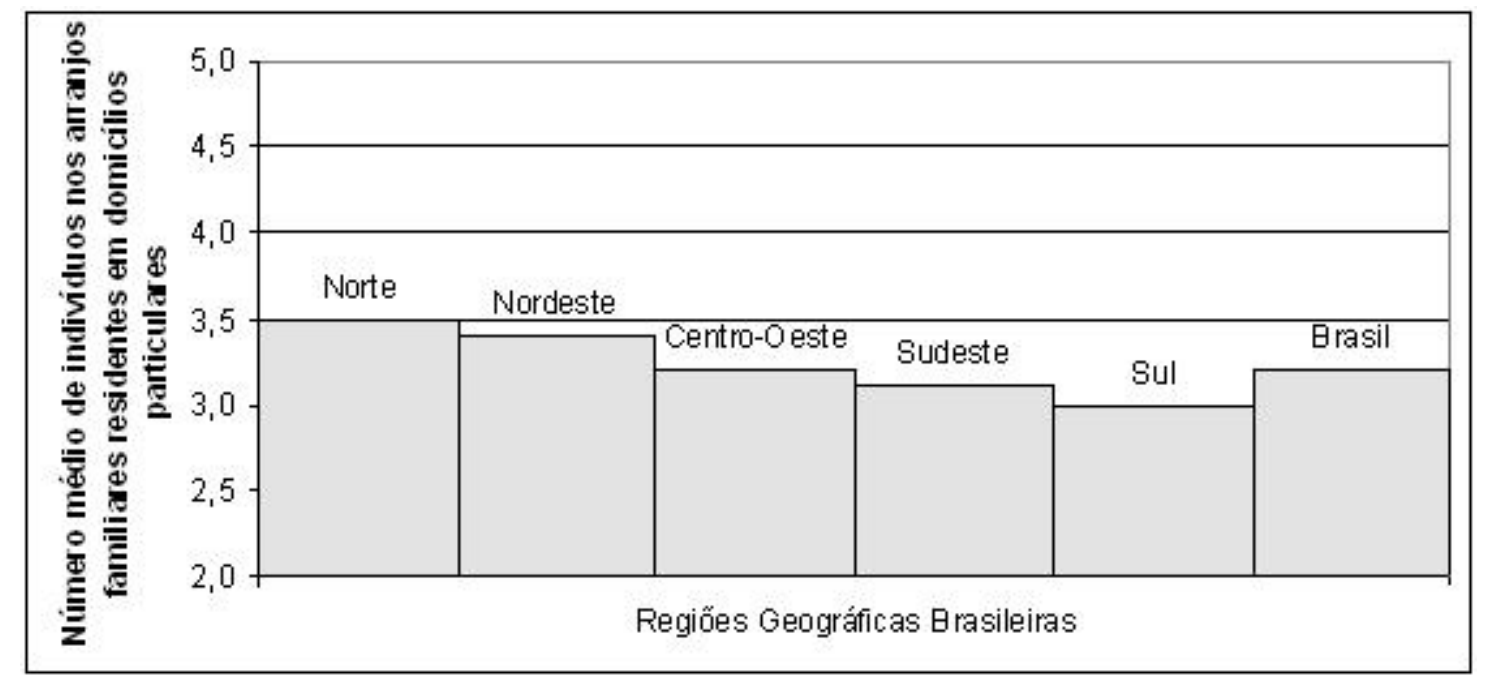

Ilustração 11 - Número médio de indivíduos por unidade familiar, residente em domicílio particular, levantado na PNAD 2006, por região geográfica Brasileira (Fonte: IBGE, 2005).

\subsubsection{O Indicador da Categoria de SustentabiLidade Autonomia INTELECTUAL}

Para a categoria de sustentabilidade social Autonomia Intelectual, o indicador adotado é a escolaridade ajustada pela duração do vínculo entre o sistema social e o sistema de produto. Da mesma forma que na categoria Atendimento de Necessidades Básicas, outros indicadores, quantitativos e agregáveis, relacionados à outras formas de educação/instrução de indivíduos, podem ser desenvolvidos de forma adequada a serem somados ao indicador proposto nesta Tese.

O artigo 205 da Constituição Federal Brasileira diz que a Educação é um direito de todos e dever do Estado e da família, e que a educação visa o pleno desenvolvimento do indivíduo, seu preparo para o exercício da cidadania e sua qualificação para o trabalho (SENADO FEDERAL, 2006).

Um sistema de produto pode ser entendido como a materialização de toda a capacidade intelectual mobilizada pelo recurso humano ao longo do ciclo de vida do produto. Os sistemas de produtos demandam capacidade intelectual do recurso humano para serem construídos, mantidos e operados.

A capacidade intelectual de indivíduos está associado não apenas à escolaridade, mas também a diversos outros fatores sócio-econômico-ambientais, que não serão discutidos neste texto. Para efeito deste método, será considerado apenas a escolaridade formal obtida nos ensinos fundamental, médio e superior, incluindo o mestrado e o doutorado. 
O ajuste da escolaridade pela duração do vínculo busca introduzir o impacto de relações de trabalho sazonais ou temporárias sobre a sustentabilidade social nesta categoria. Este ajuste não é considerado na categoria Atendimento de Necessidades Básicas porque a renda monetária é quantificada em base anual.

A escolaridade ajustada do recurso humano é medida em anos-equivalentes de estudo. Para a quantificação dos anos-equivalentes de estudo, considera-se que o indivíduo analfabeto tem 0 ano de estudo-equivalente. Para cada série completa, da primeira série do Ensino Fundamental até a terceira série do ensino médio completo, soma-se 1 ano-equivalente. Para os graus de formação de nível superior, de mestrado (strictu ou lato sensu) e de doutorado completos considera-se 5, 2 e 4 anos-equivalentes, respectivamente; e, se incompletos considera-se metade do valor da formação completa nestes níveis, independente do período decorrido desde o ingresso no curso. Ainda, para estes graus de formação é possível haver contabilização de mais de um curso e seus respectivos anos-equivalentes. No método que se propõe, os valores de anos-equivalentes, para cada nível de escolaridade, independem da duração real, em virtude das características do curso ou do desempenho do aluno. A Tabela 10 apresenta os graus de escolaridade e os respectivos anos-equivalentes de estudo propostos nesta tese.

Tabela 10 - Grau de escolaridade e respectivos anos-equivalentes de estudo adotados no método proposto nesta tese.

\begin{tabular}{|l|c|l|c|}
\hline Escolaridade & Anos-eq. & Escolaridade & Anos-eq. \\
\hline Analfabeto & 0 & Ensino Médio & 10 \\
\hline Ensino Fundamental & & Primeira série & 11 \\
\hline Primeira série & 1 & Segunda série & 12 \\
\hline Segunda série & 2 & Terceira série & 14,5 \\
\hline Terceira série & 3 & Superior e Pós-Graduação & 17 \\
\hline Quarta série & 4 & Superior incompleto & 18 \\
\hline Quinta série & 5 & Superior completo & 19 \\
\hline Sexta série & 6 & Mestrado incompleto & 21 \\
\hline Sétima série & 7 & Mestrado completo & 23 \\
\hline Oitava série & 8 & Doutorado incompleto & \\
\hline Nona série & 9 & Doutorado completo & \\
\hline
\end{tabular}




\subsubsection{A IMPORTÂNCIA DA DESIGUALDADES NA SUSTENTABILIDADE SOCIAL}

"A desigualdade na distribuição de renda entre os $20 \%$ mais ricos e os $20 \%$ mais pobres passou de 30 para 1, em 1960, a 74 para 1, em 1997. Mas, a desigualdade no acúmulo de capital pelos diversos estratos da sociedade (...) é ainda muito maior. Os $10 \%$ mais ricos têm $85 \%$ do capital mundial, enquanto que 50\% da população mundial tem apenas 1\%" (SEN \& KLIKSBERG, 2007).

A desigualdade extrema, seja na distribuição de renda, no acesso aos direitos fundamentais, ou em qualquer outra questão que afeta os indivíduos de um sistema social, sempre foi identificada como um mal. Platão (428/427 AC - 348/347 AC), em "As Leis", ao imaginar a criação de uma nova cidade, diz que o ideal seria que os futuros cidadãos, ali chegando, tivessem exatamente as mesmas posses. O ideal de Platão é que absolutamente tudo fosse comum e entre irmãos, e isto seria a mais alta excelência em justiça social. Mas Platão reconhece que o homem não está preparado para esta forma de sociedade (Não estava no tempo de Platão, Séculos V e IV antes de Cristo; ainda não está nos tempos atuais, no Século XXI depois de Cristo.) Diante da impossibilidade, devida ao estágio na natureza humana e à concreta pré-existência de desigualdades entre os indivíduos, Platão propõe um sistema para compensar as desigualdades, que segundo ele ocupa o segundo nível de excelência. Neste sistema, é necessário definir um limite inferior e um limite superior para as posses dos indivíduos, sendo que o limite inferior deve ser definido pelo "Legislador", e a partir desta quantidade, é permitido que os indivíduos acumulem até o quádruplo. Qualquer patrimônio superior a este limite, independente da origem, deveria, sob pena de multa e deshonra, ser doado metade para o Estado, metade para a Igreja. Em "República", PLATÃO diz que todo excesso causa necessariamente uma intensa reação. Por esta razão, não sendo possível a igualdade perfeita, deveriam haver os limites aceitáveis de diferença entre os indivíduos.

Diversos pensadores elaboraram sobre as causas e consequências da desigualdade, mas esta discussão desvia do interesse desta Tese. O importante é verificar que desde sempre a desigualdade é vista como um mal, e que a existência de indivíduos em condição de grande carência agrava os efeitos sociais. Esta idéia será introduzida nos critério operacionais apresentados a seguir. 


\subsection{Critérios Operacionais de Sustentabilidade Social de Produtos}

A definição mais aceita do adjetivo 'sustentável' foi cunhada no Relatório Brundtland como: “... que satisfaz as necessidades da geração atual, sem comprometer a capacidade de gerações futuras satisfazerem suas necessidades." (WCED, 1987).

Está definição é bastante vaga, ou ampla demais, para o estado atual da técnica e da arte humanas. Deste modo, é necessário o desenvolvimento de critérios operacionais, que têm escopo mais limitado e são uma simplificação das questões da sustentabilidade.

Os critérios operacionais definem, de forma clara e precisa, o limite inferior da fronteira entre a condição de sustentabilidade e a condição de não-sustentabilidade social para um sistema de produto. Entretanto, os critérios operacionais não definem limites superior. Assim, o acúmulo, de renda ou escolaridade, representa sempre um nível de sustentabilidade individual maior, a que cada indivíduo faz jus.

\subsubsection{Critérios Operacionais para Atendimento de NeCESSidades Básicas}

O Salário Mínimo Necessário garante o atendimento das necessidades básicas, segundo a Constituição Federal Brasileira. Para que um sistema de produto seja socialmente sustentável, em relação ao Atendimento de Necessidades Básicas de seu Recurso humano, é necessário que os seguintes critérios sejam atendidos:

- a renda monetária anual média do recurso humano deve ser igual, ou superior, ao limite inferior necessário para atendimento de suas necessidades básicas e de sua família, conforme estabelecido pelas leis que regem o sistema social que fornece o recurso humano; e,

- não há ocorrência de indivíduos abaixo do limite inferior estabelecido para esta renda mínima.

\subsubsection{Critérios Operacionais para Autonomia InTELECtUal}

Pela Constituição Brasileira, apenas o ensino fundamental é obrigatório e gratuito, e deve ser oferecido de forma universal como dever do Estado (SENADO FEDERAL, 2006). Atualmente, a duração do ensino fundamental é de nove anos, conforme a Lei 11.274 de 2006, que modifica a Lei 9.394 de 1996 das Diretrizes e Bases para a Educação Nacional (BRASIL, 2006). 
Em relação à Autonomia Intelectual do recurso humano, para que um sistema de produto seja socialmente sustentável é necessário que os seguintes critérios sejam atendidos:

- a escolaridade média do recurso humano deve ser igual, ou superior, à mínima que o sistema social, de origem do recurso humano, se obriga a oferecer de forma gratuita e universal; e,

- não há ocorrência de indivíduos abaixo do limite inferior estabelecido para escolaridade mínima.

\section{5 Índices Parciais de Sustentabilidade Social de Produtos}

Os índices parciais das categorias de sustentabilidade social, Atendimento de Necessidades Básicas (IpANB) e Autonomia Intelectual (IpAI), são elaborados nas seções 4.5.1 e 4.5.2 com base na Equação 1. O termo ' $X$ ' corresponde ao valor médio do indicador, renda ou escolaridade, para o conjunto de indivíduos que constituem o recurso humano, impactado pelos fatores de gravidade da desigualdade, desenvolvidos na seção 4.5.3. O termo ' $R$ ' é o valor de referência do indicador, definido nos critérios operacionais, ajustado para o fluxo de referência do sistema de produto. O valor $\pi / 2$ é introduzido propositalmente para estabelecer os valores desejados dos extremos da função de sustentabilidade social parcial.

$$
I P=\frac{\pi}{2} \times\left(\frac{X-R}{X+R}\right)
$$

Equação 1 - Modelo genérico dos índices parciais das categorias de sustentabilidade.

A llustração 12 apresenta a curva obtida da Equação 1. Quando o valor de 'X' é menor que o valor de 'R', o sistema não é socialmente sustentável, e no extremo quando ' $X$ ' é nulo para 'R' não nulo, a sustentabilidade na categoria avaliada tem o valor de $-\pi / 2$. Quando o valor de ' $X$ ' é igual ao de 'R', o sistema se encontra no limite da condição de sustentabilidade social. Quando ' $X$ ' é maior que 'R', o sistema de produto é socialmente sustentável, e à medida que o valor de ' $X$ ' cresce até o infinito, a sustentabilidade social tende a $\pi / 2$. Quando 'R' tem valor nulo, a sustentabilidade social na categoria avaliada tem sempre o valor $\pi / 2$. 


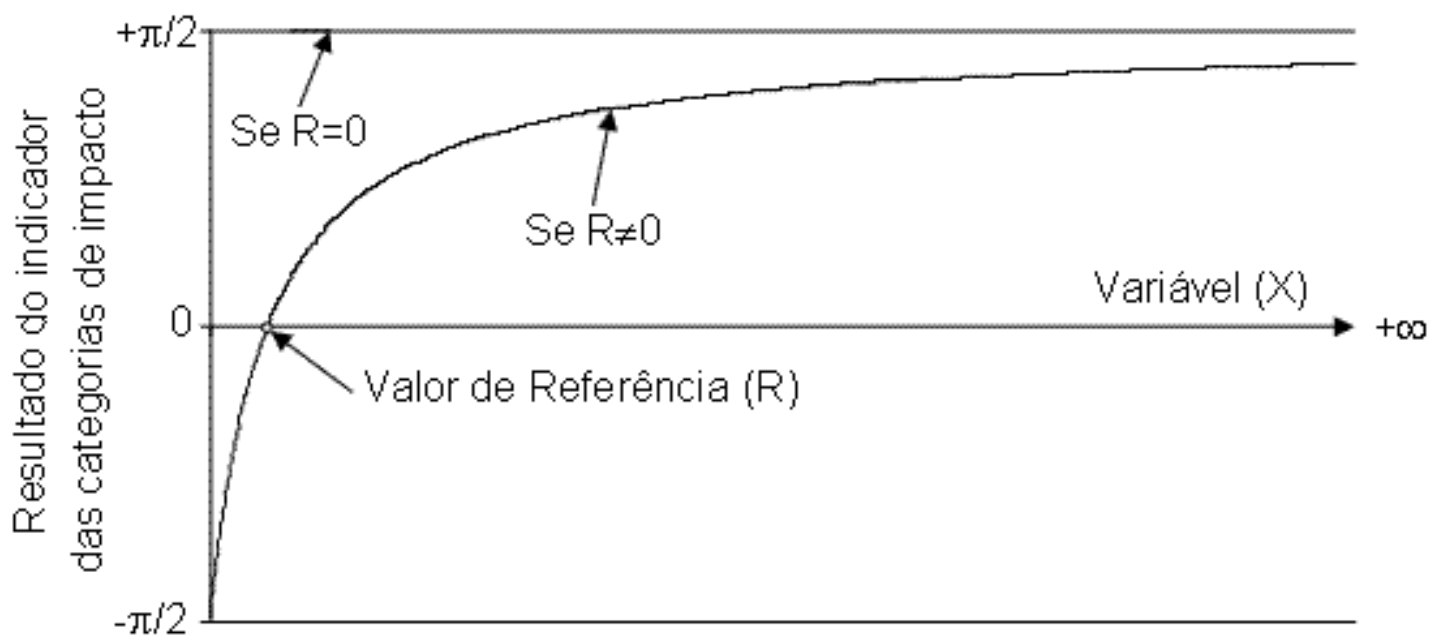

llustração 12 - Curva genérica para os índices parciais das categorias de sustentabilidade.

\subsection{1 Índice Parcial de Atendimento de Necessidades BÁsicas}

O Índice Parcial de Atendimento de Necessidades Básicas (IpANB) é um índice composto por índices parciais relacionados à esta categoria de sustentabilidade. Nesta Tese, é apresentado apenas o Índice Parcial da Renda Monetária Anual (IpRMA).

O IPRMA considera: 1) a renda monetária anual do recurso humano associada ao fluxo de referência do sistema de produto, $\overline{\overline{\$ r h}} ; 2$ ) o valor médio, para o período avaliado, da renda definida como o Salário Mínimo Necessário, $\overline{S M N}$; 3) o recurso humano associado ao fluxo de referência do sistema de produto, $r h_{F . R .}$;4) o fator de gravidade da desigualdade na distribuição da renda entre os indivíduos do conjunto recurso humano, $G i_{R}^{*}$; e, 5) o fator de gravidade da desigualdade na distribuição da renda entre os indivíduos do conjunto recurso humano e do conjunto consumidor, $G i_{R}^{* *}$. Os fatores $G i_{R}^{*}$ e $G i_{R}^{* *}$ são descritos na seção 4.5.3.

A Equação 2 apresenta a fórmula para o cálculo do IpRMA. O valor $\pi / 2$ é inserido para definir os limites inferior e superior, respectivamente $-\pi / 2$ quando $\overline{\overline{\$ r h}}$ é nulo, e $\pi / 2$ quando $\overline{\overline{\$ r h}}$ é infinitamente maior que o valor de $\left(\overline{S M C} \times r h_{F . R .}\right)$. Um sistema de produto socialmente sustentável deve ter IpRMA maior ou igual a zero. Caso contrário, o produto é socialmente não-sustentável. Os fatores $G i_{R}^{*}$ e $G i_{R}^{* *}$ variam entre um, quando a desigualdade não importa, até zero, quando a desigualdade é extremamente impactante. 


$$
I p R M A=\frac{\pi}{2} \times\left(\frac{\left(\overline{\overline{\$_{r h}}} \times G i_{R}^{*} \times G i_{R}^{* *}\right)-\left((\overline{S M N}) \times r h_{F . R .}\right)}{\overline{\overline{\$_{r h}}}+\left((\overline{S M N}) \times r h_{F . R .}\right)}\right)
$$

Equação 2 - Obtenção do índice parcial da renda monetária anual, IpRMA.

\subsection{2 ÍNDICE PARCIAL de AUTONOMIA INTELECTUAL}

O Índice Parcial de Autonomia Intelectual também é um índice composto. Entretanto, nesta tese foi desenvolvido apenas o indicador escolaridade ajustada para esta categoria de sustentabilidade.

O Índice Parcial da Escolaridade Ajustada (IpEA) tem a mesma estrutura que o IpRMA. São considerados 1) a escolaridade ajustada pela duração do vínculo do recurso humano associados ao fluxo de referência do sistema de produto, $\left.\bar{E}_{r h} ; 2\right)$ a escolaridade mínima definida como sustentável, Em; 3) o recurso humano normalizado para o fluxo de referência do sistema de produto, $r h_{F . R .}$; 4) o fator de gravidade da desigualdade na distribuição da escolaridade entre os indivíduos do subconjunto recurso humano, $G i_{E}^{*}$; e 5) o fator de gravidade da desigualdade na distribuição da escolaridade entre os indivíduos do conjunto recurso humano e do conjunto consumidores, $G i_{E}^{* *}$. A Equação 3 apresenta a fórmula de cálculo do IpEA.

$$
I p E A=\frac{\pi}{2} \times\left(\frac{\left(\bar{E} r h \times G i_{E}^{*} \times G i_{E}^{* *}\right)-\left(E m \times r h_{F . R .}\right)}{\bar{E}_{r h}+\left(E m \times r h_{F . R .}\right)}\right)
$$

Equação 3 - Obtenção do Índice Parcial Escolaridade Ajustada, IpEA.

Quando a escolaridade ajustada do recurso humano é nula, o IpEA tem o valor $-\pi / 2$. Quando a escolaridade é maior que a mínima sustentável, o índice parcial tem valor positivo e tende a $\pi / 2$ quando o valor da escolaridade do recurso humano tende a infinito. Como no caso do IpRMA, a ocorrência de valores negativos indicam uma não-sustentabilidade social do sistema de produto, enquanto que valores maiores ou igual a zero indicam sustentabilidade.

A Equação 4 apresenta a fórmula para cálculo da escolaridade ajustada do recurso humano associado ao fluxo de referência. São considerados: 1) a 
escolaridade de cada indivíduo 'i', $E_{i}$; 2) o número de meses, no período coberto pela avaliação (adotado como padrão 12 meses), de duração do vínculo, $q m_{i}$; 3) 0 número total de indivíduos do recurso humano, $n$; e, 4) o recurso humano associado ao fluxo de referência do sistema de produto, $r h_{F . R .}$.

$$
\bar{E}_{r h}=\frac{\sum_{i=1}^{n}\left(E_{i} \times q m_{i}\right)}{12 \times n} \times r h_{F . R .}
$$

Equação 4 - Escolaridade ajustada média do recurso humano associado ao fluxo de referência do sistema de produto.

\subsubsection{Gravidade da Desigualdade na Sustentabilidade Social}

Os fatores de gravidade da desigualdade entre os indivíduos do conjunto recurso humano, $G i_{x}^{*}$, e entre os indivíduos do conjunto recurso humano e do conjunto consumidor, $G i_{x}^{* *}$, propostos neste método, são baseados no índice de Gini e na curva de Lorentz, que também podem ser obtidos dos dados levantados para a condução da ACV Social. O Índice de Gini é uma das medidas de desigualdade mais conhecidas. Entretanto, ele não considera a condição dos indivíduos em relação à uma condição limite, ou seja a gravidade da desigualdade, apenas em relação ao percentual acumulado da variável.

Os elementos para o cálculo de $G i_{x}^{*}$ e $G i_{x}^{* *}$ são obtidos das curvas $\alpha$ e $\beta$ que representam o acúmulo percentual da variável de interesse em função do acúmulo percentual dos indivíduos. A curva $\alpha$ representa o acúmulo percentual da variável no valor limite para a sustentabilidade. Desta forma, $\alpha$ é uma reta que vai da origem $(0,0)$ até $(100,100)$, semelhante à curva de Lorentz no caso da igualdade perfeita. A curva $\beta$ representa o acúmulo dos valores observados em relação ao mínimo sustentável. De modo que a distribuição é representada por uma curva que tem origem no ponto $(0,0)$ e término em qualquer ponto da reta $(100, y)$. A llustração 13 apresenta curvas $\alpha$ e $\beta$ genéricas e os elementos para a obtenção de $G i_{x}^{*}$ e $G i_{x}^{* *}$. 

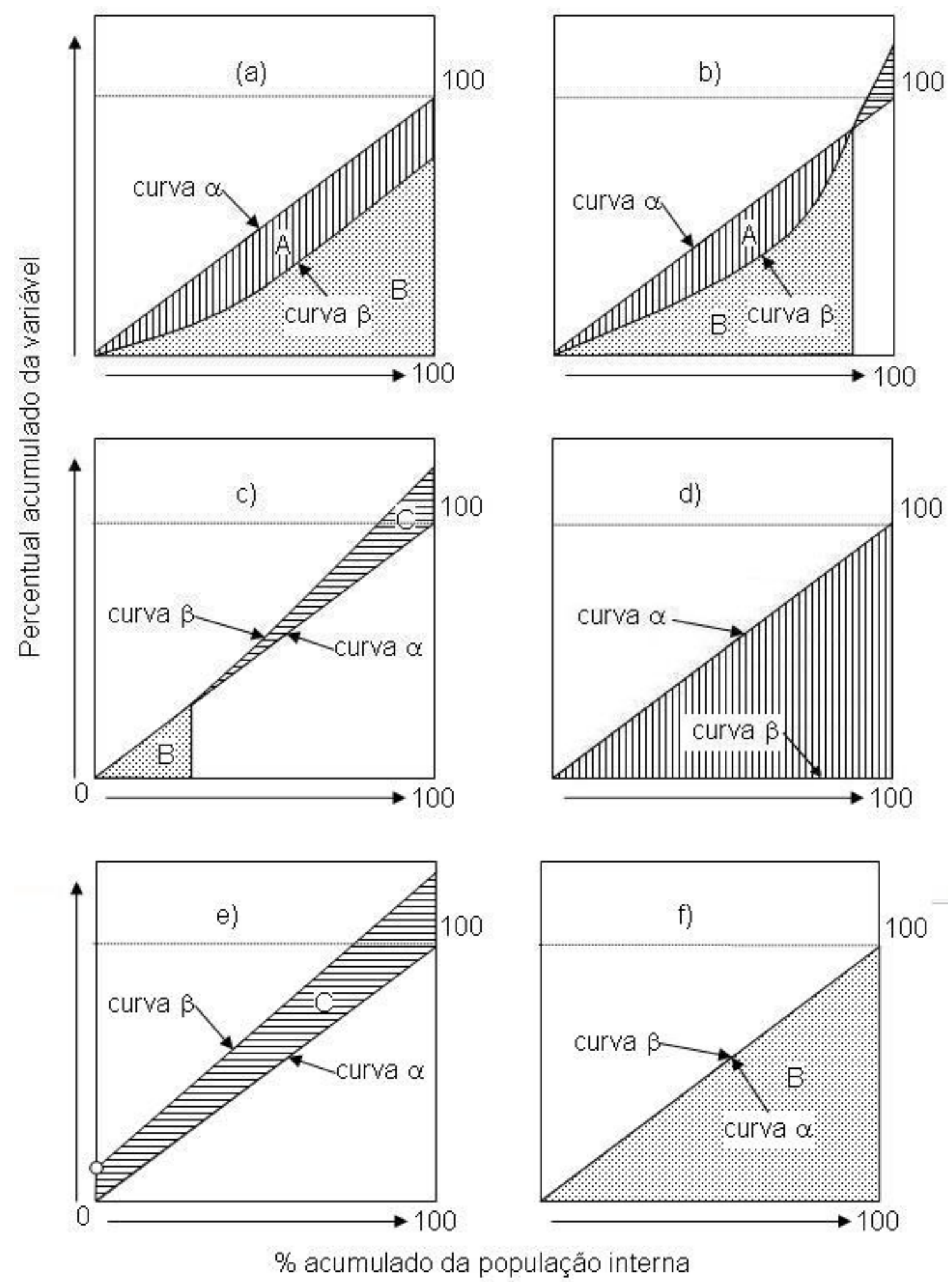

Ilustração 13 - Representação das curvas $\alpha$ e $\beta$ e das áreas A, B e C, usadas no cálculo dos fatores de gravidade da desigualdade $\mathrm{Gi}^{*} \mathrm{e} \mathrm{Gi}^{* *}$. 
A Equação 5 apresenta a fórmula para o cálculo do fator de gravidade da desigualdade na distribuição da variável entre os indivíduos do conjunto recurso humano, $G i_{x}^{*}$.

$$
G i_{x}^{*}=\frac{(B+C)}{(A+B+C)}
$$

Equação 5 - Obtenção do fator de gravidade da desigualdade na distribuição da variável entre os indivíduos do conjunto recurso humano.

O elemento A da Equação 5 corresponde ao percentual da área abaixo da curva $\alpha$ e acima da curva $\beta$, o elemento $\mathrm{C}$ corresponde ao percentual da área compreendida abaixo da curva $\beta$ e acima da curva $\alpha$ e o elemento B corresponde ao percentual da área abaixo de $\beta$, enquanto $\beta \leq \alpha$. Os três valores percentuais são obtidos em relação à área $A+B+C$. Considerando a llustração 13, em (a) a curva $\beta$ não ultrapassa a curva $\alpha$, de modo que a área $C$ tem um valor nulo e o valor de $G i_{x}^{*}$ é definido pelos valores das áreas A e B. Em (b), as curvas $\alpha$ e $\beta$ se cruzam, de modo que as áreas A, B e C possuem valores não nulos. O valor de $G i_{x}^{*}$ depende da combinação dos valores das três áreas. Em (c) a curva $\beta$ coincide com a curva $\alpha$ até certo valor do percentual cumulativo da população, após este ponto é superior à curva $\alpha$, a área A tem valor nulo. O valor de $G_{x}^{*}$ é igual a um, ou seja, não impacta o índice relativo de renda ou de escolaridade associado. A desigualdade entre os indivíduos do conjunto recurso humano não é importante, se a nenhum indivíduo deste conjunto é associado um valor abaixo do mínimo sustentável. Em (d), a única área com valor não nulo é a área $\mathrm{A}$. O valor de $G i_{x}^{*}$ é nulo, resultando em desigualdade com máxima gravidade, pois se trata de um conjunto de indivíduos totalmente desprovido. Em (e), a curva $\beta$ é maior que a curva $\alpha$ para todos os valores do eixo percentual cumulativo da população, exceto para a origem em $0 \%$ da população, onde $\alpha$ e $\beta$ possuem o mesmo valor. Assim, apenas a área $C$ tem valor não nulo. O índice $G i_{x}^{*}$ tem o valor um, como no caso (c). Em (f), as curvas $\alpha$ e $\beta$ são coincidentes, de modo que apenas a área B tem valor não nulo e, novamente, $G i_{x}^{*}$ tem valor um. 
O fator $G_{x}^{* *}$ é obtido comparando as curvas de acúmulo da variável para os indivíduos do conjunto recurso humano, $\beta_{r h}$, e para o conjunto consumidor, $\beta_{c o n s}$. A Equação 6 apresenta o sistema de equações para cálculo do fator de gravidade da desigualdade na distribuição da variável entre os indivíduos do conjunto recurso humano e do conjunto consumidor, $G i_{x}^{* *}$.

$$
G i_{x}^{* *}= \begin{cases}1, & \frac{\int \beta_{\text {cons }}}{\int \beta_{r h}} \leq 1 \text { ou } A_{r h}=0 \\ \frac{\int \beta_{r h}}{\int \beta_{\text {cons }}} \times\left(1-A_{r h}\right), & \frac{\int \beta_{r h}}{\int \beta_{\text {cons }}}<1 \text { e } 0<A_{r h} \leq 1\end{cases}
$$

Equação 6 - Obtenção do fator de gravidade da desigualdade na distribuição da variável entre os indivíduos dos subconjuntos recurso humano e consumidores.

Por definição, $G i_{x}^{* *}$ tem valor unitário, ou seja a desigualdade não é grave, em duas condições alternativas:

1) quando o resultado do acúmulo da variável para a população do conjunto consumidor, área sob curva $\beta_{\text {cons }}$, é menor ou igual que para a população do conjunto recurso humano, área sob curva $\beta_{r h}$; ou,

2) se a curva de acúmulo da variável para o conjunto recurso humano não tem desvio negativo em relação à curva da sustentabilidade mínima, $A_{r h}=0$.

Se o conjunto consumidor acumular um valor maior para a variável que o conjunto recurso humano e a curva de acúmulo da variável para a população do conjunto recurso humano apresentar um desvio negativo em relação à curva limite de sustentabilidade, $A_{r h}>0$; então $G i_{x}^{* *}$ é dado em função da razão entre o acúmulo da variável para o conjunto recurso humano e o acúmulo para o conjunto consumidor, e de $A_{r h}$. No extremo, quando todos os indivíduos do conjunto recurso humano são desprovidos, $A_{r h}=1$, o fator de gravidade da desigualdade anula completamente qualquer outro fator positivo, $G i_{x}^{* *}=0$. 


\section{6 ÍNDICE de SUSTENTABILIDADE SOCIAL DE PRODUto}

O Índice de Sustentabilidade Social de Produto (ISSP), apresentado nesta tese, é obtido a partir do Índice Parcial de Sustentabilidade de Produto, que agrega os índices parciais das categorias de sustentabilidade Atendimento de Necessidades Básicas (IpANB) e Autonomia Intelectual (IpAI), como mostra a llustração 14. As setas simples correspondem à aplicação do procedimento de agregação dos índices parciais dos indicadores que compõem as categorias de sustentabilidade. As setas duplas, correspondem à aplicação do mesmo procedimento, mas para agregar os índices das categorias de sustentabilidade. Este passo poderia ser ignorado, integrando diretamente os índices parciais de cada indicador de sustentabilidade para obtenção do IpSSP. Entretanto, é interessante conhecer a contribuição do sistema de produto para a sustentabilidade em cada categoria avaliada, pois elas correspondem às Áreas de Proteção de Interesse Social. A seta tripla corresponde à aplicação da função que transforma o índice de sustentabilidade parcial no índice de sustentabilidade final do produto.

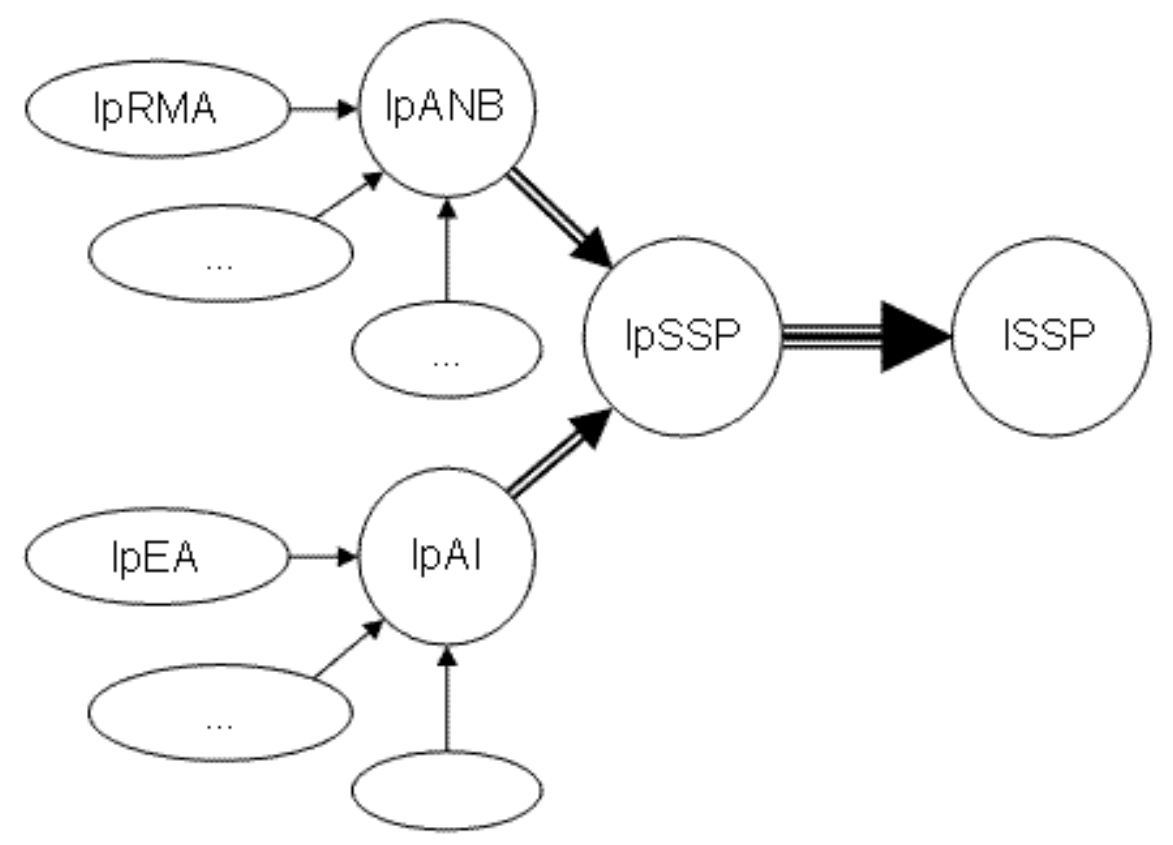

Ilustração 14 - Estrutura do Índice de Sustentabilidade Social de Produtos. 


\subsubsection{AgregaçÃo dos ÍNDICES Parciais}

No processo de agregação, podem ocorrer duas situações distintas: 1) todos os índices parciais possuem o mesmo sinal, positivo ou negativo; ou, 2) há índices parciais com sinal negativo e índices parciais com sinal positivo.

No primeiro caso, a agregação é dada pelo arco-tangente da somatória das tangentes dos índices parciais, como mostra a Equação 7.

$$
I P S=\operatorname{arctg}\left(\sum \operatorname{tg}(i p)\right)
$$

Equação 7 - Agregação de índices parciais de mesmo sinal.

Desta forma, o índice resultante é maior que a média aritmética simples dos índices parciais, e representa o arco que resulta da soma das tangentes de cada índice parcial. Este modelo garante que havendo algum caso extremo negativo, nenhuma combinação de resultados altera a condição de infinitamente não sustentável do sistema de produto. A llustração 15 apresenta quatro curvas obtidas a partir da Equação 7.

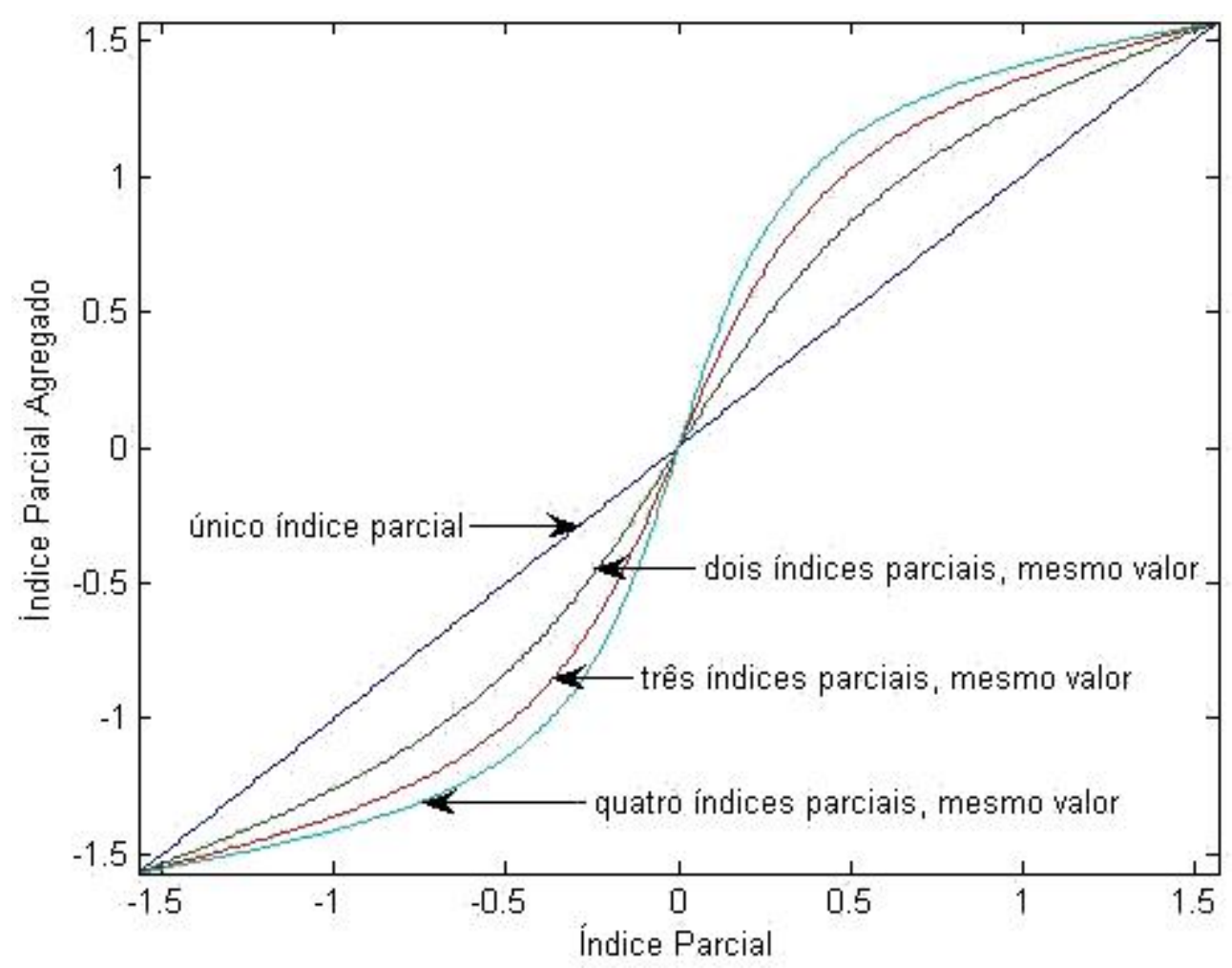

Ilustração 15 - Curvas obtidas da agregação de índices parciais com mesmo valor e sinal. 
A llustração 16 apresenta curvas obtidas a partir da aplicação da Equação 7 para combinações de dois índices parciais com valores diferentes, mas mesmo sinal. O resultado sempre ocorre abaixo da curva obtida para o caso dos dois índices terem o mesmo valor. A ocorrência do valor extremo negativo, $-\pi / 2$, para um índice parcial, determina que nenhum valor do outro índice parcial é capaz de afetar a curva, mantendo o resultado do índice parcial agregado sempre com o mesmo valor, $-\pi / 2$.

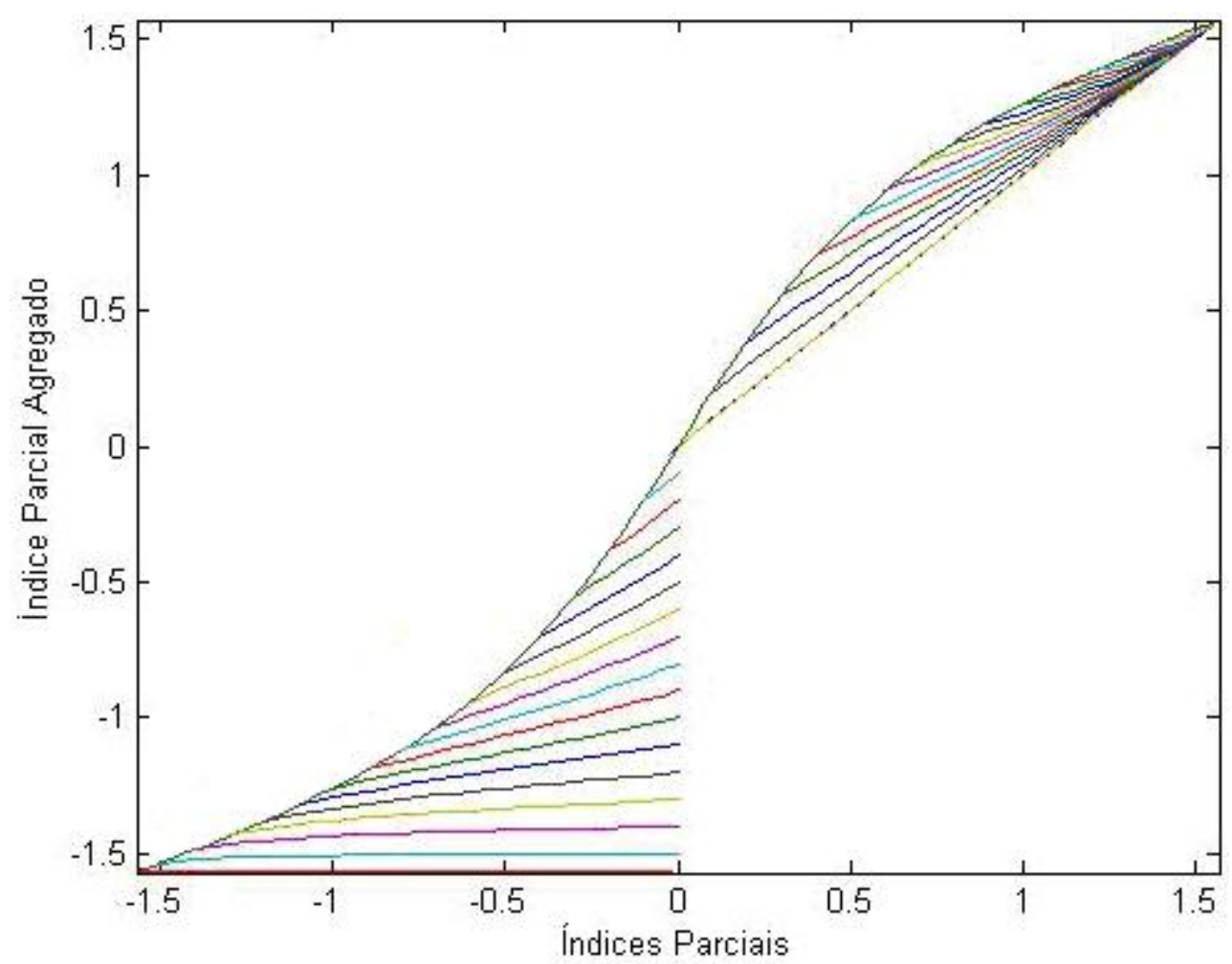

Ilustração 16 - Curvas obtidas para um único índice parcial, para a combinação de dois índices parciais de igual valor e sinal, e para combinações de índices parciais de diferentes valores, mas mesmo sinal.

No segundo caso, não se deseja permitir neste método que, ao ocorrer um ou mais índices parciais com valor negativo, qualquer combinação com índices parciais com valor positivo resulte em um índice parcial agregado com valor positivo ou nulo. A Equação 8 apresenta a fórmula para cálculo do índice agregado neste caso. Os termos ip $\Theta$ e ip $\oplus$ são obtidos pela aplicação da Equação 7 aos conjuntos de índices parciais de mesmo sinal, negativo e positivo, respectivamente. 


$$
I P S=i p \Theta-\left(i p \oplus \times \operatorname{sen}(i p \Theta) \times \cos (i p \Theta) \times\left(\frac{i p \Theta+\pi / 2}{i p \oplus+\pi / 2}\right)\right)
$$

Equação 8 - Agregação de índices parciais com sinais diferentes.

De acordo com a Equação 8, é necessário que todos os índices parciais sejam positivos ou nulos, para que o sistema de produto seja considerado sustentável. Se o valor da componente negativa, $i p \Theta$, for igual a $-\pi / 2$, nenhum valor da componente positiva, ip $\oplus$, afeta o valor do índice agregado parcial, que deverá ser igual $a-\pi / 2$. Se $i p \Theta$ for muito próximo de zero, o índice agregado parcial será maior ou igual a $i p \Theta$, mas nunca igual a zero, pois este valor de índice já define um sistema de produto como sustentável. A llustração 17 apresenta curvas obtidas com a aplicação da Equação 8.

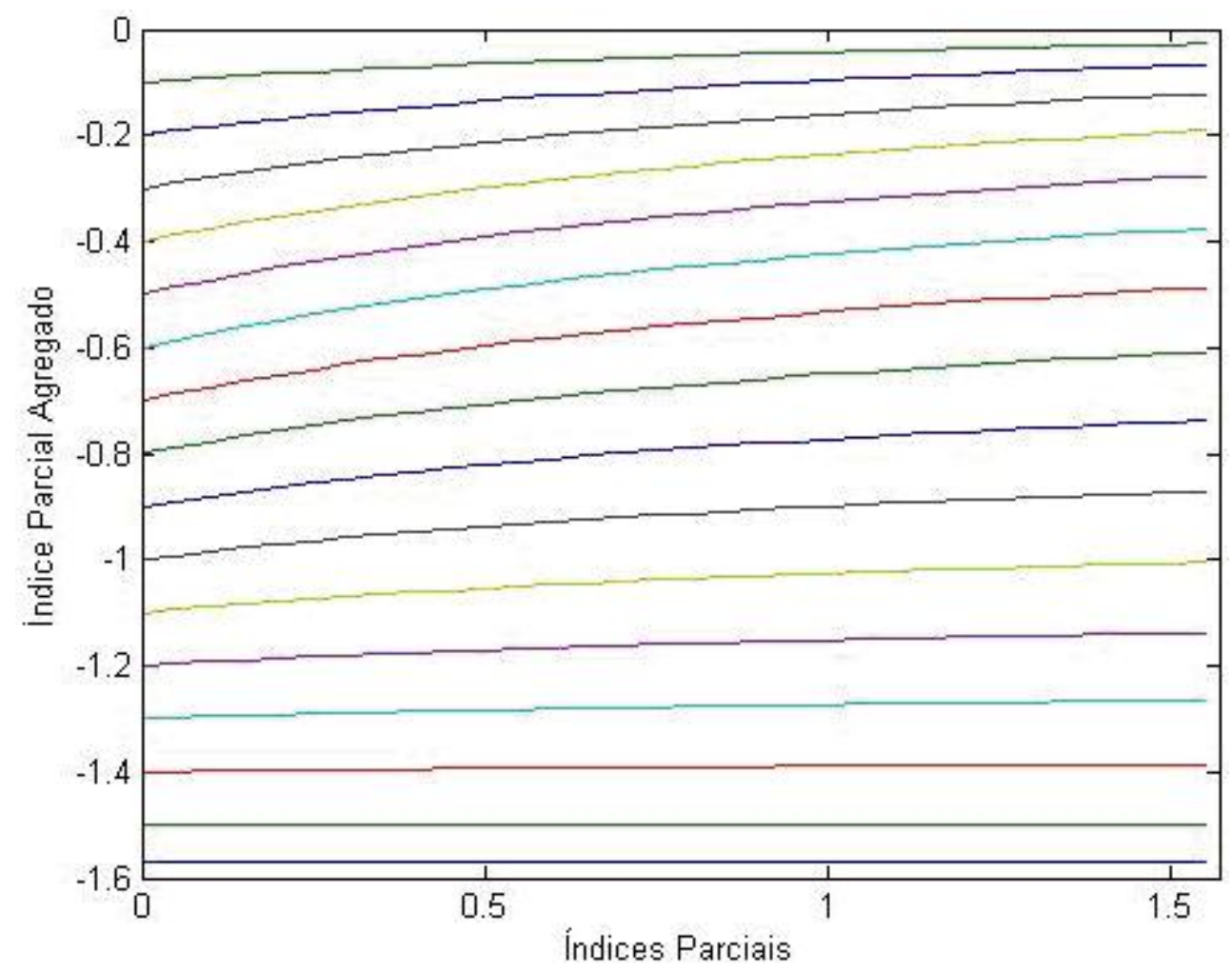

Ilustração 17 - Curvas obtidas da agregação índices parciais com sinais diferentes.

A Ilustração 18 apresenta uma visualização completa de curvas de sustentabilidade social obtidas pela aplicação da Equação 7 e da Equação 8, para uma combinações de dois índices parciais quaisquer, com a reta . 


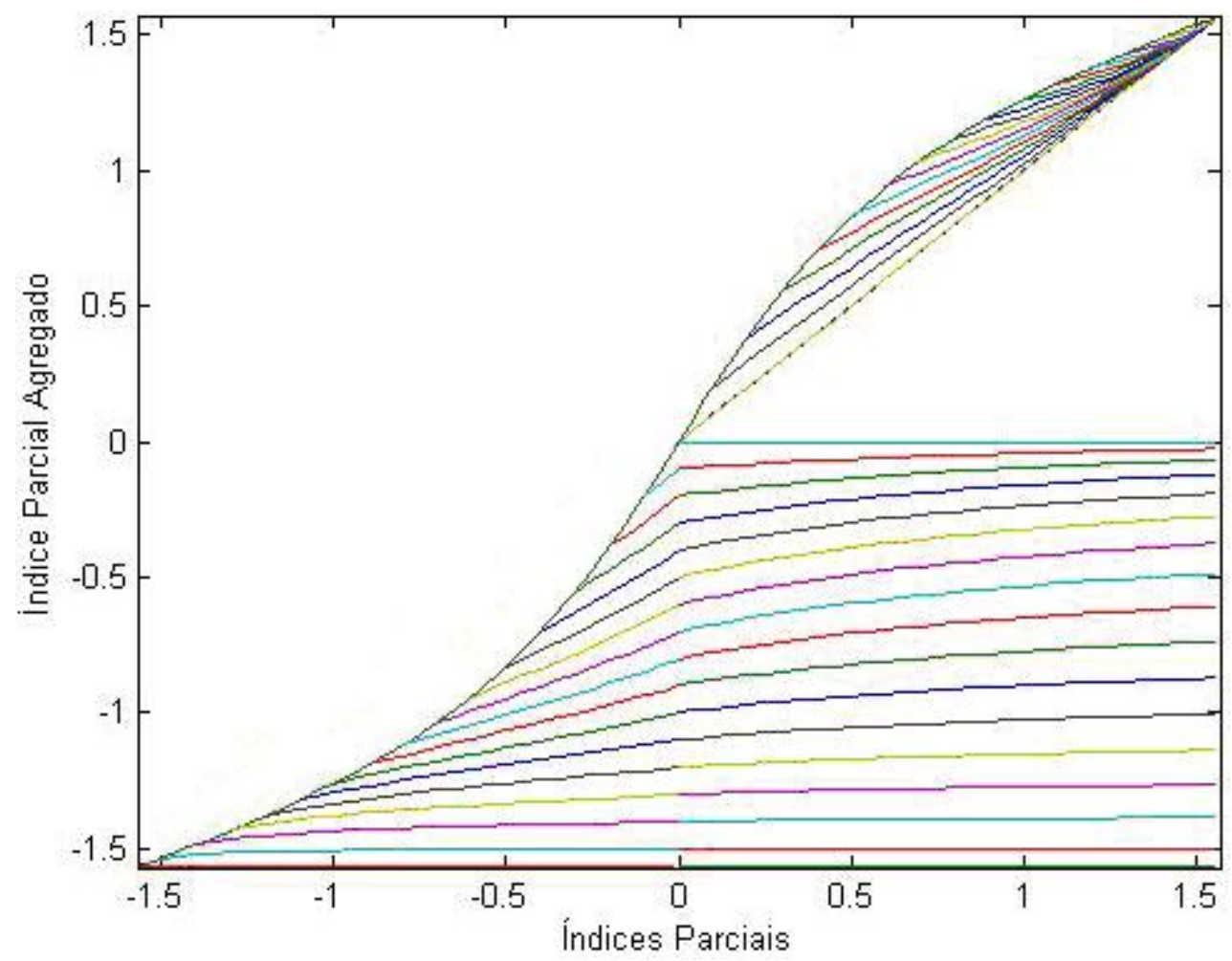

llustração 18 - Curvas possíveis para combinações de dois índices parciais quaisquer.

\subsubsection{OBtenção do Índice de Sustentabilidade de Produto}

Os índices parciais foram intencionalmente modelados para ter como limites, inferior e superior, os valores $-\pi / 2$ e $+\pi / 2$. A razão para a escolha deste intervalo é que a obtenção do Índice de Sustentabilidade Social do Produto (ISSP) é realizada através da aplicação da função tangente sobre o Índice parcial Agregado (IpSSP), como mostra a Equação 9. Se o valor obtido da aplicação da função tangente for negativo, o sistema de produto não é sustentável. Se o valor for nulo, o sistema de produto é sustentável, mas está no limite inferior desta condição. Se o valor for positivo, o sistema de produto é sustentável.

$$
I S S P=\tan (I p S S P)
$$

Equação 9 - Obtenção do Índice de Sustentabilidade de Produto.

A llustração 19 apresenta o formato da curva da função que calcula o Índice de Sustentabilidade Social do Produto. Nos limites da função, com IpSSP tendendo a $-\pi / 2$ e $+\pi / 2$, a função tangente obtêm os valores $-\infty$ e $+\infty$, respectivamente. 


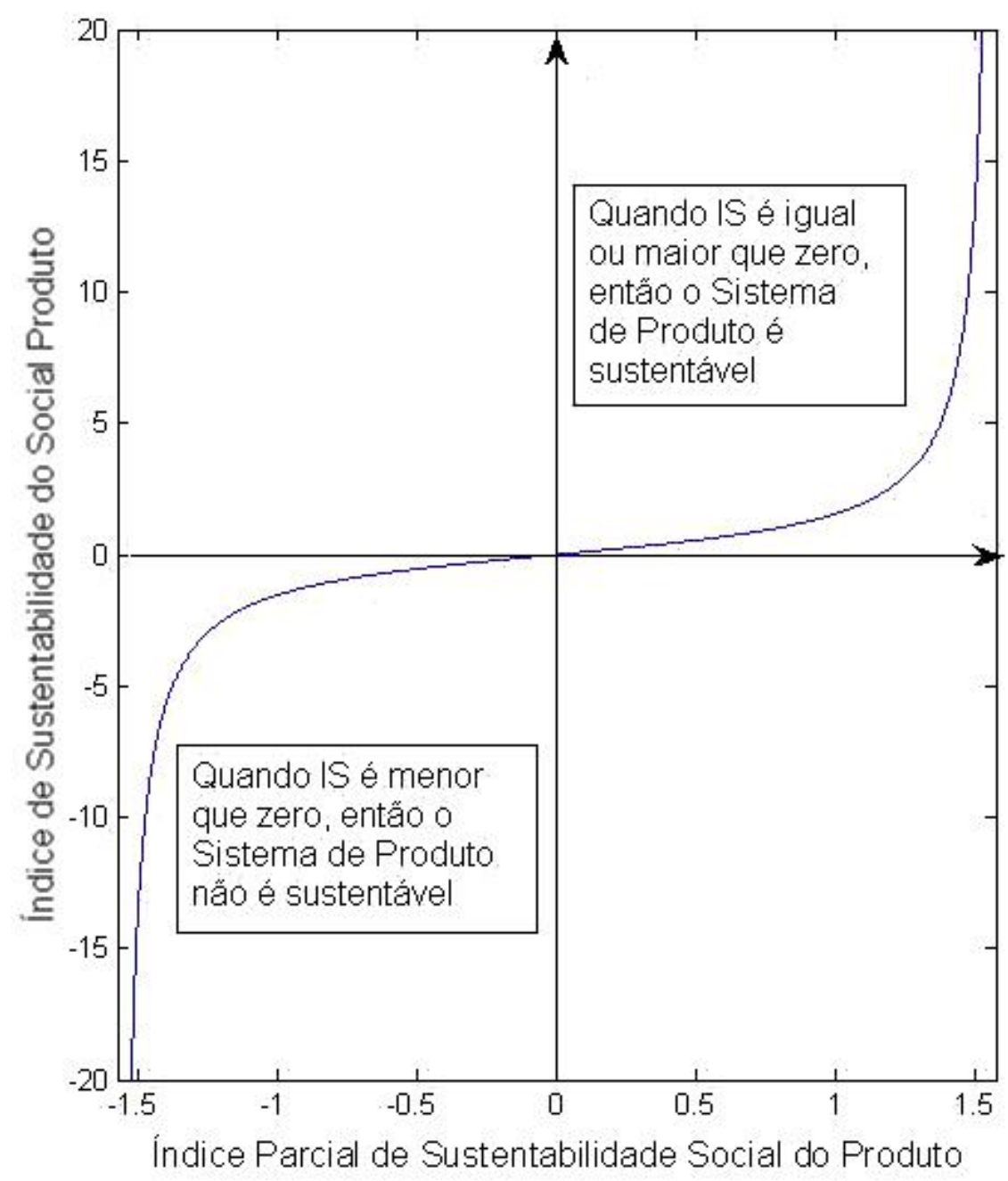

Ilustração 19 - Curva da Sustentabilidade Social de Produtos.

A sustentabilidade ser infinitamente negativa ocorre quando o recurso humano tem uma renda nula, como no caso de escravidão, e a quantidade de renda necessária para atender minimamente suas necessidades é não nula. Também causam insustentabilidade infinita do sistema de produto, empregar um conjunto de indivíduos como recurso humano, totalmente analfabeta. No outro extremo, a sustentabilidade é infinitamente positiva quando o recurso humano tem uma renda infinitamente superior à mínima necessária para atender suas necessidades, tendo assegurado uma segurança infinita de que suas necessidades básicas serão atendidas. Um conjunto de indivíduos acumulando um valor infinito de escolaridade também resulta uma sustentabilidade infinita para o sistema de produto. O modelo da categoria de sustentabilidade Autonomia Intelectual, poderia ter sido desenvolvido considerando que o valor infinito corresponderia à um grau de escolaridade equivalente aos anos de vida de cada cidadão. 


\section{AVALIAÇÃO SOCIAL DO CICLO DE VIDA DO AEHC}

\subsection{ESCOPO DA AVALIAÇÃO}

\subsubsection{Função, Unidade Funcional E FluXo de REFERÊNCIA}

O Álcool Etílico Hidratado Combustível (AEHC) é um vetor energético utilizado em veículos leves equipados com motores adequados ao uso deste combustível, de forma exclusiva ou em misturas com a gasolina tipo $\mathrm{C}$, em qualquer proporção, a critério do consumidor. A energia química armazenada no combustível é convertida, principalmente, em energia mecânica para deslocamento do veículo; mas também em térmica e elétrica para outros usos relacionados ao uso do veículo.

Portanto, a função do AEHC avaliada nesta tese é a de vetor energético para uso em veículos automotores. A unidade funcional adotada é a capacidade de armazenar 10.400 $\mathrm{kcal}^{5}$, com base no seu Poder Calorífico Inferior (PCl).

O fluxo de referência é calculado, considerando o $\mathrm{PCl}$ do $\mathrm{AEHC}$ de 6.300 kcal. $\mathrm{kg}^{-1}$ e sua densidade de $0,809 \mathrm{~kg} \cdot \mathrm{L}^{-1}$ (MME, 2008), como sendo 2,04 litros de AEHC. Por conveniência, será adotado como fluxo de referência o valor de 2 litros de $A E H C$.

\subsubsection{FRONTEIRAS DO SISTEMA DO AEHC}

As fronteiras do sistema do AEHC são definidas pelas atividades econômicas que o compõem, segundo a Classificação Nacional de Atividades Econômicas (CNAE). Uma descrição destas atividades é dada nas seções do texto que apresentam os inventários de cada atividade. A llustração 20 apresenta o sistema do AEHC considerado nesta avaliação. O consumo não é uma atividade econômica definida na CNAE. O diesel e os fertilizantes são representados por conjuntos de classes de atividade econômica, como será apresentado nas seções do texto que tratam destas atividades. A Tabela 11 apresenta as atividades que compõem o sistema do AEHC e os códigos na versão CNAE 2.0 e na versão CNAE 95. Os dados da RAIS anteriores a 2006 são disponibilizados segundo a CNAE 95. Em 2006 e 2007, os registros mais recentes, os dados são disponíveis segundo a CNAE 2.0.

\footnotetext{
${ }^{5}$ Este valor corresponde ao $\mathrm{PCl}$, em kcal.kg-1, da gasolina automotiva (MME, 2008).
} 


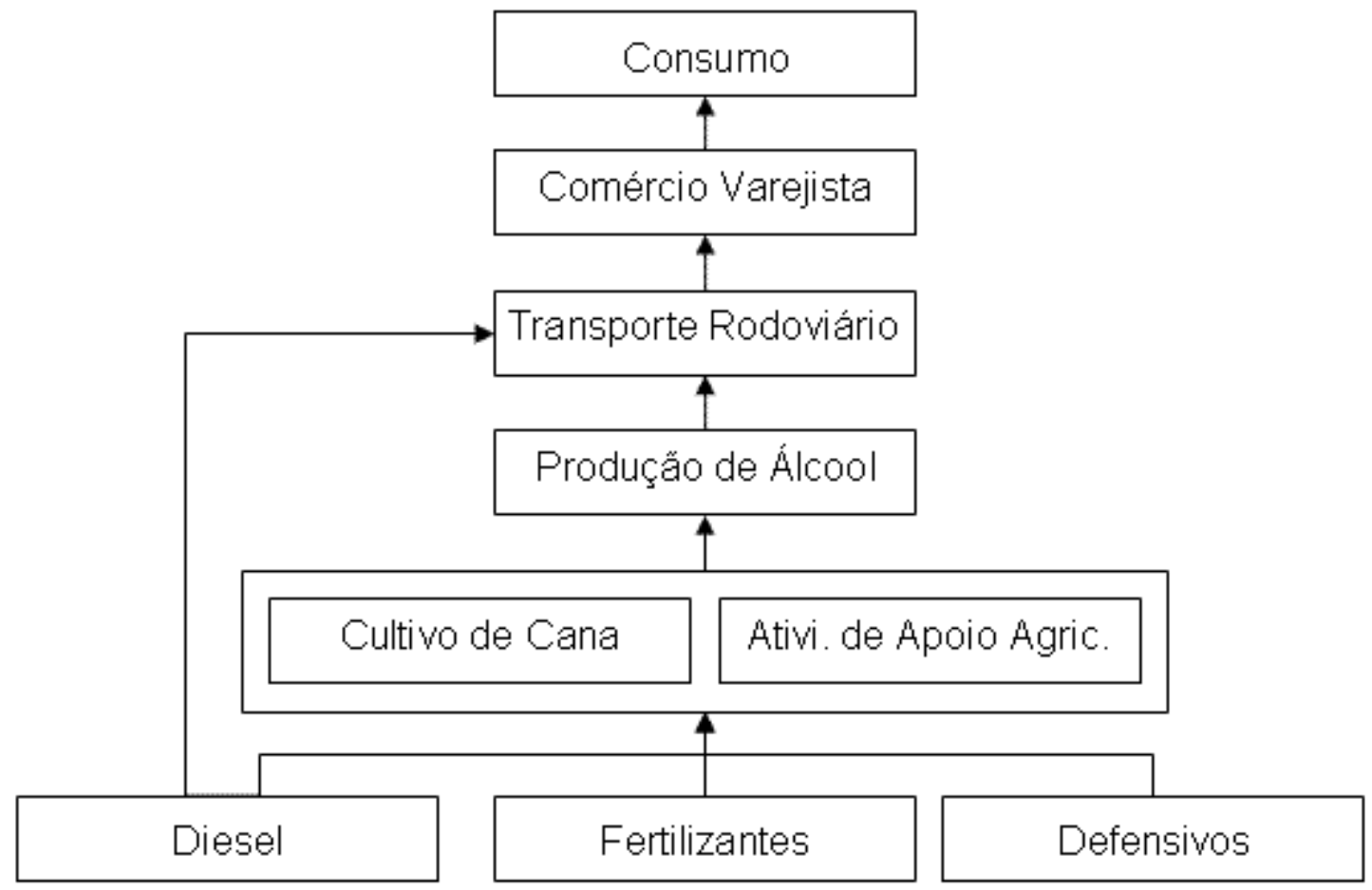

llustração 20 - Sistema do álcool etílico hidratado combustível (AEHC).

Tabela 11 - Código CNAE 2.0 e CNAE 95 das classes de atividade econômica que compõem o sistema do AEHC.

\begin{tabular}{|c|c|c|c|c|}
\hline \multicolumn{3}{|c|}{ Atividade Econômica } & CNAE 2.0 & CNAE 95 \\
\hline \multicolumn{3}{|c|}{ Com. varejista de comb. para veículos automotores } & $4731-8$ & $5050-4$ \\
\hline \multicolumn{5}{|c|}{ Transporte rodoviário de cargas } \\
\hline \multicolumn{3}{|c|}{ Fabricação de álcool } & $1931-4$ & $2340-0$ \\
\hline \multicolumn{3}{|c|}{ Cultivo de cana-de-açúcar } & $0113-0$ & $0113-9$ \\
\hline \multicolumn{3}{|c|}{ Atividades de apoio à agricultura } & 0161-0 & $0161-9$ \\
\hline \multirow[t]{4}{*}{ Diesel } & \multicolumn{2}{|c|}{ Extr. de petróleo e GN } & $0600-0$ & $1110-0$ \\
\hline & \multicolumn{2}{|c|}{ Ativ. de apoio à extração de petróleo e GN } & $0910-6$ & $1120-7$ \\
\hline & \multicolumn{2}{|c|}{ Fabricação de produtos do refino } & $1921-7$ & $2321-3$ \\
\hline & \multicolumn{2}{|c|}{ Fab. de máq. e equip. para prosp. e extr. } & $2851-8$ & $2951-3$ \\
\hline \multirow{2}{*}{\multicolumn{2}{|c|}{ Fertilizantes }} & Fabricação & $2013-4$ & $2413-9$ \\
\hline & & Fabricação de intermediários & $2012-6$ & $2412-0$ \\
\hline \multicolumn{3}{|c|}{ Fabricação de Defensivos Agrícolas } & $2051-7$ & - \\
\hline
\end{tabular}

(Fonte: IBGE, 2008 CNAEWEB) 


\subsubsection{Procedimentos de Alocação}

Para as atividades componentes do sistema do AEHC que possuem mais de um produto, o critério de alocação utilizado foi o energético. Detalhes são apresentados nas seções que descrevem os inventários de cada atividade.

\subsubsection{Tipos de Impacto E MÉtodo de Avaliação de IMPACto}

Serão considerados dois tipos de impactos sociais, desenvolvidos no método apresentado no Capítulo 4:

1) Impacto no Atendimento de Necessidades Básicas; e,

2) Impacto na Autonomia Intelectual;

O método de avaliação destes impactos também é descrito no Capítulo 4.

\subsubsection{ReQUisitos de Qualidade dos Dados}

\subsubsection{Cobertura Geográfica}

A cobertura geográfica dos dados das atividades que compõem o sistema do AEHC considera todo o território Brasileiro, a menos das atividades de cultivo de cana e atividades de apoio agrícola. Para o cultivo de cana foram levantados dados apenas para o Estado de São Paulo. Para as atividades de apoio à agricultura, o escopo geográfico foi limitado aos municípios onde o valor da produção de cana-deaçúcar representou 95\% ou mais do valor da produção total das lavouras temporárias do município, no período de 2000 a 2006.

\subsubsection{Cobertura Temporal}

Todos os dados utilizados no cálculo do índice de sustentabilidade social no ciclo de vida do AEHC, são referentes ao ano de 2007, a menos que indicado o contrário no texto referente a algum ítem específico.

\subsubsection{Fontes de Dados}

O levantamento dos dados foi realizado a partir da Relação Anual de Informações Sociais (RAIS) do Ministério do Trabalho e Emprego (MTE), através do Programa de Disseminação de Estatísticas do Trabalho (PDET). 
Ao utilizar a RAIS como fonte de dados é possível ocorrer múltipla contagem de um mesmo indivíduo, se este teve mais de um vínculo formal de trabalho ao longo de um ano. Por não incluir os indivíduos sem relação formal de trabalho e os desempregados, os dados levantados na RAIS distorcem a representação real do conjunto consumidor. De acordo com Macedo (2005), em 2003, a formalidade de empregos na economia Brasileira correspondia em média a 55\%. O setor de cana de açúcar apresentava em média $68,5 \%$ de formalidade e no Estado de São Paulo este valor era de $82,8 \%$.

O PDET não permite a recuperação de dados individuais. Os dados levantados são valores médios para grupos de indivíduos. Este fato, aumenta o erro no cálculo dos fatores de gravidade da desigualdade, da mesma forma que no cálculo do índice de Gini, pois reduz a desigualdade entre os indivíduos.

O levantamento dos dados da RAIS não considerou a idade dos indivíduos. Entretanto, como mostra a Tabela 12, com dados de 2003 a 2007, a participação de indivíduos menores de 18 é muito pequena no conjunto total de vínculos.

Tabela 12 - Distribuição dos vínculos totais declarados à RAIS e percentuais por faixa etária, de 2003 a 2007.

\begin{tabular}{|l|c|c|c|c|c|}
\hline \multicolumn{6}{|c|}{ Participação Percentual por Faixa Etária } \\
\hline F. Etária & $\mathbf{2 0 0 3}$ & $\mathbf{2 0 0 4}$ & $\mathbf{2 0 0 5}$ & $\mathbf{2 0 0 6}$ & $\mathbf{2 0 0 7}$ \\
\hline Até 17 & $1 \%$ & $1 \%$ & $1 \%$ & $1 \%$ & $1 \%$ \\
\hline de 18 a 24 & $22 \%$ & $22 \%$ & $22 \%$ & $21 \%$ & $21 \%$ \\
\hline de 25 a 29 & $18 \%$ & $18 \%$ & $18 \%$ & $19 \%$ & $19 \%$ \\
\hline de 30 a 39 & $29 \%$ & $29 \%$ & $28 \%$ & $28 \%$ & $28 \%$ \\
\hline de 40 a 49 & $20 \%$ & $20 \%$ & $20 \%$ & $20 \%$ & $20 \%$ \\
\hline de 50 a 64 & $10 \%$ & $10 \%$ & $10 \%$ & $10 \%$ & $11 \%$ \\
\hline 65 ou mais & $1 \%$ & $1 \%$ & $1 \%$ & $1 \%$ & $1 \%$ \\
\hline Ignorado & $0 \%$ & $0 \%$ & $0 \%$ & $0 \%$ & $0 \%$ \\
\hline Total & $100 \%$ & $100 \%$ & $100 \%$ & $100 \%$ & $100 \%$ \\
\hline
\end{tabular}

Os dados da Pesquisa Nacional por Amostra de Domicílios (PNAD) podem ser utilizados para estimar o erro, na quantificação dos valores médios do conjunto consumidor, que ocorre ao se utilizar os dados da RAIS. Entretanto, os resultados da PNAD são apresentados para indivíduos com 10 ou mais anos de vida e para 
indivíduos com 25 ou mais anos de vida. Como a habilitação para conduzir veículos é restrita à indivíduos maiores de 18 anos de vida, se os dados do PNAD forem utilizados é necessário considerar apenas os resultados para indivíduos com 25 anos ou mais de vida, perdendo uma parcela importante desta população. Adicionalmente, os resultados para renda apresentam os rendimentos médios mensais por grupos de indivíduos em grau de agregação muito elevado, sem informação da duração do vínculo dos indivíduos no ano. Neste texto, o conjunto consumidor sempre se refere ao caracterizado a partir dos dados da RAIS.

\subsection{InVENTÁrio Social do Álcool Etílico Hidratado Combustível}

\subsubsection{ReCuPERAÇÃo e TRATAMENTO dos Dados}

A recuperação dos dados de renda e escolaridade dos indivíduos registrados na RAIS foi realizada através da ferramenta do PDET. A Tabela 13 apresenta as variáveis definidas na especificação (filtro) para a recuperação dos dados. A inclusão das variáveis "Mês de Admissão" e "Mês de Desligamento" permite calcular a duração, em meses, de cada vínculo, em cada uma das atividades definidas pela variável "Classe de Atividade Econômica". Deste modo, é possível calcular a Escolaridade Ajustada pela Duração do Vínculo e a Renda Anual de cada Vínculo. A escolaridade é obtida pela variável "Grau de Instrução" e a Renda pela variável "Remuneração média do trabalhador". Uma tabela de resultados é gerada para cada ano, para cada atividade e para cada grau de instrução.

Tabela 13 - Exemplo de especificação da consulta e dimensões da tabela dos resultados.

\begin{tabular}{|l|c|}
\hline Variável & Categorias selecionadas \\
\hline Mês de Admissão & Todas \\
\hline Mês de Desligamento & Todas \\
\hline Grau de Instrução & Todas \\
\hline Unidade da Federação & De acordo com escopo \\
\hline Classe de Atividade Econômica & Componentes do sistema do AEHC \\
\hline Remuneração Média do Trabalhador $(\mathrm{R} \$)$ & \\
\hline
\end{tabular}

\footnotetext{
${ }^{6}$ Atualizada na competência 06/2008, de acordo com a Tabela 14.
} 
Os graus de escolaridade disponíveis na RAIS são apresentados na Tabela 14. Também é apresentado os anos equivalentes de estudo para cada grau de escolaridade. A mudança na duração do ensino fundamental de 8 para 9 anos foi inserida pelo sistema PDET automaticamente para todos os registros dos anos anteriores.

Tabela 14 - Níveis de escolaridade disponilizados na RAIS e respectivos anos equivalentes de estudo adotados no método proposto.

\begin{tabular}{|l|c|}
\hline Nível de Escolaridade & Anos eq. de estudo \\
\hline Analfabeto & 0 \\
\hline Até o 5a ano Incompleto do Ensino Fundamental & 2,5 \\
\hline $5^{a}$ ano Completo do Ensino Fundamental & 5 \\
\hline Do 6 ao 9a ano Incompleto do Ensino Fundamental & 9,5 \\
\hline Ensino Fundamental Completo & 10,5 \\
\hline Ensino Médio Incompleto & 12 \\
\hline Ensino Médio Completo & 14,5 \\
\hline Educação Superior Incompleta & 17 \\
\hline Educação Superior Completa & 19 \\
\hline Mestrado Completo & 23 \\
\hline Doutorado Completo & 9 \\
\hline
\end{tabular}

\subsubsection{Conjunto Consumidor DE AEHC}

\subsubsection{Descrição do Conjunto Consumidor de AEHC}

O Consumo não é uma atividade econômica, mas a razão da existência das atividades econômicas. Considerou-se que o total dos vínculos registrados na RAIS representa o conjunto de indivíduos que desempenham a função de consumidor para qualquer produto consumido no Brasil. Qualquer subconjunto, a menos que estejam disponíveis dados para uma caracterização mais precisa, é semelhante ao conjunto total de indivíduos consumidores, de modo que os valores de renda e escolaridade médios e os dados distribucionais são os mesmos.

O subconjunto de consumidores, que potencialmente desempenha a função específica de consumidor de AEHC é constituído por indivíduos que possuem 
habilitação tipo AB (para carro e moto) e tipo B (para carro). Como no Brasil motocicletas são movidas exclusivamente à gasolina, a parcela de habilitações tipo A (para moto) não foi incluída. Como mostra a Tabela 15, no ano de 2007, a população potencial consumidora de AEHC totalizava cerca de 31,5 milhões de indivíduos, aproximadamente $58 \%$ do conjunto total de consumidores estimado com base nos dados da RAIS para 2007.

Tabela 15 - Quantidade de habilitações tipo AB, A e B, para condução de veículos em dezembro de 2007, no Brasil.

\begin{tabular}{|c|c|c|c|c|}
\hline Carro e Moto (AB) & Moto (A) & Carro(B) & Total & Total menos moto \\
\hline 9.547 .236 & 958.327 & 21.952 .262 & 32.457 .825 & 31.499 .498 \\
\hline $29 \%$ & $3 \%$ & $68 \%$ & $100 \%$ & \\
\hline $30 \%$ & - & $70 \%$ & - & $100 \%$ \\
\hline
\end{tabular}

(Fonte: DENATRAN, 2008)

O conjunto de indivíduos potencialmente consumidores de AEHC precisa ser particionado entre os outros combustíveis comercializados no Brasil para veículos leves. Nesta partição, o percentual do consumo de gasolina na motocicletas, por indivíduos que possuem apenas habilitação tipo A, é desconsiderado. A partição dos indivíduos deste subconjunto entre os combustíveis utilizados em carros leves é realizada em base energética, considerando que todos os indivíduos consomem quantidades iguais de energia. Os combustíveis considerados são a gasolina C (mistura de gasolina tipo A (pura) com álcool etílico anidro combustível (AEAC)), álcool etílico hidratado combustível (AEHC) e gás natural veicular (GNV).

A Tabela 16 apresenta o consumo Brasileiro destes combustíveis (a gasolina tipo C é dada decomposta em gasolina tipo A e AEAC), nos anos de 2000 a 2007, em toneladas equivalentes de petróleo. Deste modo, considerando que o $A E H C$ representa cerca de $21 \%$ do consumo energético de combustíveis em veículos leves, no ano de 2007, a população estimada como consumidora de AEHC é de cerca de 6.614.894 indivíduos. 
Tabela 16 - Consumo de combustíveis veiculares no Brasil, em 2007, em toneladas equivalentes de petróleo (tep) e participação percentual.

\begin{tabular}{|c|c|c|c|c|}
\hline \multicolumn{5}{|c|}{ Consumo em toneladas equivalentes de petróleo, tep } \\
\hline GN & Gas. A & AEAC & AEHC & Total \\
\hline 2.252 & 14.287 & 3.325 & 5.287 & 25.150 \\
\hline \multicolumn{5}{|c|}{ Participação percentual em base energética } \\
\hline $9,0 \%$ & $56,8 \%$ & $13,2 \%$ & $21,0 \%$ & $100 \%$ \\
\hline
\end{tabular}

(Fonte: MME, 2008)

\subsubsection{Renda do Conjunto Consumidor no Sistema do AEHC}

Em 2007, cerca de 54,6 milhões de vínculos foram registrados na RAIS, somando uma renda anual, em valores de 2007, de cerca de 577 bilhões de Reais. A renda anual média por indivíduo no conjunto consumidor foi de $\mathrm{R} \$ 10.572,53$. Considerando os consumidores de AEHC, que somam cerca de 6,6 milhões de indivíduos, semelhante ao conjunto total da RAIS, a renda anual total destes totaliza cerca de 69,6 bilhões de Reais, como mostra a Tabela 17. A Tabela 18 apresenta o consumo de AEHC, no setor de transportes no Brasil, de 2000 a 2007, em milhares de metros cúbicos. O dado de 2007 é utilizado para cálculo da quantidade de indivíduos e sua renda anual por litro de AEHC consumido no Brasil, apresentados na Tabela 19.

Tabela 17 - Indivíduos e renda anual total, em Reais de 2007, dos conjuntos consumidor total, consumidor de combustíveis para veículos leves e de AEHC, em 2007.

\begin{tabular}{|l|c|c|c|}
\hline Consumidores & Vínculos & Renda anual Total & Renda An. Média \\
\hline RAIS total (MTE, 2008) & 54.649 .133 & $577.779 .506 .170,30$ & \multirow{2}{*}{$10.572,53$} \\
\cline { 1 - 3 } Combustíveis & 31.499 .498 & $333.029 .387 .589,94$ & \\
\cline { 1 - 3 } AEHC & $6.614 .894,58$ & $69.936 .171 .393,89$ & \\
\hline
\end{tabular}

Tabela 18 - Consumo brasileiro de AEHC no Setor de Transporte.

\begin{tabular}{|c|c|c|c|}
\hline Ano & Mil metros cúbicos & Ano & Mil metros cúbicos \\
\hline 2000 & 5.443 & 2004 & 4.835 \\
\hline 2001 & 4.257 & 2005 & 5.656 \\
\hline 2002 & 4.609 & 2006 & 7.095 \\
\hline 2003 & 3.762 & 2007 & 10.366 \\
\hline
\end{tabular}

(Fonte: MME, 2008) 
Tabela 19 - Indivíduos consumidores e renda anual por litro de AEHC consumido, em 2007.

\begin{tabular}{|c|c|}
\hline Indivíduos consumidores & Renda Anual Reais \\
\hline $6,38 \mathrm{E}-04$ & 6,747 \\
\hline
\end{tabular}

A Ilustração 21 apresenta as curvas $\alpha_{\text {cons, }} \beta_{\text {cons }}$ e de Lorentz para a distribuição de renda entre os indivíduos do conjunto consumidor. A curva $\beta_{\text {cons }}$ tem origem em $0 \%$ da renda para $0 \%$ da população e extremidade em cerca de $53 \%$ da renda mínima sustentável para $100 \%$ da população. A curva $\alpha_{\text {cons }}$ parte da origem $(0,0)$ até $(100,100))$, representando o acúmulo da renda quando todos os indivíduos ganham o mínimo sustentável. A curva de Lorentz mostra o acúmulo da renda anual em função do acúmulo dos indivíduos. Cerca de $20 \%$ dos indivíduos com menor renda acumulam apenas cerca de $5 \%$ da renda anual total. Enquanto que os $20 \%$ com as maiores rendas acumulam cerca de 30\%. A metade dos indivíduos acumula cerca de $20 \%$ da renda anual. É conveniente lembrar que a curva foi traçada utilizando valores médios de grupos segundo a duração do vínculo e, por esta razão, a diferença real entre os indivíduos foi substancialmente minimizada. Esta é a causa dos longos trechos lineares, observados a partir de cerca de $50 \%$ da população. 0 Índice de Gini calculado com estes dados tem o valor de 0,459.

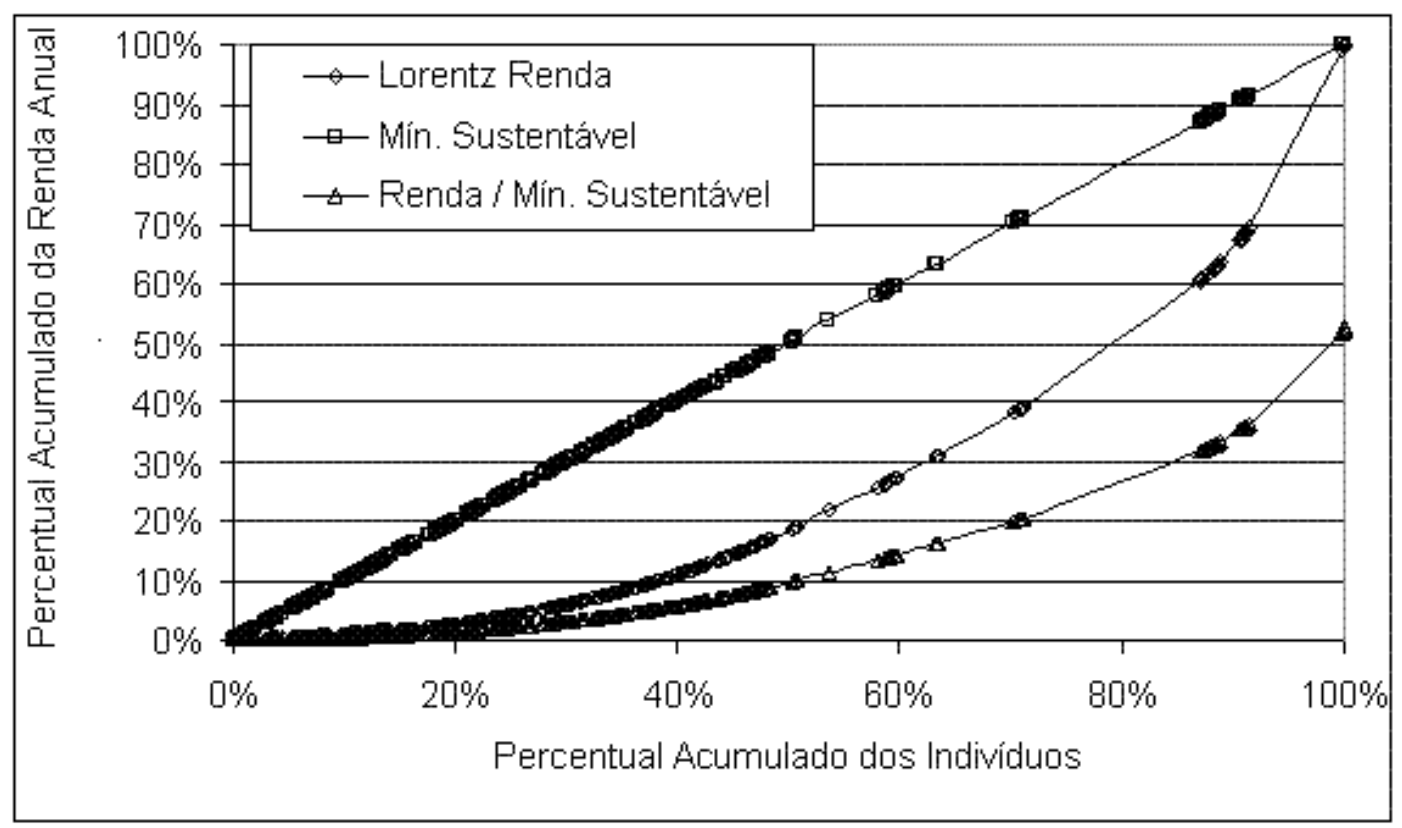

Ilustração 21 - Curvas $\alpha$ cons, $\beta$ cons e de Lorentz da distribuição da renda anual no conjunto consumidor de AEHC, em 2007. 


\subsubsection{Escolaridade do Conjunto Consumidor no Sistema do AEHC}

Em 2007, a Escolaridade Ajustada por Duração do Vínculo (EADV) média por indivíduo consumidor foi de 7,7 anos. Sem considerar a duração do vínculo, o valor da escolaridade foi de 10,7 anos equivalentes. A Tabela 20 apresenta os resultados para o conjunto consumidor total, para o conjunto consumidor de combustíveis e para o conjunto consumidor de AEHC, no ano de 2007.

Tabela 20 - Vínculos, anos equivalentes de estudo contratados totais e por vínculo, para o Conjunto Consumidor, em 2007.

\begin{tabular}{|l|c|c|c|}
\hline \multicolumn{1}{|c|}{ Consumidores } & Vínculos & AeqE Total & AeqE média \\
\cline { 1 - 3 } RAIS 2007 total (MTE, 2008). & 54.649 .133 & $419.756 .628,96$ & \\
\cline { 1 - 3 } Combustíveis & 31.499 .498 & $241.945 .706,52$ & \multirow{2}{*}{7,7} \\
\cline { 1 - 3 } AEHC & $6.614 .894,58$ & $50.808 .598,37$ & \\
\hline
\end{tabular}

A escolaridade média e a EADV são maiores que a escolaridade média estimada pela PNAD de 2006, para uma população com 25 anos ou mais de vida. A PNAD 2006 obteve uma escolaridade de 6,7 anos-equivalentes.

Uma provável causa do maior valor de escolaridade média do conjunto consumidor modelado a partir da RAIS é o fato de se considerar apenas a parcela formal do recurso humano da economia. Indivíduos com baixa escolaridade ou analfabetos têm acesso restrito ao mercado formal de trabalho. Adicionalmente, há a diferença na distribuição etária entre os resultados da RAIS e da PNAD.

A Tabela 21 apresenta o resultado da escolaridade ajustada por duração do vínculo, em anos equivalentes de estudo, do conjunto consumidor de AEHC para um litro de AEHC consumido.

Tabela 21 - Indivíduos e anos equivalentes de estudo por litro de AEHC consumido, em 2007.

\begin{tabular}{|c|c|}
\hline Indivíduos & AeqE \\
\hline $6,38 \mathrm{E}-04$ & $4,90 \mathrm{E}-03$ \\
\hline
\end{tabular}

A Ilustração 22 apresenta as curvas $\alpha_{\text {cons }} \beta_{\text {cons }}$ para a distribuição da escolaridade entre os consumidores de AEHC. A curva $\beta_{\text {cons mostra que este }}$ conjunto de indivíduos soma cerca de $85 \%$ da escolaridade mínima sustentável. A 
curva de Lorentz mostra que cerca de $20 \%$ dos indivíduos tem menos de $5 \%$ dos AeqE. Mostra também que metade da população acumula cerca de $23 \%$. O índice de Gini para esta distribuição é de 0,366.

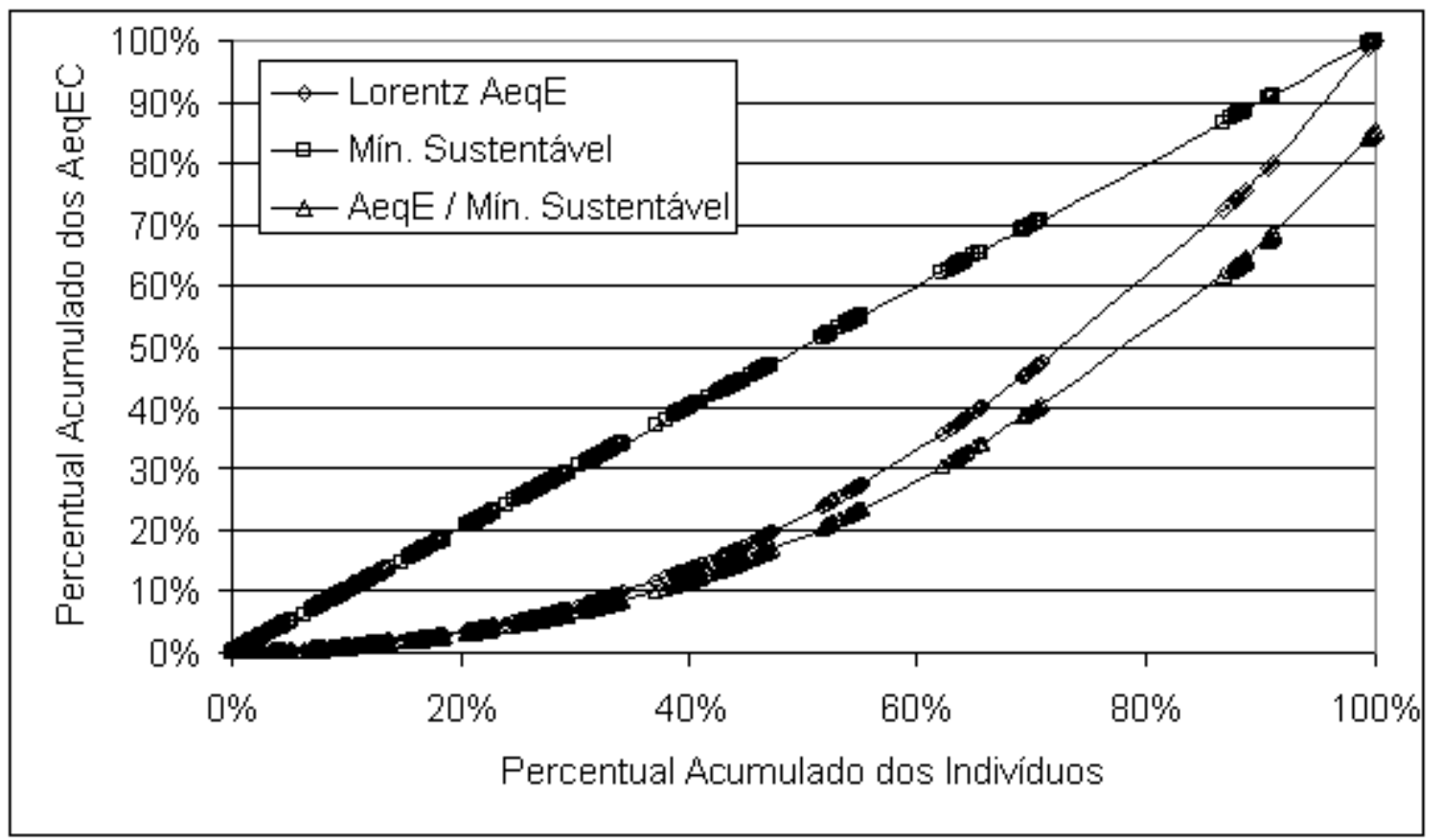

Ilustração 22 - Curvas $\alpha$ cons, $\beta$ cons e de Lorentz da distribuição dos anos equivalentes de estudo (AeqE) do Conjunto Consumidor, em 2007.

\subsubsection{INVENTÁRIO SOCIAL dO COMÉRCIO VAREJISTA DO AEHC}

\subsubsection{Renda no Comércio Varejista de AEHC}

Em 2007, o comércio varejista de combustíveis para veículos automotores empregou cerca de 385 mil pessoas, em todo o território Brasileiro, com uma renda anual total de quase 2,3 bilhões de Reais. A renda anual média por vínculos foi de cerca de R\$ 5.962,77. Estes resultados são apresentados nos Tabela 22.

Tabela 22 - Vínculos, renda anual total e média por vínculo no comércio varejista de combustíveis, em todo o Brasil, em 2007.

\begin{tabular}{|c|c|c|}
\hline Vínculos & Renda Anual Total (R\$) & Renda Anual Média por Vínculo(R\$) \\
\hline 385.064 & $2.296 .047 .611,31$ & $5.962,77$ \\
\hline
\end{tabular}

(Fonte: MTE, 2008) 
Diferentemente da Tabela 16 que exclui o óleo diesel, a Tabela 23 inclui o óleo diesel e apresenta os percentuais de participação, em base energética, dos combustíveis consumidos no setor de transportes. Assume-se que todo o consumo foi comercializado via comércio varejista. A participação do AEHC foi de $10 \%$. A Tabela 24 apresenta a quantidade de indivíduos, a renda anual total e por vínculo, alocados ao AEHC, no comércio varejista de combustível.

Tabela 23 - Participação em base energética do consumo de combustíveis no setor de transportes, em 2007.

\begin{tabular}{|l|c|}
\hline Combustível & Participação \% em base energética \\
\hline Gás Natural & $4,3 \%$ \\
\hline Gasolina Automotiva. & $27,0 \%$ \\
\hline Óleo Diesel & $52,4 \%$ \\
\hline Álcool Etílico Anidro Combustível & $6,3 \%$ \\
\hline Álcool Etílico Hidratado Combustível & $10,0 \%$ \\
\hline Total & $100,0 \%$ \\
\hline
\end{tabular}

(Fonte: MME, 2008)

Tabela 24 - Vínculos e renda anual total, alocados ao AEHC, no comércio varejista de combustíveis, em todo o Brasil, em 2007.

\begin{tabular}{|c|c|}
\hline Vínculos & Renda Anual Total (R\$) \\
\hline 38.506 & $229.604 .761,1$ \\
\hline
\end{tabular}

Supondo que todo o AEHC consumido no Brasil, apresentado na Tabela 18, foi comercializado no varejo, a Tabela 25 apresenta a quantidade de vínculos e a renda anual por litro de AEHC comercializado, em 2007.

Tabela 25 - Vínculo e renda anual no comércio varejista de combustíveis, por litro de AEHC comercializado, em 2007.

\begin{tabular}{|c|c|}
\hline Vínculos & Renda Anual \\
\hline $3,71 \mathrm{E}-06$ & $2,21 \mathrm{E}-02$ \\
\hline
\end{tabular}

A Ilustração 23 mostra as curvas $\alpha_{\mathrm{rh}}$ e $\beta_{\mathrm{rh}}$ para o comércio varejista de combustíveis. A curva $\beta_{\text {rh }}$ mostra que toda a renda anual do recurso humano 
acumulada soma menos de $30 \%$ da mínima sustentável. A curva de Lorentz mostra que cerca de $30 \%$ do conjunto recurso humano têm aproximadamente $10 \%$ da renda total. Cerca de $60 \%$ da população recebe menos de $40 \%$ da renda total. A partir de $60 \%$ da população, grandes grupos com valor médio de renda idêntico distorcem a curva de distribuição. O índice de Gini para este conjunto é de 0,293, indicando que a desigualdade entre os indivíduos é menor do que no conjunto consumidor.

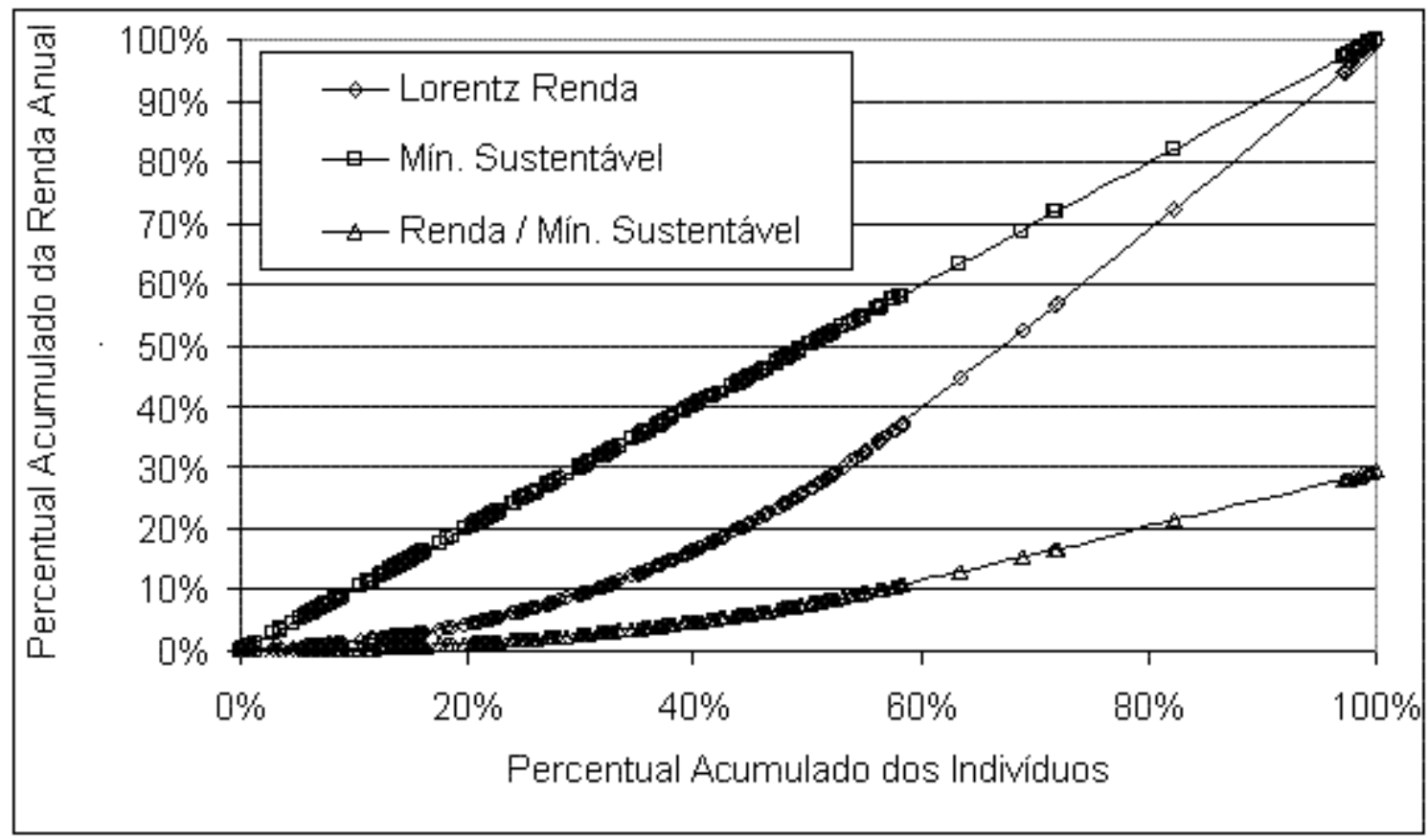

llustração 23 - Curvas $\alpha$ rh, $\beta$ rh e de Lorentz da distribuição de renda no comércio varejista de combustíveis, em 2007.

\subsubsection{Escolaridade no Comércio do AEHC}

Os indivíduos empregados no comércio varejista de combustíveis somam cerca de 2,6 milhões de anos equivalentes de estudo para a escolaridade ajustada pela duração do vínculo. A escolaridade ajustada média por indivíduo é de 6,8 anos equivalentes de estudo. Estes resultados são apresentados na Tabela 26.

Tabela 26 - Vínculos, anos equivalentes de estudos (AeqE) total e por vínculo no comércio varejista de combustíveis, em todo o Brasil, em 2007.

\begin{tabular}{|c|c|c|}
\hline Vínculos & AeqE Total & AeqE por vínculo \\
\hline 385.064 & $2.624 .891,8$ & 6,8 \\
\hline
\end{tabular}


Considerando os dados apresentados nas Tabela 18 e Tabela 23, obtém-se a Tabela 27 que apresenta a escolaridade ajustada total alocada para o AEHC e a escolaridade ajustada por litro de AEHC.

Tabela 27 - Vínculos e anos equivalentes de estudo (AeqE) total e por litro, no comércio varejista de combustíveis, em todo o Brasil, para o AEHC, em 2007.

\begin{tabular}{|c|c|c|}
\hline Vínculos & AeqE Total & AeqE por litro \\
\hline 38.506 & 262.489 & $2,53 \mathrm{E}-05$ \\
\hline
\end{tabular}

A llustração 24 apresenta as curvas $\alpha_{\mathrm{rh}}, \beta_{\mathrm{rh}}$ e de Lorentz para os indivíduos que constituem o conjunto recurso humano no comércio varejista, no ano de 2007 . A curva $\beta_{\mathrm{rh}}$ para os indivíduos do comércio varejista mostra que a escolaridade ajustada acumulada soma cerca de $75 \%$ do valor alcançado se todos os indivíduos tivessem a escolaridade mínima e vínculo ao longo de todo o ano de 2007, representado pela curva $\alpha_{\text {rh. }}$ A curva de Lorentz mostra que os $20 \%$ mais carentes acumulam apenas cerca de $10 \%$ da escolaridade ajustada total do conjunto, e que $50 \%$ dos indivíduos acumulam cerca de $25 \%$.

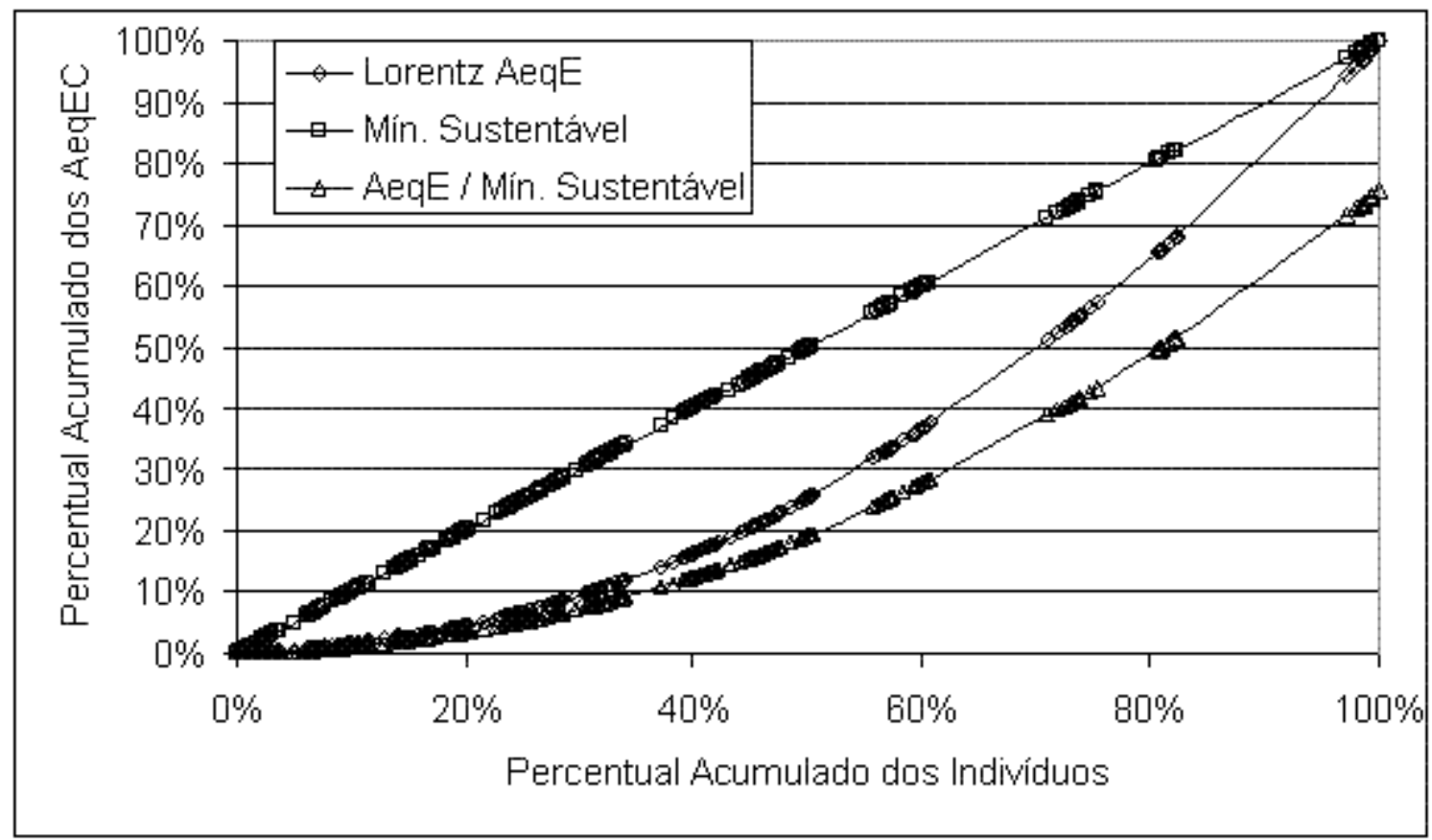

Ilustração 24 - Curvas $\alpha$ rh, $\beta$ rh e de Lorentz da distribuição dos anos equivalentes de estudo (AeqE) no comércio varejista de combustíveis, no ano de 2007. 


\subsubsection{INVENTÁRIO SOCIAL DO TRANSPORTE DE AEHC}

Para o transporte do AEHC da usina até o ponto de venda ao consumidor, foi considerada a atividade de transporte rodoviário de cargas. O transporte de combustíveis é uma sub-classe desta atividade na Classificação Nacional de Atividades Econômicas. Mas o PDET não permite a recuperação de dados neste nível de desagregação das atividades econômicas. A Tabela 28 apresenta a renda anual total, os anos equivalentes de estudo total e os valores por indivíduo.

Tabela 28 - Total de indivíduos, renda anual e anos equivalentes de estudo, total e por indivíduos, na atividade Transporte Rodoviário de Cargas, em 2007.

\begin{tabular}{|c|c|c|c|c|}
\hline Indivíduos & Renda anual (R\$) & Renda $/$ ind. & AeqE total & AeqE / ind. \\
\hline 865.984 & $6.539 .431 .848,00$ & $7.551,45$ & $5.537 .205,25$ & 6,4 \\
\hline
\end{tabular}

A llustração 25 apresenta as curvas $\alpha_{\mathrm{rh}}, \beta_{\mathrm{rh}}$ e de Lorentz da distribuição de renda entre os indivíduos que constituem o conjunto recurso humano no Transporte Rodoviário de Cargas. A curva $\beta_{\text {rh }}$ mostra que a renda anual deste conjunto soma apenas cerca de $37 \%$ da mínima sustentável. A curva de Lorentz mostra que metade dos indivíduos têm cerca de $25 \%$ da renda.

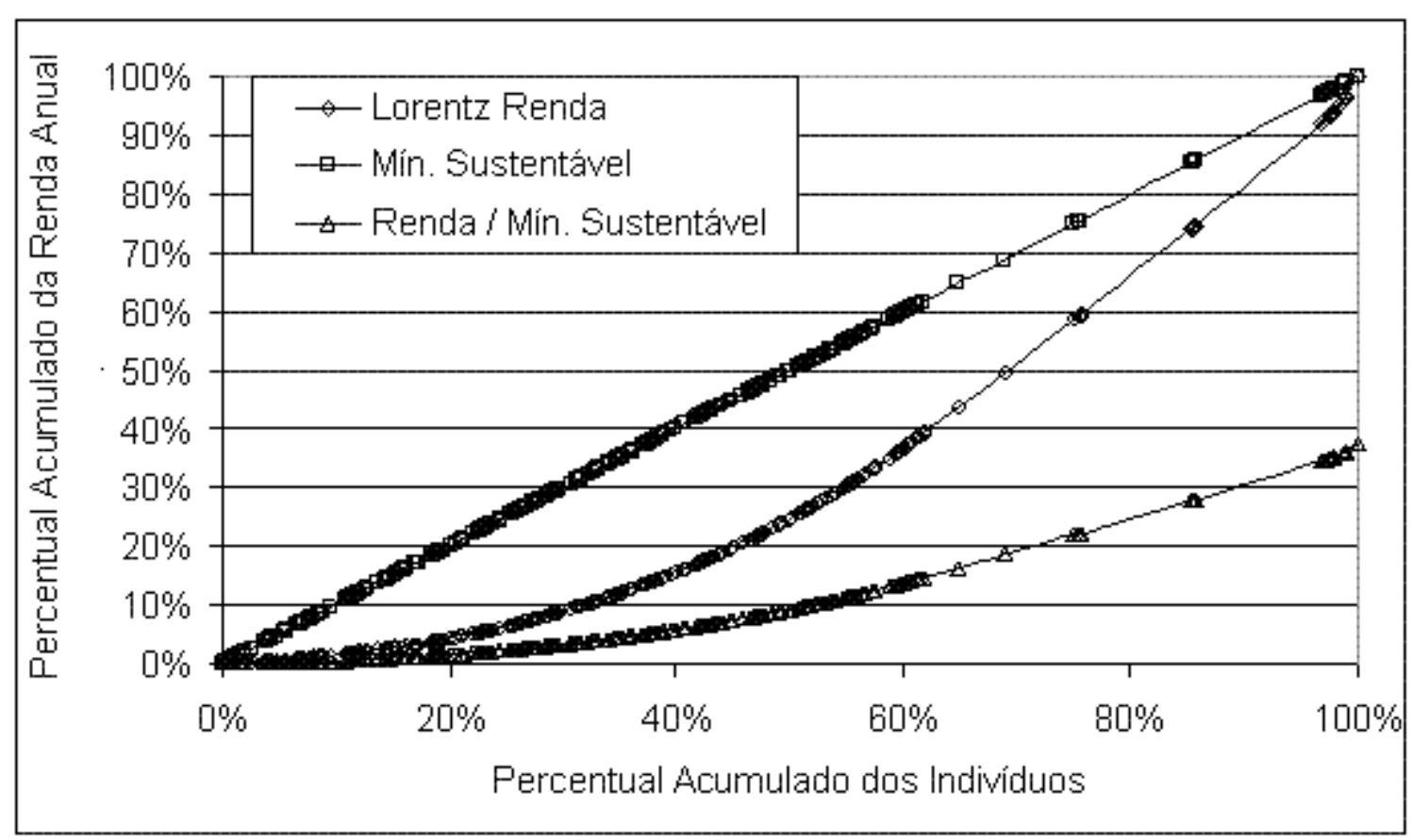

Ilustração 25 - Curvas $\alpha$ rh, $\beta$ rh e de Lorentz da distribuição de renda, no transporte rodoviário de cargas, em 2007. 
A llustração 26 apresenta as curvas $\alpha_{\mathrm{rh}}, \beta_{\mathrm{rh}}$ e de Lorentz da distribuição dos anos equivalentes de estudo entre os indivíduos do Transporte Rodoviário de Cargas. A curva $\beta_{\text {rh }}$ mostra que o conjunto acumula cerca de $70 \%$ da escolaridade mínima sustentável. A curva de Lorentz mostra que $20 \%$ dos indivíduos acumulam cerca de 5\% da EADV, e que metade dos indivíduos acumulam cerca de $25 \%$.

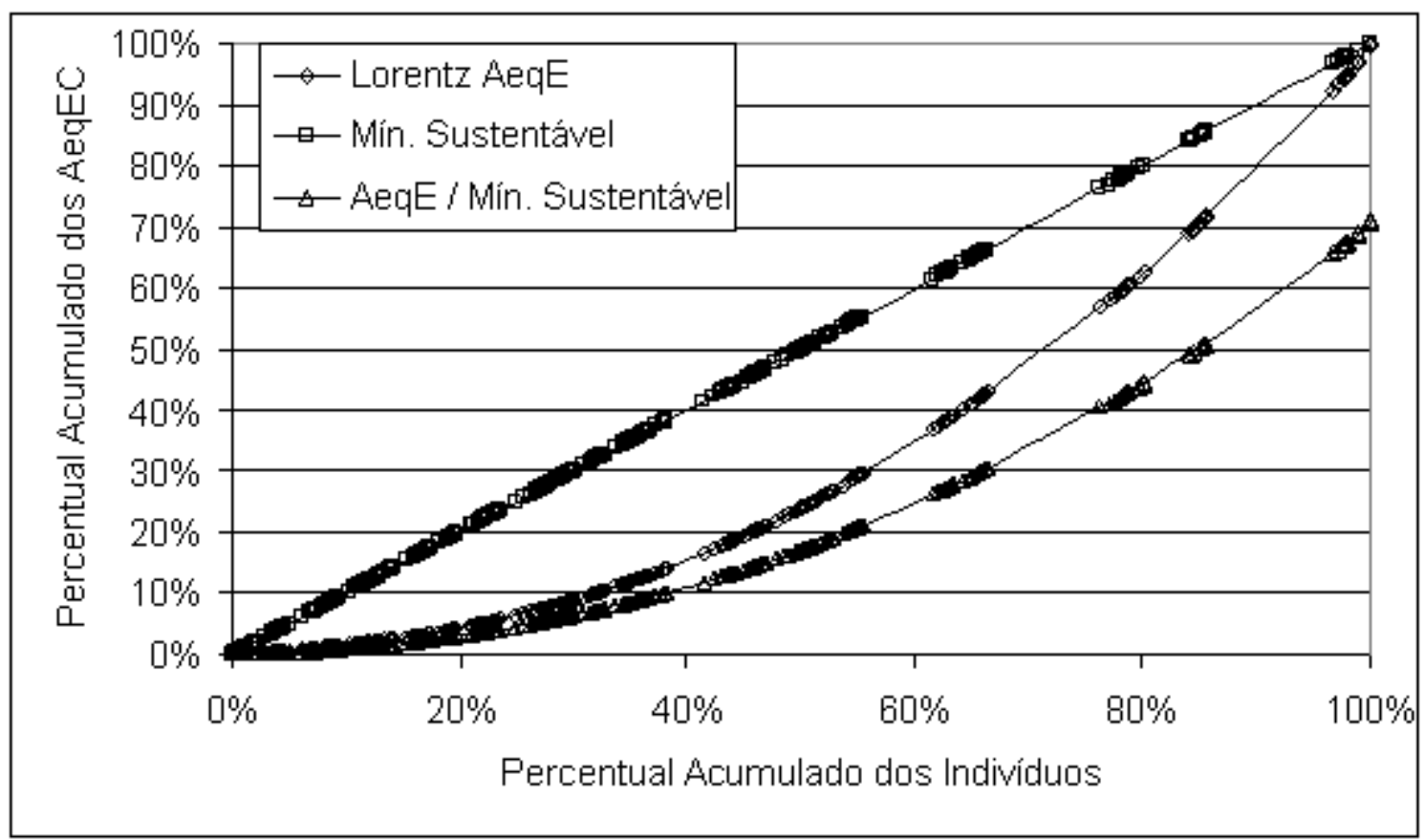

Ilustração 26 - Curvas $\alpha$ rh, $\beta$ rh e de Lorentz da distribuição dos anos equivalentes de estudo, no transporte rodoviário de cargas, em 2007.

\subsubsection{InVENTÁrio Social da Produção de AEHC}

\subsubsection{Renda na Produção do AEHC}

Em 2007, a atividade econômica de produção de álcool registrou cerca de 190 mil vínculos, que somaram uma renda anual de aproximadamente 1,35 bilhão de Reais. De 2000 a 2007, a renda média por vínculo apresentou um crescimento de cerca de 93\%, partindo de $\mathrm{R} \$ 3.650,57$ em 2000 para $\mathrm{R} \$ 7.056,54$ em 2007. A Tabela 29 apresenta estes resultados. 
Tabela 29 - Vínculos totais, renda anual total e média por vínculo, na produção de álcool etílico, no Brasil, em Reais, valores nominais, de 2000 a 2007.

\begin{tabular}{|l|c|c|c|}
\hline Ano & Vínculos & Renda an. total (R\$) & Renda an. média por vínculo (R\$) \\
\hline 2000 & 68.138 & $248.742 .559,09$ & $3.650,57$ \\
\hline 2001 & 67.127 & $276.504 .574,50$ & $4.119,13$ \\
\hline 2002 & 95.100 & $427.239 .336,73$ & $4.492,53$ \\
\hline 2003 & 101.580 & $517.109 .074,89$ & $5.090,66$ \\
\hline 2004 & 107.157 & $587.550 .103,47$ & $5.483,08$ \\
\hline 2005 & 128.363 & $742.949 .160,20$ & $5.787,88$ \\
\hline 2006 & 176.949 & $1.134 .329 .652,95$ & $6.410,49$ \\
\hline 2007 & 190.894 & $1.347 .051 .872,29$ & $7.056,54$ \\
\hline
\end{tabular}

Considerando os dados apresentados nas Tabela 30 e Tabela 31, obteve-se a produção Brasileira de AEHC e AEAC em unidades energéticas e a participação em base energética do AEHC, como mostra a Tabela 32.

Tabela 30 - Produção Brasileira de álcool etílico hidratado (AEHC) e anidro (AEAC) combustíveis, no Brasil, em mil metros cúbicos, de 2000 a 2007.

\begin{tabular}{|l|c|c|l|c|c|}
\hline Ano & AEHC (Mil $\mathbf{~ m}^{\mathbf{3}}$ ) & AEAC (Mil $\mathbf{~ m}^{\mathbf{3}}$ ) & Ano & AEHC (Mil $\mathbf{~ m}^{\mathbf{3}}$ ) & AEAC (Mil $\mathbf{~}^{\mathbf{3}}$ ) \\
\hline 2000 & 5.056 & 5.644 & 2004 & 6.789 & 7.859 \\
\hline 2001 & 4.985 & 6.481 & 2005 & 7.832 & 8.208 \\
\hline 2002 & 5.548 & 7.040 & 2006 & 9.851 & 7.913 \\
\hline 2003 & 5.638 & 8.832 & 2007 & 14.303 & 8.254 \\
\hline
\end{tabular}

(Fonte: MME, 2008)

Tabela 31 - Propriedades do álcool etílico hidratado (AEHC) e anidro (AEAC) combustíveis.

\begin{tabular}{|l|c|c|c|}
\hline Propriedade & AEHC & AEAC & Unidades \\
\hline $\mathrm{PCl}$ & 6.300 & 6.750 & $\mathrm{kcal} / \mathrm{kg}$ \\
\hline Densidade & 0,809 & 0,791 & $\mathrm{~kg} / \mathrm{L}$ \\
\hline
\end{tabular}

(Fonte: MME, 2008); 1 kcal = 4,1868 kJ 
Tabela 32 - Produção brasileira de álcool etílico hidratado (AEHC) e anidro (AEAC) no Brasil, em quilojoule, e participação do AEHC, de 2000 a 2007.

\begin{tabular}{|l|c|c|c|c|}
\hline Ano & AEHC (GJ) & AEAC (GJ) & MJ total & \% AEHC \\
\hline 2000 & $1,08 \mathrm{E}+11$ & $1,26 \mathrm{E}+11$ & $2,34 \mathrm{E}+11$ & $46 \%$ \\
\hline 2001 & $1,06 \mathrm{E}+11$ & $1,45 \mathrm{E}+11$ & $2,51 \mathrm{E}+11$ & $42 \%$ \\
\hline 2002 & $1,18 \mathrm{E}+11$ & $1,57 \mathrm{E}+11$ & $2,75 \mathrm{E}+11$ & $43 \%$ \\
\hline 2003 & $1,20 \mathrm{E}+11$ & $1,97 \mathrm{E}+11$ & $3,17 \mathrm{E}+11$ & $38 \%$ \\
\hline 2004 & $1,45 \mathrm{E}+11$ & $1,76 \mathrm{E}+11$ & $3,21 \mathrm{E}+11$ & $45 \%$ \\
\hline 2005 & $1,67 \mathrm{E}+11$ & $1,83 \mathrm{E}+11$ & $3,50 \mathrm{E}+11$ & $48 \%$ \\
\hline 2006 & $2,10 \mathrm{E}+11$ & $1,77 \mathrm{E}+11$ & $3,87 \mathrm{E}+11$ & $54 \%$ \\
\hline 2007 & $3,05 \mathrm{E}+11$ & $1,85 \mathrm{E}+11$ & $4,90 \mathrm{E}+11$ & $62 \%$ \\
\hline
\end{tabular}

(Fonte: MME, 2008)

Os dados da Tabela 29 que se referem ao conjunto total de vínculos da atividade de produção de álcool etílico, anidro e hidratado, foram multiplicados pela participação percentual em base energética do AEHC, para se obter a Tabela 33, que apresenta os vínculos e a renda anual total alocados ao AEHC.

Tabela 33 - Vínculos totais e renda anual total, alocados para a produção de álcool etílico hidratado, no Brasil, de 2000 a 2007.

\begin{tabular}{|l|c|c|c|c|c|}
\hline Ano & Vínculos & Renda an. total & Ano & vínculos & Renda an. total \\
\hline 2000 & 31.343 & 114.421 .577 & 2004 & 48.221 & 264.397 .547 \\
\hline 2001 & 28.193 & 116.131 .921 & 2005 & 61.614 & 356.615 .597 \\
\hline 2002 & 40.893 & 183.712 .915 & 2006 & 95.552 & 612.538 .013 \\
\hline 2003 & 38.600 & 196.501 .448 & 2007 & 118.354 & 835.172 .161 \\
\hline
\end{tabular}

Considerando-se os vínculos alocados em base energética ao AEHC e as quantidades em unidades energéticas e volumétrica da produção de AEHC obtémse as Tabela 34 e Tabela 35 que apresentam a quantidade de vínculos e a renda anual por quilojoule e por litro de $\mathrm{AEHC}$, respectivamente. No período, observa-se um crescimento dos vínculos e da renda anual por litro de AEHC, como mostram as Ilustração 27 e Ilustração 28. Possivelmente, este aumento é decorrente da instalação de novos estabelecimentos. 
Tabela 34 - Vínculo e renda anual, por quilojoule de AEHC, no Brasil, de 2000 a 2007.

\begin{tabular}{|l|c|c|c|c|c|}
\hline Ano & Vínculos & Renda Anual (R\$) & Ano & Vínculos & Renda Anual (R\$) \\
\hline 2000 & $2,90, E-07$ & $1,06 E-03$ & 2004 & $3,33, E-07$ & $1,82 E-03$ \\
\hline 2001 & $2,66, E-07$ & $1,10 E-03$ & 2005 & $3,69, E-07$ & $2,14 \mathrm{E}-03$ \\
\hline 2002 & $3,47, E-07$ & $1,56 E-03$ & 2006 & $4,55, E-07$ & $2,92 \mathrm{E}-03$ \\
\hline 2003 & $3,22, E-07$ & $1,64 \mathrm{E}-03$ & 2007 & $3,88, E-07$ & $2,74 \mathrm{E}-03$ \\
\hline
\end{tabular}

Tabela 35 - Vínculo e renda anual, por litro de AEHC, no Brasil, de 2000 a 2007.

\begin{tabular}{|l|c|c|c|c|c|}
\hline Ano & Vínculos & Renda Anual (R\$) & Ano & Vínculos & Renda Anual (R\$) \\
\hline 2000 & $6,20 E-06$ & 0,02 & 2004 & $7,10 E-06$ & 0,04 \\
\hline 2001 & $5,66 E-06$ & 0,02 & 2005 & $7,87 E-06$ & 0,05 \\
\hline 2002 & $7,37 E-06$ & 0,03 & 2006 & $9,70 E-06$ & 0,06 \\
\hline 2003 & $6,85 E-06$ & 0,03 & 2007 & $8,27 E-06$ & 0,06 \\
\hline
\end{tabular}

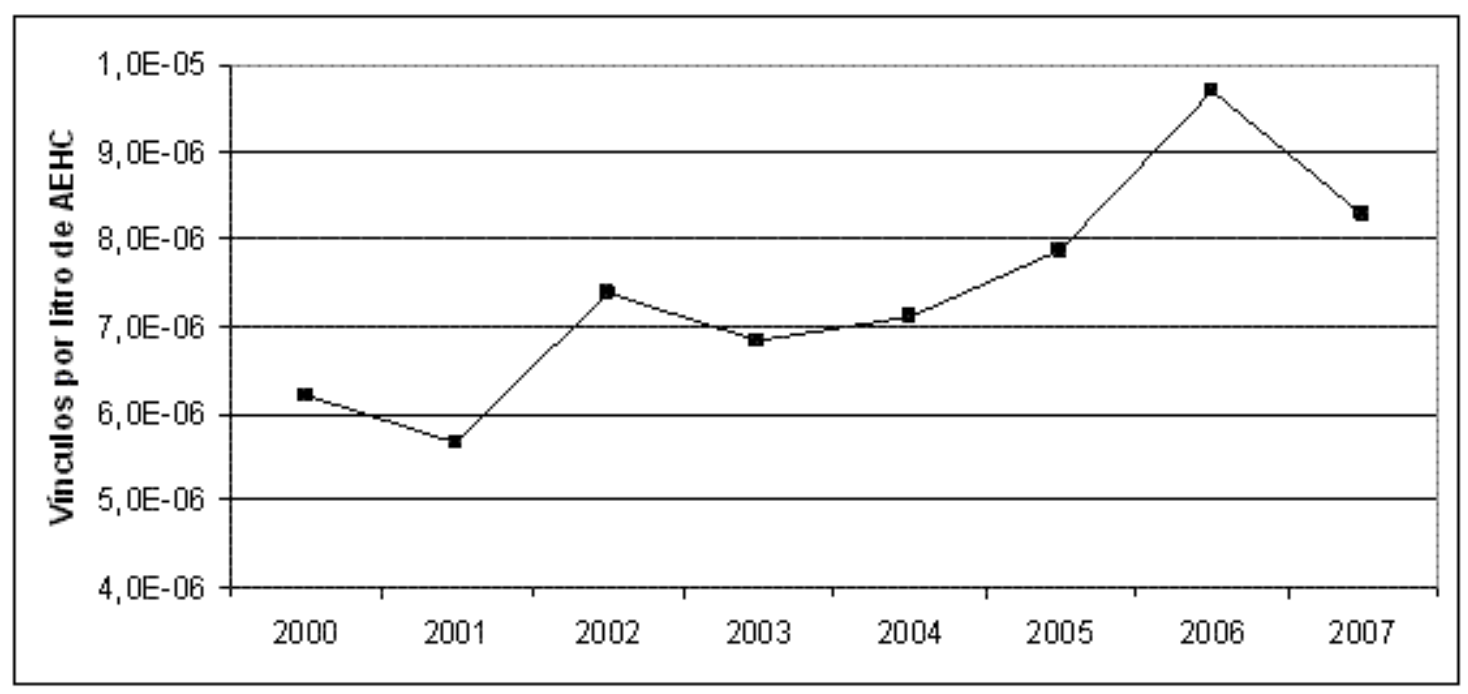

Ilustração 27 - Vínculos por litro de AEHC, no Brasil, de 2000 a 2007. 


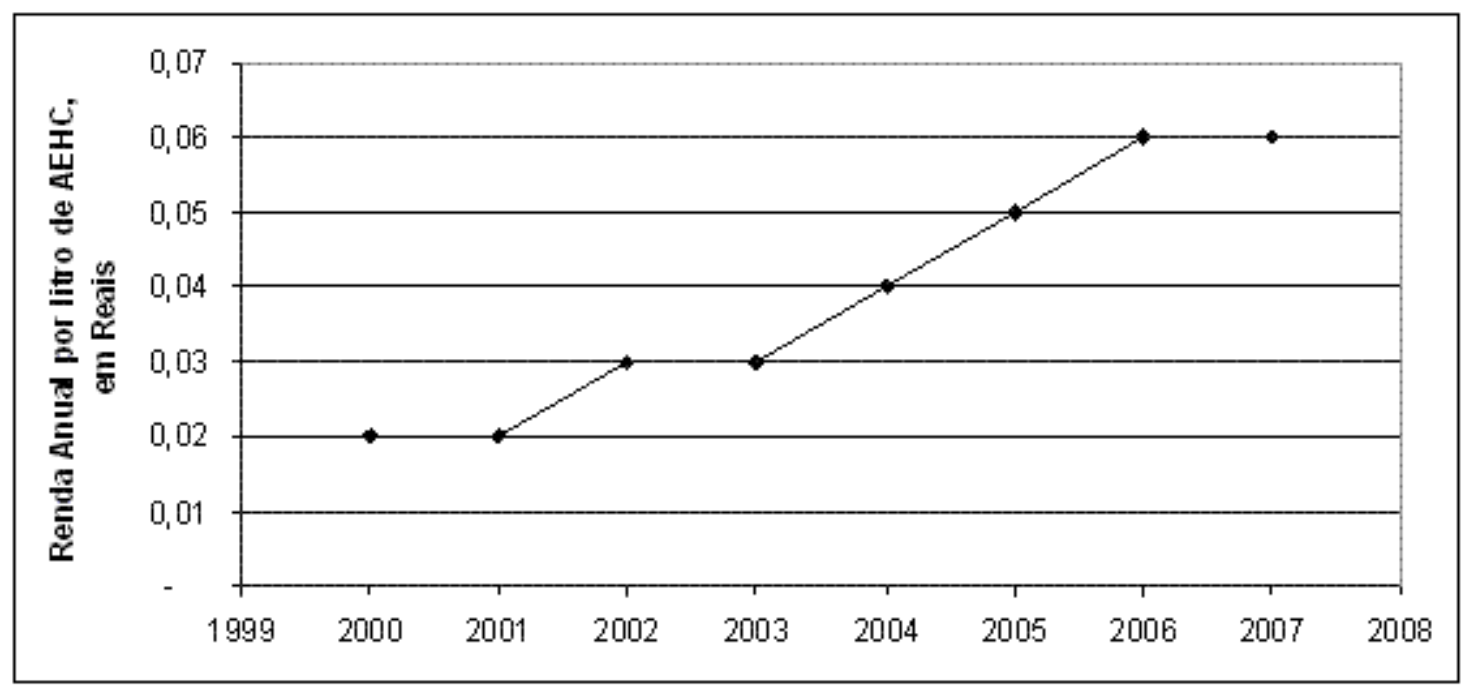

llustração 28 - Renda anual do recurso humano por litro de AEHC, no Brasil, de 2000 a 2007.

A llustração 29 apresenta as curvas $\alpha_{\mathrm{rh}}, \beta_{\mathrm{rh}}$ e de Lorentz da distribuição de renda entre os indivíduos recurso humano na produção de álcool. A curva $\beta_{\text {rh }}$ mostra o recurso humano soma apenas cerca de $35 \%$ da renda mínima sustentável. A curva de Lorentz mostra que $20 \%$ dos indivíduos têm menos de $5 \%$ da renda anual total. Metade dos indivíduos recebem cerca de $20 \%$ da renda total. Os $20 \%$ com maior rendimento recebem cerca de $45 \%$ da renda anual total.

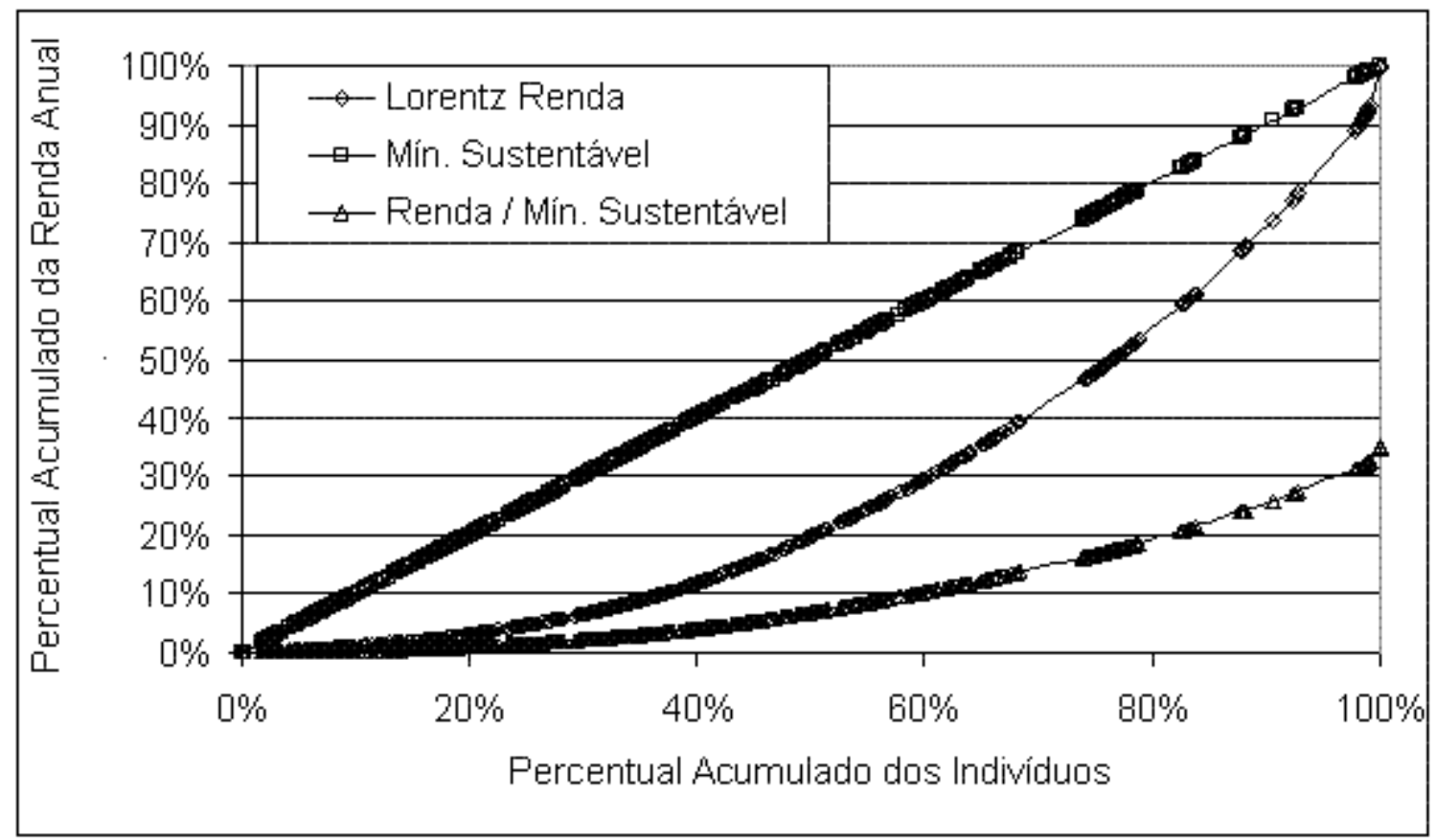

Ilustração 29 - Curvas $\alpha$ rh, $\beta$ rh e de Lorentz da distribuição de renda na produção de álcool etílico, em 2007. 


\subsubsection{Escolaridade na Produção do AEHC}

A Tabela 36 mostra que, em 2007, o conjunto recurso humano na produção de álcool somou cerca de 813 mil anos equivalentes de estudo, com um valor por indivíduos de cerca de 6,7 anos equivalentes de estudo. Observa-se desde 2000, um crescimento contínuo na EADV por indivíduo. A Tabela 37 apresenta os dados alocados em base energética para o AEHC. Os valores por quilojoule e por litro são apresentados nas Tabela 38 e Tabela 39, respectivamente.

Tabela 36 - Vínculos, anos equivalentes de estudo (AeqE) total e por vínculo, na produção de álcool etílico, no Brasil, de 2000 a 2007.

\begin{tabular}{|l|c|c|c|}
\hline Ano & Vínculos & AeqE Total & AeqE por vínculo \\
\hline 2000 & 68.138 & $238.136,2$ & 5,27 \\
\hline 2001 & 67.127 & $252.521,8$ & 5,68 \\
\hline 2002 & 95.100 & $351.332,9$ & 5,63 \\
\hline 2003 & 101.580 & $389.449,2$ & 5,72 \\
\hline 2004 & 107.157 & $439.200,3$ & 6,13 \\
\hline 2005 & 128.363 & $519.028,9$ & 6,21 \\
\hline 2006 & 176.949 & $741.578,1$ & 6,64 \\
\hline 2007 & 190.894 & $813.361,5$ & 6,69 \\
\hline
\end{tabular}

Tabela 37 - Vínculos e anos eq. de estudo (AeqE), alocados para o AEHC, de 2000 a 2007.

\begin{tabular}{|l|c|c|l|c|c|}
\hline Ano & Vínculos & AeqE & Ano & Vínculos & AeqE \\
\hline 2000 & 31.343 & 109.543 & 2004 & 48.221 & 197.640 \\
\hline 2001 & 28.193 & 106.059 & 2005 & 61.614 & 249.134 \\
\hline 2002 & 40.893 & 151.073 & 2006 & 95.552 & 400.452 \\
\hline 2003 & 38.600 & 147.991 & 2007 & 118.354 & 504.284 \\
\hline
\end{tabular}

Tabela 38 - Vínculos e anos eq. de estudo (AeqE), por quilojoule de AEHC, de 2000 a 2007.

\begin{tabular}{|l|c|c|l|c|c|}
\hline Ano & Vínculos & AeqE & Ano & Vínculos & AeqE \\
\hline 2000 & $2,90, E-07$ & $1,01 \mathrm{E}-06$ & 2004 & $3,33, \mathrm{E}-07$ & $1,36 \mathrm{E}-06$ \\
\hline 2001 & $2,66, \mathrm{E}-07$ & $1,00 \mathrm{E}-06$ & 2005 & $3,69, \mathrm{E}-07$ & $1,49 \mathrm{E}-06$ \\
\hline 2002 & $3,47, \mathrm{E}-07$ & $1,28 \mathrm{E}-06$ & 2006 & $4,55, \mathrm{E}-07$ & $1,91 \mathrm{E}-06$ \\
\hline 2003 & $3,22, \mathrm{E}-07$ & $1,23 \mathrm{E}-06$ & 2007 & $3,88, \mathrm{E}-07$ & $1,65 \mathrm{E}-06$ \\
\hline
\end{tabular}


Tabela 39 - Vínculos e anos equivalentes de estudo (AeqE), por litro de AEHC produzido no Brasil, de 2000 a 2007.

\begin{tabular}{|l|c|c|l|c|c|}
\hline Ano & Vínculos & AeqE & Ano & Vínculos & AeqE \\
\hline 2000 & $6,20 \mathrm{E}-06$ & $2,17 \mathrm{E}-05$ & 2004 & $7,10 \mathrm{E}-06$ & $2,91 \mathrm{E}-05$ \\
\hline 2001 & $5,66 \mathrm{E}-06$ & $2,13 \mathrm{E}-05$ & 2005 & $7,87 \mathrm{E}-06$ & $3,18 \mathrm{E}-05$ \\
\hline 2002 & $7,37 \mathrm{E}-06$ & $2,72 \mathrm{E}-05$ & 2006 & $9,70 \mathrm{E}-06$ & $4,06 \mathrm{E}-05$ \\
\hline 2003 & $6,85 \mathrm{E}-06$ & $2,62 \mathrm{E}-05$ & 2007 & $8,27 \mathrm{E}-06$ & $3,53 \mathrm{E}-05$ \\
\hline
\end{tabular}

A llustração 30 mostra que os indivíduos na produção de álcool acumulam cerca de $47 \%$ da EADV mínima sustentável. A curva de Lorentz mostra que $40 \%$ dos indivíduos acumulam cerca de $10 \%$ da EADV total e que os $40 \%$ mais escolarizados acumulam cerca de $75 \%$.

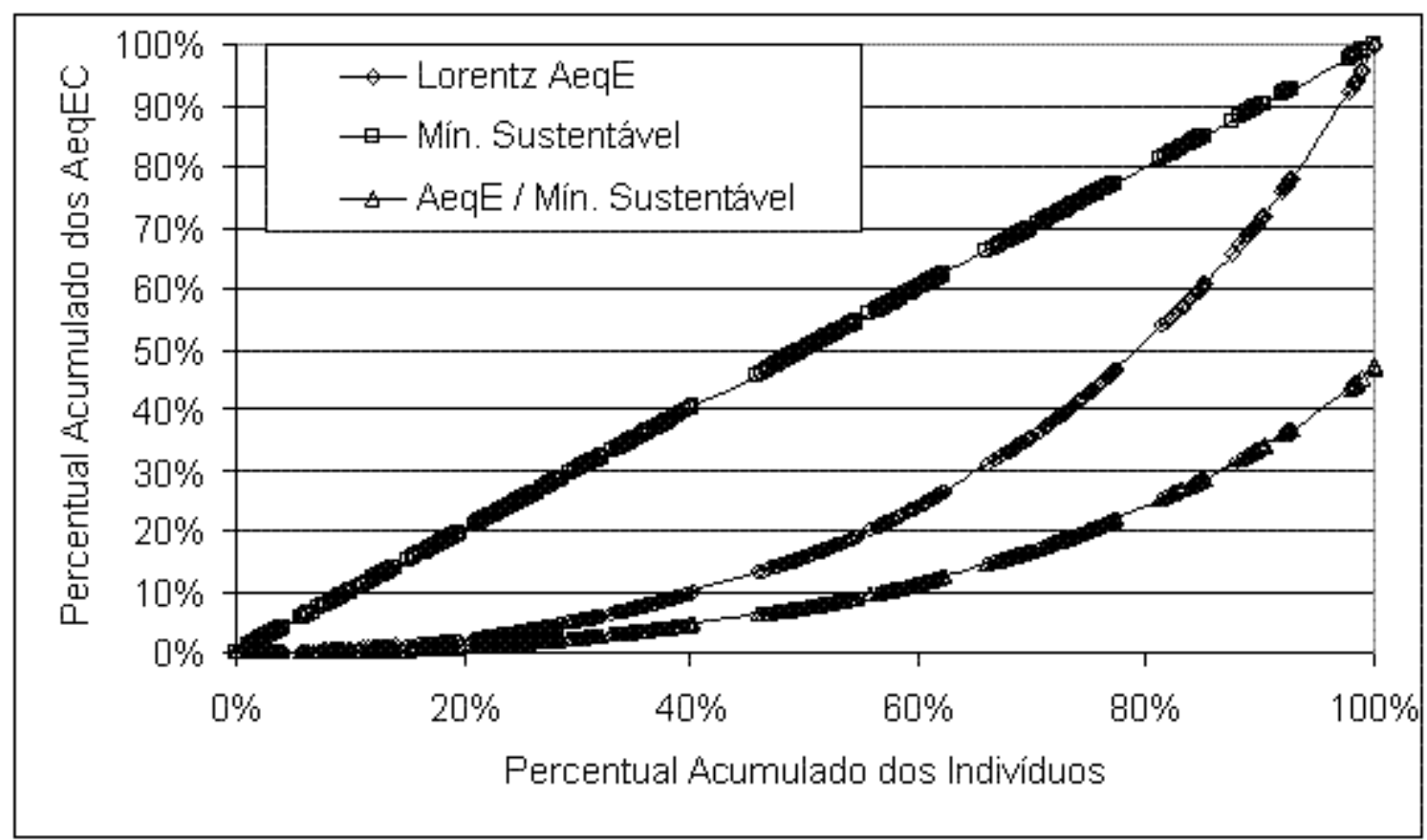

Ilustração 30 - Curvas $\alpha$ rh, $\beta$ rh e de Lorentz da distribuição dos anos equivalentes de estudo (AeqE) na produção de álcool etílico, no ano de 2007. 


\subsubsection{INVENTÁRIO SOCIAL do Cultivo de CANA-DE-Açúcar}

\subsubsection{Renda no Cultivo de Cana-de-Açúcar}

Em 2007, no Estado de São Paulo, o cultivo de cana-de-açúcar empregou cerca de 270 mil indivíduos, que receberam uma renda total de aproximadamente 2 bilhões de Reais, quase 7,5 mil Reais por indivíduo. Estes resultados, para os anos de 2000 a 2007, são apresentados na Tabela 40. Em 2007, a produção de cana do Estado de São Paulo foi de cerca de 280 milhões de toneladas, com valor de cerca de 27,3 bilhões de Reais, como mostra a Tabela 41.

Tabela 40 - Vínculos totais declarados na RAIS, Renda Anual total e por vínculo, no cultivo de cana-de-açúcar, no Estado de São Paulo, de 2000 a 2007.

\begin{tabular}{|l|c|c|c|}
\hline Ano & Vínculos & Renda An. Total (R\$) & Renda An. Média por Vínc. (R\$) \\
\hline 2000 & 182.003 & $658.165 .771,46$ & $3.616,24$ \\
\hline 2001 & 199.263 & $809.365 .383,40$ & $4.061,79$ \\
\hline 2002 & 195.206 & $843.555 .379,14$ & $4.321,36$ \\
\hline 2003 & 180.685 & $950.071 .573,78$ & $5.258,17$ \\
\hline 2004 & 190.967 & $1.079 .433 .400,21$ & $5.652,46$ \\
\hline 2005 & 220.517 & $1.353 .225 .508,69$ & $6.136,60$ \\
\hline 2006 & 247.211 & $1.670 .549 .061,68$ & $6.757,58$ \\
\hline 2007 & 268.282 & $1.999 .842 .981,06$ & $7.454,26$ \\
\hline
\end{tabular}

Tabela 41 - Quantidade de cana-de-açúcar produzida, em toneladas, e valor da produção em mil Reais, valores nominais, no Estado de São Paulo, de 2000 a 2007.

\begin{tabular}{|l|c|c|}
\hline Ano & Produção de Cana (t) & Valor da Produção (mil Reais) \\
\hline 2000 & 189.040 .000 & 10.024 .788 \\
\hline 2001 & 198.932 .127 & 13.599 .016 \\
\hline 2002 & 212.707 .367 & 18.021 .486 \\
\hline 2003 & 227.980 .860 & 19.335 .830 \\
\hline 2004 & 239.527 .890 & 18.667 .529 \\
\hline 2005 & 254.809 .756 & 20.604 .796 \\
\hline 2006 & 269.134 .237 & 26.617 .518 \\
\hline 2007 & 281.570 .104 & 27.329 .536 \\
\hline
\end{tabular}

(Fonte: IBGE, 2008) 
A partir das Tabela 40 e Tabela 41, obtém-se as Tabela 42 e Tabela 43, que apresentam a quantidade de vínculos e a renda associada por tonelada de cana e por unidade monetária, desde 2000 a 2007. A Ilustração 31 mostra um crescimento entre 2000 e 2007 da renda anual por tonelada de cana-de-açúcar produzida. Este aumento pode ser parcialmente atribuído ao crescimento da mecanização na colheita de cana-de-açúcar no Estado de São Paulo e ao aumento da Produtividade.

Tabela 42 - Vínculo e renda, por tonelada de cana, no Estado de São Paulo, de 2000 a 2007.

\begin{tabular}{|l|c|c|l|c|c|}
\hline Ano & Vínculos & Renda (R\$) & Ano & Vínculos & Renda (R\$) \\
\hline 2000 & $9,63 \mathrm{E}-04$ & 3,48 & 2004 & $7,97 \mathrm{E}-04$ & 4,51 \\
\hline 2001 & $1,00 \mathrm{E}-03$ & 4,07 & 2005 & $8,65 \mathrm{E}-04$ & 5,31 \\
\hline 2002 & $9,18 \mathrm{E}-04$ & 3,97 & 2006 & $9,19 \mathrm{E}-04$ & 6,21 \\
\hline 2003 & $7,93 \mathrm{E}-04$ & 4,17 & 2007 & $9,53 \mathrm{E}-04$ & 7,10 \\
\hline
\end{tabular}

Tabela 43 - Vínculo e renda, por unidade monetária do produto em São Paulo, de 2000 a 2007.

\begin{tabular}{|l|c|c|l|l|c|}
\hline Ano & Vínculos & Renda (R\$) & Ano & Vínculos & Renda (R\$) \\
\hline 2000 & $1,82 \mathrm{E}-05$ & 0,07 & 2004 & $1,02 \mathrm{E}-05$ & 0,06 \\
\hline 2001 & $1,47 \mathrm{E}-05$ & 0,06 & 2005 & $1,07 \mathrm{E}-05$ & 0,07 \\
\hline 2002 & $1,08 \mathrm{E}-05$ & 0,05 & 2006 & $9,29 \mathrm{E}-06$ & 0,06 \\
\hline 2003 & $9,34 \mathrm{E}-06$ & 0,05 & 2007 & $9,82 \mathrm{E}-06$ & 0,07 \\
\hline
\end{tabular}

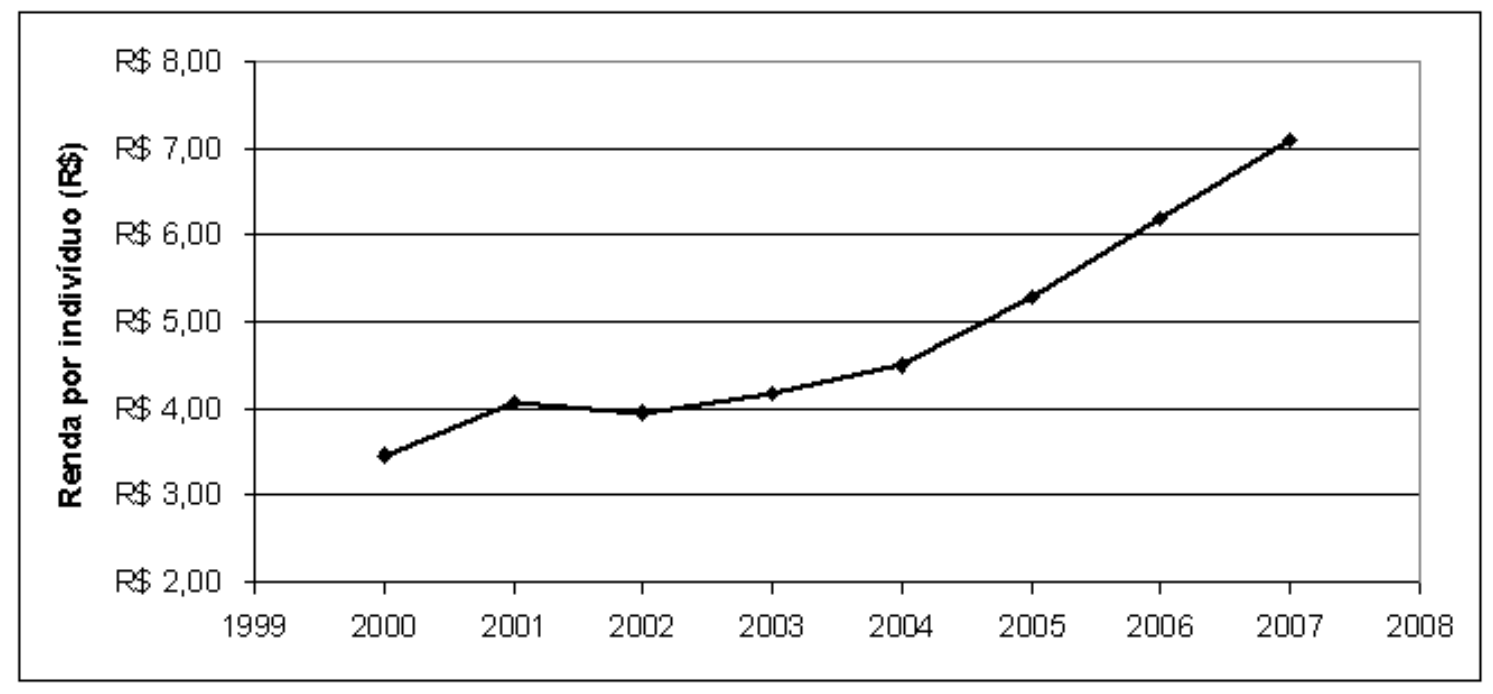

llustração 31 - Renda anual por tonelada de cana na atividade de cultivo de cana-de-açúcar, no Estado de São Paulo, de 2000 a 2007. 
A llustração 32 apresenta as curvas $\alpha_{\mathrm{rh}}, \beta_{\mathrm{rh}}$ e de Lorentz da distribuição de renda entre os indivíduos recurso humano no cultivo de cana, no Estado de São Paulo. A curva $\beta_{\text {rh }}$ mostra que este conjunto de indivíduos acumula, em 2007, cerca de $37 \%$ do valor mínimo sustentável para a renda anual. A curva de Lorentz mostra que $40 \%$ dos indivíduos somam cerca de $15 \%$ da renda. Com estes dados, o índice de Gini no cultivo da cana em São Paulo tem o valor de 0,366. Hoffmann (2005), para o ano de 2003 e considerando todo o Brasil, obteve um valor de 0,493 para o Índice de Gini. Para o Estado de São Paulo, no mesmo ano, Hoffmann (2005) calculou um Índice de Gini de 0,565, significando que a desigualdade no cultivo de cana de açúcar nesta Unidade da Federação é maior que a média do país, provavelmente pela introdução mais avançada da mecanização. O mesmo autor, para as regiões norte e nordeste, estimou o índice de Gini como 0,323, no cultivo de cana de açúcar, significando que a desigualdade é menor entre os indivíduos neste setor do que a média brasileira e do Estado de São Paulo.

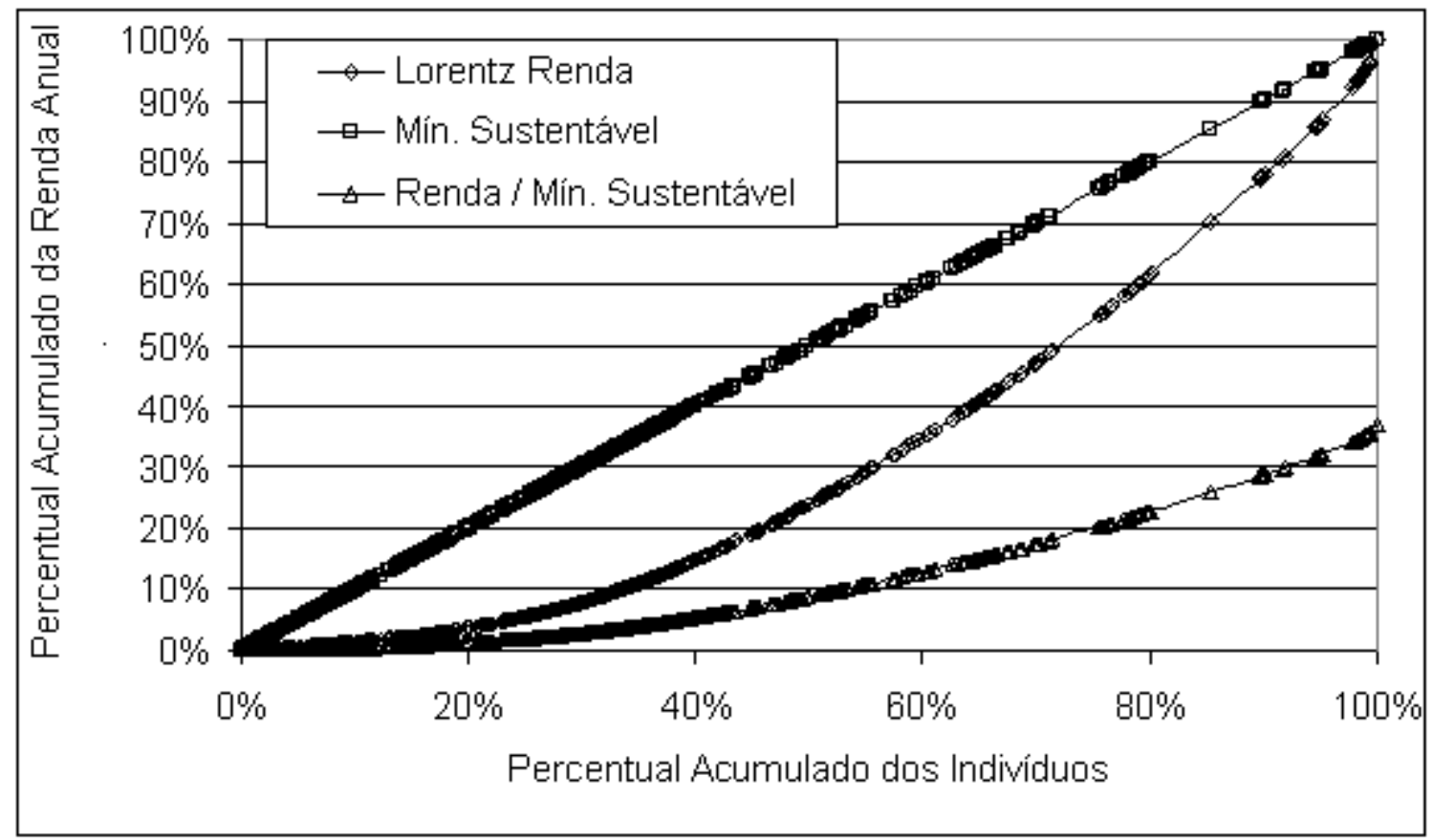

llustração 32 - Curvas $\alpha$ rh, $\beta$ rh e de Lorentz da distribuição de renda, no cultivo de cana-deaçúcar, no Estado de São Paulo, em 2007. 


\subsubsection{Escolaridade no Cultivo de Cana-de-Açúcar}

No ano de 2007, a Escolaridade Ajustada pela Duração do Vínculo (EADV) somou cerca de 1,1 milhão de anos equivalentes de estudo, com uma média por indivíduos de 4,1 anos. A EADV apresentou um crescimento contínuo desde 2000, quando foi de 3 anos equivalentes de estudo.

Tabela 44 - Vínculos, anos equivalentes de estudo total e por vínculo do conjunto recurso humano no cultivo de cana-de-açúcar, no Estado de São Paulo, de 2000 a 2007.

\begin{tabular}{|l|c|c|c|}
\hline Ano & Vínculos & AeqE Total & AeqE por vínculo \\
\hline 2000 & 182.003 & $552.873,3$ & 3,0 \\
\hline 2001 & 199.263 & $634.927,7$ & 3,2 \\
\hline 2002 & 195.206 & $639.323,6$ & 3,3 \\
\hline 2003 & 180.685 & $634.327,6$ & 3,5 \\
\hline 2004 & 190.967 & $704.280,3$ & 3,7 \\
\hline 2005 & 220.517 & $841.814,3$ & 3,8 \\
\hline 2006 & 247.211 & $988.355,5$ & 4,0 \\
\hline 2007 & 268.282 & $1.105 .885,9$ & 4,1 \\
\hline
\end{tabular}

As Tabela 45 e Tabela 46 apresentam os resultados da EADV por tonelada de cana de açúcar e por unidade monetária do valor da produção, de 2000 a 2007, no Estado de São Paulo. A llustração 33 apresenta as curvas $\alpha_{\mathrm{rh}}, \beta_{\mathrm{rh}} \mathrm{e}$ de Lorentz da distribuição dos anos equivalentes de estudo entre os indivíduos no cultivo de cana, no Estado de São Paulo, em 2007. Os indivíduos acumulam cerca de $45 \%$ do valor mínimo sustentável. Metade dos indivíduos somam cerca de 20\% da EADV total do conjunto de indivíduos.

Tabela 45 - Vínculo e anos equivalentes de estudo (AeqE) por tonelada de cana-de-açúcar, de 2000 a 2007

\begin{tabular}{|l|c|c|l|c|c|}
\hline Ano & Vínculos & AeqE & Ano & Vínculos & AeqE \\
\hline 2000 & $9,63 \mathrm{E}-04$ & $2,92 \mathrm{E}-03$ & 2004 & $7,97 \mathrm{E}-04$ & $2,94 \mathrm{E}-03$ \\
\hline 2001 & $1,00 \mathrm{E}-03$ & $3,19 \mathrm{E}-03$ & 2005 & $8,65 \mathrm{E}-04$ & $3,30 \mathrm{E}-03$ \\
\hline 2002 & $9,18 \mathrm{E}-04$ & $3,01 \mathrm{E}-03$ & 2006 & $9,19 \mathrm{E}-04$ & $3,67 \mathrm{E}-03$ \\
\hline 2003 & $7,93 \mathrm{E}-04$ & $2,78 \mathrm{E}-03$ & 2007 & $9,53 \mathrm{E}-04$ & $3,93 \mathrm{E}-03$ \\
\hline
\end{tabular}


Tabela 46 - Vínculo e anos equivalentes de estudo (AeqE) por unidade monetária do valor da produção de cana, no Estado de São Paulo, de 2000 a 2007.

\begin{tabular}{|l|c|c|l|c|c|}
\hline Ano & Vínculos & AeqE & Ano & Vínculos & AeqE \\
\hline 2000 & $1,82 \mathrm{E}-05$ & $5,52 \mathrm{E}-05$ & 2004 & $1,02 \mathrm{E}-05$ & $3,77 \mathrm{E}-05$ \\
\hline 2001 & $1,47 \mathrm{E}-05$ & $4,67 \mathrm{E}-05$ & 2005 & $1,07 \mathrm{E}-05$ & $4,09 \mathrm{E}-05$ \\
\hline 2002 & $1,08 \mathrm{E}-05$ & $3,55 \mathrm{E}-05$ & 2006 & $9,29 \mathrm{E}-06$ & $3,71 \mathrm{E}-05$ \\
\hline 2003 & $9,34 \mathrm{E}-06$ & $3,28 \mathrm{E}-05$ & 2007 & $9,82 \mathrm{E}-06$ & $4,05 \mathrm{E}-05$ \\
\hline
\end{tabular}

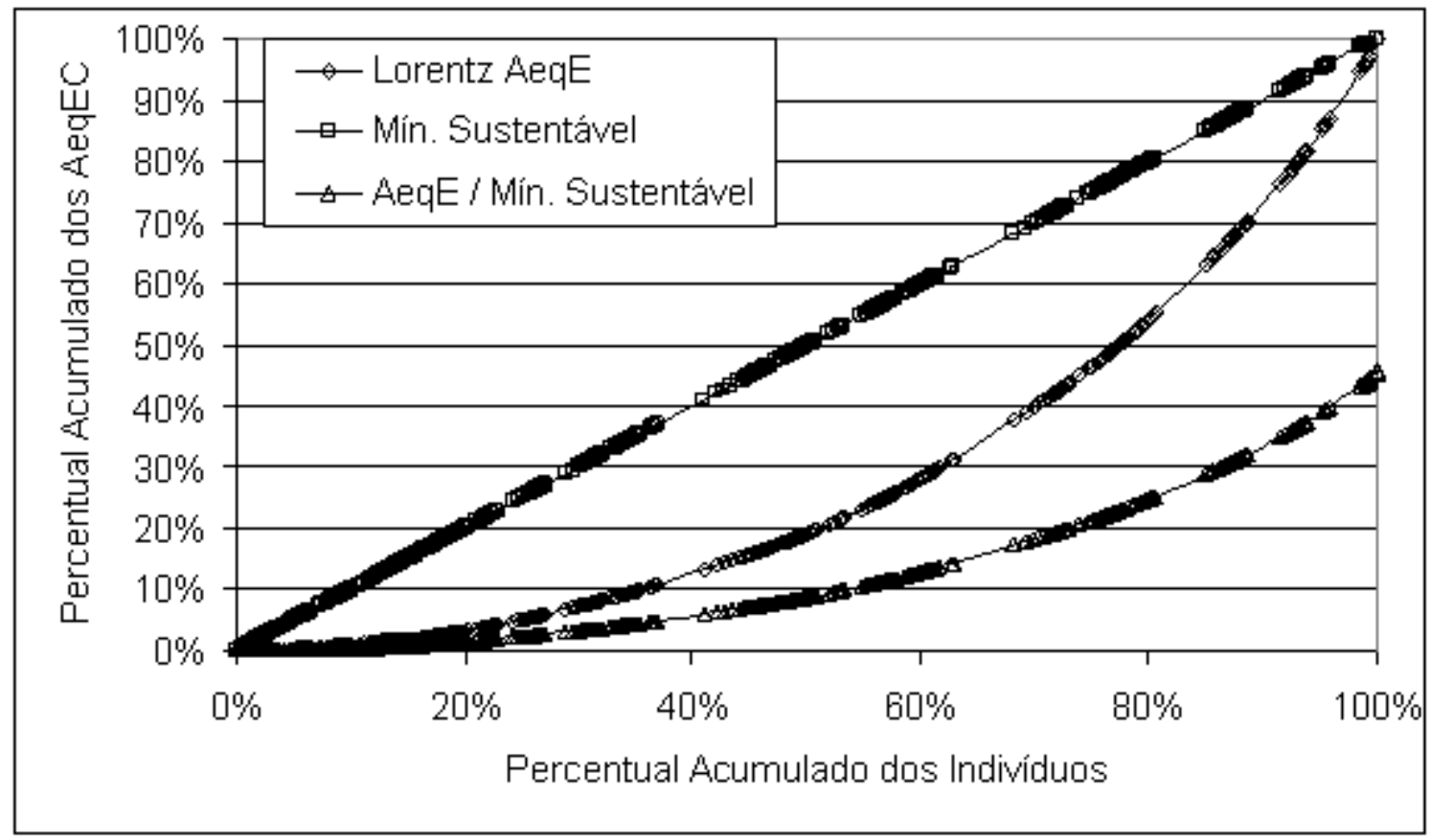

llustração 33 - Curvas $\alpha$ rh, $\beta$ rh e de Lorentz da distribuição dos anos equivalentes de estudo (AeqE), no cultivo de cana-de-açúcar, no Estado de São Paulo, em 2007.

\subsubsection{InVEnTÁrio Social das Atividades de APOIO À Agricultura}

As Atividades de Apoio Agrícola reúnem atividades comuns a diversas culturas agrícolas, cujas atividades de cultivo são descritas separadamente devido a importância econômica destas. As características dos estabelecimentos nesta atividade e do recurso humano envolvido são definidos pela cultura a que se destinam as atividades de apoio. Por esta razão, para o levantamento de dados desta atividade, foram selecionados municípios onde o cultivo da cana representou mais de 95\% do valor da produção das lavouras temporárias no período de de 2000 a 2006, apresentados na Tabela 47. O ano de 2007 foi estimado por regressão 
linear dos dados de 2000 a 2006, pois os dados da Produção Agrícola Municipal para este ano não estão disponíveis. Como mostra a Tabela 48, neste período, estes municípios foram responsáveis por cerca de 20\% da produção anual de canade-açúcar do Estado de São Paulo.

Tabela 47 - Municípios selecionados para o levantamento de dados da atividade de apoio à agricultura de Cana-de-Açúcar e produção municipal.

\begin{tabular}{|c|c|c|c|}
\hline Município Paulista & Produção (t) & Município Paulista & Produção (t) \\
\hline Piracicaba & 3.200 .000 & Ariranha & 773.500 \\
\hline Olímpia & 3.150 .000 & Iracemápolis & 747.000 \\
\hline Jaú & 2.962 .500 & São Pedro & 724.440 \\
\hline Lençóis Paulista & 2.844 .000 & Barra Bonita & 722.500 \\
\hline São Manuel & 2.610 .000 & Charqueada & 686.200 \\
\hline Penápolis & 2.560 .000 & Catiguá & 680.000 \\
\hline Dois Córregos & 2.400 .000 & Novais & 680.000 \\
\hline Pederneiras & 2.145 .000 & Sud Mennucci & 665.512 \\
\hline Ibaté & 1.498 .541 & Santa Ernestina & 649.800 \\
\hline Capivari & 1.276 .650 & Nova Europa & 610.132 \\
\hline Santa Adélia & 1.275 .000 & Américo Brasiliense & 583.685 \\
\hline Macatuba & 1.212 .650 & Igaraçu do Tietê & 544.000 \\
\hline Rio das Pedras & 1.200 .000 & Rafard & 510.988 \\
\hline Motuca & 1.190 .129 & Palmares Paulista & 510.000 \\
\hline Catanduva & 1.147 .500 & Cajobi & 442.260 \\
\hline Ribeirão Bonito & 1.135 .719 & Onda Verde & 420.000 \\
\hline Santa Lúcia & 1.036 .336 & Santa Gertrudes & 363.348 \\
\hline Bocaina & 972.000 & Paraíso & 352.750 \\
\hline Santa Bárbara d'Oeste & 960.000 & Mombuca & 325.000 \\
\hline Itapuí & 929.250 & Ipeúna & 297.506 \\
\hline Dobrada & 918.650 & Saltinho & 268.730 \\
\hline Mineiros do Tietê & 880.000 & Marapoama & 250.720 \\
\hline Orindiúva & 855.610 & Embaúba & 126.000 \\
\hline Ipaussu & 834.373 & Americana & 120.000 \\
\hline
\end{tabular}

(Fonte: IBGE, 2008) 
Tabela 48 - Produção total de cana-de-açúcar nos municípios selecionados, em todo o Estado de São Paulo, de 2000 a 2006.

\begin{tabular}{|l|c|c|c|c|}
\hline Ano & $\begin{array}{c}\text { Produção nos } \\
\text { Munic. selec. (t) }\end{array}$ & $\begin{array}{c}\text { Valor da } \\
\text { Produção dos } \\
\text { munic. selec. } \\
\text { (Mil Reais) }\end{array}$ & $\begin{array}{c}\text { Produção do } \\
\text { Estado de } \\
\text { São Paulo (t) }\end{array}$ & $\begin{array}{c}\text { Particip. \% dos } \\
\text { Munic. selec. na } \\
\text { Produção de } \\
\text { São Paulo }\end{array}$ \\
\hline 2000 & 41.731 .610 & $744.494,00$ & 189.040 .000 & $22 \%$ \\
\hline 2001 & 44.533 .167 & $1.100 .753,00$ & 198.932 .127 & $22 \%$ \\
\hline 2002 & 46.677 .994 & $1.422 .280,00$ & 212.707 .367 & $22 \%$ \\
\hline 2003 & 48.951 .147 & $1.505 .672,00$ & 227.980 .860 & $21 \%$ \\
\hline 2004 & 50.490 .419 & $1.404 .311,00$ & 239.527 .890 & $21 \%$ \\
\hline 2005 & 50.814 .515 & $1.558 .864,00$ & 254.809 .756 & $20 \%$ \\
\hline 2006 & 51.247 .979 & $1.997 .529,00$ & 269.134 .237 & $19 \%$ \\
\hline $2007^{\star}$ & 54.195 .866 & $2.055 .894,43$ & 281.570 .104 & $19 \%$ \\
\hline
\end{tabular}

(Fonte: IBGE, 2008); * - Estimado por regressão linear.

\subsubsection{Renda nas Atividades de Apoio à Agricultura}

A atividade de apoio agrícola, na região selecionada, empregou cerca de 18 mil trabalhadores, que somaram uma renda de aproximadamente 65 milhões de Reais, com valor médio por indivíduos de cerca de 3,6 mil Reais, em 2007. A Tabela 49 apresenta estes resultados desde 2000 a 2007.

Tabela 49 - Vínculos, renda anual total e média por vínculo, nas atividades de apoio agrícolas, em municípios do Estado de São Paulo selecionados, de 2000 a 2007.

\begin{tabular}{|l|c|c|c|}
\hline Ano & Vínculos & Renda Anual (R\$) & Renda Anual Média por Vínculo(R\$) \\
\hline 2000 & 9.840 & $16.236 .870,14$ & $1.650,09$ \\
\hline 2001 & 15.337 & $28.833 .281,17$ & $1.879,98$ \\
\hline 2002 & 17.136 & $35.202 .014,77$ & $2.054,27$ \\
\hline 2003 & 15.297 & $37.698 .446,88$ & $2.464,43$ \\
\hline 2004 & 19.024 & $48.908 .923,80$ & $2.570,91$ \\
\hline 2005 & 22.413 & $59.042 .627,11$ & $2.634,30$ \\
\hline 2006 & 21.113 & $57.302 .938,42$ & $2.714,11$ \\
\hline 2007 & 18.037 & $64.989 .880,70$ & $3.603,14$ \\
\hline
\end{tabular}


As Tabela 50 e Tabela 51 apresentam os resultados por tonelada de cana e por unidade monetário do valor da produção, respectivamente, desde 2000 a 2007. Observa-se no período de 2000 a 2007, que o valor da renda por tonelada de cana apresenta crescimento maior que o valor da renda por unidade monetária.

Tabela 50 - Vínculo e Renda, por tonelada de cana produzida, nas atividades de apoio à agricultura, em municípios selecionados do Estado de São Paulo, de 2000 a 2007.

\begin{tabular}{|l|c|c|l|c|c|}
\hline Ano & Vínculos & Renda (R\$) & Ano & Vínculos & Renda (R\$) \\
\hline 2000 & $2,36 E-04$ & 0,39 & 2004 & $3,77 E-04$ & 0,97 \\
\hline 2001 & $3,44 E-04$ & 0,65 & 2005 & $4,41 E-04$ & 1,16 \\
\hline 2002 & $3,67 E-04$ & 0,75 & 2006 & $4,12 E-04$ & 1,12 \\
\hline 2003 & $3,12 E-04$ & 0,77 & 2007 & $3,33 E-04$ & 1,20 \\
\hline
\end{tabular}

Tabela 51 - Vínculo e Renda, por unidade monetária em Reais de valor de produto, em municípios selecionados do Estado de São Paulo, de 2000 a 2007.Específico

\begin{tabular}{|l|c|c|l|l|c|}
\hline Ano & Vínculos & Renda (R\$) & Ano & Vínculos & Renda (R\$) \\
\hline 2000 & $1,32 \mathrm{E}-05$ & 0,02 & 2004 & $1,35 \mathrm{E}-05$ & 0,03 \\
\hline 2001 & $1,39 \mathrm{E}-05$ & 0,03 & 2005 & $1,44 \mathrm{E}-05$ & 0,04 \\
\hline 2002 & $1,20 \mathrm{E}-05$ & 0,02 & 2006 & $1,06 \mathrm{E}-05$ & 0,03 \\
\hline 2003 & $1,02 \mathrm{E}-05$ & 0,03 & 2007 & $8,77 \mathrm{E}-06$ & 0,03 \\
\hline
\end{tabular}

A Ilustração 34 apresenta as curvas $\alpha_{\mathrm{rh}}, \beta_{\mathrm{rh}}$ e de Lorentz da distribuição de renda entre os indivíduos da atividade de apoio agrícola. A curva $\beta_{\mathrm{rh}}$ mostra que este conjunto de recurso humano acumula cerca de $18 \%$ da renda mínima sustentável. A curva de Lorentz mostra que $50 \%$ da população soma cerca de $20 \%$ da renda anual total, e que os $20 \%$ mais abastados somam cerca de $45 \%$ da renda. O índice de Gini desta distribuição é de 0,432. 


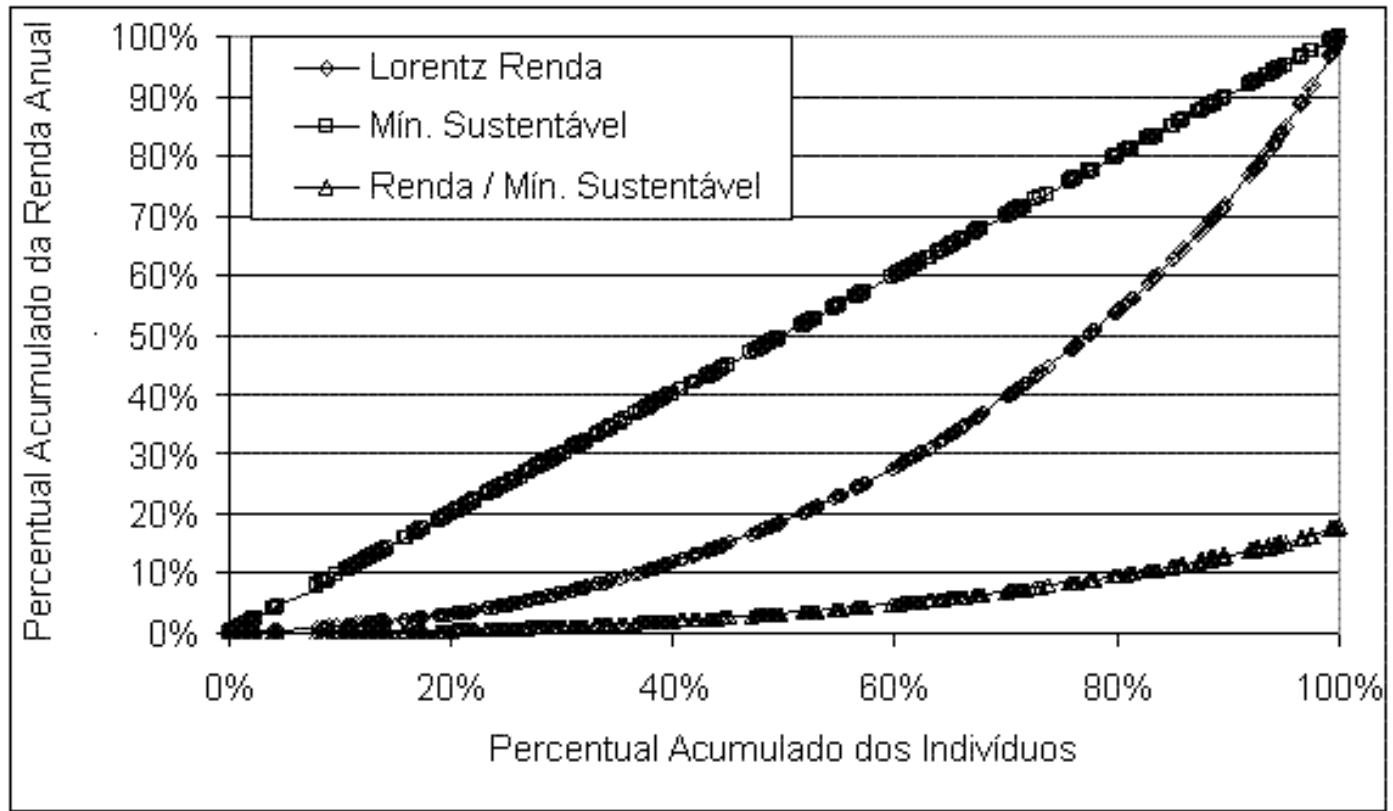

llustração 34 - Curvas $\alpha$ rh, $\beta$ rh e de Lorentz da distribuição de renda nas atividades de apoio agrícola, em municípios selecionados do Estado de São Paulo, em 2007.

\subsubsection{Escolaridade nas Atividades de Apoio à Agricultura}

Em 2007, o conjunto de indivíduos recurso humano na atividade de apoio agrícola, nos municípios selecionados somam cerca de 45 mil anos equivalentes de estudo, com uma média por indivíduos de 2,5 anos, como mostra a Tabela 52. Observa-se um crescimento da EADV no período de 2000 a 2007. As Tabela 53 e Tabela 54 apresentam os resultados por tonelada de cana e por unidade monetária do valor da produção.

Tabela 52 - Vínculos, anos equivalentes de estudo total e por vínculo, na atividade de apoio à agricultura, nos municípios selecionados do Estado de São Paulo, de 2000 a 2007.

\begin{tabular}{|l|c|c|c|}
\hline Anos & Vínculos & AeqE. Total & AeqE por vínculo \\
\hline 2000 & 9.840 & $19.857,7$ & 2,0 \\
\hline 2001 & 15.337 & $30.958,3$ & 2,0 \\
\hline 2002 & 17.136 & $35.603,6$ & 2,4 \\
\hline 2003 & 15.297 & $35.980,7$ & 2,3 \\
\hline 2004 & 19.024 & $42.891,0$ & 2,3 \\
\hline 2005 & 22.413 & $52.028,5$ & 1,9 \\
\hline 2006 & 21.113 & $40.591,8$ & 2,5 \\
\hline 2007 & 18.037 & $44.847,7$ & \\
\hline
\end{tabular}


Tabela 53- Vínculos e anos eq. de estudo (AeqE) por tonelada de cana, de 2000 a 2007.

\begin{tabular}{|c|c|c|c|c|c|}
\hline Ano & Vínculos & AeqE & Ano & Vínculos & AeqE \\
\hline 2000 & $2,36 \mathrm{E}-04$ & $4,76 \mathrm{E}-04$ & 2004 & $3,77 \mathrm{E}-04$ & $8,49 \mathrm{E}-04$ \\
\hline 2001 & $3,44 \mathrm{E}-04$ & $6,95 \mathrm{E}-04$ & 2005 & $4,41 \mathrm{E}-04$ & $1,02 \mathrm{E}-03$ \\
\hline 2002 & $3,67 \mathrm{E}-04$ & $7,63 \mathrm{E}-04$ & 2006 & $4,12 \mathrm{E}-04$ & $7,92 \mathrm{E}-04$ \\
\hline 2003 & $3,12 \mathrm{E}-04$ & $7,35 \mathrm{E}-04$ & 2007 & $3,33 \mathrm{E}-04$ & $8,28 \mathrm{E}-04$ \\
\hline
\end{tabular}

Tabela 54 - Vínculos e anos eq. de estudo (AeqE) por unidade monetária, de 2000 a 2007.

\begin{tabular}{|c|c|c|c|c|c|}
\hline Ano & Vínculos & AeqE & Ano & Vínculos & AeqE \\
\hline 2000 & $1,32 \mathrm{E}-05$ & $2,67 \mathrm{E}-05$ & 2004 & $1,35 \mathrm{E}-05$ & $3,05 \mathrm{E}-05$ \\
\hline 2001 & $1,39 \mathrm{E}-05$ & $2,81 \mathrm{E}-05$ & 2005 & $1,44 \mathrm{E}-05$ & $3,34 \mathrm{E}-05$ \\
\hline 2002 & $1,20 \mathrm{E}-05$ & $2,50 \mathrm{E}-05$ & 2006 & $1,06 \mathrm{E}-05$ & $2,03 \mathrm{E}-05$ \\
\hline 2003 & $1,02 \mathrm{E}-05$ & $2,39 \mathrm{E}-05$ & 2007 & $8,77 \mathrm{E}-06$ & $2,18 \mathrm{E}-05$ \\
\hline
\end{tabular}

A Ilustração 35 apresenta as curvas $\alpha_{\mathrm{rh}}, \beta_{\mathrm{rh}}$ e de Lorentz da distribuição dos anos equivalentes de estudo (AeqE) do recurso humano na atividade de apoio agrícola. A curva $\beta_{\mathrm{rh}}$ mostra que este conjunto de indivíduos acumula cerca de $27 \%$ da EADV mínima sustentável. A curva de Lorentz mostra que 40\% dos indivíduos têm menos que $10 \%$ da EADV total.

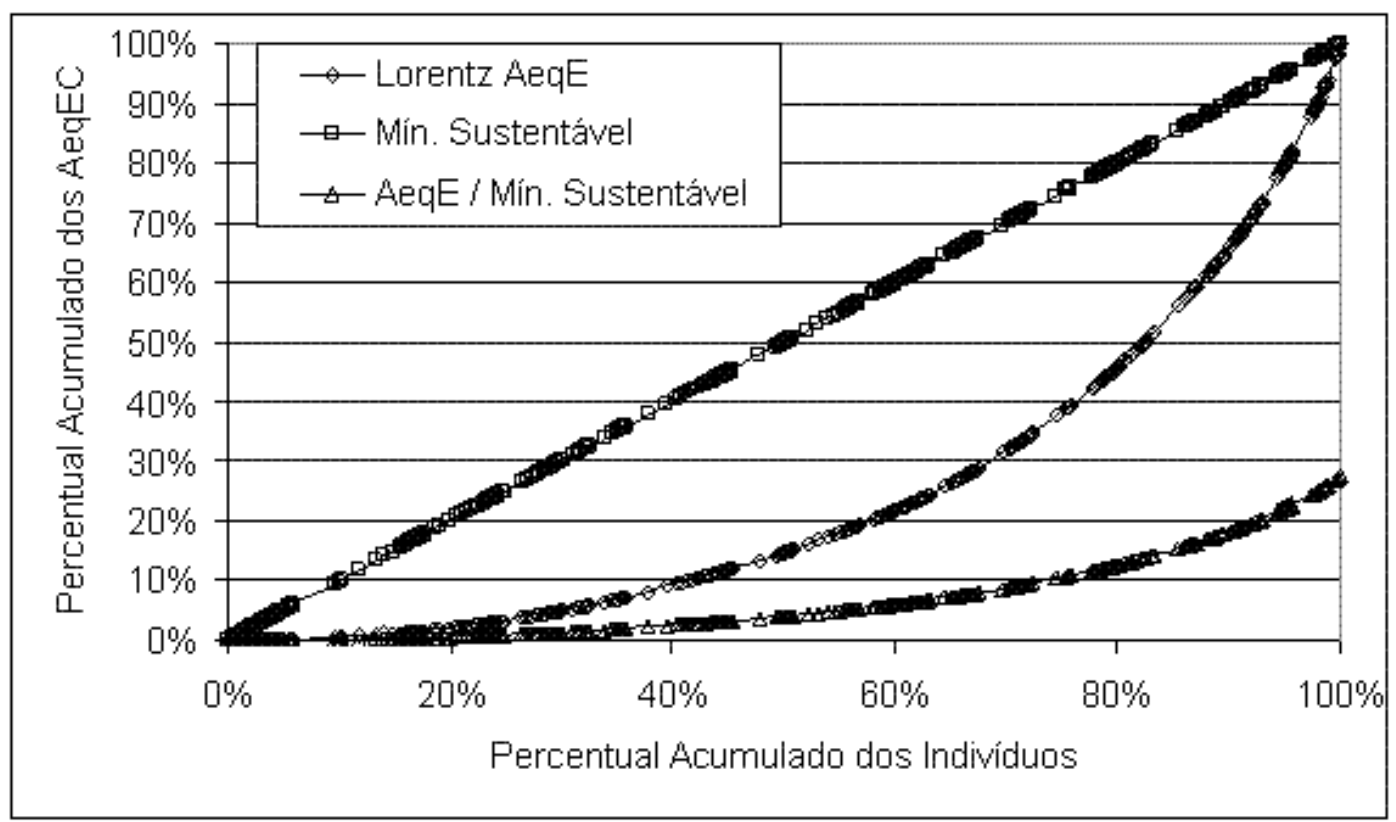

Ilustração 35 - Curvas $\alpha$ rh, $\beta$ rh e de Lorentz da distribuição dos anos eq. de estudo na atividade de apoio à agricultura, municípios selecionados do Estado de São Paulo, em 2007. 


\subsubsection{INVENTÁRIO SOCIAL do ÓlEO DIESEL}

As Classes de Atividade Econômica que constituem a cadeia produtiva do óleo diesel considerada nesta avaliação são: 1) Extração se Petróleo e Gás Natural; 2) Atividades de Apoio à Extração de Petróleo e Gás Natural; 3) Fabricação de Produtos do Refino de Petróleo; e, 4) Fabricação de Máquinas e Equipamentos para a Prospecção e Extração de Petróleo.

A Tabela 55 apresenta os balanços das refinarias Brasileiras, no período de 2000 a 2007. Em 2007, cerca de 90 mil toneladas equivalentes petróleo (tep), na forma de petróleo e líquido de gás natural (LGN) foram processados. Cerca de 33,2 mil toe na forma de óleo diesel foram produzidos, além de outros produtos energéticos e não energéticos. A llustração 36 mostra que o óleo diesel é o principal produto energético das refinarias Brasileiras, variando entre aproximadamente 32\% e 37\%, de 2000 a 2007. Neste período, o valor médio da participação do óleo diesel na produção das refinarias, em base energética, é de 35\%.

Tabela 55 - Entradas e produtos das refinarias brasileiras de 2000 a 2007, em toneladas equivalentes de petróleo (tep).

\begin{tabular}{|c|c|c|c|c|}
\hline \multirow[t]{2}{*}{ Ano } & 2000 & 2001 & 2002 & 2003 \\
\hline & 2004 & 2005 & 2006 & 2007 \\
\hline Entradas & \multicolumn{4}{|c|}{ Toneladas equivalentes de petróleo (tep) } \\
\hline \multirow[t]{2}{*}{ Petróleo e LGN } & 82.840 & 85.752 & 84.002 & 83.931 \\
\hline & 88.954 & 88.873 & 88.207 & 90.144 \\
\hline Produtos & \multicolumn{4}{|c|}{ Toneladas equivalentes de petróleo (tep) } \\
\hline \multirow[t]{2}{*}{ Óleo Diesel } & 26.188 & 27.128 & 27.330 & 29.867 \\
\hline & 33.254 & 32.560 & 32.784 & 33.211 \\
\hline \multirow[t]{2}{*}{ Óleo Combustível } & 16.947 & 17.963 & 17.083 & 15.926 \\
\hline & 16.538 & 15.605 & 15.807 & 15.853 \\
\hline \multirow[t]{2}{*}{ Gasolina } & 14.471 & 15.020 & 14.499 & 13.919 \\
\hline & 14.197 & 14.762 & 15.632 & 15.994 \\
\hline \multirow[t]{2}{*}{ Gasolina Automotiva } & 14.405 & 14.949 & 14.445 & 13.864 \\
\hline & 14.136 & 14.709 & 15.582 & 15.947 \\
\hline \multirow[t]{2}{*}{ Gasolina de Aviação } & 66 & 71 & 54 & 55 \\
\hline & 61 & 54 & 50 & 47 \\
\hline
\end{tabular}

Continua. 
Continuação da Tabela 55.

\begin{tabular}{|l|c|c|c|c|}
\hline Gás Liquefeito de Petróleo & 4.252 & 4.556 & 4.657 & 4.845 \\
\cline { 2 - 5 } & 4.986 & 5.450 & 5.071 & 5.128 \\
\hline \multirow{2}{*}{ Nafta } & 7.853 & 7.729 & 6.716 & 6.883 \\
\cline { 2 - 5 } & 6.720 & 6.527 & 6.599 & 7.109 \\
\hline Querosene & 3.245 & 3.244 & 3.165 & 3.276 \\
\cline { 2 - 5 } & 3.498 & 3.426 & 3.112 & 3.330 \\
\hline Querosene lluminante & 167 & 191 & 187 & 159 \\
\cline { 2 - 5 } & 93 & 41 & 31 & 21 \\
\hline Ouerosene de Aviação & 3.079 & 3.052 & 2.978 & 3.117 \\
\cline { 2 - 5 } & 3.405 & 3.385 & 3.081 & 3.310 \\
\hline Produtos Não Energéticos & 4.716 & 5.311 & 5.453 & 5.381 \\
\cline { 2 - 5 } & 5.640 & 6.199 & 6.174 & 6.414 \\
\cline { 2 - 5 } & 4.496 & 4.033 & 4.300 & 3.626 \\
\cline { 2 - 5 } & 3.955 & 4.061 & 4.697 & 4.565 \\
\hline
\end{tabular}

(Fonte: MME, 2008)

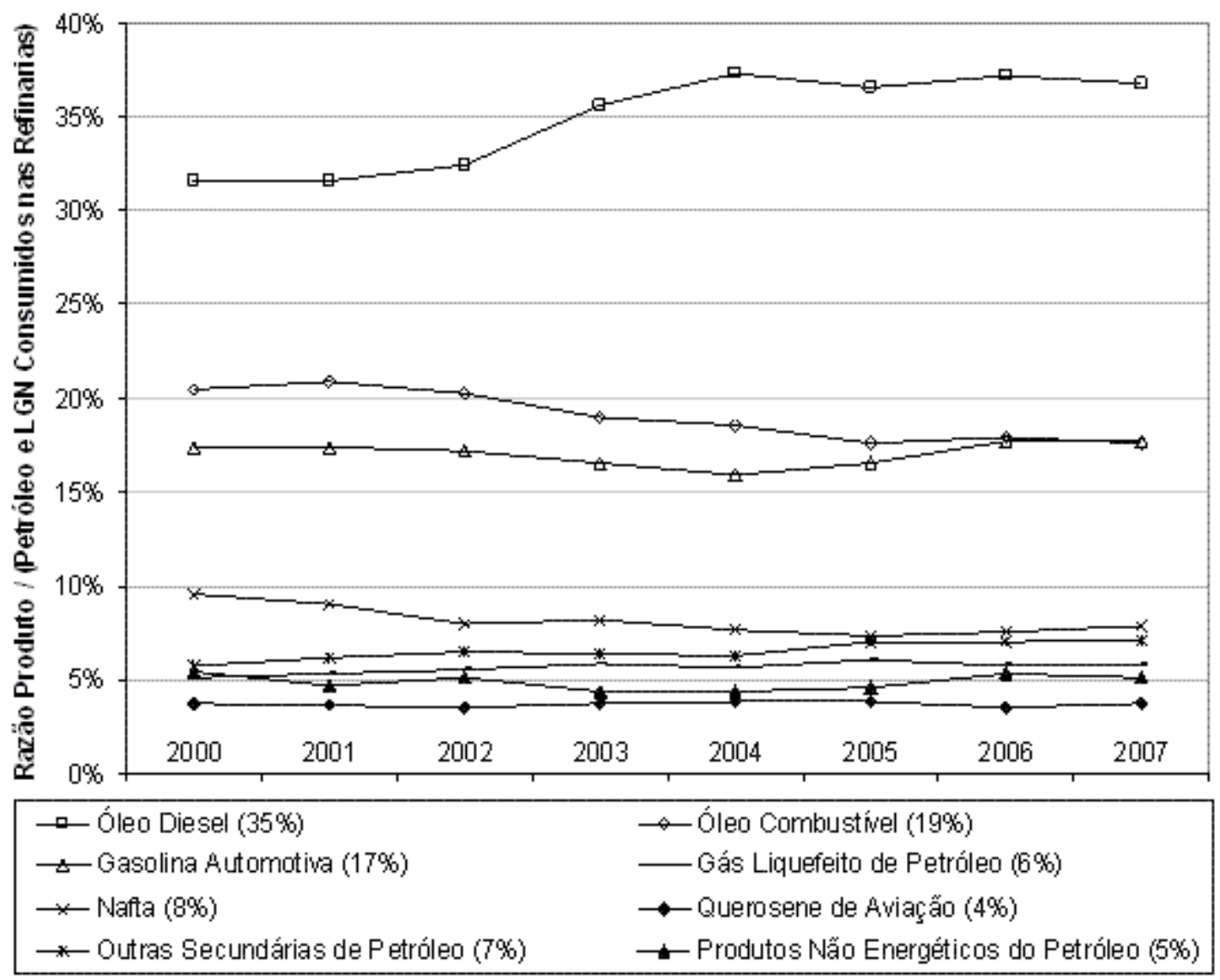

Ilustração 36 - Participação percentual dos produtos, em relação ao consumo de petróleo e líquido de gás natural nas refinarias, de 2000 a 2007 (MME, 2008). 


\subsubsection{Renda na Cadeia Produtiva do Óleo Diesel}

Em 2007, a cadeia produtiva dos derivados de petróleo empregou cerca de 77,3 mil trabalhadores, com uma renda anual de aproximadamente 5,6 bilhões de Reais, e uma renda anual média por vínculo de quase 72 mil Reais. A quantidade de indivíduos empregados e a renda anual média por vínculo apresentaram um expressivo crescimento no período de 2000 a 2007, como mostra a Tabela 56.

Tabela 56 - Vínculos Totais, Renda Anual Total e Renda Anual média por Vínculo, na cadeia produtiva do petróleo, no Brasil, de 2000 a 2007.

\begin{tabular}{|l|c|c|c|}
\hline Ano & Vínculos & Renda Anual Total & Renda Anual média por vínculo \\
\hline 2000 & 26.734 & $547.330 .698,72$ & $20.473,21$ \\
\hline 2001 & 32.356 & $911.891 .897,99$ & $28.183,08$ \\
\hline 2002 & 44.405 & $1.688 .961 .620,83$ & $38.035,39$ \\
\hline 2003 & 51.230 & $2.381 .647 .263,96$ & $46.489,31$ \\
\hline 2004 & 54.282 & $2.856 .769 .535,34$ & $52.628,30$ \\
\hline 2005 & 61.756 & $3.496 .930 .641,03$ & $56.624,95$ \\
\hline 2006 & 77.467 & $5.115 .770 .565,13$ & $66.038,06$ \\
\hline 2007 & 77.367 & $5.586 .351 .057,48$ & $72.205,86$ \\
\hline
\end{tabular}

A Tabela 57 apresenta a participação do óleo diesel, em base energética, e os volumes de óleo diesel produzidos nas refinarias, de 2000 a 2007. Com os dados da participação, obtém-se os resultados alocados ao óleo diesel, apresentados na Tabela 58. Considerando os volumes produzidos e os resultados alocados ao óleo diesel, obtém-se os resultados por litro de diesel, apresentados na Tabela 59.

Tabela 57 - Participação percentual do óleo diesel no total dos produtos das refinarias Brasileiras, em base energética e produção em mil metros cúbicos.

\begin{tabular}{|l|c|c|l|c|c|}
\hline Ano & Particip. & Produção (Mil m ${ }^{\mathbf{3}}$ ) & Ano & Particip. & Produção (Mil m ${ }^{\mathbf{3}}$ ) \\
\hline 2000 & $31,6 \%$ & 31.316 & 2004 & $37,4 \%$ & 39.235 \\
\hline 2001 & $31,6 \%$ & 32.369 & 2005 & $36,6 \%$ & 38.396 \\
\hline 2002 & $32,5 \%$ & 32.752 & 2006 & $37,2 \%$ & 38.729 \\
\hline 2003 & $35,6 \%$ & 35.421 & 2007 & $36,8 \%$ & 39.516 \\
\hline
\end{tabular}

(Fonte: MME, 2008) 
Tabela 58 - Vínculos, renda an. total e média por vínculo, para o diesel, Brasil, de 2000 a 2007.

\begin{tabular}{|c|c|c|c|c|c|}
\hline Ano & Vínculos & Renda Anual & Ano & Vínculos & Renda Anual \\
\hline 2000 & 8.448 & $172.956 .500,80$ & 2004 & 20.301 & $1.068 .431 .806,22$ \\
\hline 2001 & 10.224 & $288.157 .839,76$ & 2005 & 22.603 & $1.279 .876 .614,62$ \\
\hline 2002 & 14.432 & $548.912 .526,77$ & 2006 & 28.818 & $1.903 .066 .650,23$ \\
\hline 2003 & 18.238 & $847.866 .425,97$ & 2007 & 28.471 & $2.055 .777 .189,15$ \\
\hline
\end{tabular}

Tabela 59 - Vínculos e renda por litro de diesel produzido.

\begin{tabular}{|c|c|c|c|c|c|}
\hline Ano & Vínculos & Renda & Ano & Vínculos & Renda \\
\hline 2000 & $2,70 \mathrm{E}-07$ & $5,52 \mathrm{E}-03$ & 2004 & $5,17 \mathrm{E}-07$ & $2,72 \mathrm{E}-02$ \\
\hline 2001 & $3,16 \mathrm{E}-07$ & $8,90 \mathrm{E}-03$ & 2005 & $5,89 \mathrm{E}-07$ & $3,33 \mathrm{E}-02$ \\
\hline 2002 & $4,41 \mathrm{E}-07$ & $1,68 \mathrm{E}-02$ & 2006 & $7,44 \mathrm{E}-07$ & $4,91 \mathrm{E}-02$ \\
\hline 2003 & $5,15 \mathrm{E}-07$ & $2,39 \mathrm{E}-02$ & 2007 & $7,20 \mathrm{E}-07$ & $5,20 \mathrm{E}-02$ \\
\hline
\end{tabular}

A llustração 37 apresenta as curvas $\alpha_{\mathrm{rh}}, \beta_{\mathrm{rh}}$ e de Lorentz da distribuição de renda entre os indivíduos da cadeia produtiva dos derivados de petróleo. A curva $\beta_{\mathrm{rh}}$ mostra que este conjunto de indivíduos acumula uma renda cerca de 250\% maior que a mínima sustentável, e que apenas cerca de 23\% dos indivíduos têm renda anual menor que a mínima sustentável. Grandes grupos de indivíduos distorcem substancialmente a curva a partir de $30 \%$ da população, reduzindo a qualidade da curva de Lorentz para estimar a desigualdade neste conjunto.

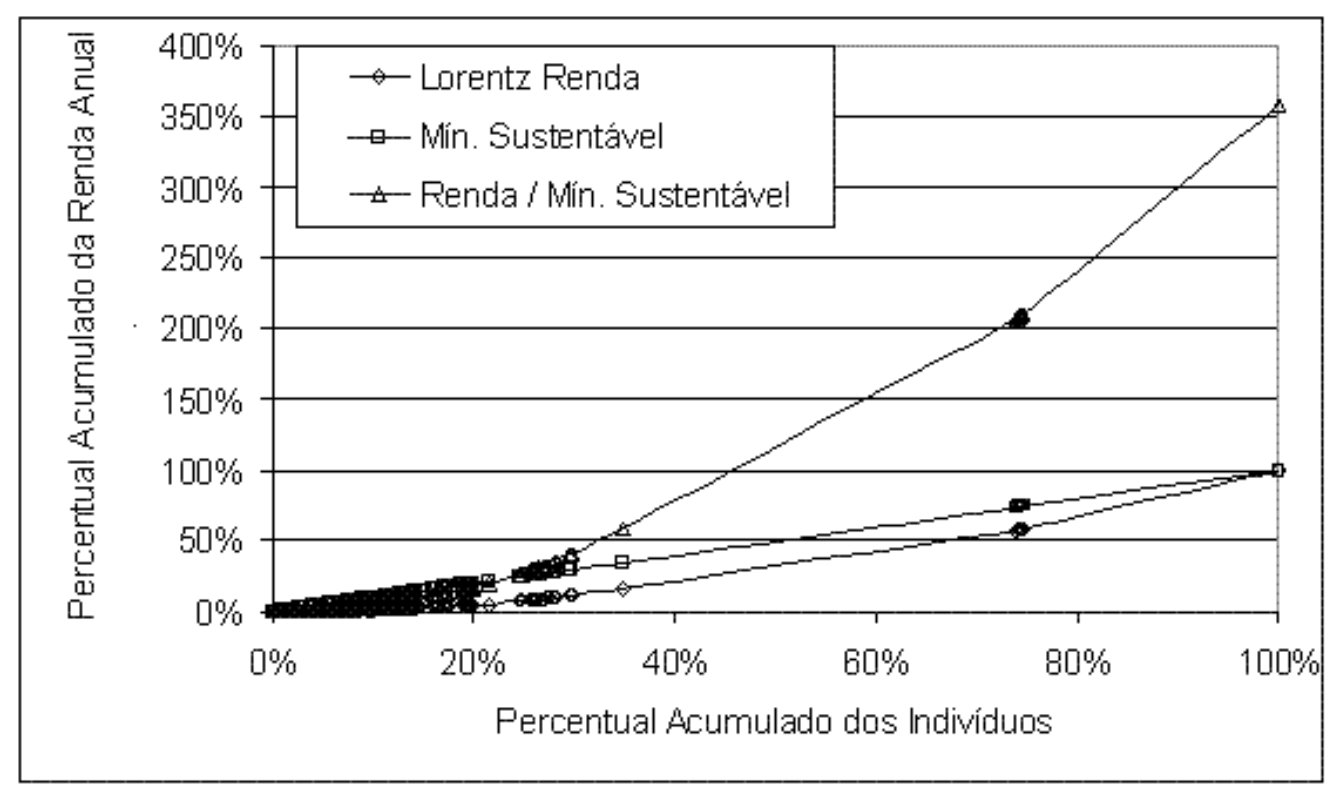

Ilustração 37 - Curvas $\alpha$ rh, $\beta$ rh e de Lorentz da distribuição de renda na cadeia do diesel, 2007. 


\subsubsection{Escolaridade na Cadeia Produtiva do Óleo Diesel}

Em 2007, o conjunto recurso humano na cadeia produtiva dos derivados de petróleo somam cerca de 930 mil anos equivalentes de estudo, com uma média por indivíduos de 12 anos, como mostra a Tabela 60. As Tabela 61 e Tabela 62 apresentam os resultados alocados, em base energética, ao óleo diesel e os resultados por litro de diesel, respectivamente.

Tabela 60 - Vínculos, anos equivalentes de estudo total e por vínculo na cadeia produtiva dos produtos das refinarias.

\begin{tabular}{|l|c|c|c|}
\hline Ano & Vínculos & AeqE Total & AeqE por vínculo \\
\hline 2000 & 26.734 & $229.064,1$ & 8,6 \\
\hline 2001 & 32.356 & $294.621,4$ & 9,1 \\
\hline 2002 & 44.405 & $461.381,5$ & 10,4 \\
\hline 2003 & 51.230 & $543.315,9$ & 10,6 \\
\hline 2004 & 54.282 & $599.009,1$ & 11,0 \\
\hline 2005 & 61.756 & $651.527,2$ & 10,6 \\
\hline 2006 & 77.467 & $897.317,8$ & 11,6 \\
\hline 2007 & 77.367 & $929.685,6$ & 12,0 \\
\hline
\end{tabular}

Tabela 61 - Vínculos e anos eq. de estudo (AeqE) alocados ao diesel em base energética.

\begin{tabular}{|l|c|c|l|c|c|}
\hline Anos & Vínculos & AeqE total & Anos & Vínculos & AeqE total \\
\hline 2000 & 8.448 & $72.384,25$ & 2004 & 20.301 & $224.029,41$ \\
\hline 2001 & 10.224 & $93.100,35$ & 2005 & 22.603 & $238.458,94$ \\
\hline 2002 & 14.432 & $149.949,00$ & 2006 & 28.818 & $333.802,20$ \\
\hline 2003 & 18.238 & $193.420,45$ & 2007 & 28.471 & $342.124,31$ \\
\hline
\end{tabular}

Tabela 62 - Vínculos e anos equivalentes de estudo (AeqE) por litro de óleo diesel.

\begin{tabular}{|l|c|c|l|c|c|}
\hline Ano & Vínculos & AeqE & Ano & Vínculos & AeqE \\
\hline 2000 & $2,70 \mathrm{E}-07$ & $2,31 \mathrm{E}-06$ & 2004 & $5,17 \mathrm{E}-07$ & $5,71 \mathrm{E}-06$ \\
\hline 2001 & $3,16 \mathrm{E}-07$ & $2,88 \mathrm{E}-06$ & 2005 & $5,89 \mathrm{E}-07$ & $6,21 \mathrm{E}-06$ \\
\hline 2002 & $4,41 \mathrm{E}-07$ & $4,58 \mathrm{E}-06$ & 2006 & $7,44 \mathrm{E}-07$ & $8,62 \mathrm{E}-06$ \\
\hline 2003 & $5,15 \mathrm{E}-07$ & $5,46 \mathrm{E}-06$ & 2007 & $7,20 \mathrm{E}-07$ & $8,66 \mathrm{E}-06$ \\
\hline
\end{tabular}


A llustração 38 apresenta as curvas $\alpha_{\mathrm{rh}}, \beta_{\mathrm{rh}}$ e de Lorentz da distribuição dos anos equivalentes de estudo entre os indivíduos deste conjunto. A curva $\beta_{\mathrm{rh}}$ mostra que os indivíduos acumulam cerca de $135 \%$ em relação à escolaridade mínima sustentável, e que metade dos indivíduos têm uma escolaridade maior que a mínima sustentável. Da mesma forma que para a distribuição da renda, grandes grupos de indivíduos distorcem a curva de Lorentz.

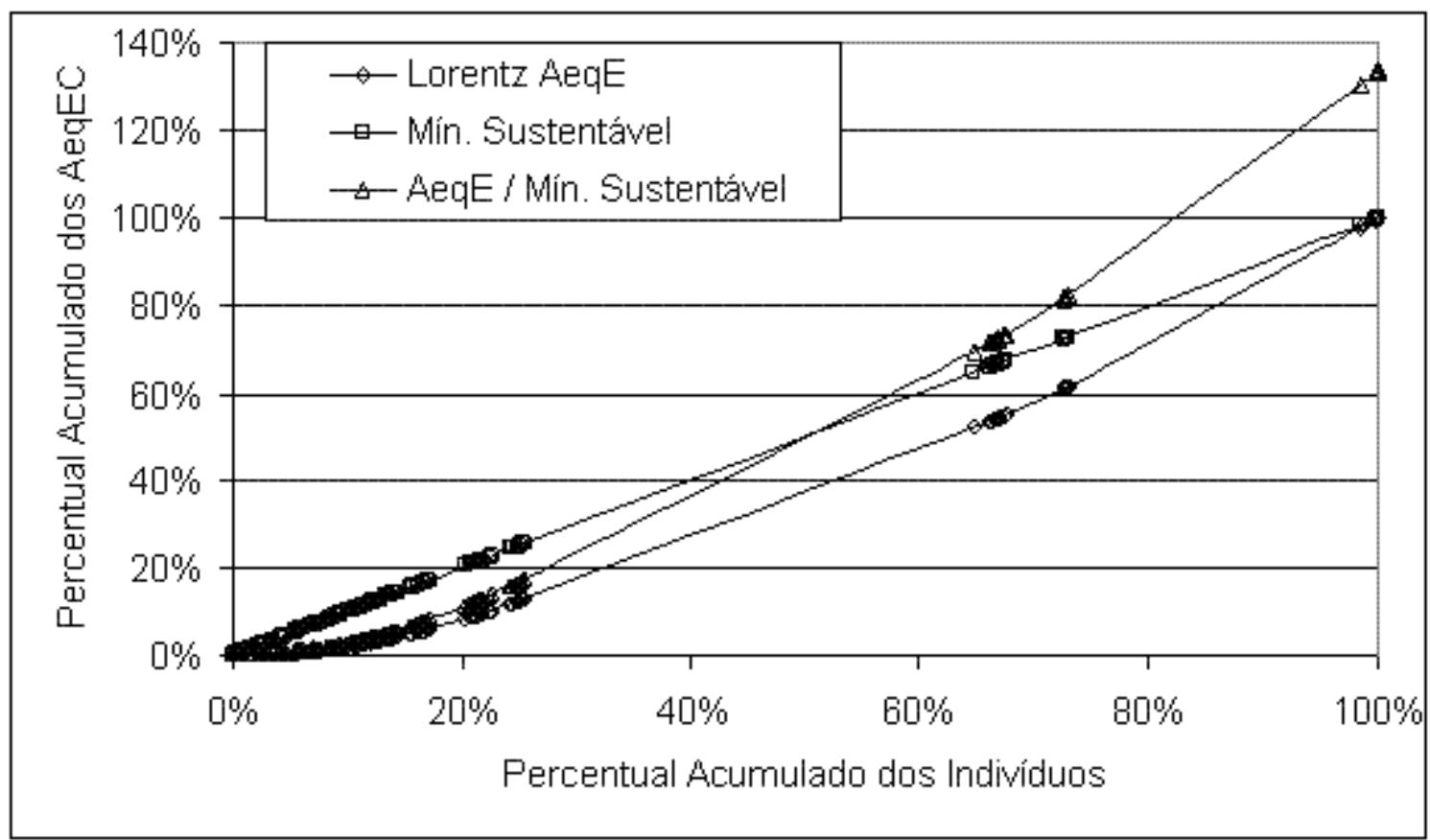

llustração 38 - Curvas $\alpha$ rh, $\beta$ rh e de Lorentz da distribuição dos anos equivalentes de estudo (AeqE) do Conjunto recurso humano da cadeia produtiva do óleo diesel, em 2007.

\subsubsection{InVENTÁrio Social dos Fertilizantes Agrícolas}

As Classes de Atividade Econômica que constituem a cadeia produtiva dos fertilizantes, considerada nesta avaliação, são 1) Fabricação de Adubos e Fertilizantes; e, 2) Fabricação de Intermediários para fertilizantes.

\subsubsection{Renda na Cadeia Produtiva dos Fertilizantes Agrícolas}

Em 2007, quase 30 mil trabalhadores estavam empregados nestas atividades, somando uma renda anual de quase 538 milhões de Reais, e com renda anual por indivíduos de quase 18 mil Reais, como mostra a Tabela 63. Considerando-se a produção Brasileira de fertilizantes apresentada na Tabela 64, obtém-se a Tabela 65 que mostra a quantidade de vínculos e a renda por quilograma de fertilizante. 
Tabela 63 - Vínculos totais declarados na RAIS, Renda Anual total e média do período, na produção de fertilizantes agrícolas, no Brasil, em 2007.

\begin{tabular}{|c|c|c|}
\hline Vínculos & Renda Anual Total & Renda Anual média por vínculo \\
\hline 29.895 & $537.732 .481,04$ & $17.987,37$ \\
\hline
\end{tabular}

Tabela 64 - Produção Nacional de Fertilizantes Intermediários, em 2007.

\begin{tabular}{|c|c|}
\hline Produção & Unidade \\
\hline 9.815 .709 & toneladas \\
\hline
\end{tabular}

(Fonte: ANDA, 2007)

Tabela 65 - Vínculos e renda por quilograma de fertilizante, em 2007.

\begin{tabular}{|c|c|}
\hline Vínculos & Renda Anual Total \\
\hline $3,05 \mathrm{E}-06$ & $5,48 \mathrm{E}-02$ \\
\hline
\end{tabular}

A llustração 39 apresenta as curvas $\alpha_{r h}$, $\beta_{r h}$ e de Lorentz da distribuição da renda entre os indivíduos deste conjunto, em 2007. a curva $\beta_{\text {rh }}$ mostra que este conjunto de indivíduos acumula quase $90 \%$ da renda mínima sustentável. A curva de Lorentz mostra que $40 \%$ dos indivíduos têm cerca de $10 \%$ da renda.

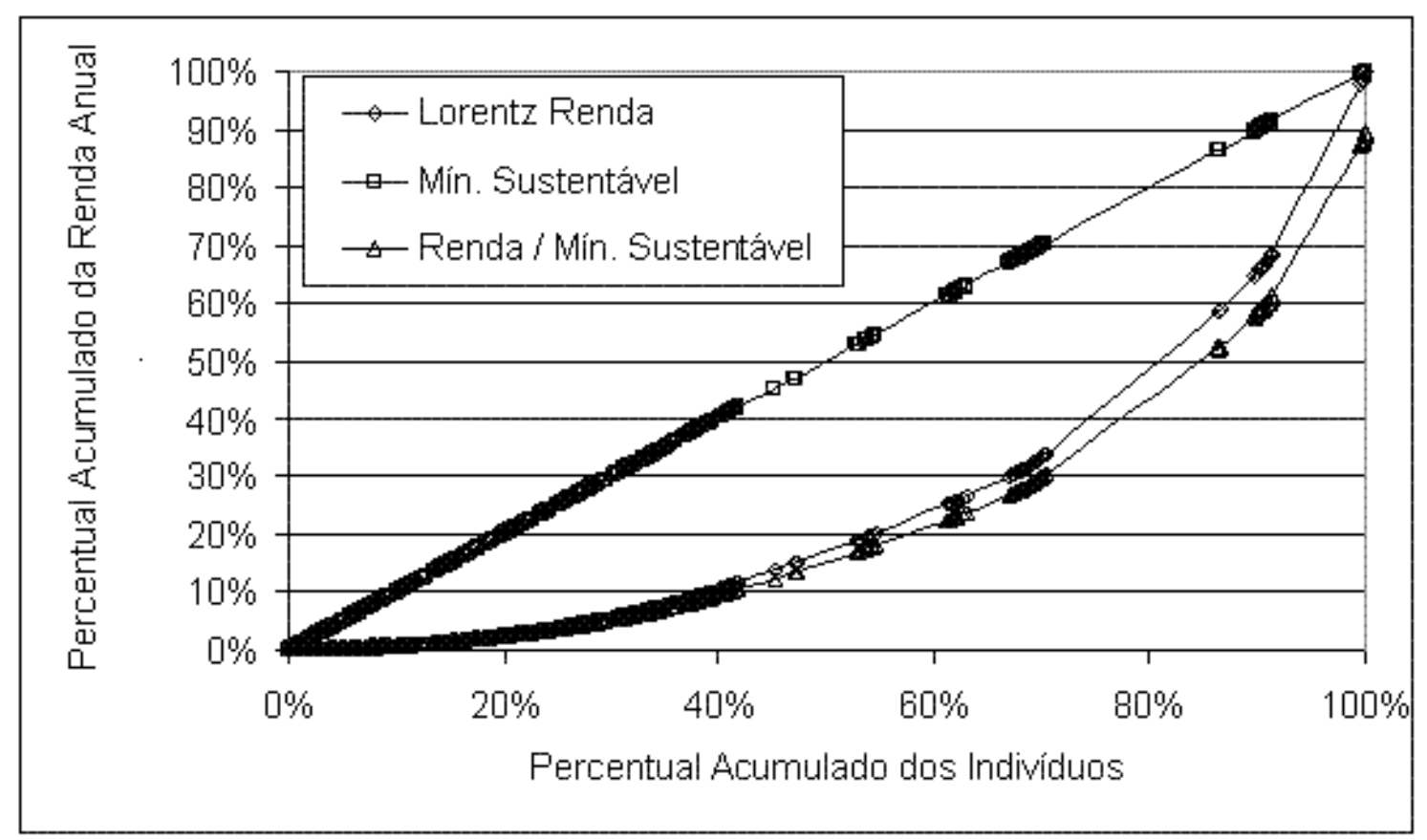

llustração 39 - Curvas $\alpha$ rh, $\beta$ rh e de Lorentz da distribuição de renda na cadeia produtiva dos fertilizantes agrícolas, em 2007. 


\subsubsection{Escolaridade na Cadeia Produtiva dos Fertilizantes Agrícolas}

Os indivíduos deste conjunto somam quase 238 mil anos equivalentes de estudo, com média de 8 anos por indivíduo, como mostra a Tabela 66. A Tabela 67 apresenta o resultado da EADV por quilograma de fertilizante.

Tabela 66 - Vínculos e anos equivalentes de estudo na cadeia produtiva dos fertilizantes agrícolas, em todo o Brasil, nos anos de 2006 e 2007.

\begin{tabular}{|c|c|c|}
\hline Vínculos & AeqE Total & AeqE por vínculo \\
\hline 29.895 & $237.999,8$ & 8,0 \\
\hline
\end{tabular}

Tabela 67 - Vínculos e anos equivalente de estudo por quilograma de fertilizante.

\begin{tabular}{|c|c|}
\hline Vínculos & AeqE \\
\hline $3,05 \mathrm{E}-06$ & $2,42 \mathrm{E}-05$ \\
\hline
\end{tabular}

A Ilustração 40 apresenta as curvas $\alpha_{\mathrm{rh}}, \beta_{\mathrm{rh}}$ e de Lorentz da distribuição dos anos eq. de estudo entre os indivíduos da cadeia produtiva dos fertilizantes. A curva $\beta_{\text {rh }}$ mostra que este conjunto de indivíduos somam quase 90\% da EADV mínima sustentável. Metade dos indivíduos têm cerca de 25\% da EADV total do conjunto.

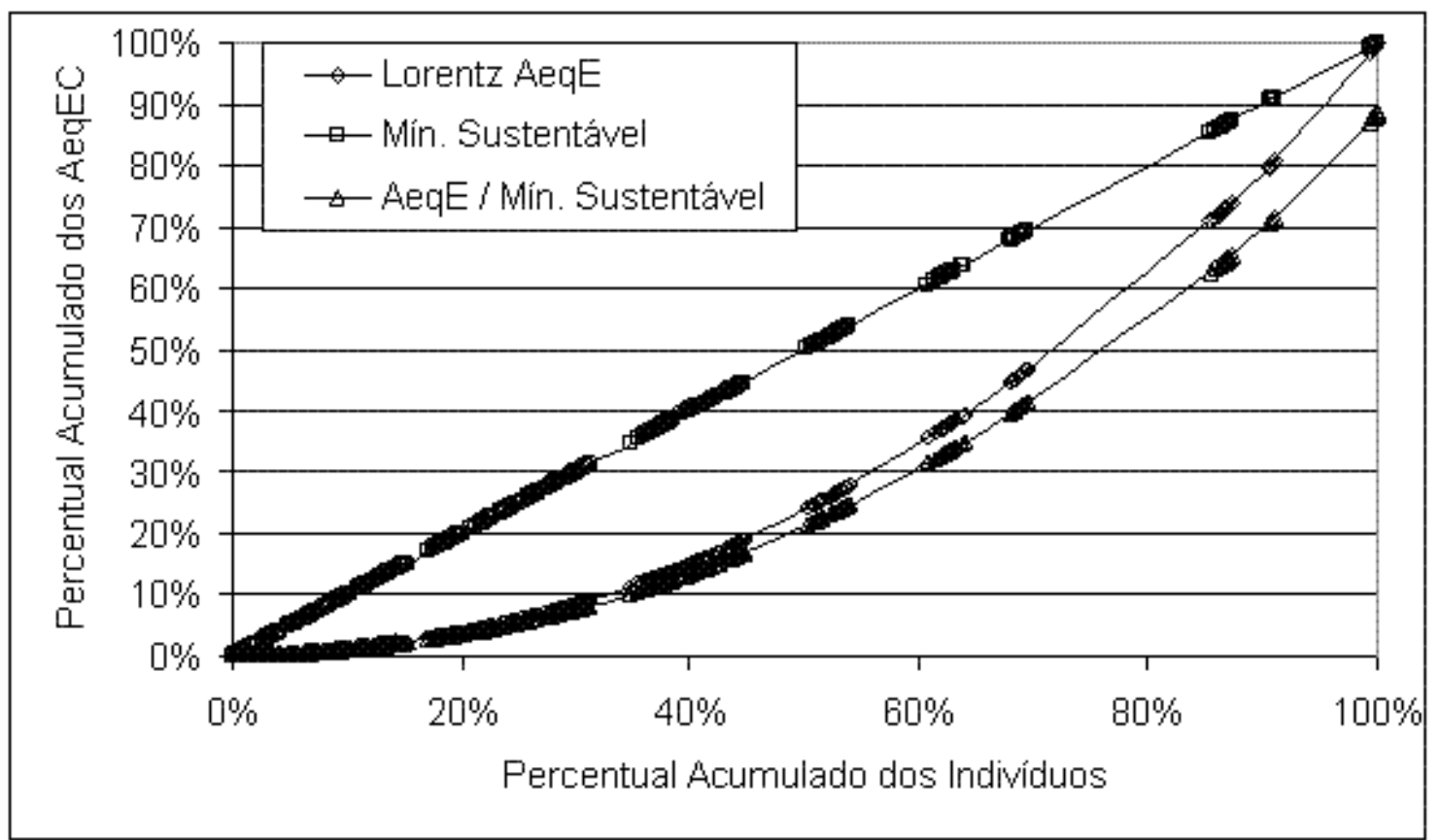

llustração 40 - Curvas $\alpha$ rh, $\beta$ rh e de Lorentz da distribuição dos anos equivalentes de estudo (AeqE) da cadeia produtiva dos fertilizantes agrícolas, em 2007. 


\subsubsection{InVENTÁRIO SOCIAL dos DefEnsivos AgRícolas}

\subsubsection{Renda na Produção de defensivos agrícolas}

Em 2007, a atividade de fabricação de defensivos agrícolas no Brasil empregou 5.238 indivíduos, que somaram uma renda de cerca de 209 milhões de Reais, com uma renda média por indivíduo de quase 40 mil Reais, como mostra a Tabela 68.

Tabela 68 - Vínculos totais declarados na RAIS, Renda Anual total e média do período, na produção de defensivos agrícolas, no Brasil, de 2006 a 2007.

\begin{tabular}{|c|c|c|}
\hline Vínculos & Renda Anual Total & Renda Anual média por vínculo \\
\hline 5.238 & $209.202 .696,08$ & $39.939,42$ \\
\hline
\end{tabular}

A Tabela 69 apresenta dados de 2000 a 2007 da produção de ingredientes ativos para defensivos agrícolas. Os dados de 2006 e 2007 foram estimados por regressão linear da série de dados de 2000 a 2005. A Tabela 70 apresenta os resultados para vínculo e renda por quilograma de ingrediente ativo.

Tabela 69 - Produção da Indústria de Defensivos Agrícolas.

\begin{tabular}{|l|c|c|c|}
\hline Ano & Produto Comercial & Ingrediente Ativo & Unidade \\
\hline 2001 & 328.413 & 151.533 & $\mathrm{t}$ \\
\hline 2002 & 306.429 & 145.552 & $\mathrm{t}$ \\
\hline 2003 & 375.048 & 182.446 & $\mathrm{t}$ \\
\hline 2004 & 463.604 & 214.725 & $\mathrm{t}$ \\
\hline 2005 & 485.969 & 232.232 & $\mathrm{t}$ \\
\hline $2006^{\star}$ & 533.579 & 254.469 & $\mathrm{t}$ \\
\hline $2007^{*}$ & 580.807 & 277.526 & $\mathrm{t}$ \\
\hline
\end{tabular}

(Fonte: SINDAG ${ }^{7}$ apud MDIC, 2006)

Tabela 70 - Vínculo e renda anual por quilograma de ingrediente ativo produzido.

\begin{tabular}{|c|c|}
\hline Vínculos & Renda (R\$) \\
\hline $1,89 E-05$ & 0,75 \\
\hline
\end{tabular}

\footnotetext{
${ }^{7}$ Não referenciado pelo documento consultado.
} 
A llustração 41 apresenta as curvas $\alpha_{\mathrm{rh}}, \beta_{\mathrm{rh}}$ e de Lorentz da distribuição de renda no conjunto recurso humano na fabricação de defensivos agrícolas. A curva $\beta_{\text {rh }}$ mostra que este conjunto de indivíduos acumula uma renda igual a cerca de duas vezes a mínima sustentável e que cerca de $30 \%$ dos indivíduos somam uma renda anual maior que a mínima sustentável. A curva de Lorentz mostra que $20 \%$ dos indivíduos têm uma renda anual que soma menos de $5 \%$ da renda anual total.

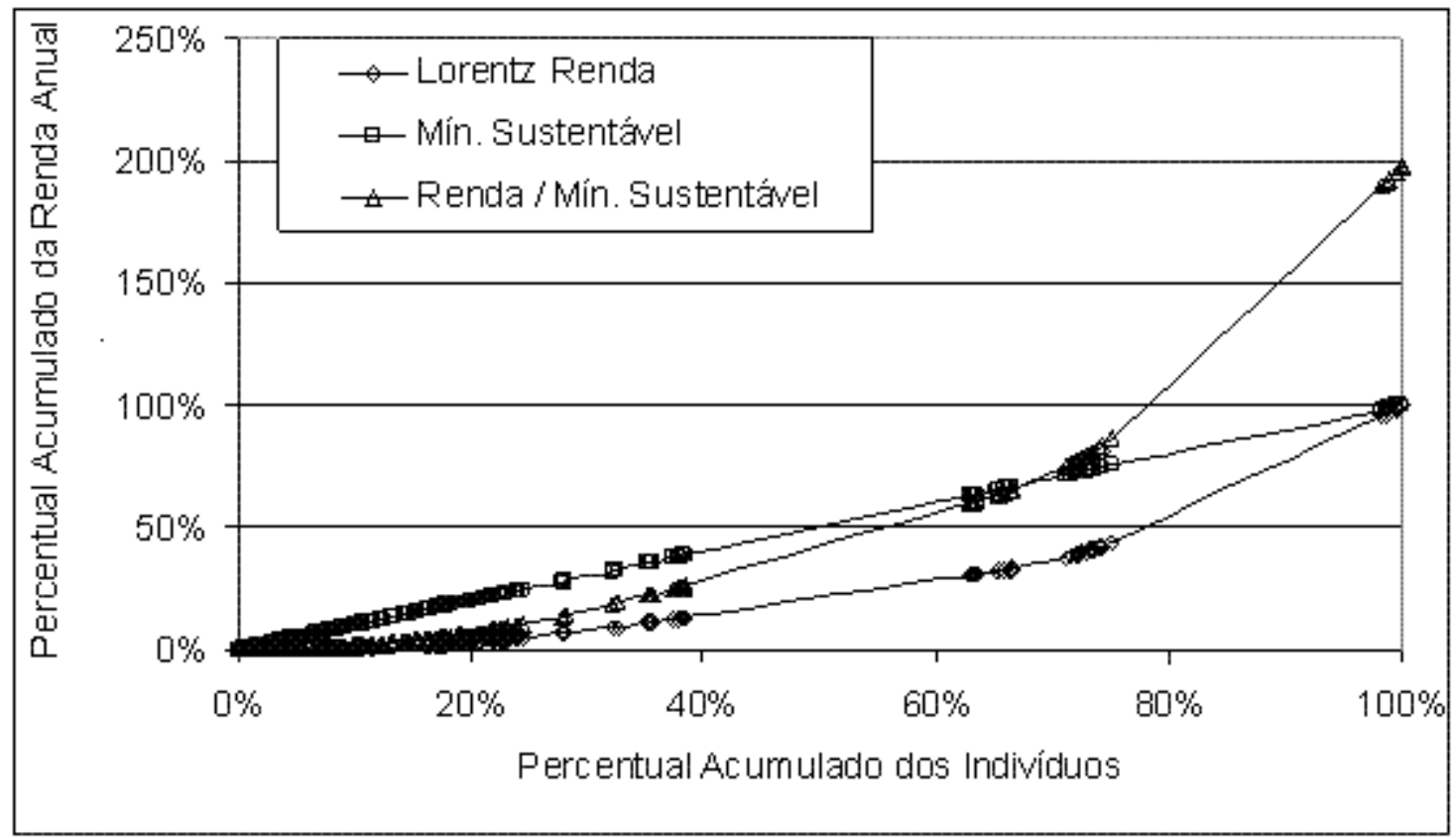

llustração 41 - Curvas $\alpha$ rh, $\beta$ rh e de Lorentz da distribuição de renda na produção de defensivos agrícolas, em 2007.

\subsubsection{Escolaridade na Produção de Defensivos Agrícolas}

Os indivíduos recurso humano na fabricação de defensivos agrícolas acumulam uma EADV de quase 57 mil anos equivalentes de estudo, com uma média de 10,9 anos por indivíduo, como mostra a Tabela 71.

Tabela 71 - Vínculos e anos equivalentes de estudo na produção de defensivos agrícolas, em todo o Brasil, em 2006 e 2007.

\begin{tabular}{|c|c|c|}
\hline Vínculos & AeqE Total & AeqE por vínculo \\
\hline 5.238 & $56.894,5$ & 10,9 \\
\hline
\end{tabular}


A llustração 42 apresenta as curvas $\alpha_{\mathrm{rh}}, \beta_{\mathrm{rh}} \mathrm{e}$ de Lorentz da distribuição dos anos equivalentes de estudo. A curva $\beta_{\mathrm{rh}}$ mostra que os indivíduos acumulam EADV superior à mínima sustentável em cerca de 20\%, e que aproximadamente $25 \%$ dos indivíduos possuem uma EADV maior que a mínima sustentável. A curva de Lorentz mostra que $40 \%$ dos indivíduos somam cerca de $20 \%$ da EADV total.

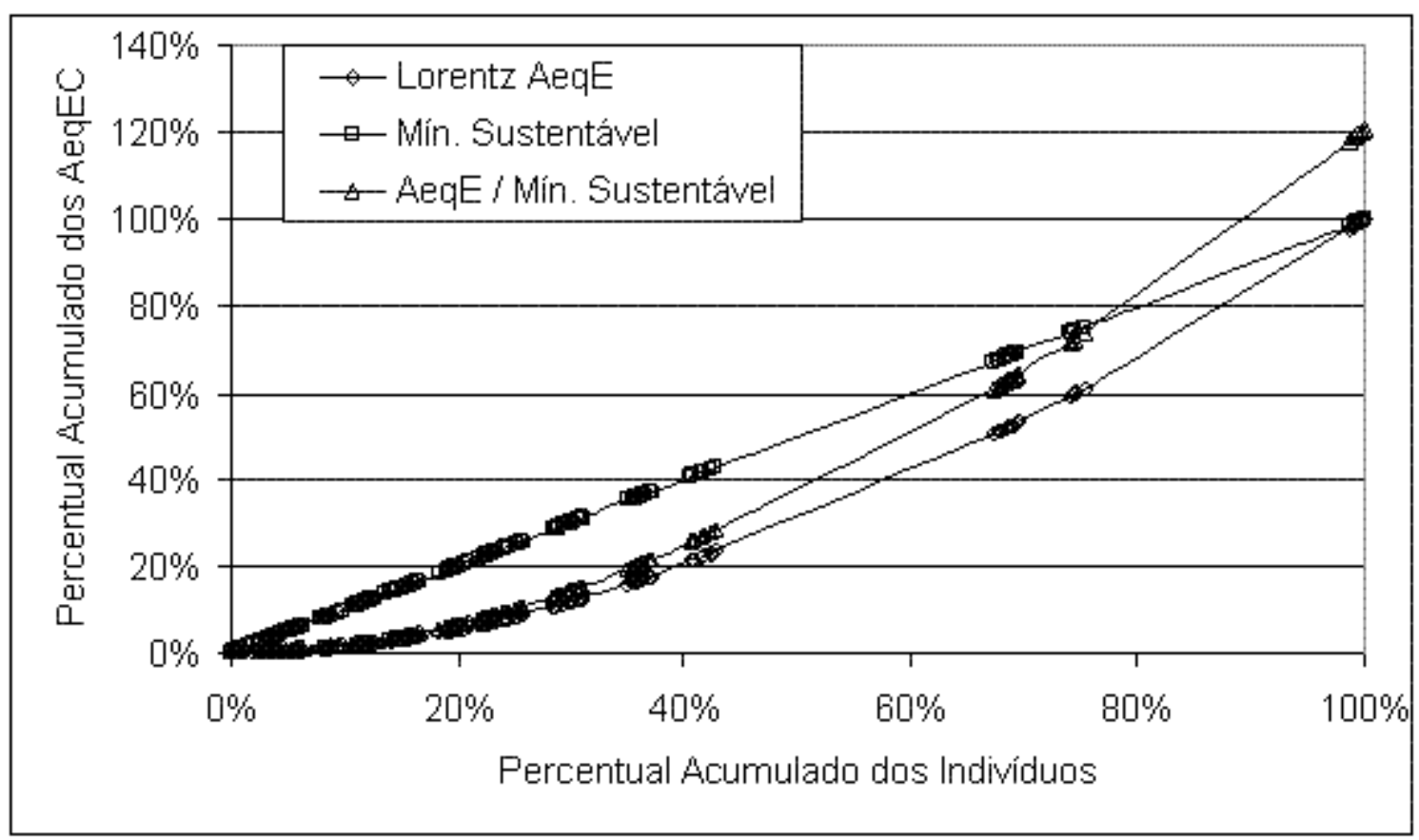

Ilustração 42 - Curvas $\alpha$ rh, $\beta$ rh e de Lorentz da distribuição dos anos equivalentes de estudo (AeqE) na produção de defensivos agrícolas, em 2007.

\subsubsection{InVENTÁRIO SOCIAL AGREgAdo do AEHC}

O inventário social agregado é construído a partir dos inventários dos componentes individuais do sistema do AEHC. As relações entre os componentes do sistema do AEHC são baseadas no fluxo de referência para a unidade funcional adotada nesta avaliação. O inventário individual de cada componente do sistema do AEHC, em base unitária para o seu produto, é multiplicado por um fator para ajuste ao fluxo de referência. O fator de ajuste para cada atividade corresponde à quantidade de cada produto intermediário requerido para atender o fluxo de referência do sistema. A seção seguinte apresenta a obtenção destes fatores. 


\subsubsection{Cálculo do Fluxo Físico no Sistema do AEHC}

Os fluxos físicos que conectam os componentes do sistema de produto são determinados em função do fluxo de referência da unidade funcional definida. Para o fluxo de referência de dois litros de AEHC consumidos, considera-se que dois litros são comercializados, dois litros são transportados e dois litros são produzidos.

$\mathrm{Na}$ atividade de produção de AEHC, é considerada uma eficiência industrial de 90,6 litros de AEHC por tonelada de cana. Este valor é obtido de Macedo et al (2004) que afirmam que um rendimento de 88 litros de álcool anidro (AEAC) por tonelada de cana pode ser considerado como típico do Centro-Sul Brasileiro, e que a produção de AEHC pode ser estimada como 3\% maior que a de AEAC. Deste modo, a entrada de cana na produção de AEHC para atender ao fluxo de referência é de 22 quilogramas. Estes 22 quilogramas de cana são produzidos conjuntamente pelas atividades de cultivo de cana e atividades de apoio agrícola.

A demanda de óleo diesel é calculada para as atividades de cultivo de cana e atividade apoio agrícola como sendo de 37,2 mililitros, a partir dos dados de Macedo et al. (2004) que calculam a demanda nas operações agrícolas e de transporte de cana como sendo 1,69 litros de diesel por tonelada de cana.

A demanda de óleo diesel para a atividade de distribuição de AEHC, das usinas até os postos de combustíveis, é estimada a partir de dados de (OMETTO, 2005). Segundo este autor, são necessários 1,56 litro de diesel para transportar cerca de 1.236 litros de AEHC à uma distância média de $150 \mathrm{~km}$. A quantidade de diesel para 0 fluxo de referência de 2 litros de AEHC é obtido como cerca de 2,5 mililitros.

A partir dos dados obtidos para o consumo de diesel na fase agrícola e no transporte do AEHC, o consumo total de diesel no sistema do AEHC avaliado nesta tese é estimado como sendo de 0,04 litros de diesel por 2 litros de AEHC consumidos.

A demanda de fertilizante é estimada de Macedo (2005), onde o consumo total de fertilizante é dado como 0,46 tonelada por hectare de cana. A produtividade de cana por área é considerada como 68,7 tonelada por hectare (MACEDO et al., 2004).

A demanda de defensivos é calculada a partir dos dados de consumo em quilogramas de ingrediente ativo dado em MACEDO (2005). O consumo por hectare estimado por estes autores é de $2,34 \mathrm{~kg}$ de ingredientes ativos por hectare. 


\subsubsection{Cálculo do Recurso Humano para o Fluxo de Referência}

Os fatores de adequação para agregar as populações das diferentes atividades são obtidos pela razão entre a quantidade de indivíduos necessários para atender o fluxo de referência, em cada componente do sistema de produto, pelo total dos indivíduos ocupados na atividade, no ano de referência. Cada indivíduo, ou grupo homogêneo de indivíduos, das populações de cada componente do sistema do AEHC é multiplicado por este fator. Desta forma, obtém-se a população de recurso humano e consumidores ao longo do sistema de ciclo de vida do AEHC em função do fluxo de referência. Estes fatores são apresentados na Tabela 72.

Tabela 72 - Fatores de ajuste das populações das atividades para o fluxo de referência.

\begin{tabular}{|l|c|}
\hline \multicolumn{1}{|c|}{ Componentes do sistema do AEHC } & Fatores de ajuste da população \\
\hline Consumidor AEHC & $1,92898 \mathrm{E}-10$ \\
\hline Comércio Varejista de Combustíveis & $1,92695 \mathrm{E}-11$ \\
\hline Produção de Álcool & $8,66449 \mathrm{E}-11$ \\
\hline Cultivo de Cana & $7,81491 \mathrm{E}-11$ \\
\hline Atividades de Apoio & $4,06165 \mathrm{E}-10$ \\
\hline Diesel & $3,72252 \mathrm{E}-13$ \\
\hline Fertilizantes & $1,53036 \mathrm{E}-11$ \\
\hline Defensivos & $2,70619 \mathrm{E}-12$ \\
\hline Transporte de Cargas & $6,6052 \mathrm{E}-12$ \\
\hline
\end{tabular}

\subsubsection{Resultados da Avaliação Social do AEHC}

A llustração 43 apresenta o sistema do AEHC com os fluxos físicos que conectam os componentes do sistema, e respectivas quantidades de indivíduos, em função do fluxo de referência calculado na seção 5.1.1. 


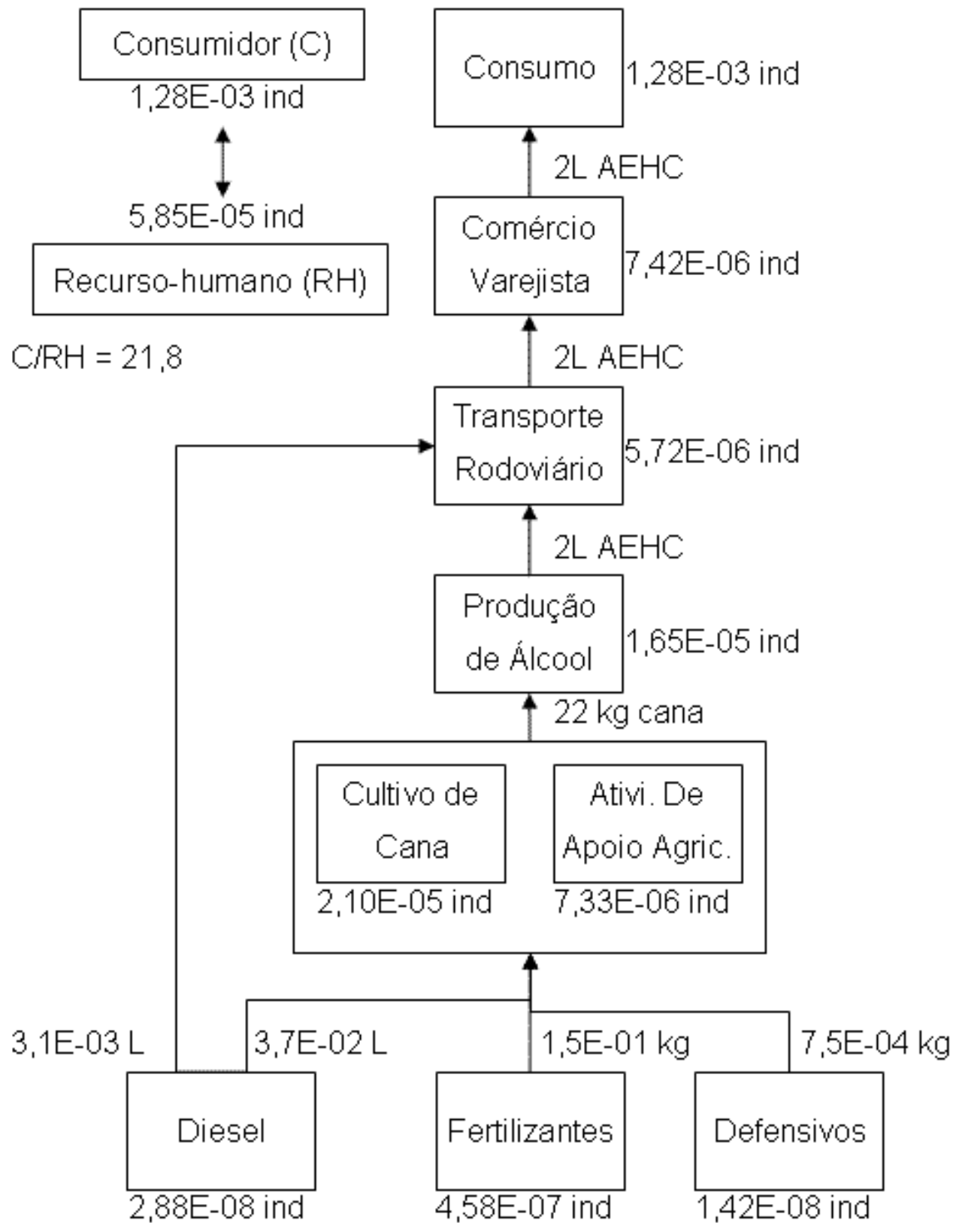

llustração 43 - Sistema de Produto do AEHC com os fluxos físicos e de recurso humano em função do fluxo de referência.

A Tabela 73 resume os resultados da quantificação dos indivíduos e da renda e apresenta o valor mínimo sustentável correspondente. Tanto o conjunto total de indivíduos (consumidor e recurso humano), como os grupos consumidor e recurso humano individualmente estão abaixo do valor mínimo sustentável para a renda. $\mathrm{O}$ valor para o conjunto consumidor corresponde a cerca de 52\% do mínimo sustentável. Enquanto que para o conjunto recurso humano, o valor da renda média anual corresponde a cerca de 34\% do mínimo sustentável. 
Tabela 73 - Resultados para renda anual média e a mínima sustentável requerida para a população total, a população consumidora e a população recurso humano do sistema do AEHC, em função do fluxo de referência.

\begin{tabular}{|c|c|c|}
\hline Indivíduos & Renda Anual (R\$) & Renda Anual Mínima Sustentável (R\$) \\
\hline \multicolumn{3}{|c|}{ População Total do Sistema de Produto AEHC } \\
\hline $1,33 \mathrm{E}-03$ & 13,89 & 26,90 \\
\hline \multicolumn{3}{|c|}{ População Sistema Consumidora de Produto AEHC } \\
\hline $1,28 \mathrm{E}-03$ & 13,49 & 25,72 \\
\hline \multicolumn{3}{|c|}{ População Sistema Recurso humano de Produto AEHC } \\
\hline $5,85 \mathrm{E}-05$ & 0,40 & 1,18 \\
\hline
\end{tabular}

A Tabela 74 apresenta os resultados para a Escolaridade Ajustada pela Duração do Vínculo. No conjunto recurso humano, a escolaridade calculada, 4,6 anos equivalentes de estudo, corresponde a cerca de metade da escolaridade mínima sustentável. O subconjunto consumidor tem uma escolaridade ajustada por duração do vínculo de 7,7 AeqE e que corresponde a cerca de 85\% do valor mínimo sustentável.

Tabela 74 - Resultados para anos equivalentes de escolaridade contratada média e a mínima sustentável requerida para a população total, a população consumidora e a população recurso humano do sistema do AEHC.

\begin{tabular}{|c|c|c|}
\hline Indivíduos & AeqE & AeqE Mínimo Sustentável \\
\hline \multicolumn{3}{|c|}{ População Total do Sistema de Produto AEHC } \\
\hline $1,33 \mathrm{E}-03$ & $1,0 \mathrm{E}-02$ & $1,2 \mathrm{E}-02$ \\
\hline \multicolumn{3}{|c|}{ População Sistema Consumidora de Produto AEHC } \\
\hline $1,28 \mathrm{E}-03$ & $9,80 \mathrm{E}-03$ & $1,1 \mathrm{E}-02$ \\
\hline \multicolumn{2}{|c|}{ População Sistema Recurso humano de Produto AEHC } \\
\hline $5,85 \mathrm{E}-05$ & $2,66 \mathrm{E}-04$ & $5,3 \mathrm{E}-04$ \\
\hline
\end{tabular}

A renda acumulada do recurso humano soma cerca de $34 \%$ da renda mínima sustentável, como mostra a curva $\beta_{\mathrm{rh}}$ na llustração 44. A curva de Lorentz mostra que $40 \%$ dos indivíduos que desempenham a função recurso humano detêm cerca de $15 \%$ da renda. Enquanto que os $20 \%$ mais abastados detêm cerca de $40 \%$. Os 
resultados da análise distribucional no conjunto consumidor, baseada na llustração 21, é apresentada na seção 5.2.2.2.

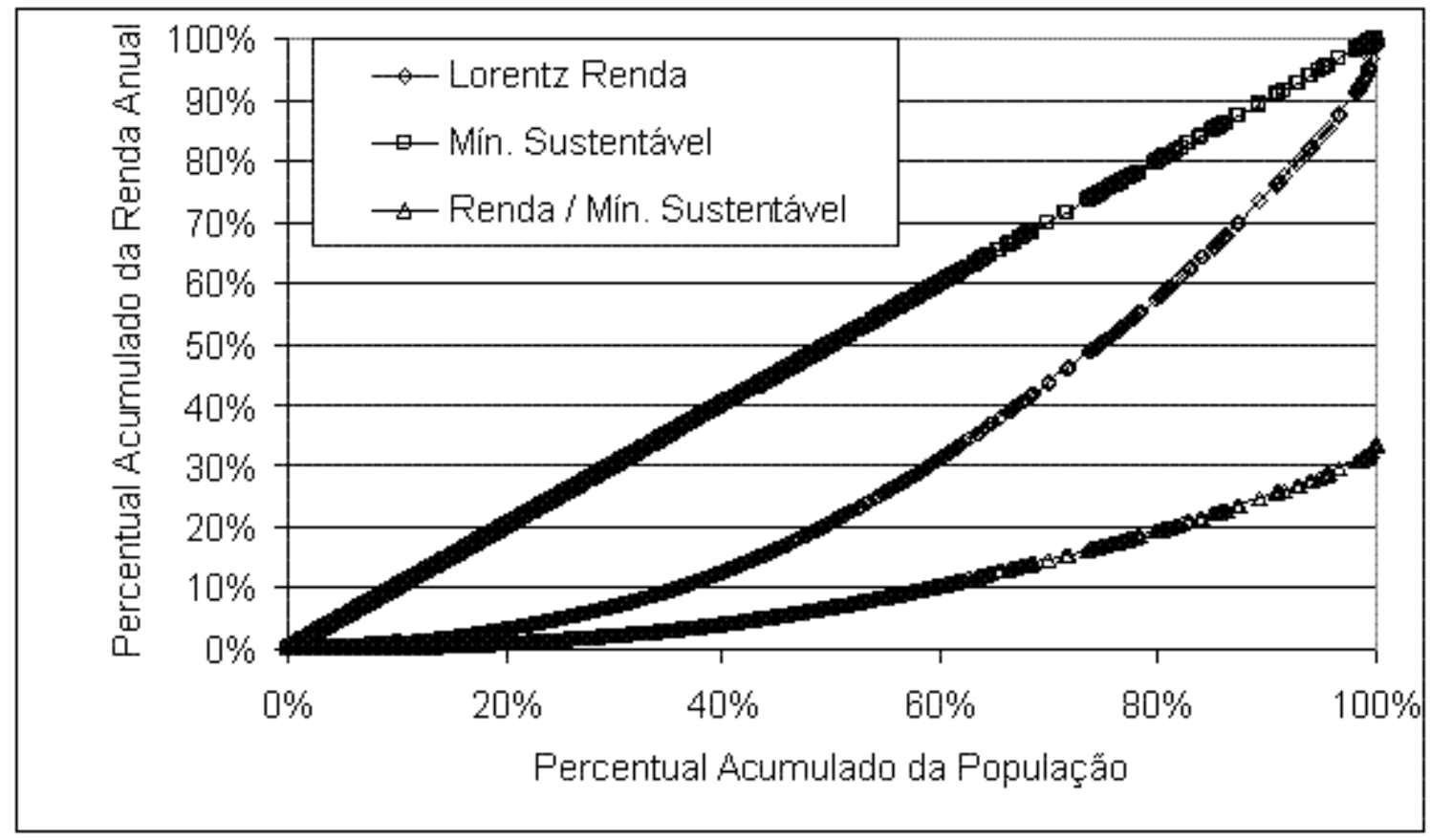

llustração 44 - Curvas $\alpha$ rh, $\beta$ rh e de Lorentz da distribuição da renda no conjunto recurso humano do sistema do AEHC, em 2007.

A llustração 45 apresenta as curvas $\alpha_{\mathrm{rh}}, \beta_{\mathrm{rh}}$ e de Lorentz da distribuição dos anos equivalentes de estudo entre os indivíduos do conjunto recurso humano no sistema do AEHC. A curva $\beta_{\mathrm{rh}}$ mostra que este conjunto de indivíduos acumula apenas metade dos anos equivalentes de estudo mínimo sustentável. A curva de Lorentz mostra que $40 \%$ destes indivíduos acumulam cerca de $13 \%$ dos AeqE total. Enquanto que os 20\% mais instruídos acumulam 50\% dos AeqE.

A partir das curvas $\alpha_{\mathrm{rh}}, \beta_{\mathrm{rh}}, \alpha_{\text {cons }}$ e $\beta_{\text {cons, }}$ para renda e escolaridade, calculamse os fatores de gravidade da desigualdade na distribuição da renda e da escolaridade entre os indivíduos do conjunto recurso humano, $G i_{x}^{*}$, e entre o conjunto recurso humano e o conjunto consumidor, $G i_{x}^{* *}$. A Tabela 75 apresenta os elementos de cálculo necessários e, adicionalmente, os índices de Gini para os conjuntos da população, recurso humano e consumidor. 


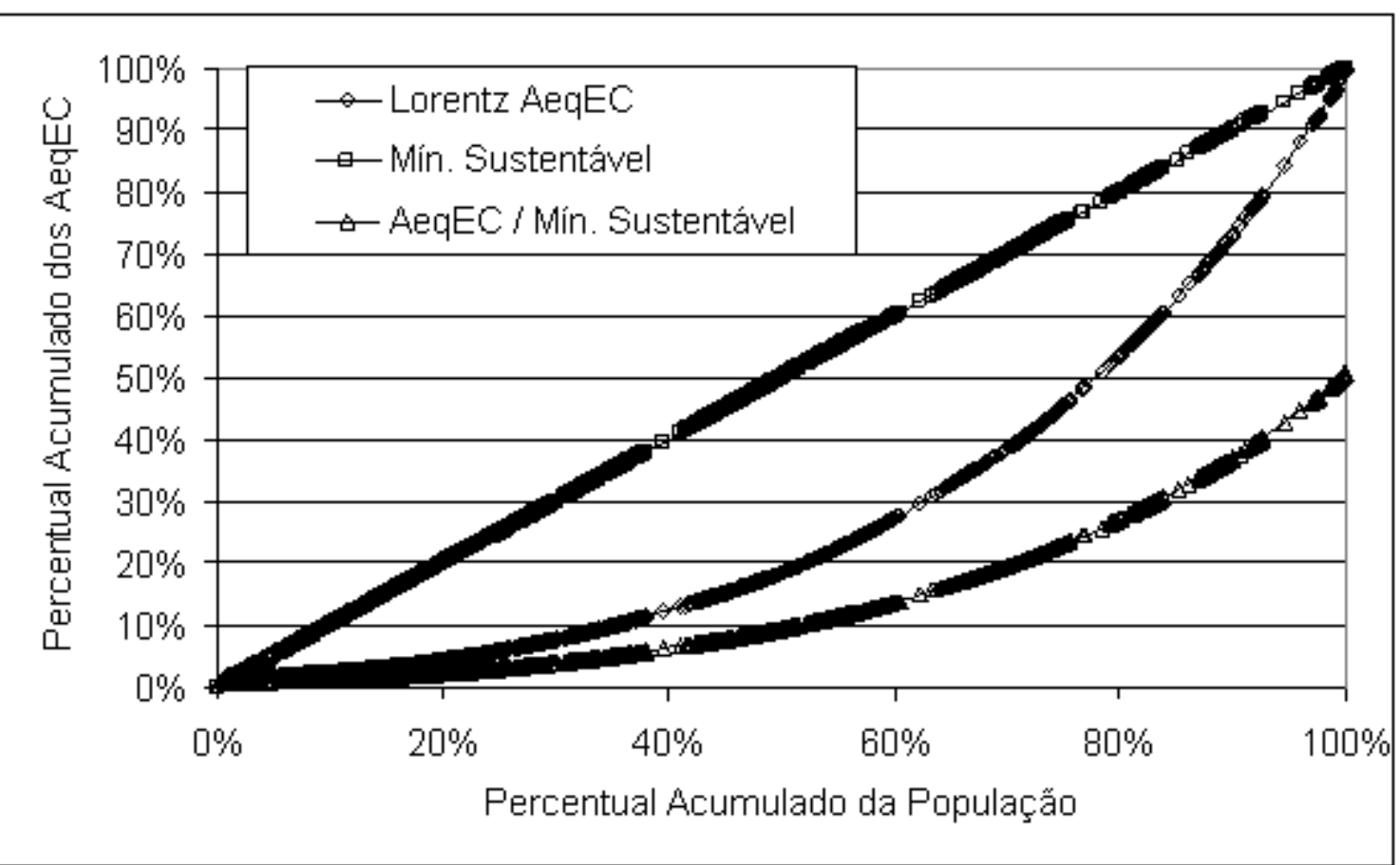

llustração 45 - Curvas $\alpha$ rh, $\beta$ rh e de Lorentz da distribuição da escolaridade contratada no conjunto recurso humano, no ano de 2007, para o sistema do AEHC.

Tabela 75 - Elementos de cálculos dos fatores de gravidade na desigualdade na distribuição de renda e de escolaridade, fatores de gravidade e índice de Gini.

\begin{tabular}{|c|c|c|c|c|}
\hline \multirow{2}{*}{$\begin{array}{c}\text { Elementos de } \\
\text { cálculo }\end{array}$} & \multicolumn{2}{|c|}{ Na distribuição de renda } & \multicolumn{2}{|c|}{ Na distribuição de AeqE } \\
\hline & rh & cons & rh & cons \\
\hline A & 0,40 & 0,36 & 0,36 & 0,23 \\
\hline B & 0,10 & 0,14 & 0,14 & 0,27 \\
\hline $\mathrm{C}$ & 0 & 0 & 0 & 0 \\
\hline \multicolumn{5}{|c|}{ Fatores de gravidade da desigualdade na distribuição } \\
\hline $\mathrm{Gi}^{*}$ & \multicolumn{2}{|l|}{0,20} & \multicolumn{2}{|l|}{0,29} \\
\hline $\mathrm{Gi}^{\star \star}$ & \multicolumn{2}{|l|}{0,43} & \multicolumn{2}{|l|}{0,35} \\
\hline $\mathrm{Gi}^{\star} \times \mathrm{Gi}^{\star \star}$ & \multicolumn{2}{|l|}{0,086} & \multicolumn{2}{|l|}{0,1015} \\
\hline \multicolumn{5}{|l|}{ Índice de Gini } \\
\hline Gini & 0,401 & 0,459 & 0,427 & 0,366 \\
\hline
\end{tabular}

Os fatores de gravidade da desigualdade na distribuição da renda e da escolaridade exerceram grande influência, reduzindo os valores calculados para as variáveis no conjunto recurso humano a cerca de $8,6 \%$ e 10,1\% do valor calculado, respectivamente para a renda e a escolaridade. 


\subsection{Sustentabilidade Social do Álcool Etílico Hidratado Combustível}

Com base nos resultados obtidos, aplicando-se as equações desenvolvidas no Capítulo 4 obtém-se o Índice de Sustentabilidade Social do AEHC com o valor de 3,7 e sinal negativo, como mostra a Tabela 76. Portanto, nesta avaliação preliminar obtém-se como conclusão que o sistema do AEHC não é socialmente sustentável em relação aos parâmetros sociais adotados.

Com base nos resultados da análise dos dados de distribuição de renda e escolaridade dos conjuntos de indivíduos, recurso humano e de consumidor no sistema de produto do AEHC, obteve-se os resultados dos indicadores de sustentabilidade Renda Monetária Anual (IpRMA) e Escolaridade Ajustada (IpEA) como sendo $-1,14$ e $-0,99$, respectivamente. Como foi desenvolvido apenas um indicador para cada categoria de sustentabilidade, o IpRMA para a categoria de Atendimento de Necessidades Básicas e o IpEA para a categoria de Autonomia Intelectual, os resultados dos índices destas categorias, respectivamente IpANB e IpAI, têm os mesmos valores que os resultados destes indicadores. A agregação destes resultados gerou o índice parcial de sustentabilidade calculado como -1,31.

Tabela 76 - Resultados da avaliação de sustentabilidade social

\begin{tabular}{|l|c|}
\hline Índices & Valor \\
\hline IpRMA - Resultado do indicador para Renda Média Anual & $-1,14$ \\
\hline IpANB - Parcial de Atendimento de Necessidades Básicas & $-1,14$ \\
\hline IpEA - Resultado do indicador para Escolaridade Ajustada & $-0,99$ \\
\hline IpAI - Parcial de Autonomia Intelectual & $-0,99$ \\
\hline IpSSP - Índice Agregado Parcial & $-1,31$ \\
\hline ISSP - Índice de Sustentabilidade do AEHC & $-3,7$ \\
\hline
\end{tabular}

Como mostra a Tabela 77, os subconjuntos de indivíduo com maior peso no conjunto recurso humano são os das atividades de cultivo de cana $(35,9 \%)$, produção de álcool $(28,3 \%)$, comércio varejista $(12,7 \%)$ e atividades de apoio agrícolas (12,5\%). Os valores médio de renda e de escolaridade destes subconjuntos, bem como o perfil distribucional da renda e escolaridade determinam a sustentabilidade do sistema de produto. Ao incluir os indivíduos do conjunto consumidor, estes representam 95,6\% dos indivíduos do sistema do AEHC. 
A Tabela 78 mostra que o recurso humano no cultivo de cana possui cerca de $39 \%$ da renda, a atividade de apoio agrícola possui 7\%, a produção de álcool acumula 29\%, o transporte de combustíveis soma $11 \%$ e o comércio de varejista de combustíveis soma cerca de $11 \%$.

Para os anos equivalentes de estudo, o cultivo de cana soma $32 \%$, a atividade de apoio soma 7\%, a produção de álcool soma 26\%, o comércio soma 19\% e o transporte de combustíveis soma 14\%, como mostra a Tabela 79.

Tabela 77 - Indivíduos normalizados para o fluxo de referência no sistema do AEHC.

\begin{tabular}{|l|c|c|c|}
\hline Componente do sistema do AEHC & Indivíduos & \%RH & \%Sistema \\
\hline Consumidor AEHC & $1,28 \mathrm{E}-03$ & - & 95,6 \\
\hline Comércio Varejista de Combustíveis & $7,42 \mathrm{E}-06$ & 12,7 & 0,6 \\
\hline Transporte de Cargas & $5,72 \mathrm{E}-06$ & 9,8 & 1,2 \\
\hline Produção de Álcool & $1,65 \mathrm{E}-05$ & 28,3 & 1,6 \\
\hline Cultivo de Cana & $2,10 \mathrm{E}-05$ & 35,9 & 0,5 \\
\hline Atividades de Apoio & $7,33 \mathrm{E}-06$ & 12,5 & 0,0 \\
\hline Diesel & $2,88 \mathrm{E}-08$ & 0,0 & 0,0 \\
\hline Fertilizantes & $4,58 \mathrm{E}-07$ & 0,8 & 0,0 \\
\hline Defensivos & $1,42 \mathrm{E}-08$ & 0,0 & 0,4 \\
\hline Total de indivíduos no recurso humano & $5,85 \mathrm{E}-05$ & 100 & 4,4 \\
\hline Total de Indivíduos no sistema do AEHC & $1,33 \mathrm{E}-03$ & - & 100 \\
\hline
\end{tabular}

Tabela 78 - Renda da população do sistema do AEHC, normalizada para o fluxo de referência.

\begin{tabular}{|l|c|c|c|}
\hline Componente do sistema do AEHC & Renda (R\$) & \%RH & \%Sistema \\
\hline Consumidor AEHC & $1,35 \mathrm{E}+01$ & & 97 \\
\hline Comércio Varejista de Combustíveis & $4,42 \mathrm{E}-02$ & 11 & 0 \\
\hline Transporte de Cargas & $4,32 \mathrm{E}-02$ & 11 & 0 \\
\hline Produção de Álcool & $1,17 \mathrm{E}-01$ & 29 & 1 \\
\hline Cultivo de Cana & $1,56 \mathrm{E}-01$ & 39 & 1 \\
\hline Atividades de Apoio & $2,64 \mathrm{E}-02$ & 7 & 0 \\
\hline Diesel & $2,08 \mathrm{E}-03$ & 1 & 0 \\
\hline Fertilizantes & $8,23 \mathrm{E}-03$ & 2 & 0 \\
\hline Defensivos & $5,66 \mathrm{E}-04$ & 0 & 0 \\
\hline Total Recursos Humanos (RH) & $3,98 \mathrm{E}-01$ & 100 & 3 \\
\hline Total Sistema do AEHC & $1,39 \mathrm{E}+01$ & & 100 \\
\hline
\end{tabular}


Tabela 79 - Anos equivalentes de estudo da população total do sistema do AEHC, normalizados para o fluxo de referência de 2 litros de AEHC.

\begin{tabular}{|l|c|c|c|}
\hline Componente do sistema do AEHC & AeqE & \%RH & \%Sistema \\
\hline Consumidor AEHC & $9,80 \mathrm{E}-03$ & & 97 \\
\hline Comércio Varejista de Combustíveis & $5,06 \mathrm{E}-05$ & 19 & 1 \\
\hline Transporte de Cargas & $3,66 \mathrm{E}-05$ & 14 & 0 \\
\hline Produção de Álcool & $7,05 \mathrm{E}-05$ & 26 & 1 \\
\hline Cultivo de Cana & $8,64 \mathrm{E}-05$ & 32 & 1 \\
\hline Atividades de Apoio & $1,82 \mathrm{E}-05$ & 7 & 0 \\
\hline Diesel & $3,46 \mathrm{E}-07$ & 0 & 0 \\
\hline Fertilizantes & $3,64 \mathrm{E}-06$ & 1 & 0 \\
\hline Defensivos & $1,54 \mathrm{E}-07$ & 0 & 0 \\
\hline Total Recursos Humanos (RH) & & 100 & 3 \\
\hline Total Sistema do AEHC & & & 100 \\
\hline
\end{tabular}




\section{CONCLUSÕES E CONSIDERAÇÕES FINAIS}

Os indicadores, das categorias de sustentabilidade social, desenvolvidos para a Avaliação Social do Ciclo de Vida de Produtos atenderam aos requisitos de serem agregáveis ao longo do sistema de produto e de serem relacionáveis à unidade funcional através do fluxo de referência. Quanto maior a renda do conjunto de indivíduos recurso humano, que dá acesso ao Atendimento de Necessidades Básicas definidas com base em uma renda mínima sustentável, melhor é para o perfil de sustentabilidade do sistema de produto. Da mesma forma, quanto maior a escolaridade ajustada, que dá oportunidade de autonomia intelectual aos indivíduos, melhor é para a avaliação do sistema.

Tanto para renda como para escolaridade ajustada, podem ser adotados outros valores de referência, de modo a melhor representar a interação entre o sistema de produto e o sistema social. Como exemplo, pode-se adotar os valores médios de renda e escolaridade do sistema social. Assim, se o sistema de produto tiver um valor médio para a variável inferior ao definido como mínimo sustentável, mas superior ao valor médio do sistema social, verifica-se uma contribuição relativa positiva para o desenvolvimento do sistema social atribuída à existência do sistema de produto. Vale lembrar que o sistema social deve ser socialmente autosustentável.

O modelo de agregação garante que a avaliação do sistema é governada pela questão mais carente. Desta forma, tomadores de decisão são orientados a priorizar o desenvolvimento das questões em que o sistema de produto tem maior carência.

Novos indicadores paras as categorias propostas podem ser desenvolvidos, como rendas não monetárias e outras rendas monetárias não incluídas na renda anual (bônus, prêmios, participação nos lucros etc.) para a categoria Atendimento de Necessidades Básicas. Para a categoria de sustentabilidade Autonomia Intelectual podem ser desenvolvidos anos equivalentes para cursos, treinamentos, experiência profissional etc.

Adicionalmente, a modelagem da cadeia de impactos pode ser extendida para ir além dos impactos às categorias de sustentabilidade propostos, até o dano à categoria de Saúde Humana, medida em Anos de Vida Ajustados pela Deficiência e morte prematura (DALY), semelhante ao que propõem Norris (2006) e Weidema (2006). 
Quanto à viabilidade de aplicação do método, a disponibilidade dos dados da Relação Anual de Informações Sociais (RAIS), com periodicidade anual, torna exequível a condução de avaliações sociais de sistemas de produto onde a participação dos vínculos de trabalho informal não seja muito elevada. Os resultados podem ser refinados pela combinação de outras fontes de dados complementares como a Pesquisa Nacional de Amostra por Domicílio. Os censos setoriais e outras fontes de dados publicados pelo Instituto Brasileiro de Geografia e Estatística também podem complementar os dados da RAIS.

Em relação à avaliação preliminar do sistema do álcool etílico hidratado combustível (AEHC), conclui-se que o AEHC não é socialmente sustentável para os parâmetros de sustentabilidade selecionados nesta Tese. Isto se deve basicamente ao fato do extrato do sistema social, que lhe provém o recurso humano necessário, não ter um desenvolvimento social adequado frente aos ideais constitucionais da sociedade a que pertence.

Quanto à categoria de sustentabilidade Atendimento das Necessidades Básicas, o conjunto total dos indivíduos possui potencialmente garantidas o acesso a aproximadamente metade de suas necessidades básicas. Os indivíduos do subconjunto recurso humano possuem, da mesma forma potencialmente garantidos, cerca de um terço de suas necessidades básicas. Diz-se potencialmente garantidos o atendimento das necessidades básicas, pois cada indivíduo é livre para fazer uso de sua renda da forma como lhe convém, e não obrigatoriamente no atendimento das necessidades definidas como básicas pela sua sociedade.

$\mathrm{Na}$ categoria de sustentabilidade Autonomia Intelectual, o conjunto dos indivíduos que desempenham a função recurso humano acumulam uma escolaridade ajustada pela duração do vínculo de aproximadamente metade do mínimo sustentável que corresponde à situação em que todos têm 9 anos equivalentes de estudo, ou Ensino Fundamental completo.

A baixa qualificação exigida do recurso humano, principalmente para trabalhos manuais na fase agrícola, permite o acesso ao trabalho de massas que não teriam oportunidades em outros setores da economia. Este acesso é positivo, mas transfere para o sistema de produto responsabilidades que são do sistema social. Educação mínima para autonomia intelectual e uma Renda Básica de 
Cidadania $^{8}$ para o provimento de cada indivíduo são características intrínsecas de um sistema social sustentável.

A relação entre consumidor e recurso humano para o sistema de produto do AEHC é de aproximadamente 22 para 1, ou seja cada trabalhador neste sistema de produto atende 22 consumidores. Este resultado sugere a importância da necessidade de aumentar a produtividade por recurso humano, uma vez que o valor agregado do produto é baixo, de modo a tornar economicamente viável a sustentabilidade social.

A evolução tecnológica do sistema do álcool etílico hidratado combustível, com consequente demanda de recurso humano mais qualificado e, portanto, melhor remunerado, embora reduzida, contribui mais para o desenvolvimento social sustentável do país.

A aplicação deste método a outros sistemas de produto, especialmente outros combustíveis veiculares, combinada com a Avaliação Ambiental do Ciclo de Vida e a Avaliação de Custos no Ciclo de Vida tem potencial de constituir uma poderosa ferramenta para a avaliação de sustentabilidade de produtos.

\footnotetext{
${ }^{8}$ SUPLICY, E. M. Renda Básica de Cidadania: A Resposta dada pelo Vento. $3^{\mathrm{a}}$ ed. Porto Alegre: L\&PM POCKET. 136 p. 2006.
} 


\section{REFERÊNCIAS}

ANDA - Associação Nacional para Difusão de Adubos. Anuário Estatístico do Setor de Fertilizantes. São Paulo: ANDA, 2007.

ANDRADE, M. C. Modernização e Pobreza: a expansão da agroindústria canavieira e seu impacto ecológico e social. São Paulo:Editora da UNESP. ISBN 85-7139-0665. 1994.

BARTHEL, L. Use of Statistical Sources of Social Data for Sustainability Assessment. [S.I.: s.n], 2006.

BAUMANN, H. \& TILLMAN, A.M. The Hitch Hiker's Guide to LCA. An orientation in life cycle assessment methodology and application. Lund: Studentlitteratur AB. ISBN 91-44-02364-2. 2004.

BRASIL.República Federativa do Brasil. Lei $\mathbf{1 1 . 2 7 4}$ de 6 de fevereiro de 2006.

CHEHEBE, J.R.B. Análise do ciclo de Vida de Produtos: Ferramenta Gerencial da ISO 14.000. Rio de Janeiro: Qualitymark. ISBN. 1998.

DENATRAN - Departamento Nacional de Trânsito. (Brasil) RENAEST - Registro Nacional de Acidentes e Estatísticas de Trânsito. Condutores Brasileiros. Evolução dos condutores por categoria - 2003 a 2007. www.denatran.gov.br. Acessado em Dezembro de 2008. 
DIEESE - Departamento Intersindical de Estatística e Estudos Sócio-Econômicos. Salário Mínimo Constitucional.Nota técnica 8. 2005.

DREYER, L.C., HAUSCHILD, M.Z., SCHIERBECK, J. A Framework for Social Life Cycle Impact Assessment. International Journal of Life Cycle Assessment. v. 11 n.2, p. 88-97, 2006.

GRIEßHAMMER, R. et. al. Feasibility study: integration of social aspects into LCA. discussion paper from UNEP-SETAC Task Force integration of social aspects in LCA meetings in Bologna (January 2005), Lille (May 2005) and Brussels (November 2005). Freiburg, Germany. 2006.

HAES, H.A.U. The Scientific Basis for SLCA. International Journal of Life Cycle Assessment. v.13 n. 2, p 95, 2008.

HAUSCHILD, M.; DREYER, L.C.; JORGENSEN, A. Assessing Social Impacts in a Life Cycle Perspective - Lessons Learned. CIRP Annals - Manufacturing Technology. n. 57, p 21-24. 2008.

HEIJUNGS, R. \& SUH, S. The Computational Structure of Life Cycle Assessment. Dordrecht: Kluwer Academic Publishers.ISBN 1-4020-0672-1. 2002.

HENDRICKSON, C.T., LAVE, L.B. \& MATTHEWS, H.S. Environmental Life Cycle Assessment of Goods and Services. An Input-Output Approach. Washington: Resoucres for the Future. ISBN 1-933115-24-6. 2006. 
HOFFMANN R. O rendimento das pessoas ocupadas na agroindústria canavieira no Brasil. In: MACEDO (2005).

HUNKELER, D. Societal LCA Methodology and Case Study. International Journal of Life Cycle Assessment. v.11,n.6, p. 371-382, 2006.

HUTCHINS, M. J.; SUTHERLAND, J. W. An exploration of measures of social sustainability and their application to supply chain decisions. Journal of Cleaner Production. n. 16. p 1688-1698, 2008.

IBGE - Instituto Brasileiro de Geografia e Estatística. Pesquisa Nacional por Amostra de Domicílios (PNAD). Rio de Janeiro: IBGE, 2005.

. Produção Agrícola municipal. www.ibge.gov.br. Acessado em 2008.

ISO - International Organization for Standardization. ISO14040 - Environmental management - Life cycle assessment - Principles and framework. Genebra: ISO copyright Office. 2006.

. ISO 14044 - Environmental Management - Life cycle assesment Requirements and guidelines. Genebra: ISO copyright Office. 2006.

JORGENSEN, A.; LE BOCQ, A.; NAZARKINA, L.; HAUSCHILD, M. Methodologies for Social Life Cycle Assessment. International Journal of Life Cycle Assessment. v.13, n.2, p. 96-103, 2008. 
KLÖPFFER, W. Life Cycle Sustainability Assessment of Products. International Journal of Life Cycle Assessment. v.13, n.2, p. 89-95, 2008.

KRUSE, S. A.; FLYSJÖ, A.; KASPERCZYK, N.; SCHOLZ, A. J. Socioeconomic Indicators as a Complement to Life Cycle Assessment : an Application to Salmon Production Systems. International Journal of Life Cycle Assessment. v.14 , n.1, p. 8-18, 2009.

LABUSCHAGNE, C., BRENT, A.C. Social Indicators for Sustainable Project and Technology Life Cycle Management in the Process Industry. International Journal of Life Cycle Assessment. v. 11, n.1, p. 3-15,2006.

MACEDO, I. C. (org). A Energia da Cana-de-Açúcar - Doze estudos sobre a agroindústria da cana-de-açúcar no Brasil e a sua sustentabilidade. São Paulo: Berlendis \& Vertecchia: UNICA - União da Agroindústria Canavieira do Estado de São Paulo. 2005.

MACEDO, I. C.; LEAL, M. R. L. V.; SILVA, J. E. Balanço da emissões de gases de efeito estufa na produção e no uso do etanol no Brasil. Secretaria do Meio Ambiente do Estado de São Paulo. Abril, 2004.

MDIC - Ministério do Desenvolvimento, Indústria e Comércio Exterior. Secretaria do Desenvolvimento da Produção. Nota Técnica n 47/06/CGTP/DESIT/SDP. Fórum de Competitividade de Agroquímicos, 2006.

MME - Ministério de Minas e Energia. (Brasil). Balanço Energético Nacional com Ano-Base 2007. 2008. 
MTE - Ministério do Trabalho e Emprego. (Brasil). Programa de Disseminação de Estatísticas do Trabalho. Relação de Informações Sociais (RAIS). Acesso online às bases de dados. www.mte.gov.br. Acessado em 11 de Setembro de 2008.

NORRIS, G.A. Social Impacts in Product Life Cycles: Towards Life Cycle Attribute Assessment. International Journal of Life Cycle Assessment. v.11,n. 1, p.97-104, 2006. Special Issue

O'BRIEN, M., DOIG, A., CLIFT, R. Social and Environmental Life Cycle Assessment . International Journal of Life Cycle Assessment. v.1, n.4, p. 231-237,1996.

OMETTO, A.R. Avaliação do ciclo de vida do álcool etílico hidratado combustível pelos métodos EDIP, exergia e emergia. Tese (Doutorado em Hidráulica e Saneamento) - Escola de Engenharia de São Carlos, Univerdade de São Paulo, São Carlos. 209p. 2005.

PETROBRAS. Glossário : relações com o Investidor. Disponível em: <http:// www.petrobras.com.br>. Acesso em: 28 Out. 2008.

PLATÃO. Les Lois . In: Platon - Chambry, Émile (Trad.) Oeuvres Complètes. 43.ed. . Paris : Ed Guarnier, 1946. (Collection des Classiques Guarnier)

PLATÃO. République . In: Baccou, Robert (Trad.) Platon : Oeuvres Complètes. 263.ed. Paris: Guarnier, 1950. 
SCHMIDT, I.et.al.Balance: Managing Sustainability of Products and Processes with the Socio-Eco-Efficiency Analysis by BASF. Greener Management International n.45, p. 79-94, 2004.

SEN, Amartya \& KLIKSBERG, Bernardo. Primero la Gente. Uma mirada desde la ética del desarrollo a los principales problemas del mundo globalizado. Deusto: Barcelona. 2007.

SENADO FEDERAL, Secretaria Especial de Editoração e Publicações, subsecretaria de editorações técnicas. Constituição da República Federativa do Brasil. Brasília. 2006.

SPILLEMAECKERS, S. The Belgian Social Label: A Governmental Application of Social LCA. 2007.Disponível em:http://web.fuberlin.de/ffu/calcas/Spillemaeckers_Belgian.pdf Acesso em: 28 Sep.2007.

WCED - The World Commission on Environment and Development. Towards sustainable development. In: .Our Common Future. Londres: Oxford University Press, 1987. p 44-66.

WEIDEMA, B. P. The Integration of Economic and Social Aspects in Life Cycle Impact Assessment. International Journal of Life Cycle Assessment. v.11,n. 1, p. 89-96, 2006. Special Issue

WEIDEMA, B.P. ISO 14044 also Applies to Social LCA. International Journal of Life Cycle Assessment.v.10, n.6, p. 381-381, 2005. 